\title{
HEALTHY LIFESTYLE FACTORS AND ACADEMIC PERFORMANCE IN SECONDARY SCHOOL STUDENTS: DADOS STUDY
}

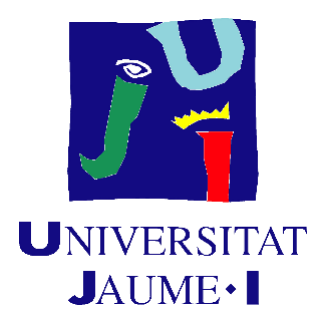

Mireia Adelantado Renau

PhD Thesis Supervisor: Diego Moliner Urdiales

September 2019 

Healthy lifestyle factors and academic performance in secondary school students: DADOS study

Mireia Adelantado Renau 



\section{Healthy lifestyle factors and academic performance in secondary school students: \\ DADOS study}

Hábitos saludables y rendimiento académico en estudiantes de educación secundaria obligatoria: proyecto DADOS

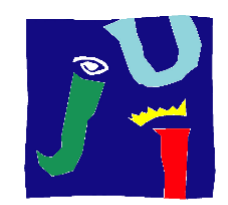

UNIVERSITAT

JAUME $\mathbf{I}$

PROGRAMA DE DOCTORADO EN EDUCACIÓN

ESCUELA DE DOCTORADO DE LA UNIVERSITAT JAUME I

Memoria presentada por Mireia Adelantado Renau para optar al grado de doctora por la Universitat Jaume I

Doctoranda:

Mireia Adelantado Renau

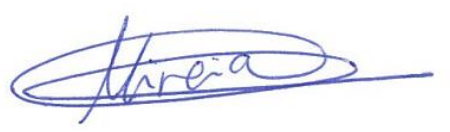

Director de tesis:

Diego Moliner Urdiales

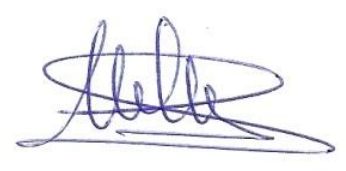

Castelló de la Plana, May 2019 
To those who once gave me a chance A las/os que alguna vez me dieron una oportunidad 


\section{RESEARCH PROJECT AND FUNDING}

The present PhD Thesis was performed as a result of the DADOS (Deporte, ADOlescencia y Salud) study, a research project conducted by the members of the Physical Activity, Fitness and Health (LIFE) research group at the University Jaume I (www.grupolife.uji.es), which was supported by:

- The Spanish Ministry of Economy and Competitiveness, MINECO (DEP201345515-R), Plan Estatal de Investigación Científica y Técnica y de Innovación 2013 Programa Estatal de Investigación, Desarrollo e Innovación Orientada a los Retos de la Sociedad.

- University Jaume I, UJI (P1·1A2015-05), Pla de promoció de la investigació de la Universitat Jaume I 2015, Programa de foment de projectes d'investigació.

- Sunny Sport research grant from the Schweppes Suntory Spain Company.

The PhD candidate, Mireia Adelantado Renau, was supported by:

- Predoctoral Research Grant from UJI (PREDOC/2015/13), Pla de promoció de la investigació de la Universitat Jaume I 2015, Programa de suport a la formació i incorporació de personal investigador.

- Mobility grants from UJI (E-2017-13 and E-2018-21), Plans de promoció de la investigació de la Universitat Jaume I 2017 i 2018. Programa de mobilitat del personal investigador. 


\section{LIST OF PUBLICATIONS}

The present PhD Thesis comprises the following eight scientific publications.

The Web of Science (WOS) Journal Citation Reports (JCR) statistics reported refer to the most recent data (year 2017).

1. Adelantado-Renau M, Beltran-Valls MR, Migueles JH, Artero EG, Legaz-Arrese A, Capdevila-Seder A, Moliner-Urdiales D. Associations between objectively measured and self-reported sleep with academic and cognitive performance in adolescents: DADOS study. Journal of Sleep Research. 2019; e12811. doi:10.1111/jsr.12811. [Epub ahead of print]

WOS (JCR) Impact Factor: 3.433; Category: Neurosciences; Rank: 100/261 (Q2)

2. Adelantado-Renau M, Diez-Fernandez A, Beltran-Valls MR, Soriano-Maldonado A, Moliner-Urdiales D. The effect of sleep quality on academic performance is mediated by Internet use time: DADOS study. Jornal de Pediatria (Rio J). 2018; S0021-7557(18)30013-5. doi:10.1016/j.jped.2018.03.006. [Epub ahead of print]

WOS (JCR) Impact Factor: 1.690; Category: Pediatrics; Rank: 63/124 (Q3)

3. Adelantado-Renau M, Beltran-Valls MR, Esteban-Cornejo I, Martínez-Vizcaíno V, Santaliestra-Pasías AM, Moliner-Urdiales D. The influence of adherence to the Mediterranean diet on academic performance is mediated by sleep quality in adolescents. Acta Paediatrica. 2019; 108(2): 339-346. doi:10.1111/apa. 14472.

WOS (JCR) Impact Factor: 2.580; Category: Pediatrics; Rank: 28/124 (Q1)

4. Adelantado-Renau M, Beltran-Valls MR, Toledo-Bonifás M, Bou-Sospedra C, Pastor MC, Moliner-Urdiales D. The risk of eating disorders and academic performance in adolescents: DADOS study. Nutrición Hospitalaria. 2018; 35(5): 1201-1207. doi:10.20960/nh.1778.

WOS (JCR) Impact Factor: 0.845; Category: Nutrition \& Dietetics; Rank: 70/83 (Q4)

5. $\quad$ Adelantado-Renau M, Beltran-Valls MR, Mota J, Moliner-Urdiales D. Circulating inflammatory biomarkers and academic performance in adolescents: DADOS study. [submitted for publication] 
6. Adelantado-Renau M, Jiménez-Pavón D, Beltran-Valls MR, Ponce-González JG, Chiva-Bartoll Ó, Moliner-Urdiales D. Fitness and academic performance in adolescents. The mediating role of leptin: DADOS study. European Journal of Pediatrics. 2018; 177(10): 1555-1563. doi:10.1007/s00431-018-3213-z.

WOS (JCR) Impact Factor: 2.242; Category: Pediatrics; Rank: 42/124 (Q2)

7. Beltran-Valls MR, Adelantado-Renau M, Castro-Piñero J, Sánchez-López M, Moliner-Urdiales D. Cardiorespiratory fitness and academic performance association is mediated by weight status in adolescents: DADOS study. European Journal of Pediatrics. 2018; 177(7): 1037-1043. doi:10.1007/ s00431-018-3159-1.

WOS (JCR) Impact Factor: 2.242; Category: Pediatrics; Rank: 42/124 (Q2)

8. Adelantado-Renau M, Jiménez-Pavón D, Beltran-Valls MR, Moliner-Urdiales D. Independent and combined influence of healthy lifestyle factors on academic performance in adolescents: DADOS Study. Pediatric Research. 2019; 85, 456462. doi:10.1038/s41390-019-0285-z. [Epub ahead of print] WOS (JCR) Impact Factor: 3.123; Category: Pediatrics; Rank: 16/124 (Q1)

Mireia Adelantado Renau was involved in the data collection, data analyses and drafting of the manuscript for each of the included scientific publications.

This thesis has been accepted by the co-authors of the publications listed above that have waved the right to present them as a part of another PhD Thesis. 


\section{TABLE OF CONTENTS}

$\begin{array}{ll}\text { Abstract [Resumen] } & 15\end{array}$

$\begin{array}{ll}\text { Framework } & 17\end{array}$

$\begin{array}{lr}\text { General introduction } & 19\end{array}$

Aims [Objetivos] 33

$\begin{array}{ll}\text { Manuscripts } & 37\end{array}$

Study 1 Associations between objectively measured and self-reported sleep with academic and cognitive performance in adolescents: DADOS study

Study 2 The effect of sleep quality on academic performance is mediated by Internet use time: DADOS study

Study 3 The influence of adherence to the Mediterranean diet on academic performance is mediated by sleep quality in adolescents

Study 4 The risk of eating disorders and academic performance in adolescents: DADOS study

Study 5 Circulating inflammatory biomarkers and academic 83 performance in adolescents: DADOS study

Study 6 Fitness and academic performance in adolescents. The mediating role of leptin: DADOS study

Study 7 Cardiorespiratory fitness and academic performance association is mediated by weight status in adolescents: DADOS study

Study $8 \quad$ Independent and combined influence of healthy lifestyle factors on academic performance in adolescents: DADOS Study

Conclusions [Conclusiones]

Implications and future perspectives 


\section{ABSTRACT}

High academic performance during adolescence is considered a strong predictor of future work conditions and health status. Since adolescence is an important time frame in terms of development of academic skills and establishment of healthy lifestyle factors, it is likely that these factors have an influence on adolescents' academic performance. Thus, the main aim of this $\mathrm{PhD}$ Thesis was to investigate the associations and the possible mechanisms between healthy lifestyle factors and academic performance in secondary school students.

A total of 274 secondary school students (aged 13.9 \pm 0.3 years) from the DADOS (Deporte, ADOlescencia y Salud) study were involved in the present PhD Thesis.

The main findings of the present PhD Thesis reveal that academic performance in secondary school students is 1) positively associated with sleep quality (mediated by internet use time); 2) positively associated with adherence to the Mediterranean diet (mediated by sleep quality) and daily meal frequency, and negatively associated with the risk of eating disorders; 3) negatively associated with tumor necrosis factor-a; 4) positively associated with cardiorespiratory fitness (mediated by leptin concentration and body composition) and muscular strength (mediated by leptin concentration); 5) not associated with physical activity levels, and negatively associated with screen media usage.

Overall, the present PhD Thesis indicates a positive association between healthy lifestyle factors and academic performance in secondary school students. 


\section{RESUMEN}

Un rendimiento académico alto durante la adolescencia se considera un potente predictor de la empleabilidad y del estado de salud en etapas posteriores de la vida. La adolescencia es un periodo muy importante en lo que se refiere a desarrollo de habilidades académicas y adquisición de hábitos saludables. Por lo que dichos hábitos podrían influir en el rendimiento académico de los adolescentes. Por ello, el objetivo principal de esta Tesis Doctoral fue investigar las asociaciones y los posibles mecanismos entre los hábitos saludables y el rendimiento académico en estudiantes de educación secundaria obligatoria.

Un total de 274 estudiantes de educación secundaria obligatoria (13.9 \pm 0.3 años), participantes del proyecto DADOS (Deporte, ADOlescencia y Salud) fueron incluidos en los estudios de esta Tesis Doctoral.

Los principales hallazgos de la presente Tesis Doctoral revelan que el rendimiento académico en estudiantes de educación secundaria obligatoria: 1) se asocia positivamente con la calidad del sueño (a través del tiempo de uso de internet); 2) se asocia positivamente con la adherencia a la dieta Mediterránea (a través de la calidad del sueño), y la frecuencia diaria de comidas, y negativamente con el riesgo de padecer trastornos de la alimentación; 3) se asocia negativamente con la concentración del factor de necrosis tumoral-a; 4) se asocia positivamente con la resistencia cardiorrespiratoria (a través de la concentración de leptina y de la composición corporal) y la fuerza muscular (a través de la concentración de leptina); 5) no se asocia con los niveles de actividad física, y se asocia negativamente con el tiempo empleado en actividades de pantalla.

La presente Tesis Doctoral indica una asociación positiva entre los hábitos saludables y el rendimiento académico en estudiantes de educación secundaria obligatoria. 


\section{FRAMEWORK}

The present PhD Thesis provides new insights on the associations between healthy lifestyle factors and academic performance in secondary school students within the context of the DADOS (Deporte, ADOlescencia y Salud) study. The DADOS study is a 3-year longitudinal research project (from the academic year $2015 / 16$ to the academic year 2017/18) aimed to assess the influence of physical activity on health, psychological wellness and academic performance through adolescence.

DADOS study contributes to the development of international strategies such as the Global Strategy on Diet, Physical Activity and Health (World Health Organization), as well as, of national strategies such as the NAOS strategy (Strategy for Nutrition, Physical Activity and the Prevention of Obesity, Ministerio de Sanidad, Servicios Sociales e Igualdad) and the Integral Plan on Physical Activity and Sport (A+D Plan 2010-2020, Spanish National Sport Council). Thus, the results obtained from the present PhD Thesis will be relevant not only to provide scientific information, but also to establish new initiatives and school-based programs aimed to improve both, health status and academic performance in secondary school students.

This PhD Thesis is structured around four parts: general introduction, aims, manuscripts and conclusions. The parts of general introduction, aims and conclusions are divided into five sections. Each section addresses the importance of a different lifestyle factor for academic performance in secondary school students: 1) sleep; 2) diet; 3) circulating inflammatory biomarkers; 4) physical fitness; and 5) physical activity and sedentary behaviours. The aims were approached through eight scientific publications included in the part manuscripts. The present PhD Thesis has been designed and developed in accordance with the Universitat Jaume I Doctorate Regulations (approved on 26 January 2012, with last modification on 25 July 2013) and with the Doctoral Programme in Education Regulations for the academic year 2015/2016, both based on the Royal Decree 99/2011, of 28 January, which regulates official doctoral studies (information retrieved from: www.uji.es/estudis/centres/escoladoctorat/normativa/normestudi/). 


\section{General}

\section{Introduction}




\section{GENERAL INTRODUCTION}

The Spanish educational system is structured on two compulsory educational levels that are primary education and secondary education. The Royal Decree 126/2014, of 28 February, which regulates primary education curricula, states that primary education comprises six academic years, from 6 to 12 years of age. The Royal Decree $1105 / 2014$, of 26 December, which regulates secondary education curricula, states that secondary education comprises four academic years, from 12 to 16 years of age.

\section{ACADEMIC PERFORMANCE: DEFINITION AND CURRENT STATE}

Academic performance refers to educational goals that students have to reach in a particular period of time, ${ }^{1}$ and can be assessed through several academic indicators such as school dropout and academic grades, or using standardized tests.

\section{SCHOOL DROPOUT}

School dropout is a progressive process that ends with a personal choice of leaving school. ${ }^{2}$ In terms of adolescent school dropout, Spain has been pointed out as the country with the second greatest incidence within the European Union. Data from 2016-2017 from the Spanish Ministry of Education and Vocational Training show that between
$11 \%$ and $15 \%$ of adolescents did not pass to the next academic year of secondary education (see figure 1). ${ }^{3}$ In fact, only $75.6 \%$ of Spanish adolescents successfully finished the studies of secondary education, with a higher rate in girls than in boys (see figure 2). In the Valencian Community, the incidence of adolescents not passing each academic year of secondary education is greater than that showed by national statistics (see figure 1), and revealed that only the $66.7 \%$ of adolescents graduated from the secondary school system (see figure 2 ). ${ }^{3}$

\section{ACADEMIC GRADES}

Academic grades are the most used academic performance indicators. In Spain, academic grades are represented using a ten-point scale, where 0 is the worst and 10 is the best, and a score of $\geq 5$ is needed to pass each subject. ${ }^{3}$ Previous research has proposed individual grades of mathematics and language as the most relevant academic grades because of the key role that executive function (i.e., cognitive flexibility, cognitive inhibition and working memory) plays on these areas of knowledge. ${ }^{4}$ In consonance with these findings, Spanish students should repeat the academic year whether they fail more than two, or these specific two subjects. ${ }^{3}$ Moreover, the grade point average (GPA), defined as an average of all examinable subjects, is also widely used as an indicator of academic performance possibly due to its determinant role for college selection and admission. 


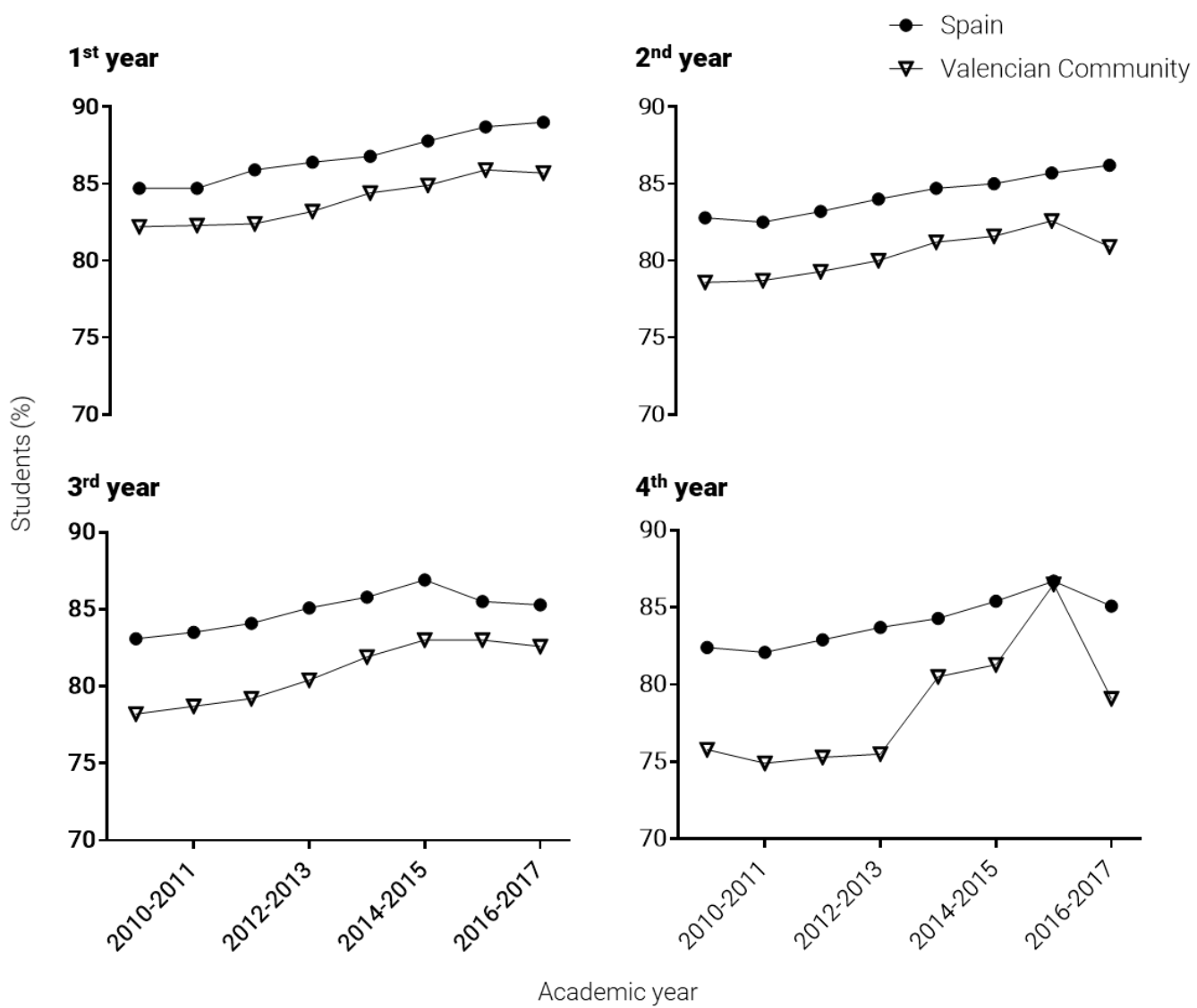

Figure 1. Percentage of students successfully passing to the next academic year of secondary education.

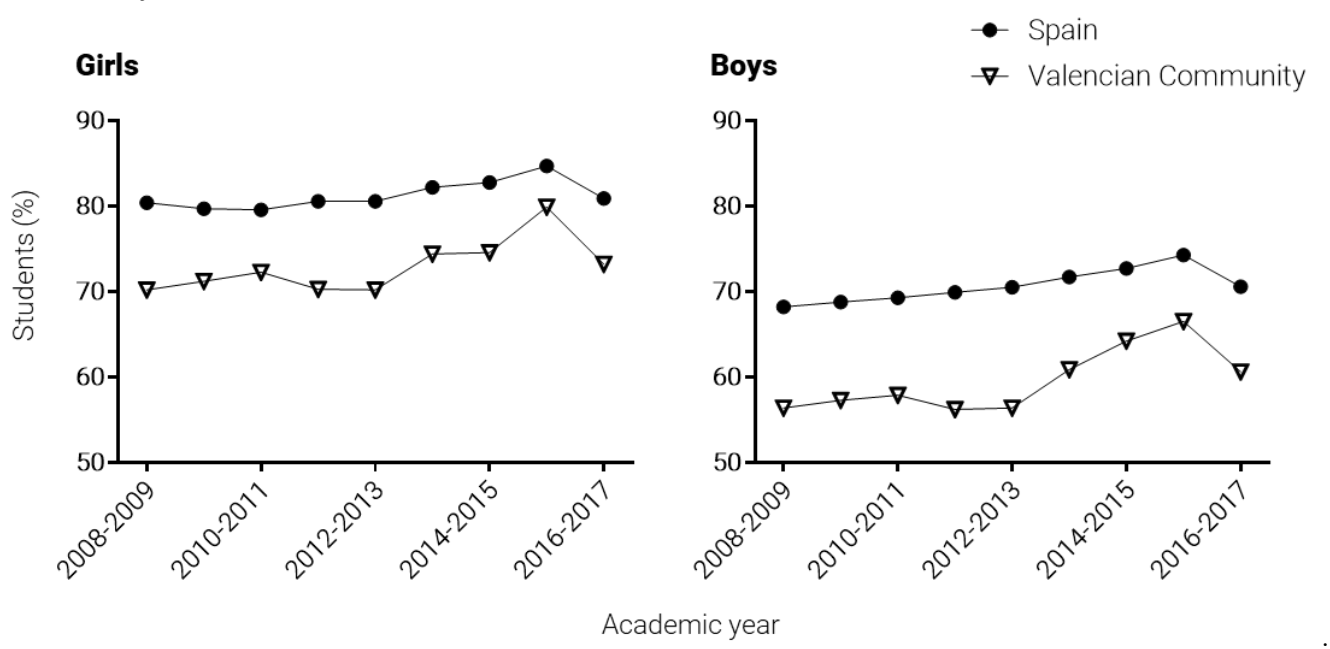

Figure 2. Percentage of students graduated from the secondary school system. 
STANDARDIZED TESTS

Standardized tests can be used to assess academic abilities, attitudes, and even behaviours. One of the most renowned tests of academic performance is included in the Programme for International Student Assessment (PISA), a triennial international survey which evaluates education systems worldwide by assessing the skills and knowledge of students aged 15 years old. According to the last PISA report (2015), Spain showed similar scores in science, better scores in reading and poorer scores in mathematics compared to the mean values of the countries included in the Organisation for Economic Cooperation and Development (OECD) (see figure 3). ${ }^{5}$

Regarding the Valencian Community, students show slightly better scores in science and reading, and lower scores in mathematics compared to the OECD values. ${ }^{5}$

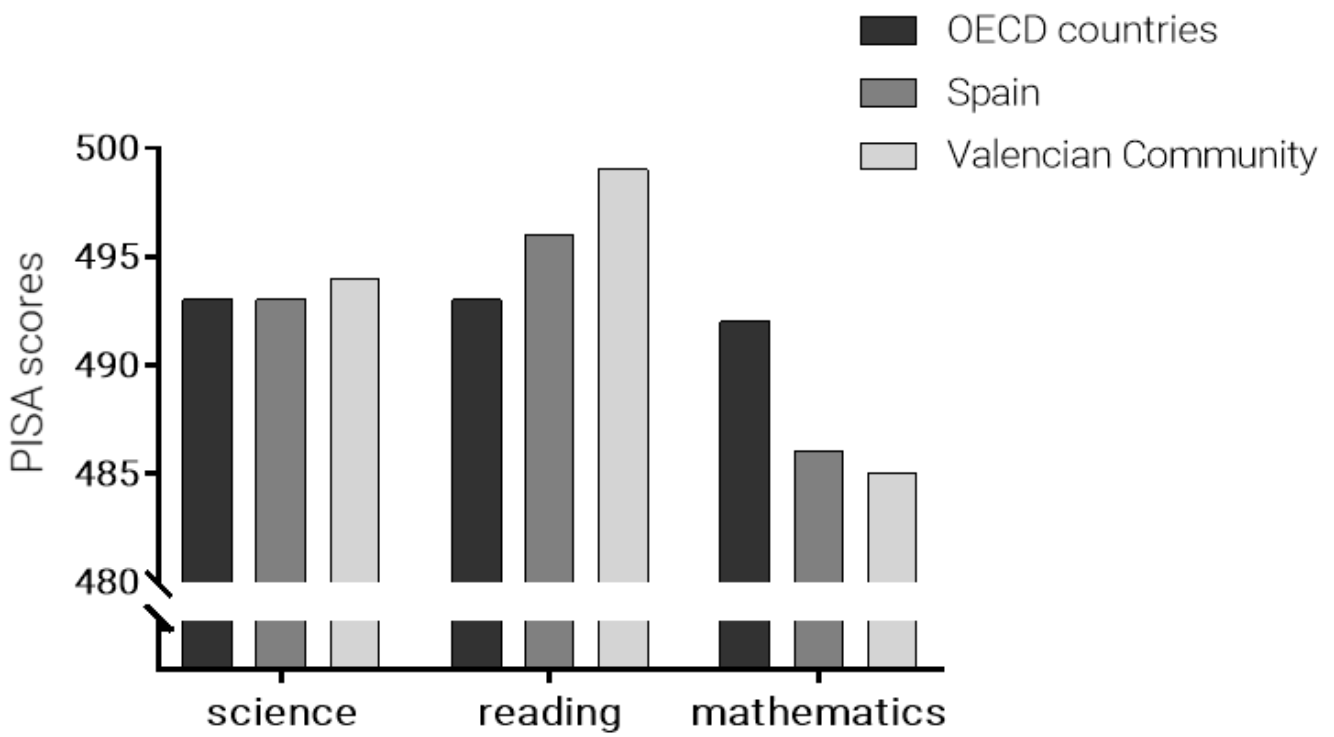

Figure 3. Skills and knowledge results obtained in the Programme for International Student Assessment (PISA) 2015. OECD: Organisation for Economic Cooperation and Development. 


\section{HEALTHY LIFESTYLE FACTORS AND ACADEMIC PERFORMANCE}

Adolescence is a crucial period of life often viewed as an important time frame in terms of development of cognitive skills and establishment of healthy lifestyle factors. Successful academic performance during this life stage is considered a strong predictor not only of future work conditions, ${ }^{6}$ but also of health status. ${ }^{7}$ Thus, to elucidate through solid scientific evidence the influence of healthy lifestyle factors on academic performance in secondary school students is an emerging concern to health and education professionals.

\section{SECTION 1. SLEEP AND ACADEMIC PERFORMANCE}

Sleep is defined as an active, repetitive and reversible brain process of reduced perception and responsiveness to environmental stimuli. 8,9 Sleep patterns, including sleep duration (i.e., total sleep time per night) and sleep quality (i.e., the satisfaction level of the sleep experience) can be subjectively (e.g., sleep logs, questionnaires, interviews) or objectively measured (e.g., actigraphy, polysomnography).

The association between sleep patterns and academic performance has been the focus of a considerable number of studies during the last years. In fact, a large meta-analysis suggested that both, sleep quality and sleep duration were positively related to school performance in children and adolescents. ${ }^{10}$ However, another meta-analysis published only two years later revealed that children's sleep duration (but not sleep quality) was positively associated with executive function and academic performance, but not with intelligence, attention or memory. ${ }^{11}$ More recently, experimental sleep manipulation research in adolescents has indicated that sleep restrictions do not seem to alter cognitive functioning, while sleep disruptions could adversely affect cognition. ${ }^{12}$ Thus, although most of the studies seem to indicate a positive association between sleep and academic performance, results are not conclusive probably due to methodological issues (e.g., heterogeneity in study samples and measurement tools, lack of control for potential confounders, etc.). Therefore, it is of particular interest to clarify the association between sleep and academic performance in order to explore different ways to improve academic performance based on sleep behaviours and practices.

\section{SECTION 2. DIET AND ACADEMIC PERFORMANCE}

Diet represents the quantity, frequency and composition of all food regularly consumed by a person. Thus, diet can be analysed through several issues such as dietary habits (e.g., frequency of consuming carbohydrate foods), dietary patterns (e.g., adherence to the Mediterranean diet, number of meals per day, skipping breakfast), and nutritionrelated disorders (e.g., anorexia nervosa, bulimia nervosa). The analysis of diet can be performed using questionnaires, interviews or even food records. 
There is a growing body of evidence showing that specific dietary habits such as consuming fish, milk, fruits, or vegetables may positively influence academic performance in adolescents. ${ }^{13}$ However, prior literature suggests that due to the synergistic effects of each food components, dietary patterns seem to be more strongly related to cognitive function than individual foods. ${ }^{13}$ For instance, adherence to the Mediterranean diet, characterised by a high consumption of plant based foods, a low intake of red meat, a low-to-moderate consumption of fish, and the use of olive oil as the principal source of fat, has shown to be directly associated with academic performance in adolescents. ${ }^{14,15}$ In addition, other appropriate dietary patterns such as regular five-meal-a-day or not skipping breakfast have also been positively associated with academic performance in youths. ${ }^{16}$

Eating disorders are defined as complex diseases characterised by disruptive eating behaviours. ${ }^{17}$ Some studies have examined the association between these eating disorders and academic performance showing nonconclusive results since inverse ${ }^{18}$ and null ${ }^{19}$ associations have been reported. Since limited research has been undertaken, to elucidate the association between diet and academic performance in secondary school students is important in order to develop effective diet-based interventions within the school context, and thereby to achieve both, health and academic benefits.
SECTION 3. CIRCULATING

INFLAMMATORY BIOMARKERS AND ACADEMIC PERFORMANCE

Inflammation is a natural immune system response to injury, infectious agent or oxidative stress. Despite the fact that this mechanism can confer immune protection, promoting tissue survival, repair, and recovery, a prolonged activation of the peripheral immune system could lead to a state of systemic low-grade inflammation, with deleterious effects on health. ${ }^{20}$

Inflammatory biomarkers can be classified into different groups of proteins with specific effects on a wide variety of biological processes, including immunity and inflammation acute phase response (e.g., white blood cells, C-reactive protein, and cytokines such as interleukin- 6 and tumor necrosis factor- $a$ ), appetite and energy balance, insulin sensitivity and glucose metabolism (e.g., adipokines such as leptin and adiponectin).

\section{Circulating}

inflammatory

biomarkers can be mainly assessed through blood (plasma or serum) and salivary analyses. Interestingly, although salivary analysis offers a less-invasive alternative to blood-based circulating inflammatory biomarkers measurement, it has been proposed that inflammatory biomarkers derived from saliva samples may only reflect systemic inflammation predominately produced by the liver and not that one produced by other tissues. ${ }^{21}$

Inflammatory biomarkers have shown to play a key role in the pathogenesis of several cardiovascular 
and metabolic diseases such as atherosclerosis, diabetes, autoimmune diseases and cancer. ${ }^{22,23}$ Moreover, an emerging body of evidence suggests that high levels of circulating inflammatory biomarkers might alter brain functioning and structure. ${ }^{24}$ In fact, circulating inflammatory biomarkers could access the central nervous system crossing the blood-brain barrier, ${ }^{25}$ and also be expressed by astroglia, microglia, neurons and endothelial cells within the brain. ${ }^{26}$ Thus, it is likely that elevated concentrations of circulating inflammatory biomarkers influence cognitive processes, and in turn, academic performance in youths.

Prior research investigating the relationship between circulating inflammatory biomarkers and cognition in humans have mainly focused on the two endpoints of the lifespan, that is, preterm infants and elderly populations. ${ }^{27-30}$ However, in developing adolescents, limited research has only shown a negative relationship between salivary Creactive protein and cognitive function, ${ }^{31}$ and a negative association of white blood cells, C-reactive protein and interleukin- 6 measured in blood with school grades. ${ }^{32}$ Thus, further studies are needed to clarify how inflammation is linked to cognitive function, as well as to academic performance in secondary school students. This evidence would help education and health professionals to explore new pathways to enhance academic performance.
SECTION 4. PHYSICAL FITNESS AND ACADEMIC PERFORMANCE

Health-related physical fitness can be defined as a summative measure of health and skill-related attributes involved in the performance of physical activity and/or physical exercise, including cardiorespiratory fitness, muscular strength, speed-agility, and body composition. ${ }^{33}$ Cardiorespiratory fitness, reflects the overall capacity of the cardiovascular and respiratory systems, as well as the capacity to carry out prolonged physical exercise. ${ }^{34}$ Muscular strength refers to the ability to carry out work against a resistance, while speedagility is the ability to move the body quickly, changing direction while maintaining control and balance..$^{34}$ Finally, body composition reflects the relative percentage of muscle, fat, bone and other tissues that comprise the body. ${ }^{35}$

Components of physical fitness can be objectively measured using laboratory and field-based tests. Laboratory tests require sophisticated systems and instruments, as well as qualified staff. Field-based tests have been proposed as a good alternative to laboratory tests due to facilities in administration, time efficiency and low cost. Recently, the ALPHA (Assessing Levels of PHysical Activity) has been revealed as strongly reliable health-related fitness test battery for adolescents. ${ }^{36,37}$ The ALPHA battery includes the following tests: 1) the 20-m shuttle run test to assess cardiorespiratory fitness; 2) the handgrip strength and the standing long jump tests to measure upper and lower 
muscular strength, respectively; 3) the 4x10-m shuttle run test to assess speedagility; and 4) body mass index (weight/height squared), waist circumference, and skinfold thicknesses (triceps and subscapular) to assess body composition.

In addition to the well-established positive relationship between physical fitness and health, ${ }^{33,38,39}$ there is an increasing evidence suggesting an association between physical fitness and academic performance during adolescence. 1,40,41 Prior large reviews have reported a strong positive association between cardiorespiratory fitness and adolescents' academic performance, ${ }^{41,42}$ which may be related to the positive influence of cardiorespiratory fitness on brain structure and function. ${ }^{43}$ In addition, unhealthy body composition (i.e., overweight and obesity) has shown to negatively influence academic performance in adolescents. ${ }^{44}$ However, the relationship of muscular strength and speed-agility with academic performance remains unclear. ${ }^{41}$ Thus, a deeper understanding of the association between physical fitness components and academic performance in secondary school students is needed to establish feasible and effective intervention programs aimed to promote both, positive health and better academic performance.

SECTION 5. PHYSICAL ACTIVITY,
SEDENTARY BEHAVIOURS AND
ACADEMIC PERFORMANCE

\footnotetext{
Physical activity and sedentary behaviours are related, but not
}

complementary concepts. Physical activity reflects any bodily movement produced by skeletal muscles that implies an increase in energy expenditure. ${ }^{34}$ However, sedentary behaviours can be defined as sitting or lying down activities which do not involve an increasing of energy expenditure. ${ }^{45}$ Although physical activity and sedentary behaviours are different constructs, both can be assessed using subjective (e.g., questionnaires, interviews) or objective tools (e.g., actigraphy, pedometers, calorimetry).

A growing body of literature suggests that regular physical activity may positively influence academic performance during adolescence. ${ }^{42,46}$ In addition, there is a strong evidence revealing a negative association between sedentary behaviours and adolescents' academic performance. ${ }^{47}$ Specifically, screen media usage has shown to be the most popular leisure-time sedentary behaviour among secondary school students, with a $28 \%$ of them engaged in screen-based sedentary activities more than $4 \mathrm{~h}$ per day. ${ }^{48}$ However, the vast majority of previous studies assessed physical activity and sedentary behaviours using subjective tools.

More investigation is still needed for a better understanding of the association of physical activity and sedentary behaviours with academic performance in secondary school students in order to design new strategies for the improvement of health and academic performance. 


\section{REFERENCES}

1. Donnelly JE, Hillman $\mathrm{CH}$, Castelli $\mathrm{D}$, Etnier JL, Lee S, Tomporowski P, Lambourne K, Szabo-Reed A. Physical activity, fitness, cognitive function, and academic achievement in children: a systematic review. Med Sci Sports Exerc. 2016; 48(6): 1197-1222.

doi:10.1249/MSS.0000000000000901

2. Fernández Enguita $M$, Mena Martínez L, Rivière Gómez J. Fracaso y abandono escolar en España. Vol 29. Barcelona; 2010.

3. Spanish Ministry of Education and Vocational Training. Enseñanzas no universitarias. Alumnado. Resultados académicos - Ministerio de Educación, Cultura y Deporte. 2018. [Accessed January 7, 2019]. Available from: http://www.educacionyfp.gob.es/servicio s-al-ciudadano-

mecd/estadisticas/educacion/no-

universitaria/alumnado/resultados.html.

4. Bull R, Scerif G. Executive functioning as a predictor of children's mathematics ability: inhibition, switching, and working memory. Dev Neuropsychol. 2001; 19(3): 273-293.

doi:10.1207/S15326942DN1903_3

5. Organisation for Economic Cooperation and Development. PISA 2015. Results in focus. 2018. [Accessed May 11, 2019]. Available from: http://www.oecd.org/pisa /pisa-2015-results-in-focus.pdf.
6. French MT, Homer JF, Popovici I, Robins PK. What you do in high school matters: high school GPA, educational attainment, and labor market earnings as a young adult. East Econ J. 2015; 41(3): 370-386. doi:10.1057/eej.2014.22

7. Lê-Scherban F, Diez Roux A V., Li Y, Morgenstern $H$. Does academic achievement during childhood and adolescence benefit later health? Ann Epidemiol. 2014; 24(5): 344-355. doi:10.1016/j.annepidem.2014.02.008

8. Dahl RE, Lewin DS. Pathways to adolescent health: Sleep regulation and behavior. J Adolesc Heal. 2002; 31(6 SUPPL.): 175-184. doi:10.1016/S1054139X(02)00506-2

9. Krueger JM, Frank MG, Wisor JP, Roy S. Sleep function: Toward elucidating an enigma. Sleep Med Rev. 2016; 28: 42-50. doi:10.1016/j.smrv.2015.08.005

10. Dewald JF, Meijer AM, Oort FJ, Kerkhof GA, Bogels SM. The influence of sleep quality, sleep duration and sleepiness on school performance in children and adolescents: A meta-analytic review. Sleep Med Rev. 2010; 14(3): 179189. doi:10.1016/j.smrv.2009.10.004

11. Astill RG, Van der Heijden KB, Van Ijzendoorn MH, Van Someren EJW. Sleep, cognition, and behavioral problems in school-age children: A century of research meta-analyzed. Psychol Bull. 2012; 138(6): 1109-1138. doi:10.1037/a0028204 
12. Bruin EJ De, Run C Van, Staaks J, Meijer AM. Effects of sleep manipulation on cognitive functioning of adolescents: a systematic review. Sleep Med Rev. 2017: 32: 45-57.

doi:10.1016/j.smrv.2016.02.006

13. Burrows T, Goldman S, Pursey K, Lim $\mathrm{R}$. Is there an association between dietary intake and academic achievement: a systematic review. J Hum Nutr Diet. 2017; 30(2): 117-140. doi:10.1111/jhn.12407

14. Esteban-Cornejo I, Izquierdo-Gomez R, Gómez-Martínez S, Padilla-Moledo C, Castro-Piñero J, Marcos A, Veiga OL. Adherence to the Mediterranean diet and academic performance in youth: the UP\&DOWN study. Eur J Nutr. 2016; 55(3): 1133-1140. doi:10.1007/s00394-0150927-9

15. Vassiloudis I, Yiannakouris $\mathrm{N}$, Panagiotakos DB, Apostolopoulos K, Costarelli $V$. Adherence to the Mediterranean diet and specific lifestyle habits are associated with academic performance in Greek adolescents. Med J Nutrition Metab. 2017; 10(2): 93-103. doi:10.3233/MNM-16133

16. Kim SY, Sim S, Park B, Kong IG, Kim J$H$, Choi HG. Dietary habits are associated with school performance in adolescents. Medicine (Baltimore). 2016; 95(12): e3096.

doi:10.1097/MD.0000000000003096

17. Mairs R, Nicholls D. Assessment and treatment of eating disorders in children and adolescents. Arch Dis Child. 2016; 101(12): 1168-1175.

doi:10.1136/archdischild-2015-309481

18. Veses AM, Gómez-Martínez S, Pérez de Heredia F, Esteban-Cornejo I, Castillo R, Estecha S, García-Fuentes M, Veiga OL, Calle ME, Marcos A. Cognition and the risk of eating disorders in Spanish adolescents: the AVENA and AFINOS studies. Eur J Pediatr. 2015; 174: 229-236. doi:10.1007/s00431-014-2386-3

19. Gil García E, Ortiz Gómez T, Fernández Soto ML. Social profiles, diet, and prediction of eating disorders in urban andalusian adolescents. Aten primaria. 2007; 39(1): 7-11. doi:10.1157/13098270

20. Brüünsgaard $H$, Pedersen BK. Agerelated inflammatory cytokines and disease. Immunol Allergy Clin North Am. 2003; 23(1): 15-39. doi:10.1016/S08898561(02)00056-5

21. Salimetrics. Salivary biomarkers of inflammation. Salivary Bioscience Bulletin; 2011.

22. Hotamisligil GS. Inflammation and metabolic disorders. Nature. 2006; 444(7121): 860-867.

doi:10.1038/nature05485

23. Libby P. Inflammation and cardiovascular disease mechanisms. Am J Clin Nutr. 2006; 83(2): 456S-460S. doi:10.1093/ajcn/83.2.456S 
24. McAfoose J, Baune BT. Evidence for a cytokine model of cognitive function. Neurosci Biobehav Rev. 2009; 33(3): 355366. doi:10.1016/j.neubiorev.2008.10.005

25. Banks WA, Lynch JL, Price TO. Cytokines and the blood-brain barrier. In: The neuroimmunological basis of behavior and mental disorders. Boston, MA: Springer US; 2009: 3-17. doi:10.1007/978-0-387-84851-8_1

26. Dantzer R, O'Connor JC, Freund GG, Johnson RW, Kelley KW. From inflammation to sickness and depression: when the immune system subjugates the brain. Nat Rev Neurosci. 2008; 9(1): 46-56. doi:10.1038/nrn2297

27. Kuban KCK, Joseph RM, O'Shea TM, Heeren $T$, Fichorova RN, Douglass $L$, Jara H, Frazier JA, Hirtz D, Rollins JV, Paneth $N$. Circulating inflammatory-associated proteins in the first month of life and cognitive impairment at age 10 years in children born extremely preterm. J Pediatr. 2017; 180: 116-123.e1.

doi:10.1016/j.jpeds.2016.09.054

28. O'Shea TM, Shah B, Allred EN, Fichorova RN, Kuban KCK, Dammann O, Leviton A. Inflammation-initiating illnesses, inflammation-related proteins, and cognitive impairment in extremely preterm infants. Brain Behav Immun. 2013; 29: 104-112.

doi:10.1016/j.bbi.2012.12.012

29. Rose J, Vassar R, Cahill-Rowley K, Hintz SR, Stevenson DK. Neonatal biomarkers of inflammation: correlates of early neurodevelopment and gait in verylow-birth-weight preterm children. Am J Perinatol. 2015; 33(1): 71-78. doi:10.1055/s-0035-1557106

30. Yang J, Fan C, Pan L, Xie M, He Q, Li D, Wang S. C-reactive protein plays a marginal role in cognitive decline: a systematic review and meta-analysis. Int J Geriatr Psychiatry. 2015; 30(2): 156-165. doi:10.1002/gps.4236

31. Cullen AE, Tappin BM, Zunszain PA, Dickson $H$, Roberts RE, Nikkheslat $N$, Khondoker $\mathrm{M}$, Pariante $\mathrm{CM}$, Fisher $\mathrm{HL}$, Laurens KR. The relationship between salivary C-reactive protein and cognitive function in children aged 11-14 years: Does psychopathology have a moderating effect? Brain Behav Immun. 2017; 66: 221-229. doi:10.1016/j.bbi.2017.07.002

32. Esteban-Cornejo I, Martinez-Gomez D, Gómez-Martínez S, del Campo-Vecino J, Fernández-Santos J, Castro-Piñero J, Marcos A, Veiga OL. Inflammatory biomarkers and academic performance in youth. The UP \& DOWN Study. Brain Behav Immun. 2016; 54: 122-127. doi:10.1016/j.bbi.2016.01.010

33. Ruiz JR, Castro-Piñero J, Artero EG, Ortega FB, Sjöström M, Suni J, Castillo MJ. Predictive validity of health-related fitness in youth: A systematic review. $\mathrm{Br} \mathrm{J}$ Sports Med. 2009; 43(12): 909-923. doi:10.1136/bjsm.2008.056499

34. Ortega FB, Cadenas-Sanchez C, Lee D, Ruiz JR, Blair SN, Sui X. Fitness and fatness as health markers through the 
lifespan. An overview of current knowledge. Prog Prev Med. 2018; 3(2): e0013.

35. Corbin CB, Lindsey R, Welk G. Concepts of physical fitness: active lifestyles for wellness. 13th edition. New York: McGraw-Hill; 2006.

36. Ruiz JR, Castro-Piñero J, EspañaRomero V, Artero EG, Ortega FB, Cuenca MM, Jimenez-Pavón D, Chillón P, GirelaRejón MJ, Mora J, Gutiérrez A, Suni J, Sjöström M, Castillo MJ. Field-based fitness assessment in young people: The ALPHA health-related fitness test battery for children and adolescents. $\mathrm{Br} \mathrm{J}$ Sports Med. 2011; 45(6): 518-524.

doi:10.1136/bjsm.2010.075341

37. Castro-Piñero J, Artero EG, EspañaRomero V, Ortega FB, Sjöström M, Suni J, Ruiz JR. Criterion-related validity of fieldbased fitness tests in youth: a systematic review. Briitish J Sport Med. 2010; 44(13): 934-943. doi:10.1136/bjsm.2009.058321

38. Ortega FB, Ruiz JR, Castillo MJ, Sjöström M. Physical fitness in childhood and adolescence: a powerful marker of health. Int J Obes. 2008; 32(1): 1-11. doi:10.1038/sj.ijo.0803774

39. Smith JJ, Eather $\mathrm{N}$, Morgan PJ, Plotnikoff RC, Faigenbaum AD, Lubans DR. The health benefits of muscular fitness for children and adolescents: a systematic review and meta-analysis. Sport Med. 2014; 44(9): 1209-1223. doi:10.1007/s40279-014-0196-4
40. Fonseca del Pozo F, Valle Alonso J, Vaquero Álvarez $M$, Orr $S$, Llorente Cantarero F. Physical fitness as an indicator of health status and its relationship to academic performance during the prepubertal period. Heal Promot Perspect. 2017; 7(4): 197-204. doi:10.15171/hpp.2017.35

41. Santana CCA, Azevedo LB, Cattuzzo MT, Hill JO, Andrade LP, Prado WL. Physical fitness and academic performance in youth: a systematic review. Scand J Med Sci Sport. 2017; 27(6): 579-603. doi:10.1111/sms. 12773

42. Marques A, Santos DA, Hillman $\mathrm{CH}$, Sardinha LB. How does academic achievement relate to cardiorespiratory fitness, self-reported physical activity and objectively reported physical activity: a systematic review in children and adolescents aged 6-18 years. Br J Sports Med. 2018; 52(16): 1039.

doi:10.1136/bjsports-2016-097361

43. Chaddock L, Erickson KI, Prakash RS, Kim JS, Voss MW, VanPatter M, Pontifex $\mathrm{MB}$, Raine LB, Konkel A, Hillman $\mathrm{CH}$, Cohen NJ, Kramer AF. A neuroimaging investigation of the association between aerobic fitness, hippocampal volume, and memory performance in preadolescent children. Brain Res. 2010; 1358: 172-183. doi:10.1016/j.brainres.2010.08.049

44. Saevarsson ES, Gudmundsdottir SL, Kantomaa M, Arngrimsson SA, Sveinsson T, Skulason S, Johannsson E. Above average increases in body fat from 9 to 15 years of age had a negative impact on 
academic performance, independent of physical activity. Acta Paediatr. 2019; 108(2): 347-353. doi:10.1111/apa.14459

45. Pate RR, O'Neill JR, Lobelo F. The evolving definition of "sedentary". Exerc Sport Sci Rev. 2008; 36(4): 173-178. doi:10.1097/JES.0b013e3181877d1a

46. Álvarez-Bueno C, Pesce C, CaveroRedondo I, Sánchez-López M, GarridoMiguel M, Martínez-Vizcaíno V. Academic achievement and physical activity: a meta-analysis. Pediatrics. 2017; 140(6): e20171498. doi:10.1542/peds.2017-1498

47. Carson V, Hunter S, Kuzik N, Gray CE, Poitras VJ, Chaput JP, Saunders TJ, Katzmarzyk PT, Okely AD, Connor Gorber S, Kho ME, Sampson M, Lee H, Tremblay MS. Systematic review of sedentary behaviour and health indicators in schoolaged children and youth: an update. Appl Physiol Nutr Metab. 2016; 41: S240-S265. doi:10.1139/apnm-2015-0630

48. Marshall SJ, Gorely T, Biddle SJH. A descriptive epidemiology of screen-based media use in youth: a review and critique. $J$ Adolesc. 2006; 29(3): 333-349. doi:10.1016/j.adolescence.2005.08.016 


\section{Aims}

[Objetivos] 


\section{AIMS}

The main aim of this $\mathrm{PhD}$ Thesis was to investigate the associations and the possible mechanisms between healthy lifestyle factors and academic performance in secondary school students.

The aim mentioned above was approached by the following specific aims according to five sections:

SECTION 1. SLEEP AND ACADEMIC PERFORMANCE

- To analyse the association between sleep patterns and academic performance in secondary school students (Studies 1, 2, 8).

- To examine the role of screen media usage on the association between sleep patterns and academic performance in secondary school students (Study 2).

SECTION 2. DIET AND ACADEMIC PERFORMANCE

- To analyse the association between dietary patterns and academic performance in secondary school students (Studies 3, 8).

- To examine the role of sleep patterns on the association between dietary patterns and academic performance in secondary school students (Study 3).

- To analyse the association between the risk of eating disorders and academic performance in secondary school students (Study 4).
SECTION 3. CIRCULATING

INFLAMMATORY BIOMARKERS AND

ACADEMIC PERFORMANCE

- To analyse the association between circulating inflammatory biomarkers and academic performance in secondary school students (Study 5).

SECTION 4. PHYSICAL FITNESS AND ACADEMIC PERFORMANCE

- To analyse the association between physical fitness and academic performance in secondary school students (Studies 6, 7).

- To examine the role of leptin on the association between physical fitness and academic performance in secondary school students (Study 6).

- To examine the role of body composition on the association between physical fitness and academic performance in secondary school students (Study 7).

SECTION 5. PHYSICAL ACTIVITY, SEDENTARY BEHAVIOURS AND ACADEMIC PERFORMANCE

- To analyse the association of physical activity and sedentary behaviours with academic performance in secondary school students (Study 8). 


\section{OBJETIVOS}

El objetivo principal de la presente Tesis Doctoral fue investigar las asociaciones y los posibles mecanismos entre los hábitos saludables y el rendimiento académico en estudiantes de educación secundaria obligatoria.

El objetivo arriba mencionado se alcanzó a través de los siguientes objetivos específicos estructurados en cinco secciones:

SECCIÓN 1. SUEÑO Y RENDIMIENTO ACADÉMICO

- Analizar la asociación entre patrones de sueño y rendimiento académico en estudiantes de educación secundaria obligatoria (Estudios 1, 2, 8).

- Examinar el papel del tiempo empleado en actividades de pantalla en la asociación entre patrones de sueño y rendimiento académico en estudiantes de educación secundaria obligatoria (Estudio 2).

\section{SECCIÓN 2. DIETA Y RENDIMIENTO} ACADEMICO

- Analizar la asociación entre patrones de dieta y rendimiento académico en estudiantes de educación secundaria obligatoria (Estudios 3, 8).

- Examinar el papel de los patrones de sueño en la asociación entre patrones de dieta y rendimiento académico en estudiantes de educación secundaria obligatoria (Estudio 3).

- Analizar la asociación entre el riesgo de padecer trastornos de la alimentación y el rendimiento académico en estudiantes de educación secundaria obligatoria (Estudio 4).

SECCIÓN 3. BIOMARCADORES DE INFLAMACIÓN Y RENDIMIENTO ACADÉMICO

- Analizar la asociación entre los biomarcadores de inflamación y el rendimiento académico en estudiantes de educación secundaria obligatoria (Estudio 5).

SECCIÓN 4. CONDICIÓN FISICA Y RENDIMIENTO ACADÉMICO

- Analizar la asociación entre la condición física y el rendimiento académico en estudiantes de educación secundaria obligatoria (Estudios 6, 7).

- Examinar el papel de la leptina en la asociación entre condición física y rendimiento académico en estudiantes de educación secundaria obligatoria (Estudio 6).

- Examinar el papel de la composición corporal en la asociación entre condición física y rendimiento académico en estudiantes de educación secundaria obligatoria (Estudio 7).

SECCIÓN 5. ACTIVIDAD FÍSICA, COMPORTAMIENTOS SEDENTARIOS Y RENDIMIENTO ACADÉMICO

- Analizar la asociación de la actividad física y los comportamientos sedentarios con el rendimiento académico en estudiantes de educación secundaria obligatoria (Estudio 8). 
Manuscripts 
Study 1

Associations between objectively measured and selfreported sleep with academic and cognitive performance in adolescents: DADOS study 


\title{
Associations between objectively measured and self-reported sleep with academic and cognitive performance in adolescents: DADOS study
}

\author{
Mireia Adelantado-Renau ${ }^{1}$ (i) | Maria Reyes Beltran-Valls ${ }^{1}$ | Jairo H. Migueles ${ }^{2}$ | \\ Enrique G. Artero $^{3,4}$ | Alejandro Legaz-Arrese ${ }^{5}$ | Ana Capdevila-Seder ${ }^{1}$ | \\ Diego Moliner-Urdiales ${ }^{1}$
}

${ }^{1}$ LIFE Research Group, University Jaume I, Castellón, Spain

${ }^{2}$ PROFITH "PROmoting FITness and Health through physical activity" Research Group. Department of Physical and Sports Education, Faculty of Sport Sciences, University of Granada, Granada, Spain ${ }^{3}$ Department of Education. Faculty of Education Sciences, University of Almeria, Almeria, Spain

${ }^{4}$ SPORT Research Group (CTS-1024) CERNEP Research Center, University of Almería, Almería, Spain

${ }^{5}$ Section of Physical Education and Sports, University of Zaragoza, Zaragoza, Spain

Correspondence

Diego Moliner-Urdiales, Human Sciences Faculty, Department of Education, University Jaume I, Castellon, Spain.

Email: dmoliner@uji.es

Funding information

University Jaume I of Castellon, Grant/ Award Number: P1.1A2015-05; Spanish Ministry of Economy and Competitiveness, Grant/Award Number: DEP2013-45515-R

\begin{abstract}
Summary
Adequate sleep has been positively related with health and school achievement outcomes during adolescence. The aim of this study was to investigate the associations of objectively measured and self-reported sleep duration and quality with academic and cognitive performance in adolescents. This study was conducted with 257 adolescents (13.9 \pm 0.3 years) from the DADOS study (Deporte, ADOlescencia y Salud). Objectively measured and self-reported sleep duration and quality were obtained by a wristworn GENEActiv accelerometer and the Spanish version of Pittsburgh Sleep Quality Index questionnaire, respectively. Academic performance was analysed through schoo records using four indicators: math, language, science and grade point average score. Cognitive performance was measured using the Spanish version of the "SRA Test of Educational Ability". After Benjamini-Hochberg correction for the false discovery rate, objectively measured sleep duration was negatively associated with verbal ability ( $\beta$ $=-0.179, p=.004)$, whilst self-reported sleep quality was positively associated with academic performance $(\beta$ ranging from 0.209 to 0.273 ; all $p<.001$ ). These associations remained significant after further controlling for physical fitness and physical activity. Conversely, there were no associations between self-reported sleep duration and objective sleep quality with academic and cognitive performance. Our findings fit in line with previous research showing that sleep quality may play an important role on adolescents' academic performance. Further interventional research is needed to clar ify the mechanisms by which sleep is related to academic performance in youth.

KEYWORDS

adolescence, cognition, school performance, sleep patterns
\end{abstract}

\section{1 | INTRODUCTION}

Sleep is defined as an active, repetitive and reversible brain process of reduced perception and responsiveness to environmental stimuli (Dahl \& Lewin, 2002; Krueger, Frank, Wisor, \& Roy, 2016). Insufficient sleep duration and quality have emerged as critical indicators for physical and mental health, being associated with adverse health consequences such as obesity, diabetes, cardiovascular risk, cognitive diseases or cancer (Chaput et al., 2016; Owens, 2014). During adolescence, often viewed as an important time frame in terms of acquisition and development of academic and cognitive skills (Andersen, 2016; Patton \& Viner, 2007), sleep might play a key role in memory 
consolidation, brain plasticity (Frank \& Benington, 2006) and cognitive functioning (Shochat, Cohen-Zion, \& Tzischinsky, 2014; Wheaton, Chapman, \& Croft, 2016). Likewise, sleep seems to be essential to achieve academic success, which is closely linked to future work achievement, wealth and health status (French, Homer, Popovici, \& Robins, 2015).

The relationship between sleep and cognition in youth has been the focus of a considerable number of studies during the last decade. Dewald, Meijer, Oort, Kerkhof, and Bogels (2010) revealed that sleepiness was the sleep variable more strongly related to school performance $(r=-133)$, followed by sleep quality $(r=.096)$ and sleep duration $(r=.069)$. Two years later, a large meta-analysis conducted by Astill, Van der Heijden, Van ljzendoorn, and Van Someren (2012) reported a positive association of sleep duration (but not sleep efficiency) with children's executive functioning and school performance, but not with intelligence, attention or memory. In addition, experimental sleep manipulation research has shown that restricted sleep had small or no effects on cognitive functioning, while disrupted sleep could seriously affect cognitive processes in adolescents (De Bruin, van Run, Staaks, \& Meijer, 2017).

Despite the fact that most studies indicate a positive association of sleep variables with academic and cognitive performance, results are not conclusive probably due to methodological limitations (Curcio, Ferrara, \& De Gennaro, 2006; De Bruin et al., 2017; Dewald et al., 2010; Wang et al., 2016). In fact, the vast majority of previous studies assessed sleep duration and quality using subjective tools (e.g. sleep logs, questionnaires or interviews), included only grade point average (GPA) score or indirect teachers' reports as academic performance indicators, focused on adolescents with sleep disturbances, or did not control for potential confounders with great influence on sleep and cognition such as socioeconomic level, physical activity (PA) or physical fitness (Álvarez-Bueno et al., 2017; Coe, Peterson, Blair, Schutten, \& Peddie, 2013; Mota \& Vale, 2010; Shochat et al., 2014). Thus, the present study aimed to analyse the associations of objectively measured and self-reported sleep duration and quality with academic and cognitive performance in healthy adolescents.

\section{2 | METHODS}

\section{1 | Participants}

The DADOS (Deporte, ADOlescencia y Salud) Study is a 3-year longitudinal research project (from 2015 to 2017) aimed to assess the influence of competitive PA on health, cognition and psychological wellness through adolescence. All the participants were recruited from secondary schools and sport clubs, and met the general DADOS inclusion criteria: born in 2001, enrolled in 2nd grade of secondary school and free of any chronic disease. From the total DADOS study sample $(n=274)$, a sub-sample with 257 adolescents (135 boys) with valid baseline data for at least sleep variables and academic and cognitive performance were included in the analysis.

Adolescents and their parents or guardians were informed of the nature and characteristics of the study, and all provided a written informed consent. The DADOS study protocol was designed in accordance with the ethical guidelines of the Declaration of Helsinki 1961 (last revision of Fortaleza, Brazil, 2013) and approved by the Research Ethics Committee of the University Jaume I of Castellon.

\section{2 | Anthropometry}

Anthropometric characteristics were assessed twice by trained members of the DADOS research group following standardized procedures (Beltran-Valls et al., 2018). Average measures were used for data analysis. Briefly, body weight was measured to the nearest $0.1 \mathrm{~kg}$ using an electronic scale (SECA 861, Hamburg, Germany), lightly dressed and without shoes. Height was measured to the nearest $0.1 \mathrm{~cm}$ using a wall-mounted stadiometer (SECA 213, Hamburg, Germany). Body mass index was calculated as weight/height square $\left(\mathrm{kg} \mathrm{m}^{-2}\right)$.

\section{3 | Objectively measured and self-reported sleep duration}

Daily sleep duration was objectively measured using a triaxial GENEActiv accelerometer (Activinsights, Kimbolton, UK). Participants wore the accelerometer on their non-dominant wrist for at least four consecutive 24-hr days, including two weekend days and two weekdays. This device has been found to be valid to examine sleep ( $\kappa=$ $0.85[0.06]$ ) (te Lindert \& Van Someren, 2013). Accelerometers were programmed to collect data at a sampling frequency of $100 \mathrm{~Hz}$. Data were stored in gravity $(\mathrm{g})$ units $\left(1 \mathrm{~g}=9.81 \mathrm{~m} \mathrm{~s}^{-2}\right)$. The raw acceleration output was aggregated in 1-5 epochs using the GENEActiv postprocessing PC software (version 2.2; GENEActiv). Sleep duration was calculated using the Sadeh algorithm (Sadeh, Sharkey, \& Carskadon, 1994), implemented in the Excel macro provided by the Activinsights company, and expressed as average hours per day.

Subjective information on sleep duration was estimated from the Pittsburgh Sleep Quality Index (PSQI) questionnaire (Royuela Rico \& Macias Fernández, 1997) through the following questions: "during the past month, when have you usually gone to bed at night?" and "during the past month, when have you usually gotten up in the morning?" Sleep duration was calculated as the difference between bedtime and time for getting up.

\subsection{Objectively measured and self-reported sleep quality}

We derived sleep efficiency $\%$, [total sleep time/assumed sleep time] $\times 100$ ) as an objective indicator of sleep quality assessed by GENEActiv accelerometer $(\kappa=0.85[0.06])$ (te Lindert \& Van Someren, 2013). The raw acceleration output was aggregated in 60-s epochs using the GENEActiv postprocessing PC software. Sleep efficiency was measured by the sleep-wake scoring algorithm (Sadeh et al., 1994) included in the macro provided by the Activinsights company and expressed as average percentage per day.

Likewise, the total score from the Spanish version of the PSQI questionnaire was used as a subjective indicator of sleep quality over 
the last month (Royuela Rico \& Macías Fernández, 1997). It includes 19 questions in seven components of sleep quality: subjective sleep quality, sleep duration, sleep latency, habitual sleep efficiency, sleep disturbance, use of sleep medication, and daytime dysfunction. The seven component scores are rated on a 3-point ascending scale, ranging the global score of the PSQI from 0 to 21 (Cronbach's $\alpha=$ 0.81). Because higher values in the global PSQI score indicate worse sleep quality, values were reversed.

\subsection{Academic and cognitive performance}

Based on the information provided by each school's secretary office, academic performance was assessed through the final grades from the 1st course of secondary school using four indicators: math, language, science and GPA score. Language is the grade of Catalan; the official teaching language at school. GPA score was defined as the single average for geography and history, science, math, Spanish, Catalan, English and physical education grades. All the subjects were rated with a 10-point scale, where 0 is the worst and 10 is the best.

Cognitive performance was measured using the Spanish version of the validated Science Research Associates Test of Academic Abilities (Thurstone \& Thurstone, 2004). This test measures the subject's ability to learn by evaluating three basic skills: verbal ability (command of language); numeric ability (speed and precision in performing operations with numbers and quantitative concepts); and reasoning ability (the aptitude to find logical ordination criteria in sets of numbers, figures or letters). Scores for the three areas were obtained by adding positive answers. Overall academic ability was calculated by adding the three area scores (verbal + numeric + reasoning). This battery test provides three complexity levels based on the age range of the sample. The present work used the level 3 designed for adolescents aged $14-18$ years (reliability: verbal $\alpha=$ 0.74 , numeric $\alpha=0.87$, reasoning $\alpha=0.77$, and overall academic ability $\alpha=0.89$; Thurstone $\&$ Thurstone, 2004).

\section{6 | Covariates}

Pubertal stage was self-reported according to the five stages defined by Tanner and Whitehouse (1976). It is based on external primary and secondary sex characteristics, which are described by the participants using standard pictures according to Tanner instructions.

The Family Affluence Scale "FAS" developed by Currie et al. (2008) was used as a proxy of socioeconomic status (SES), which is based on material conditions in the family such as car ownership, bedroom occupancy, computer ownership and home internet access.

Cardiorespiratory fitness (CRF) was assessed using the 20-m Shuttle Run Test as described by Léger, Mercier, Gadoury, and Lambert (1988). The number of finished laps was registered for each participant. Likewise, maximum oxygen uptake $\left(\mathrm{VO}_{2 \max }, \mathrm{ml} \mathrm{kg}^{-1} \mathrm{~min}^{-\mathbf{1}}\right)$ was estimated using the equations reported by Léger et al. (1988). Because this equation uses stages completed instead of laps, we decided to use the number of laps to not lose sensitivity in the measure.
Participants' PA level was objectively measured using the GENEActiv accelerometer. This device provides a reliable fcoefficient of variation intra-instrument $=1.4 \%$ and coefficient of variation inter-instrument $=2.1 \%$; Esliger et al., 2011) and valid assessment of PA in young people ( $r=.925, p=.001$; Phillips, Parfitt, \& Rowlands, 2013) The raw acceleration output was aggregated in 1-s epochs using the GENEActiv post-processing PC software, and PA was expressed as average minutes per day in sedentary, light, moderate and vigorous PA. According to Phillips et al. (2013), GENEActiv cut-off points for sedentary, light, moderate and vigorous intensities in children are < $7,7-19,20-60$ and $>60 \mathrm{mg}$.

\section{7 | Data analysis}

Study sample characteristics are presented as mean \pm standard deviation and percentages for continuous and categorical variables, respectively. All variables were checked for normality using both graphical (normal probability plots) and statistical (Kolmogorov-Smirnov test) procedures. Due to its skewed distribution, moderate PA vigorous PA, and moderate-to-vigorous PA (MVPA) were log-transformed before analysis. As preliminary analyses showed no significant interactions of sex with sleep variables in relation to academic and cognitive performance (all $p>.10$ ), all analyses were performed for the whole sample.

Sex differences were assessed using t-test for continuous variables and chi-squared test for nominal variables. The effect size, Cohen's $d$, was calculated and interpreted following the cut-offs established by Cohen (1988): small ( $\sim 0.20)$, medium ( 0.5) or large ( 0.8$)$. In addition, intra-class correlation coefficients (ICC) were performed by using two-way mixed models to investigate the agreement between objectively measured and self-reported sleep variables.

We performed partial correlations controlling for sex, pubertal stage and SES to examine the relationship among sleep variables, academic and cognitive performance. Likewise, linear regressions were used to analyse the associations of objectively measured and self-reported sleep duration and quality with academic and cognitive performance. A total of three regression models were performed including different cofounders: model 1 included sex, pubertal stage and SES; model 2 included model 1 plus CRF (laps); model 3 included model 1 plus MVPA.

Additionally, we divided the sample based on objective and selfreported sleep duration (short: $<8 \mathrm{hr}$ versus long: $\geq 8 \mathrm{hr}$; Hirshkowitz et al., 2015), and sleep quality categories (poor versus good; objective: $<85 \%$ versus $\geq 85 \%$; self-reported: PSQI $>5$ versus $\leq 5$; Buysse, Reynolds, Monk, Berman, \& Kupfer, 1989), and analysed the differences between-groups in academic and cognitive performance using one-way analysis of covariance (ANCOVA) adjusted for sex, pubertal stage and SES. For each ANCOVA effect, a Cohen's $d$ is reported (Cohen, 1988).

We conducted the Benjamini-Hochberg correction for assessing multiple comparisons between sleep (duration and quality) and academic and cognitive performance, by defining statistical significance 
as a Benjamini-Hochberg false discovery rate "Q" $<0.05$ (Benjamini \& Hochberg, 1995). All the analyses were performed using the IBM SPSS Statistics for Windows version 22.0 (IBM, Armonk, NY), and the level of significance was set to $p<.05$.

\section{3 | RESULTS}

Table 1 shows the descriptive characteristics of the participants. Boys presented lower SES $(p<.05)$, were taller, more physically active, and showed higher levels of physical fitness than girls (all $p$ $<.001)$. Objective measurements of both sleep duration and quality were significantly higher in girls, while self-reported sleep duration and quality were significantly higher in boys (all $p<.05$ ). There were no differences between sexes in academic performance but, regarding cognitive performance, boys showed higher numeric ability than girls $(14.8$ versus $12.0 ; p<.001)$. ICCS showed very low agreement between objectively measured and self-reported sleep duration (ICC $=0.16 ; p=.072$ ), and no agreement between objectively measured and self-reported sleep quality ( $\mid C C=0.00 ; p=.458$ ).

Partial correlations among the study variables, controlling for sex, pubertal stage and SES, are presented in Table S1 in Supplementary Information. Objective sleep duration was negatively correlated with verbal ability $(r=-.178 ; p<.05)$, and self-reported sleep quality was positively correlated with numeric ability $(r=.129 ; p<.05)$ and all the academic performance indicators (correlation coefficients ranged from 0.204 to 0.266 ; all $p<.001$ ). However, after correcting for multiple comparisons, the association between self-reported sleep quality and numeric ability disappeared. All the academic performance indicators were positively related to all the cognitive performance indicators (correlation coefficients ranged from 0.292 to $0.527 ; p \leq .001$ ).

Tables 2 and 3 show linear regression models on the associations of objectively measured and self-reported sleep duration and quality with academic and cognitive performance. Regarding sleep duration, only objective sleep duration was negatively associated with verbal ability after controlling for sex, pubertal stage and SES ( $\beta=-0.179$; $p<.01$ ). According to sleep quality, only self-reported sleep quality was positively associated with academic performance ( $\beta$ ranged from 0.209 to $0.273 ; p<.001)$ and numeric ability $(\beta=0.127 ; p<.05)$. The results remained significant after additional adjustments for CRF and MVPA (models 2 and 3) but, after Benjamini-Hochberg correction, the association between self-reported sleep quality and numeric ability disappeared.

ANCOVA analyses adjusted for sex, pubertal stage and SES revealed that adolescents sleeping less than $8 \mathrm{hr}$ per day, using the objective measurement, showed higher verbal ability (19.3 versus 17.9; $p=.028$, Cohen's $d=0.271$ ). No differences were found for academic and cognitive performance between self-reported sleep duration and objectively measured sleep quality categories (data not shown). However, adolescents with self-reported good sleep quality showed higher scores in all the academic performance indicators (all $p<.05$, Cohen's $d$ ranging from 0.22 to 0.37 ; Figure 1). After conducting Benjamini-Hochberg corrections, only self-reported good sleep quality remained significantly related to higher scores in math.

\section{DISCUSSION}

The main findings of the present study revealed a positive association of self-reported sleep quality with academic performance in adolescents, showing that sleep quality could play an important role on academic outcomes. Moreover, regarding cognitive performance, objective sleep duration was negatively associated with verbal ability. This study adds new scientific evidence about the controversial relationship of sleep and cognition by using objective and standardized methods of assessing sleep (i.e. actigraphy), and by including in the analysis potential confounders such as pubertal stage, SES, fitness and PA levels.

Comparisons between sexes revealed contradictory results regarding sleep variables; girls showed longer objective sleep duration and better objective sleep quality, while boys showed better measurements of self-reported sleep variables. These controversial results fit in line with Dewald et al. (2010) who analysed 50 studies suggesting that differences between objective and self-reported sleep measurements could be partially explained by individuals' distinct experiences of sleep (e.g. experiences in girls versus boys) and different subjective sleep components (e.g. sleepiness, feeling rested).

Sleep duration is defined as the total sleep time per night. Our study reveals no associations of sleep duration with academic and cognitive performance, except for verbal ability. Conversely, prior systematic reviews and meta-analysis have evidenced a generalized positive association of sleep duration with academic performance in children and adolescents (Chaput et al., 2016; Dewald et al., 2010), while contradictory results have been reported for cognitive performance (Astill et al., 2012; Chaput et al., 2016). In fact, Astill et al. (2012) found a positive association of sleep duration with children's cognition and performance, whilst Chaput et al. (2016) reported controversial results suggesting that those children and adolescents with sleep durations far outside the normal range could have other health disorders, which may impair academic and cognitive outcomes. Interestingly, Perkinson-Gloor, Lemola, and Grob (2013) showed that adolescents sleeping less than $8 \mathrm{hr}$ per night had lower school grades, and revealed a mediating effect of daytime tiredness and behavioural persistence in this association. The inter-studies differences could be partially explained by the use of different tools in order to measure sleep duration (subjective versus objective), as well as by the individual differences in adolescents' academic and cognitive performance.

Sleep quality is defined as the satisfaction level of the sleep experience. Our analyses indicate a significant positive association of self-reported sleep quality, but not objectively measured, with academic performance. Analysis according to sleep quality categories revealed higher scores in math among those adolescents with selfreported good sleep quality (PSQI $\leq 5$ ). These results concur with previous studies revealing a positive association of self-reported sleep quality and academic performance during youth (Baert, Omey, \& Verhaest, 2015; Duarte et al., 2014; Mak, Lee, Ho, Lo, \& Lam, 2012). Good sleep quality reduces sleepiness (Pilcher, Ginter, \& Sadowsky, 1997) at school time, with positive effects on attention and memory (Carskadon, 2011), which might improve academic 
TABLE 1 Characteristics of the study population by sex $(n=257)$

\begin{tabular}{|c|c|c|c|c|c|}
\hline$n(\%)$ & $\begin{array}{l}\text { All } \\
257(100)\end{array}$ & $\begin{array}{l}\text { Boys } \\
135(52.5)\end{array}$ & $\begin{array}{l}\text { Girls } \\
122(47.5)\end{array}$ & $p$ & Cohen's $d$ \\
\hline \multicolumn{6}{|l|}{ Demographics } \\
\hline Age (years) & $13.88 \pm 0.30$ & $13.88 \pm 0.29$ & $13.89 \pm 0.30$ & .817 & 0.029 \\
\hline \multicolumn{6}{|l|}{ Tanner stage } \\
\hline Stage 2 & $21(8)$ & $14(10)$ & $7(6)$ & & \\
\hline Stage 3 & $85(33)$ & $43(32)$ & $42(34)$ & .044 & \\
\hline Stage 4 & $127(49)$ & $60(44)$ & $67(55)$ & & \\
\hline Stage 5 & $24(9)$ & $18(13)$ & $6(5)$ & & \\
\hline SES score $(0-8)$ & $4.20 \pm 1.38$ & $4.02 \pm 1.33$ & $4.39 \pm 1.42$ & .028 & 0.275 \\
\hline \multicolumn{6}{|l|}{ Anthropometry } \\
\hline Height $(\mathrm{cm})$ & $163.13 \pm 7.83$ & $164.75 \pm 8.51$ & $161.35 \pm 6.58$ & $<.001$ & 0.447 \\
\hline Weight (kg) & $54.23 \pm 9.33$ & $54.56 \pm 9.72$ & $53.87 \pm 8.91$ & .551 & 0.075 \\
\hline Body mass index $\left(\mathrm{kg} \mathrm{m}^{-2}\right)$ & $20.30 \pm 2.72$ & $19.99 \pm 2.56$ & $20.64 \pm 2.85$ & .056 & 0.239 \\
\hline \multicolumn{6}{|l|}{ Sleep duration } \\
\hline Objective (hr per day) & $8.00 \pm 0.88$ & $7.87 \pm 0.92$ & $8.16 \pm 0.81$ & .007 & 0.338 \\
\hline Objective good sleep duration & $132(51)$ & $65(48)$ & $67(55)$ & .318 & \\
\hline Self-reported (hr per day) & $8.21 \pm 0.81$ & $8.33 \pm 0.70$ & $8.07 \pm 0.90$ & .012 & 0.321 \\
\hline Self-reported good sleep duration & $164(64)$ & $95(70)$ & $69(57)$ & .027 & \\
\hline \multicolumn{6}{|l|}{ Sleep quality } \\
\hline Objective (\%) & $82.96 \pm 8.03$ & $81.98 \pm 8.11$ & $84.05 \pm 7.84$ & .039 & 0.259 \\
\hline Objective good sleep quality & $113(44)$ & $52(39)$ & $61(50)$ & .064 & \\
\hline Self-reported $(0-21\rangle$ & $4.86 \pm 2.81$ & $4.23 \pm 2.70$ & $5.57 \pm 2.76$ & $<.001$ & 0.491 \\
\hline Self-reported good sleep quality & $163(63)$ & $99(73)$ & $64(53)$ & $<.001$ & \\
\hline \multicolumn{6}{|l|}{ Academic performance $(0-10)$} \\
\hline Math & $6.84 \pm 1.59$ & $6.96 \pm 1.60$ & $6.71 \pm 1.57$ & .209 & 0.158 \\
\hline Language & $6.75 \pm 1.53$ & $6.61 \pm 1.51$ & $6.89 \pm 1.55$ & .145 & 0.183 \\
\hline Science & $6.96 \pm 1.68$ & $6.88 \pm 1.68$ & $7.04 \pm 1.68$ & .448 & 0.095 \\
\hline GPA & $7.10 \pm 1.28$ & $7.03 \pm 1.29$ & $7.17 \pm 1.27$ & .381 & 0.110 \\
\hline \multicolumn{6}{|l|}{ Cognitive performance } \\
\hline Verbal $(0-50)$ & $18.60 \pm 5.31$ & $19.01 \pm 5.81$ & $18.14 \pm 4.68$ & .186 & 0.165 \\
\hline Reasoning $(0-30)$ & $16.51 \pm 5.89$ & $16.09 \pm 5.67$ & $16.98 \pm 6.11$ & .229 & 0.151 \\
\hline Numeric $(0-30)$ & $13.44 \pm 4.77$ & $14.78 \pm 4.56$ & $11.96 \pm 4.58$ & $<.001$ & 0.617 \\
\hline Overall $(0-110)$ & $48.55 \pm 12.68$ & $49.87 \pm 12.84$ & $47.07 \pm 12.38$ & .077 & 0.222 \\
\hline \multicolumn{6}{|l|}{ Physical fitness } \\
\hline 20-m SRT (laps) & $64.43 \pm 24.76$ & $77.76 \pm 20.90$ & $49.69 \pm 19.90$ & $<.001$ & 1.375 \\
\hline $\mathrm{VO}_{2}\left(\mathrm{ml} \mathrm{kg}{ }^{-1} \min ^{-1}\right)$ & $50.28 \pm 6.72$ & $53.99 \pm 5.33$ & $46.17 \pm 5.64$ & $<.001$ & 1.425 \\
\hline \multicolumn{6}{|l|}{ PA (min per day) $)^{a}$} \\
\hline Moderate & $75.87 \pm 23.10$ & $81.56 \pm 25.00$ & $69.57 \pm 18.99$ & $<.001$ & 0.540 \\
\hline Vigorous & $12.28 \pm 8.28$ & $15.54 \pm 7.80$ & $8.67 \pm 7.24$ & $<.001$ & 0.912 \\
\hline Moderate-to-vigorous & $88.15 \pm 28.21$ & $97.10 \pm 29.18$ & $78.24 \pm 23.49$ & $<.001$ & 0.712 \\
\hline
\end{tabular}

Data are presented as mean \pm standard deviation or frequency (\%). Differences between sex were examined by $t$-test or chi-squared test. Values in bold font indicate significant results. GPA, grade point average; PA, physical activity; SES, socioeconomic status; $S R T$, shuttle run test; VO 2 max, maximum oxygen uptake. Good sleep duration: $\geq 8 \mathrm{hr}$ per day. Objective good sleep quality: efficiency $\geq 85 \%$. Self-reported good sleep quality: PSQI $\leq 5$. Overall indicates the sum of the threc abilitics scores.

a Values were natural log-transformed before analysis, but non-transformed values are presented in the table.

performance (Moore \& Meltzer, 2008). Differences between objective and self-reported sleep quality measurements could be caused by methodological issues. Despite actigraphy has been revealed as a validated method for assessing sleep quality, this methodology only assesses sleep efficiency - without capturing other large individual differences in the sleep experience-during a few days, while 
TABLE 2 Associations of objectively measured and self-reported sleep duration and quality with academic performance in adolescents ( $n=$ 257)

\begin{tabular}{|c|c|c|c|c|c|c|c|c|}
\hline & \multicolumn{4}{|c|}{ Sleep duration } & \multicolumn{4}{|c|}{ Sleep quality } \\
\hline & \multicolumn{2}{|c|}{ Objective } & \multicolumn{2}{|c|}{ Self-reported } & \multicolumn{2}{|c|}{ Objective } & \multicolumn{2}{|c|}{ Self-reported } \\
\hline & $\beta$ & $p$ & $\beta$ & $p$ & $\beta$ & $p$ & $\beta$ & $p^{a}$ \\
\hline \multicolumn{9}{|l|}{ Model 1} \\
\hline Math & -0.055 & .384 & 0.110 & .082 & -0.003 & .960 & 0.245 & $<.001$ \\
\hline Language & -0.047 & .461 & 0.042 & .512 & -0.015 & .817 & 0.209 & $<.001$ \\
\hline Science & -0.042 & .511 & 0.021 & .743 & -0.049 & .437 & 0.273 & $<.001$ \\
\hline GPA & -0.071 & .260 & 0.048 & .449 & -0.033 & .598 & 0.223 & $<.001$ \\
\hline \multicolumn{9}{|l|}{ Model 2} \\
\hline Math & -0.041 & .510 & 0.113 & .071 & -0.012 & .842 & 0.249 & $<.001$ \\
\hline Language & -0.038 & .551 & 0.044 & .489 & -0.021 & .742 & 0.212 & $<.001$ \\
\hline Science & -0.034 & .598 & 0.023 & .719 & -0.055 & .384 & 0.275 & $<.001$ \\
\hline GPA & -0.059 & .354 & 0.051 & .417 & -0.042 & .500 & 0.227 & $<.001$ \\
\hline \multicolumn{9}{|l|}{ Model 3} \\
\hline Math & -0.060 & .344 & 0.114 & .071 & 0.001 & .986 & 0.246 & $<.001$ \\
\hline Language & -0.056 & .382 & 0.049 & .442 & -0.007 & .917 & 0.211 & $<.001$ \\
\hline Science & -0.045 & .484 & 0.023 & .726 & -0.048 & .457 & 0.273 & $<.001$ \\
\hline GPA & -0.074 & .247 & 0.050 & .435 & -0.032 & .612 & 0.223 & $<.001$ \\
\hline
\end{tabular}

Values are standardized regression coefficients $(\beta)$. Values in bold font indicate significant results. Confounders in model 1: sex, pubertal stage and SES. Confounders in model 2: model $1+$ CRF (laps). Confounders in model 3: model 1 + MVPA. GPA, grade point average.

${ }^{a}$ These associations remained significant after Benjamini-Hochberg correction.

TABLE 3 Associations of objectively measured and self-reported sleep duration and quality with cognitive performance in adolescents $(n=$ 257)

\begin{tabular}{|c|c|c|c|c|c|c|c|c|}
\hline & \multicolumn{4}{|c|}{ Sleep duration } & \multicolumn{4}{|c|}{ Sleep quality } \\
\hline & \multicolumn{2}{|c|}{ Objective } & \multicolumn{2}{|c|}{ Self-reported } & \multicolumn{2}{|c|}{ Objective } & \multicolumn{2}{|c|}{ Self-reported } \\
\hline & $\beta$ & $p$ & $\beta$ & $p$ & $\beta$ & $p$ & $\beta$ & $p$ \\
\hline \multicolumn{9}{|l|}{ Model 1} \\
\hline Verbal & -0.179 & $.004^{a}$ & -0.075 & .235 & -0.081 & .200 & 0.043 & .505 \\
\hline Reasoning & -0.003 & .967 & -0.010 & .871 & -0.017 & .793 & 0.073 & .258 \\
\hline Numeric & -0.009 & .883 & 0.044 & .470 & 0.075 & .217 & 0.127 & .039 \\
\hline Overall & -0.080 & .207 & -0.020 & .755 & -0.013 & .832 & 0.100 & .119 \\
\hline \multicolumn{9}{|l|}{ Model 2} \\
\hline Verbal & -0.171 & .007 & -0.073 & .247 & -0.088 & .165 & 0.046 & .477 \\
\hline Reasoning & 0.000 & .999 & -0.010 & .879 & -0.019 & .771 & 0.074 & .253 \\
\hline Numeric & 0.003 & .958 & 0.047 & .439 & 0.067 & .267 & 0.131 & .033 \\
\hline Overall & -0.071 & .265 & -0.017 & .782 & -0.020 & .751 & 0.103 & .108 \\
\hline \multicolumn{9}{|l|}{ Model 3} \\
\hline Verbal & -0.177 & $.005^{\circ}$ & -0.080 & .210 & -0.087 & .174 & 0.042 & .514 \\
\hline Reasoning & -0.016 & .801 & 0.001 & .992 & -0.004 & .952 & 0.076 & .240 \\
\hline Numeric & -0.015 & .814 & 0.049 & .425 & 0.081 & .184 & 0.128 & .038 \\
\hline Overall & -0.087 & .171 & -0.015 & .817 & -0.007 & .908 & 0.101 & .115 \\
\hline
\end{tabular}

Values are standardized regression coefficients $(\beta)$. Values in bold font indicate significant results. Confounders in model 1: sex, pubertal stage and SES. Confounders in model 2: model $1+$ CRF (laps). Confounders in model 3: model $1+$ MVPA. Overall indicates the sum of the three abilities scores.

${ }^{a}$ This association remained significant after Benjamini-Hochberg correction. 

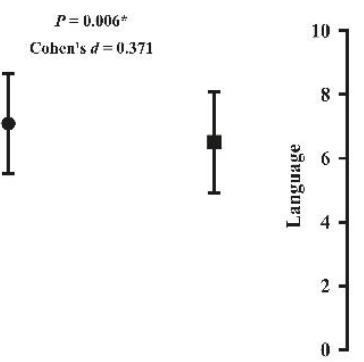

$$
P=0.038
$$

Cohen's $d=0.219$

FIGURE 1 Analysis of covariance assessing differences in academic performance by self-reported sleep quality categories in adolescents. Estimated mean (dots) and $95 \%$ confidence intervals ( $\mathrm{Cls}$; error bars) represent values after sex, pubertal stage and socioeconomic status (SES) adjustments. Self-reported good sleep quality: PSQI score $\leq 5$; poor sleep quality: PSQI score $>5$. PSQI, Pittsburgh Sleep Quality Index. ${ }^{\star}$ This association remained significant after BenjaminiHochberg correction
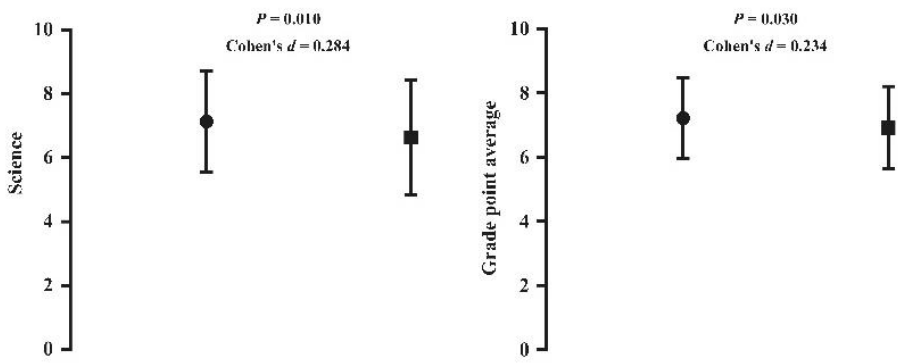

subjective tools such as the PSQI questionnaire assess other specific components (e.g. sleep latency, use of sleep medication, sleep disturbance), providing an overall sleep quality index over the last month.

\section{1 | Limitations}

The main strengths of our study comprise the inclusion of objective and self-reported sleep duration and quality measurements, a wide range of academic and cognitive performance indicators, and the relatively large and age-matched sample of healthy adolescents (13.9 \pm 0.3 years). Moreover, potential confounders such as pubertal stage, SES, fitness and PA levels have been considered given their great influence on sleep and cognition during adolescence (Álvarez-Bueno et al., 2017; Carskadon, 2011; Coe et al., 2013; Mota \& Vale, 2010; Shochat et al, 2014). However, our results should be interpreted cautiously due to the cross-sectional design of our study, which limits our ability to make assumptions about the causal nature of the relationships analysed.

\section{5 | CONCLUSIONS}

In conclusion, the present study adds new information about the association of sleep duration and quality with academic and cognitive performance in adolescents, suggesting that sleep quality may play an important role on academic outcomes. Our findings are of great significance due to the growing body of evidence suggesting that promoting healthy sleep practices in adolescents may prevent academic failure with an important positive impact on adulthood. These facts reinforce the need for including sleep hygiene behaviours and practices, and sleep assessment as part of school-based public health and educational support programs. Therefore, we consider that families, educators and policy-makers should take into account our results in order to promote healthy sleep, and to achieve academic success among children and adolescents. Further, longitudinal and interventional studies examining the effects of different objectively measured and self-reported sleep variables on academic and cognitive performance during adolescence are needed.

\section{ACKNOWLEDGEMENTS}

The DADOS study is funded by the Spanish Ministry of Economy and Competitiveness, MINECO (DEP2013-45515-R) and by the Jaume I University of Castellon, UЛ (P1.1A2015-05). This work is partly supported by a Sunny Sport research grant from the Schweppes Suntory Spain Company. M. A. R. is supported by a Predoctoral Research Grant from UI (PREDOC/2015/13). E. G. A. is supported by a Ramón y Cajal research fellowship (RYC-201416390).

\section{AUTHORS' CONTRIBUTIONS}

M. A. R. was involved in the data collection and analysis, and drafting of the initial manuscript. M. R. B. V. and A. C. S. were involved in the data collection and critical revision of the manuscript. J. H. M., 
E. G. A. and A. L. A. were involved in the critical revision of the manuscript. D. M. U. was involved in the study design and data collection, manuscript preparation, and critical revision. All the authors have read and approved the final manuscript.

\section{CONFLICT OF INTEREST}

No conflicts of interest were declared.

\section{ORCID}

Mireia Adelantado-Renau (iD) https://orcid.org/0000-0001-6124-8876

\section{REFERENCES}

Álvarez-Bueno, C., Pesce, C., Cavero-Redondo, I., Sánchez-López, M., Garrido-Miguel, M., \& Martínez-Vizcaíno, V. (2017). Academic achievement and physical activity: A meta-analysis. Pediatrics, 140, e20171498.

Andersen, S. L. (2016). Commentary on the special issue on the adolescent brain: Adolescence, trajectories, and the importance of prevention. Neuroscience and Biobehavioral Reviews, 70, 329-333.

Astill, R. G., Van der Heijden, K. B., Van ljzendoorn, M. H., \& Van Somcren, E. J. W. (2012). Slecp, cognition, and bchavioral problems in school-age children: A century of research meta-analyzed. Psychological Bulletin, 138, 1109-1138.

Baert, S., Omey, E., \& Verhaest, D. (2015). Mister Sandman, bring me good marks! On the relationship between slecp quality and academic achievement. Social Science and Medicine, 130, 91-98.

Beltran-Valls, M. R., García Artero, E., Capdevila-Seder, A., Legaz-Arrese, A., Adclantado-Rcnau, M., \& Molincr-Urdialcs, D. (2018). Regular practice of competitive sports does not impair sleep in adolescents: DADOS study. Pediatric Exercise Science, 30, 229-236.

Benjamini, Y., \& Hochberg, Y. (1995). Controlling the false discovery rate: A practical and powerful approach to multiple testing. Journal of the Royal Statistical Society Series B (Methodological), 57, 289-300.

Buysse, D. J., Reynolds, C. F., Monk, T. H., Berman, S. R., \& Kupfer, D. J. (1989). The Pittsburgh sleep quality index: A new instrument for psychiatric practice and research. Psychiatry Research, 28, 193-213.

Carskadon, M. A. (2011). Sleep's effects on cognition and learning in adolescence. Progress in Brain Research, 190, 137143.

Chaput, J., Gray, C. E., Poitras, V. J., Carson, V., Gruber, R., Olds, T., ... Tremblay, M. S. (2016). Systematic review of the relationships between sleep duration and health indicators in school-aged children and youth. Applied Physiology, Nutrition and Metabolism, 41, S266\$282.

Coe, D. P., Peterson, T., Blair, C. Schutten, M. C., \& Peddie, H. (2013). Physical fitness, academic achievement, and socioeconomic status in school-aged youth, Journal of School Health, 83, 500-507.

Cohen, J. (1988). Statistical power analysis for the behavioral sciences. Hillsdale: Lawrence Erlbaum.

Curcio, G., Ferrara, M., \& De Gennaro, L. (2006). Sleep loss, learning capacity and academic performance. Sleep Medicine Reviews, 10, 323337.

Currie, C., Molcho, M., Boyce, W., Holstein, B., Torsheim, T., \& Richter, M. (2008). Researching health inequalities in adolescents: The development of the Health Behaviour in School-Aged Children (HBSC) Family Affluence Scale. Social Science and Medicine, 66, 1429-1436.

Dahl, R. E., \& Lewin, D. S. (2002). Pathways to adolescent health: Sleep regulation and bchavior. Journal of Adolescent Heaith, 31, 175184
De Bruin, E. J., van Run, C., Staaks, J., \& Meijer, A. M. (2017). Effects of sleep manipulation on cognitive functioning of adolescents: A systematic review. Sleep Medicine Reviews, 32, 45-57.

Dewald, J. F., Mcijer, A. M., Oort, F. J., Kerkhof, G. A., \& Bogels, S. M. (2010). The influence of sleep quality, sleep duration and sleepiness on school performance in children and adolescents: A meta-analytic revicw. Sleep Medicine Reviews, 14, 179189.

Duarte, J., Nelas, P., Chaves, C., Ferreira, M., Coutinho, E., \& Cunha, M (2014). Sleep-wake patterns and their influence on school performance in Portuguese adolescents. Atención Primaria, 46, 160-164.

Esliger, D. W., Rowlands, A. V., Hurst, T. L., Catt, M., Murray, P., \& Eston, R. G. (2011). Validation of the GENEA accelerometer. Medicine and Science in Sports and Exercise, 43, 1085-1093.

Frank, M. G., \& Benington, J. H. (2006). The role of sleep in memory consolidation and brain plasticity: Dream or reality? Neuroscientist, 12 , $477-488$.

French, M. T., Homer, J. F., Popovici, I., \& Robins, P. K. (2015). What you do in high school matters: High school GPA, educational attainment, and labor market earnings as a young adult. Eastern Economic Journal, 41, 370-386.

Hirshkowitz, M., Whiton, K., Albert, S. M., Alessi, C., Bruni, O., DonCarlos, L., ... Adams Hillard, P. J. (2015). National Sleep Foundation's sleep time duration recommendations: Methodology and results summary. Sleep Health, 1, 40-43.

Krueger, J. M., Frank, M. G., Wisor, J. P., \& Roy, S. (2016). Sleep function: Toward elucidating an enigma. Sleep Medicine Reviews, 28, 42-50.

Léger, L. A., Mercier, D., Gadoury, C., \& Lambert, J. (1988). The multistage 20 metre shuttle run test for aerobic fitness. Journal of Sports Sciences, 6, 93-101.

te Lindert, B. H., \& Van Someren, E. J. (2013). Sleep estimates using microelectromechanical systems (MEMS). Sleep, 36, 781-789.

Mak, K. K., Lee, S. L., Ho, S. Y., Lo, W. S., \& Lam, T. H. (2012). Sleep and academic performance in Hong Kong adolescents. Journal of School Health, 82, 522-527.

Moore, M., \& Meltzer, L. J. (2008). The sleepy adolescent: Causes and consequences of sleepiness in teens. Paediatric Respiratory Reviews, 9, 114120.

Mota, J., \& Vale, S. (2010). Associations between sleep quality with cardiorespiratory fitness and $\mathrm{BMI}$ among adolescent girls. American journal of Human Biology, 22, 473-475.

Owens, J.; Adolescent Sleep Working Group, Committee on Adolescence (2014). Insufficient sleep in adolescents and young adults: An update on causes and consequences. Pediatrics, 134, e921-e932.

Patton, G. C., \& Viner, R. (2007). Pubertal transitions in health. Lancet $369,1130-1139$

Perkinson-Gloor, N., Lemola, S., \& Grob, A. (2013). Sleep duration, positive attitude toward life, and academic achicvement: The role of daytime tiredness, behavioral persistence, and school start times. Journal of Adolescence, 36, 311-318.

Phillips, L., Parfitt, G., \& Rowlands, A. (2013). Calibration of the GENEA accelerometer for assessment of physical activity intensity in children. Journal of Science and Medicine in Sport. 16, 124-128.

Pilcher, J. J., Ginter, D. R., \& Sadowsky, B. (1997). Sleep quality versus sleep quantity: Relationships between sleep and measures of health, well-being and sleepiness in college students. Journal of Psychosomatic Research, 42, 583-596.

Royuela Rico, A., \& Macías Fernández, J. (1997). Propiedades Clinimétricas De La Versión Castellana Del Cuestionario De Pittsburg. VigiliaSueño, 9, 81-94.

Sadeh, A., Sharkey, K. M., \& Carskadon, M. A. (1994). Activity-based sleep-wake identification: An empirical test of methodological issues. Sleep, 17, 201-207.

Shochat, T., Cohen-Zion, M., \& Tzischinsky, O. (2014). Functional consequences of inadequate sleep in adolescents: A systematic review. Sleep Medicine Reviews, 18, 75-87. 
Tanner, J. M., \& Whitehouse, R. H. (1976). Clinical longitudinal standards for height, weight, height velocity, weight velocity, and stages of puberty. Archives of Disease in Childhood, 51, 170-179.

Thurstonc, L. L., \& Thurstonc, T. G. (2004). TEA Test de Aptitudes Escolares (Scholar Aptitudes Test), 77, 11th edn. Madrid: TEA Ediciones S.A.

Wang, G., Ren, F., Liu, Z., Xu, G., Jiang, F., Skora, E., \& Lcwin, D. S. (2016). Sleep patterns and academic performance during preparation for college entrance exam in Chinese adolescents. Journal of School Health, 86, 298-306.

Wheaton, A. G., Chapman, D. P., \& Croft, J. B. (2016). School start times, sleep, behavioral, health, and academic outcomes: A review of the literature. Journal of School Health, 86, 363-381.

\section{SUPPORTING INFORMATION}

Additional supporting information may be found online in the Supporting Information section at the end of the article.

How to cite this article: Adelantado-Renau M, Beltran-Valls

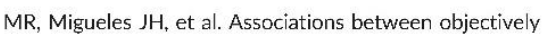
measured and self-reported sleep with academic and cognitive performance in adolescents: DADOS study. J Sieep Res. 2019;e12811. https://doi.org/10.1111/jsr.12811 
Study 2

The effect of sleep quality on academic performance is mediated by Internet use time: DADOS study 


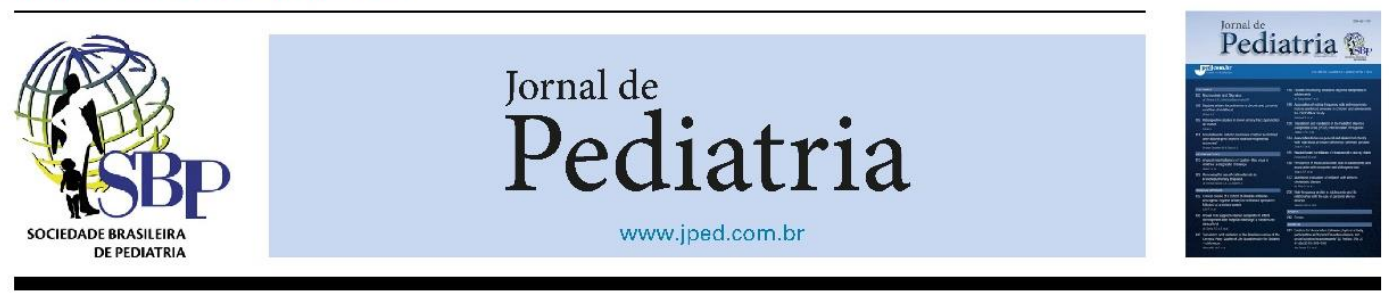

ORIGINAL ARTICLE

\section{The effect of sleep quality on academic performance is mediated by Internet use time: DADOS study}

\section{Mireia Adelantado-Renau ${ }^{a}$, Ana Diez-Fernandez ${ }^{\mathrm{b}, \mathrm{c}}$, Maria Reyes Beltran-Valls $^{\mathrm{a}, \mathrm{d}}$, Alberto Soriano-Maldonado ${ }^{e, f}$, Diego Moliner-Urdiales ${ }^{a, *}$}

\footnotetext{
a Universitat Jaume I, LIFE Research Group, Department of Education, Castellon, Spain

b Universidad de Castilla-La Mancha, Social and Health Care Research Center, Cuenca, Spain

' Universidad de Castilla-La Mancha, Faculty of Nursing, Cuenca, Spain

'Universitat Rovira i Virgili, Escola Universitària de la Salut i l'Esport (EUSES), Tarragona, Spain

e Universidad de Almeria, Faculty of Education Sciences, Department of Education, Almeria, Spain

${ }^{f}$ Universidad de Almería, SPORT Research Group (CTS-1024), CERNEP Research Center, Almería, Spain
}

Received 5 January 2018; accepted 28 March 2018

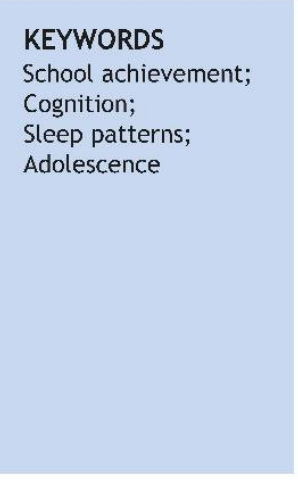

\begin{abstract}
Objective: The aims of the present study were to analyze the association of sleep patterns with academic and cognitive performance in adolescents, and to test the potential mediating effect of different activities of screen media usage on this association.

Methods: A sample of 269 adolescents ( 140 boys) aged 14 years from the baseline data of the Deporte, ADOlescencia y Salud study completed questionnaires about sleep quality, cognitive performance, and leisure-time sedentary behaviors. Sleep duration was objectively computed using a wrist-worn GENEActiv accelerometer and academic performance was analyzed through school records.

Results: Sleep quality (but not sleep duration) was associated with all the academic performance indicators (all $p<0.05$ ). Analysis of covariance revealed higher grades among adolescents with better sleep quality (PSQI $\leq 5$; all $p<0.05$ ). These analyses showed no differences regarding cognitive performance. Internet use time was revealed as a mediator of the association between sleep quality and academic performance, being significant for all academic performance indicators ( $P_{M}$ ranging from $15.5 \%$ to $16.0 \%$ ).
\end{abstract}

\footnotetext{
Please cite this article as: Adelantado-Renau M, Diez-Fernandez A, Beltran-Valls MR, Soriano-Maldonado A, Moliner-Urdiales D. The effect of sleep quality on academic performance is mediated by Internet use time: DADOS study. J Pediatr (Rio J). 2018. https://doi.org/10.1016/j.jped.2018.03.006

* Corresponding author.

E-mail: dmoliner@uji.es (D. Moliner-Urdiales).
}

https://doi.org/10.1016/j.jped.2018.03.006

0021-7557/@ 2018 Sociedade Brasileira de Pediatria. Published by Elsevier Editora Ltda. This is an open access article under the CC BY-NC-ND license (http://creativecommons.org/licenses/by-nc-nd/4.0/). 


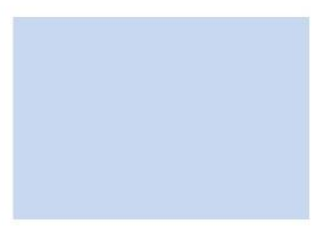

\section{PALAVRAS-CHAVE}

Desempenho escolar; Cognição; Padrões de sono; Adolescência
Conclusions: The association between sleep quality and academic performance in adolescents is mediated by time of Internet use. Overall, reducing Internet use in adolescents could be an achievable intervention for improving sleep quality, with potentially positive effects on academic performance.

(c) 2018 Sociedade Brasileira de Pediatria. Published by Elsevier Editora Ltda. This is an open access article under the CC BY-NC-ND license (http://creativecommons.org/licenses/by-nc-nd/ $4.0 /)$.

0 efeito da qualidade do sono no desempenho acadêmico é mediado pelo tempo de uso da internet: Estudo DADOS

\section{Resumo}

Objetivo: Os objetivos do presente estudo foram analisar a associação dos padrões de sono com o desempenho acadêmico e cognitivo em adolescentes e testar o efeito mediador potencial de diferentes atividades com uso de dispositivos (mídias) com tela nesta associação.

Métodos: Uma amostra de 269 adolescentes (140 meninos) com idade de 14 anos, da linha de base do estudo DADOS (Deporte, ADOlescencia y Salud) preencheu uma série de questionários sobre qualidade do sono, desempenho cognitivo e comportamentos sedentários no lazer. A duração do sono foi calculada objetivamente utilizando um acelerômetro de pulso GENEActiv, e o desempenho acadêmico foi analisado através de registros escolares.

Resultados: A qualidade do sono (mas não a duração do sono) foi associada a todos os indicadores de desempenho acadêmico (todos os valores de $p<0,05$ ). A análise de covariância revelou notas mais altas nos adolescentes com melhor qualidade de sono (PSQI $\leq 5$; todos os valores de $p<0,05)$. Essas análises não mostraram diferenças em relação ao desempenho cognitivo. O tempo de uso da Internet revelou-se como um mediador da associação entre qualidade do sono e desempenho acadêmico, sendo significativo para todos os indicadores de desempenho acadêmico ( $P_{M}$ variando de 15,5\% a 16,0\%).

Conclusões: A associação entre qualidade do sono e desempenho acadêmico em adolescentes é mediada pelo tempo de uso da internet. No geral, reduzir o tempo de uso da internet pelos adolescentes pode ser uma intervenção viável para melhorar a qualidade do sono, com efeitos potencialmente positivos no desempenho acadêmico.

(c) 2018 Sociedade Brasileira de Pediatria. Publicado por Elsevier Editora Ltda. Este é um artigo Open Access sob uma licença CC BY-NC-ND (http://creativecommons.org/licenses/by-nc-nd/4. $0 /)$.

\section{Introduction}

Screen media usage (SMU), defined as screen-based activities such as mobile phone use, Internet surfing, computer use, videogames, and television, is the most popular leisuretime sedentary behavior among children and adolescents. ${ }^{1}$ Recent studies have focused on the association between SMU and a wide range of adverse health consequences ${ }^{2}$ such as obesity, cardiovascular disease risk, ${ }^{3}$ unhealthy diet, ${ }^{4}$ low academic and cognitive performance,,$^{5,6}$ and poor sleep patterns. $^{7}$

Cognitive and academic performance have been directly related with work achievement and career success during adulthood. ${ }^{8}$ Despite the fact that many studies have shown the negative effects of SMU on cognition during childhood and adolescence, ${ }^{5,6}$ results remain inconclusive depending on the analyzed leisure-time sedentary behavior. Recent evidence has shown a negative effect of television time on school performance ${ }^{9}$ and a positive impact of videogame time on cognitive abilities. ${ }^{10}$ However, Internet use time has been less studied, possibly due to the new growth of this SMU activity among youth. Recently, Kim et al. ${ }^{11}$ revealed that academic performance was positively associated with
Internet use for study, but negatively associated with Internet when used for other purposes. Interestingly, Syväoja et al. ${ }^{12}$ found that SMU was only linked to academic performance when considering later bedtime, highlighting the importance of considering together sleep, SMU, and cognition in adolescents.

Sleep patterns, including sleep quality and duration, are considered particularly important for physiological and psychological development, having implications on cognition during adolescence. ${ }^{13,14}$ Recently, several studies and systematic reviews have suggested an adverse association between sleep patterns and SMU. ${ }^{7,15-17}$ For instance, in a longitudinal study, Lemola et al. ${ }^{18}$ found that SMU at night was negatively associated with sleep duration and positively associated with sleep difficulties in a sample of 362 adolescents.

Adolescence is a crucial period of life often viewed as an important time frame in terms of development of cognitive abilities and establishment of many health-related behaviors such as sleep. There is compelling evidence that links sleep patterns to cognition during this period of life. ${ }^{13,14,19}$ Although previous studies have mostly focused on sleep duration, sleep quality, defined as the satisfaction level of 
the sleep experience, is currently considered a stand-alone component of sleep due to its specific influence on cognition. In fact, poor sleep quality has been associated with impairments in memory, concentration, and learning, leading to poor academic performance. ${ }^{14,19}$

Due to the important role of sleep on academic and cognitive performance in adolescents, and the previously demonstrated independent associations of SMU with cognition and with sleep patterns, elucidating the relationship between these behaviors and their impact on academic performance is of major interest. To the best of the authors' knowledge, no previous study has analyzed the mediating role of SMU on the sleep-cognition association. Therefore, statistical analyses of mediation are needed to examine the percentage of the total effect explained by SMU as potential mediator. Thus, the aims of the present study were to analyze the association of sleep patterns with academic and cognitive performance in adolescents, and to test the mediating effect of the different activities of SMU on this association.

\section{Methods}

\section{Study design and participants}

The DADOS (Deporte, ADOlescencia y Salud) study is a threeyear longitudinal research project (from 2015 to 2017) aimed to assess the influence of physical activity on health, cognition, and psychological wellness through adolescence. All the participants were recruited from secondary schools and sport clubs of Castellón (Spain), and met the general DADOS inclusion criteria: born in 2001, enrolled in second grade of secondary school, and free of any chronic disease. The results presented in this study belong to baseline data obtained between February and May of 2015. From the total DADOS study sample $(n=274)$, five adolescents did not complete the assessment protocol. Thus, the final sample had 269 adolescents ( 140 boys) with valid baseline data for sleep patterns, SMU, as well as academic and cognitive performance.

Adolescents and their parents or guardians were informed of the nature and characteristics of the study, and all provided written informed consent. The DADOS study protocol was designed in accordance with the ethical guidelines of the 1961 Declaration of Helsinki (last revision of Fortaleza, Brazil, 2013) and approved by the Research Ethics Committee of the Jaume I University of Castellón.

\section{Physical characteristics of the study sample}

Measures were assessed in duplicate by trained members of the DADOS research group following standardized procedures. The average measure was used for data analysis. Briefly, body weight was measured to the nearest $0.1 \mathrm{~kg}$ using an electronic scale (SECA 861 - Hamburg, Germany); subjects were lightly dressed and shoeless. Height was measured to the nearest $0.1 \mathrm{~cm}$ using a wall-mounted stadiometer (SECA 213 - Hamburg, Germany). Body mass index (BMI) was calculated as weight/ height square $\left(\mathrm{kg} / \mathrm{m}^{2}\right)$.
Pubertal status was self-reported according to the five stages defined by Tanner and Whitehouse. ${ }^{20}$

\section{Sleep data}

The Spanish version of the Pittsburgh Sleep Quality Index (PSQI) questionnaire was used to assess sleep quality over the last month. ${ }^{21}$ It includes 19 questions referring to seven components of sleep quality: subjective sleep quality, sleep duration, sleep latency, habitual sleep efficiency, sleep disturbance, use of sleep medication, and daytime dysfunction. Each component score is rated on a three-point scale, with 0 points indicating ideal sleep quality and 3 points indicating poor sleep quality. The overall PSQI score is the sum of all component scores, ranging from 0 to 21 , with lower scores representing better sleep quality. The PSQI provides a sensitive measure to identify poor sleep quality if total PSQI score is $>5$ and good sleep quality if total PSQI score is $\leq 5$. Because the overall PSQI score is inversely related to sleep quality, it was multiplied by -1 for an easier understanding of the results.

Daily sleep duration was objectively measured by a GENEActiv accelerometer (Activinsights Ltd - Kimbolton, United Kingdom). It has been found reliable to examine sleep (kappa $=0.85 \pm 0.06) .{ }^{22}$ Sleep duration was calculated by the algorithm included in the macro provided by the Activinsights company. In addition, to check possible inconsistencies in the accelerometer data, participants kept a sleep log of their sleep-wake schedule. A high level of agreement was observed between the accelerometer and the participants' sleep log data. Only in a few cases were the results discrepant, and then the data from the nonconsistent day removed. All participants included data of at least four complete days (two weekend days and two weekdays). By combining all registered days for each participant, sleep duration was then expressed as average $\mathrm{h} /$ day. According to the definition of the National Sleep Foundation, for adolescent populations, good sleep duration is defined as $\geq 8 \mathrm{~h}$ per day.

\section{Academic performance}

Based on the information provided by the secretary office of each school, academic performance was assessed through the final grades from the first course of secondary school on a ten-point scale. According to previous scientific literature, four indicators were used to define academic performance: individual grades for the core subjects (math and Spanish), an average of the core subjects, and grade point average (GPA) score. GPA score was defined as the single average for geography and history, natural science, math, Spanish, Catalan, English, and physical education grades.

\section{Cognitive performance}

Cognitive performance was measured using the Spanish version of the "SRA Test of Educational Ability" (TEA)..$^{23}$ This test provides general measures of three areas of intelligence and skills of learning: verbal (command of language), numeric (speed and precision in performing operations 
with numbers and quantitative concepts), and reasoning (the ability to find logical order in sets of numbers, figures, or letters) abilities. Scores for the three areas were obtained by adding positive answers. Overall cognitive performance was calculated by adding the three area scores (verbal + numeric + reasoning). Based on the age range of our sample, level three of the TEA questionnaire was used (reliability: verbal $\alpha=0.74$, numeric $\alpha=0.87$, reasoning $\alpha=0.77$, and overall cognitive performance $\alpha=0.89$ ).

\section{Screen media usage}

Leisure-time sedentary behaviors were assessed using the HELENA (Healthy Lifestyle in Europe by Nutrition in Adolescence) sedentarism questionnaire, designed ad hoc. ${ }^{24}$ For both weekdays and weekend days, adolescents reported the number of hours spent on television, videogames, Internet surfing, and mobile phone use. Seven possible answers were available for each item: no time, less than $1 / 2 \mathrm{~h} ; 1 / 2-1 \mathrm{~h}$; $1-2 \mathrm{~h} ; 2-3 \mathrm{~h} ; 3-4 \mathrm{~h}$; and, more than $4 \mathrm{~h}$. The mean time of each answer was used to calculate the daily overall time for each sedentary behavior as follows: $1 / 7 \times(2 \times$ weekend day hours $+5 \times$ weekday hours).

\section{Statistical analysis}

The descriptive characteristics of the study sample are presented as mean \pm standard deviation unless otherwise stated. The Kolmogorov-Smirnov test and histograms were used to check for normal distribution, and data for the PSQI score were log-transformed before statistical analysis. Sex differences were assessed by analysis of variance (ANOVA) for continuous variables and by the chi-squared test for categorical variables. For each ANOVA, the effect size, partial eta squared $\left(\eta^{2}\right)$, was calculated and interpreted following the Cohen's guidelines: small, $0.01<\eta^{2}<0.06$; medium, $0.06 \leq \eta^{2}<0.14$; and large, $\eta^{2} \geq 0.14 .{ }^{25}$ Preliminary analyses showed no significant interactions among sex and sleep variables (all $p>0.10$ ); therefore, all analyses were performed with the total sample.

Data analysis took three steps. Firstly, in order to confirm the relationships among the sleep patterns, SMU variables, and cognitive and academic performance indicators, a series of partial correlations were performed, controlling for sex and pubertal status. From these analyses, Internet use was identified for further analysis owing to its consistently strong associations with sleep quality and academic and cognitive performance. Internet use was categorized as low (first and second tertiles; $5.8 \pm 6.2$ and $37.8 \pm 9.6 \mathrm{~min} /$ day, respectively) and high (third tertile; $118.0 \pm 57.7 \mathrm{~min} /$ day). Analysis of covariance (ANCOVA) models were used to assess differences in academic and cognitive performance across categories of sleep quality and Internet use, controlling for sex, and pubertal status (model 1), and with further adjustment for Internet use or sleep quality depending on the fixed factor (model 2). For each ANCOVA effect, a partial $\eta^{2}$ is reported. ${ }^{25}$ Finally, separate mediation analyses were performed using the PROCESS macro in order to elucidate whether the association between sleep quality and academic performance was mediated by the Internet use time. The following steps for mediation were used: the first equation regressed the mediator (Internet use) on the independent variable (sleep quality). The second equation regressed the dependent variable (math, Spanish, core subjects, and GPA) on the independent variable. The third equation regressed the dependent variable on both the independent variable and the mediator variable. Mediation was considered significant when 0 was not in the $95 \%$ confidence interval of the indirect effects (estimated by bootstrapping), as recommended by Preacher and Hayes. ${ }^{26} P_{M}(\%)$, or how much of the total effect was explained by mediation, was calculated as follows: (indirect effect/total effect) $\times 100$. All the analyses were performed using IBM SPSS Statistics for Windows version 22.0 (IBM Corp.; Armonk, NY, United States), and the level of significance was set to $p<0.05$.

\section{Results}

Table 1 presents descriptive characteristics of the study sample by sex. Boys were taller than girls $(p<0.001)$. Good sleep quality (total PSQI score $\leq 5$ ) was reported by $74 \%$ of boys and $54 \%$ of girls $(p<0.001)$. The $47 \%$ of the boys and the $54 \%$ of the girls presented good sleep duration $(\geq 8 \mathrm{~h} /$ day; $p<0.01$ ). No differences between sexes were found in academic performance. Regarding cognitive performance indicators, boys showed higher values for numeric and overall ability than girls ( 14.8 vs. 11.9 and 50.0 vs. 47.0 ; both $p<0.05$ ). Boys showed higher daily videogame time than girls $(p<0.001)$ whereas girls showed higher daily mobile phone use time $(p<0.01)$.

Table 2 shows the partial correlations among the study variables after controlling for sex and pubertal status. Sleep quality was negatively associated with videogame time, Internet time, and mobile phone use time, and positively associated with all the academic performance indicators included in the study (all $p<0.05$ ). Sleep duration was only associated with verbal ability $(p \leq 0.001)$. Internet use was negatively associated with all academic performance indicators, reasoning ability, and overall cognitive performance (all $p<0.05$ ). Mobile phone use was negatively associated with GPA $(p<0.05)$. No associations of videogame and TV time with academic and cognitive performance indicators were found.

Mean differences in academic and cognitive performance by sleep quality and Internet use categories, controlling for sex and pubertal status (model 1), are shown in Table 3. Analysis of covariance (ANCOVA) showed that adolescents with good sleep quality (total PSOI score $\leq 5$ ) presented better academic performance for math, core subjects and GPA, and lower Internet use time (all $p<0.05$ ). Regarding Internet use categories, adolescents spending lower Internet use time had higher GPA, better reasoning ability and overall cognitive performance, and better sleep quality (model 1 ; $p<0.05$ ). The effect sizes were small in all the reported significant associations. Results were similar when sleep quality was included as a confounder (model 2). As the results changed when Internet use was included as a confounder with sleep quality categories as the fixed factor and academic performance as dependent variable (model 2), Internet use time was revealed as a possible mediator variable on the association of sleep quality with academic performance. 
Table 1 Characteristics of the study population by sex.

\begin{tabular}{|c|c|c|c|c|c|}
\hline & All $(n=269)$ & Boys $(n=140)$ & Girls $(n=129)$ & $p$ & $\eta^{2}$ \\
\hline \multicolumn{6}{|l|}{ Demographics } \\
\hline Age (years) ${ }^{a}$ & $13.9 \pm 0.3$ & $13.9 \pm 0.3$ & $13.9 \pm 0.3$ & 0.903 & 0.000 \\
\hline Tanner stage $(I-V)(\%)$ & $0 / 8 / 34 / 48 / 10$ & $0 / 10 / 32 / 44 / 14$ & $0 / 5 / 36 / 54 / 5$ & & \\
\hline \multicolumn{6}{|l|}{ Anthropometry ${ }^{a}$} \\
\hline Height $(\mathrm{cm})$ & $163.0 \pm 7.9$ & $164.6 \pm 8.6$ & $161.2 \pm 6.8$ & 0.000 & 0.049 \\
\hline Weight $(\mathrm{kg})$ & $54.1 \pm 9.2$ & $54.5 \pm 9.6$ & $53.7 \pm 8.8$ & 0.486 & 0.002 \\
\hline BMI $\left(\mathrm{kg} / \mathrm{m}^{2}\right)$ & $20.3 \pm 2.7$ & $20.0 \pm 2.5$ & $20.6 \pm 2.9$ & 0.059 & 0.014 \\
\hline \multicolumn{6}{|l|}{ Sleep } \\
\hline Sleep quality $(0-21)^{a}$ & $4.8 \pm 2.8$ & $4.2 \pm 2.7$ & $5.5 \pm 2.7$ & 0.000 & 0.071 \\
\hline Good sleep quality ${ }^{b}$ & $65(174)$ & $74(104)$ & $54(70)$ & 0.001 & \\
\hline Sleep duration $(h)^{a}$ & $8.0 \pm 0.9$ & $7.8 \pm 1.0$ & $8.1 \pm 0.8$ & 0.006 & 0.028 \\
\hline Good sleep duration ${ }^{\mathrm{b}}$ & $50(135)$ & $47(66)$ & $54(69)$ & 0.326 & \\
\hline \multicolumn{6}{|c|}{ Academic performance $(0-10)^{\mathrm{a}}$} \\
\hline Math & $6.8 \pm 1.6$ & $7.0 \pm 1.6$ & $6.7 \pm 1.6$ & 0.196 & 0.006 \\
\hline Spanish & $6.9 \pm 1.5$ & $6.7 \pm 1.5$ & $7.1 \pm 1.5$ & 0.075 & 0.013 \\
\hline Core subjects & $6.9 \pm 1.5$ & $6.8 \pm 1.5$ & $6.9 \pm 1.5$ & 0.838 & 0.000 \\
\hline GPA & $7.1 \pm 1.3$ & $7.1 \pm 1.3$ & $7.2 \pm 1.3$ & 0.420 & 0.003 \\
\hline \multicolumn{6}{|l|}{ Cognitive performance ${ }^{a}$} \\
\hline Verbal ability $(0-50)$ & $18.7 \pm 5.3$ & $19.1 \pm 5.9$ & $18.2 \pm 4.6$ & 0.131 & 0.009 \\
\hline Numeric ability $(0-30)$ & $13.4 \pm 4.8$ & $14.8 \pm 4.6$ & $11.9 \pm 4.5$ & 0.000 & 0.094 \\
\hline Reasoning ability $(0-30)$ & $16.5 \pm 5.8$ & $16.1 \pm 5.6$ & $16.9 \pm 6.0$ & 0.239 & 0.005 \\
\hline Overall $(0-110)$ & $48.6 \pm 12.6$ & $50.0 \pm 12.8$ & $47.0 \pm 12.2$ & 0.049 & 0.015 \\
\hline \multicolumn{6}{|l|}{ SMU $(\min / \text { day })^{\mathrm{a}}$} \\
\hline Videogames & $34.5 \pm 44.0$ & $45.4 \pm 45.9$ & $22.7 \pm 38.7$ & 0.000 & 0.066 \\
\hline Internet & $53.3 \pm 58.5$ & $47.4 \pm 57.6$ & $59.7 \pm 59.1$ & 0.086 & 0.013 \\
\hline Mobile phone & $111.0 \pm 84.3$ & $97.0 \pm 79.6$ & $126.1 \pm 86.8$ & 0.004 & 0.031 \\
\hline Television & $90.9 \pm 52.9$ & $92.4 \pm 53.0$ & $89.4 \pm 53.0$ & 0.647 & 0.001 \\
\hline
\end{tabular}

Data are presented as ${ }^{a}$ mean \pm standard deviation or ${ }^{b}$ frequency $\%(n)$. Differences between sexes were examined by ${ }^{a}$ analysis of the variance test or ${ }^{b}$ the chi-squared test. Values in bold font indicate significant results.

BMI, body mass index; Good sleep quality, PSQI score $\leq 5$; Good sleep duration, total sleep time $\geq 8 \mathrm{~h}$ per night. Core subjects indicates the mean of math and Spanish; GPA, grade point average; Overall indicates the sum of the three ability scores; SMU, screen media usage.

Table 2 Partial correlations of the study variables, controlling for sex and pubertal status.

\begin{tabular}{|c|c|c|c|c|c|c|c|c|c|c|}
\hline & \multicolumn{2}{|c|}{ Sleep patterns } & \multicolumn{4}{|c|}{ Academic performance } & \multicolumn{4}{|c|}{ Cognitive performance } \\
\hline & $\begin{array}{l}\text { Sleep } \\
\text { quality }\end{array}$ & $\begin{array}{l}\text { Sleep } \\
\text { duration }\end{array}$ & Math & Spanish & $\begin{array}{l}\text { Core } \\
\text { subjects }\end{array}$ & GPA & Verbal & Numeric & Reasoning & Overall \\
\hline \multicolumn{11}{|l|}{ Sleep patterns } \\
\hline Sleep quality & - & -0.085 & $0.225^{\mathrm{b}}$ & $0.143^{a}$ & $0.194^{\mathrm{a}}$ & $0.205^{b}$ & 0.034 & 0.111 & 0.071 & 0.088 \\
\hline Sleep duration & -0.085 & - & -0.038 & -0.064 & -0.053 & -0.073 & $-0.198^{b}$ & -0.018 & 0.006 & -0.087 \\
\hline \multicolumn{11}{|l|}{ SMU } \\
\hline Videogames & $-0.150^{a}$ & 0.048 & -0.051 & -0.050 & -0.054 & -0.076 & -0.014 & -0.005 & 0.009 & -0.004 \\
\hline Internet & $-0.179^{a}$ & 0.001 & $-0.193^{a}$ & $-0.165^{a}$ & $-0.206^{b}$ & $-0.221^{\mathrm{b}}$ & -0.068 & -0.100 & $-0.178^{a}$ & $-0.148^{\mathrm{a}}$ \\
\hline Mobile phone & $-0.131^{a}$ & 0.004 & -0.092 & -0.110 & -0.113 & $-0.143^{a}$ & -0.034 & -0.089 & -0.112 & -0.099 \\
\hline Television & -0.001 & 0.091 & -0.003 & -0.028 & -0.026 & -0.057 & 0.116 & -0.049 & -0.079 & -0.006 \\
\hline
\end{tabular}

Core subjects indicates the mean of math and Spanish; GPA, grade point average; Overall indicates the sum of the three ability scores; SMU, screen media usage.

$p$-value $={ }^{a} p<0.05$ and ${ }^{b} p \leq 0.001$.

\section{Mediation analysis}

Based on previous statistical analyses, we tested Internet use time as a potential mediator of the association between sleep quality and academic performance, controlling for sex and pubertal status (Fig. 1). Sleep quality was associated with academic performance, and the change from poor to good sleep quality was associated with an increase in academic performance, ranging from 0.28 points for Spanish to 0.57 points for math. In addition, the change from poor to good sleep quality was associated with 18.5 less minutes spent using Internet per day (a path; $p<0.05$ ), and Internet use time was negatively associated with academic performance (b path; all $p<0.05$ ). The mediation effect of Internet 


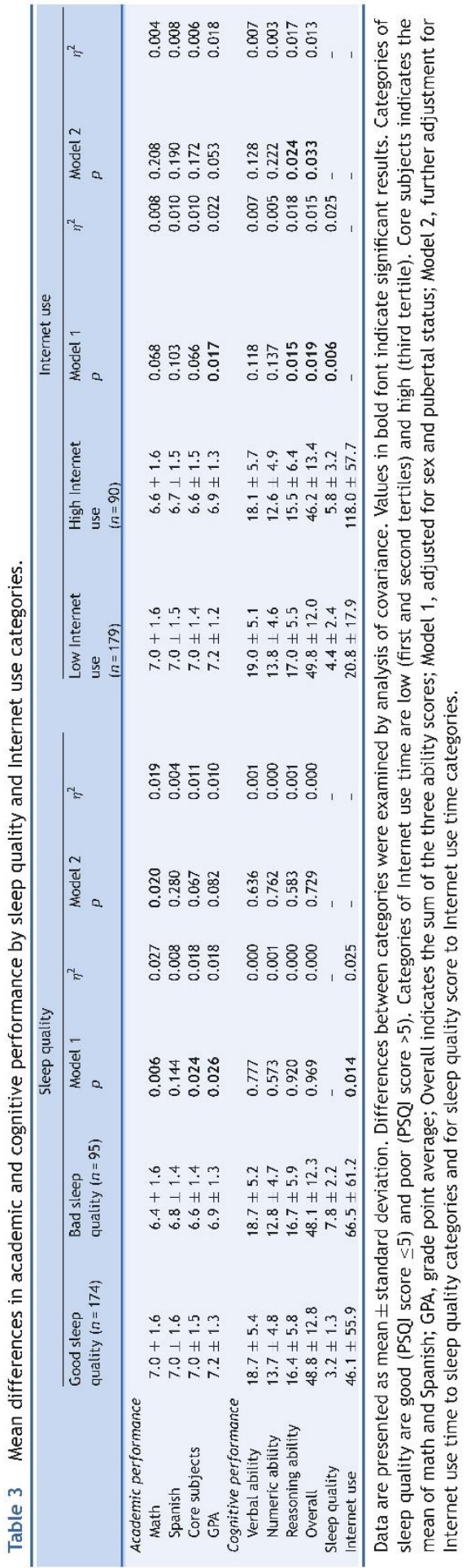



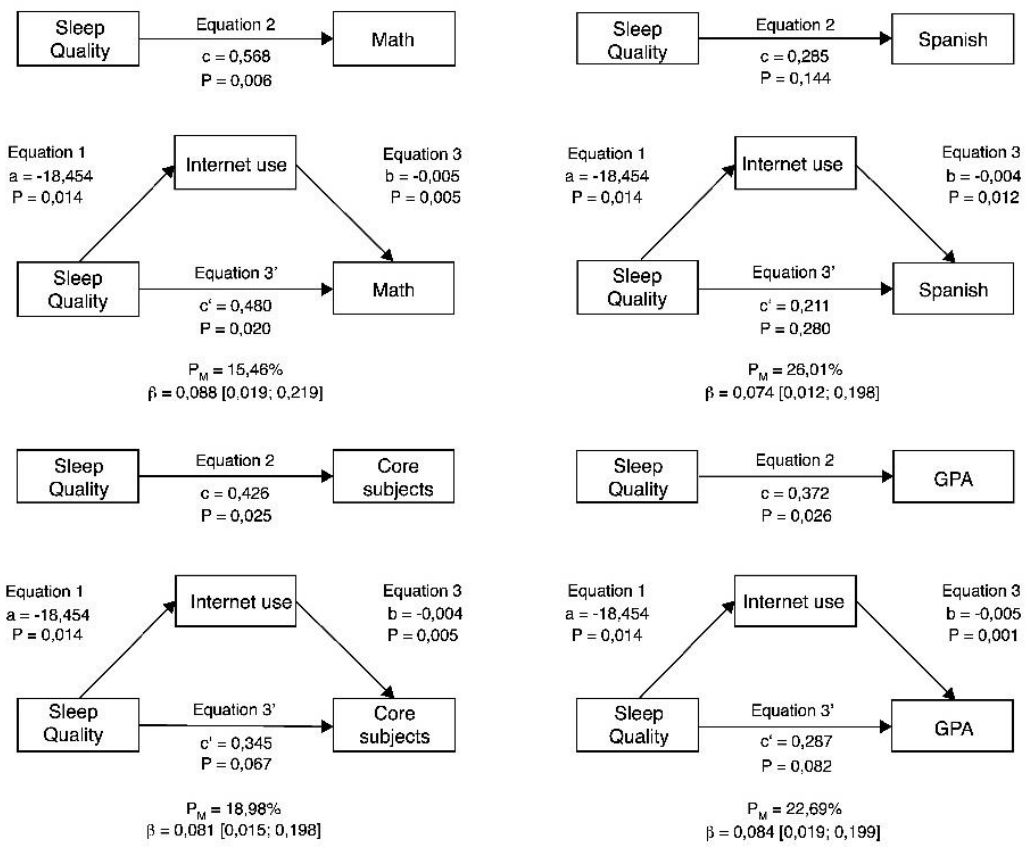

Figure 1 Internet use mediation models of the relationship between sleep quality and academic performance indicators, controlling for sex and pubertal status. Core subjects indicates the mean of math and Spanish; GPA, grade point average; $\beta=$ indirect effect; [ $\mathrm{LLCl}$; ULCI], lower and upper levels for $95 \%$ confidence interval of the indirect effect between sleep quality and academic performance.

use time on the relationship between sleep quality and academic performance was significant for all academic performance indicators (math $P_{M}=15.46 \%$; Spanish $P_{M}=26.01 \%$; core subjects $P_{M}=18.98 \%$, and GPA $P_{M}=22.69 \%$ ).

\section{Discussion}

The results of the present study concur with previous research, evidencing a positive association between sleep quality and academic performance in adolescents. ${ }^{14}$ The data fit in line with previous studies showing a negative influence of Internet use on both sleep quality ${ }^{16,17}$ and academic performance. ${ }^{5,6}$ The main finding of this study reveals a mediating effect of Internet use time on the association between sleep quality and academic performance. These results contribute to the current scientific knowledge by suggesting that Internet use time could partially explain the association between sleep quality and academic performance in adolescents.

These results partially concur with the authors' hypothesis, showing that better self-reported sleep quality (but not objectively-measured sleep duration) was statistically associated with higher report-card academic performance (but not with cognitive performance). Additional analyses revealed that adolescents with good sleep quality (PSQI $\leq 5)$ had higher school grades than those with poor sleep quality ( $\mathrm{PSQI}>5$ ). Consistent with these findings, several studies have analyzed this association using both subjective and objective sleep measures. ${ }^{8,14}$ For instance, Gruber et al. ${ }^{8}$ analyzed a sample of 75 children, showing that better academic performance was associated with higher objectively-measured sleep efficiency but not with objective sleep duration. Interestingly, a large review that examined the associations of sleep quality and duration with school performance showed that sleep quality was more strongly associated with school performance than sleep duration. ${ }^{14}$ In fact, it has been recommended to treat sleep quality and duration as two separate sleep domains, since they seem to contribute differently to academic performance and because of the low correlation between them. ${ }^{14}$ The large individual differences in the sleep experience, which can be captured by subjective tools but not by accelerometry due its methodological limitations, could explain the divergences between the present results and those found in the scientific literature. Several potential mechanisms by which sleep quality may positively influence academic performance have been postulated. First, poor sleep quality has been closely linked to adverse effects on prefrontal cortex cognitive processes, which may negatively influence working memory and executive function. ${ }^{19} \mathrm{Sec}$ ond, poor sleep quality reduces daytime alertness ${ }^{27}$ which in turn might affect attention, leading to academic performance impairment. 
Previous literature is showing a growing interest about the association of SMU with sleep and cognition. Many of the studies show an inverse association of Internet use time with both sleep quality ${ }^{15,28}$ and academic performance. ${ }^{11}$ No previous studies have analyzed the mediating effect of SMU on the association between sleep quality and academic performance. Among all the SMU variables analyzed, the present results revealed a mediating effect of Internet use time on the association between sleep quality and academic performance. Diverse mechanisms could explain the role of Internet use found in this study. First, social networking and time spent online have been suggested to increase physical and emotional arousal, which could interfere with sleep quality. ${ }^{29}$ Second, the bright light from screens before sleeping may have an acute alerting effect. ${ }^{30}$ Finally, Internet use time might replace time for study, which together with poorer sleep quality, may result in lower academic performance.

Limitations of the present study include its crosssectional design, which precludes establishing the causal direction of the observed associations, and the use of selfreported questionnaires to assess leisure-time sedentary behaviors and sleep quality. However, this study has several strengths, including the objective assessment of sleep duration by accelerometry, the inclusion of a wide range of leisure-time sedentary behaviors, the homogeneous characteristics of the adolescent sample, and the inclusion of pubertal status as a confounder.

These findings could have important implications from an educational and public health perspective, revealing that sleep quality in adolescents is more strongly related with academic performance than sleep duration. Moreover, the association between sleep quality and academic performance is mediated by Internet use time. Thus, if confirmed prospectively, reducing Internet use time in adolescents might be an achievable intervention for improving sleep quality with potentially positive effects on academic performance.

\section{Funding}

Spanish Ministry of Economy and Competitiveness, MINECO (DEP2013-45515-R).

Jaume I University of Castellón, UJI (P1-1A2015-05).

Schweppes Suntory Spain Company.

\section{Conflicts of interest}

The authors declare no conflicts of interest.

\section{Acknowledgements}

The DADOS Study is funded by the Ministerio de Economía, Industria y Competitividad, MINECO (DEP2013-45515-R) and by the Jaume I University of Castellón, UJI (P1.1A2015-05). This work is partly supported by a Sunny Sport research grant from the Schweppes Suntory Spain Company. M.A.R. is supported by a Predoctoral Research Grant from UJI (PREDOC $/ 2015 / 13$ ).

\section{References}

1. Marshall. SJ, Gorely T, Biddle SJ. A descriptive epidemiology of screen-based media use in youth: a review and critique. J Adolesc. 2006;29:333-49.

2. de Rezende LF, Rodrigues Lopes M, Rey-López JP, Matsudo VK, Luiz OdoC. Sedentary behavior and health outcomes: an overview of systematic reviews. PLOS ONE. 2014;9:e105620.

3. Hardy LL, Denney-Wilson E, Thrift AP, Okely AD, Baur LA. Screen time and metabolic risk factors among adolescents. Arch Pediatr Adolesc Med. 2010;164:643-9.

4. Garcia-Continente X, Pérez-Giménez A, Espelt A, Nebot Adell $M$. Factors associated with media use among adolescents: a multilevel approach. Eur J Public Health. 2013;24:5-10.

5. Morita N, Nakajima T, Okita K, Ishihara T, Sagawa M, Yamatsu K. Relationships among fitness, obesity, screen time and academic achievement in Japanese adolescents. Physiol Behav. 2016;163:161-6.

6. Faught EL, Gleddie D, Storey KE, Davison CM, Veugelers PJ. Healthy lifestyle behaviors are positively and independently associated with academic achievement: an analysis of selfreported data from a nationally representative sample of Canadian early adolescents. PLOS ONE. 2017;12:1-14.

7. Gozal D. Sleep and electronic media exposure in adolescents: the rule of diminishing returns. J Pediatr (Rio J). 2017;93:545-7.

8. Gruber R, Somerville G, Enros P, Paquin S, Kestler M, GilliesPoitras E. Sleep efficiency (but not sleep duration) of healthy school-age children is associated with grades in math and languages. Sleep Med. 2014;15:1517-25.

9. Yan $H$, Zhang $R$, Oniffrey TM, Chen G, Wang $Y$, Wu $Y$, et al. Associations among screen time and unhealthy behaviors, academic performance, and well-being in Chinese adolescents. Int J Environ Res Public Health. 2017;14:1-15.

10. Mack DJ, Wiesmann H, Ilg UJ. Video game players show higher performance but no difference in speed of attention shifts. Acta Psychol (Amst). 2016;169:11-9.

11. Kim SY, Kim MS, Park B, Kim JH, Choi HG. The associations between Internet use time and school performance among Korean adolescents differ according to the purpose of Internet use. PLOS ONE. 2017;12:1-14.

12. Syväoja HJ, Kankaanpää A, Kallio J, Hakonen H, Kulmala JS Hillman $\mathrm{CH}$, et al. The relation of physical activity, sedentary behaviors and academic achievement are mediated by fitness and bedtime. J Phys Act Health. 2018;15:135-43.

13. Sun W, Ling J, Zhu X, Lee TM, Li SX. Association between weekday-weekend sleep discrepancy and academic performance: systematic review and meta-analysis. Sleep Med. 2017;40:e318-9.

14. Dewald JF, Meijer AM, Oort FJ, Kerkhof GA, Bogels SM. The influence of sleep quality, sleep duration and sleepiness on school performance in children and adolescents: a meta-analytic review. Sleep Med Rev. 2010;14:179-89.

15. Amra B, Shahsavari A, Shayan-Moghadam R, Mirheli O, MoradiKhaniabadi B, Bazukar $M$, et al. The association of sleep and late-night cell phone use among adolescents. J Pediatr (Rio J). 2017;93:560-7

16. Hale L, Kirschen GW, LeBourgeois MK, Gradisar M, Garrison MM, Montgomery-Downs $\mathrm{H}$, et al. Youth screen media habits and sleep: sleep-friendly screen behavior recommendations for clinicians, educators, and parents. Child Adolesc Psychiatr Clin N Am. 2018;27:229-45.

17. LeBourgeois MK, Hale L, Chang A-M, Akacem LD, MontgomeryDowns HE, Buxton OM. Digital media and sleep in childhood and adolescence. Pediatrics. 2017;140:592-6.

18. Lemola S, Perkinson-Gloor N, Brand S, Dewald-Kaufmann JF, Grob A. Adolescents' electronic media use at night, sleep disturbance, and depressive symptoms in the smartphone age. $J$ Youth Adolesc. 2015;44:405-18. 
19. Bruin EJDe, Run CVan, Staaks J, Meijer AM. Effects of sleep manipulation on cognitive functioning of adolescents: a systematic review. Sleep Med Rev. 2016:1-13.

20. Tanner JM, Whitehouse RH. Clinical longitudinal standards for height, weight, height velocity, weight velocity, and stages of puberty. Arch Dis Child. 1976;51:170-9.

21. Royuela Rico A, Macías Fernández J. Propiedades clinimétricas de la versión castellana del cuestionario de Pittsburg. VigiliaSueño. 1997; 9:81-94.

22. Te Lindert BH, Van Someren EJ. Sleep estimates using microelectromechanical systems (MEMS). Sleep. 2013;36:781-9.

23. Thurstone LL, Thurstone TG. TEA Test de Aptitudes Escolares (Scholar Aptitudes Test), 77, 11 th ed. Madrid: TEA Ediciones S.A.; 2004.

24. Rey-López JP, Vicente-Rodriguez G, Ortega FB, Ruiz JR, Martinez-Gómez D, De Henauw S, et al. Sedentary patterns and media availability in European adolescents: the HELENA study. Prev Med (Baltim). 2010;51:50-5.
25. Cohen J. Statistical power analysis for the behavioral sciences. Hillsdale: Lawrence Erlbaum; 1988.

26. Preacher KJ, Hayes AF. Asymptotic and resampling strategies for assessing and comparing indirect effects in multiple mediator models. Behav Res Methods. 2008;40:879-91.

27. Moore M, Meltzer LJ. The sleepy adolescent: causes and consequences of sleepiness in teens. Paediatr Respir Rev. 2008;9:114-21.

28. Woods HC, Scott H. \#Sleepyteens: social media use in adolescence is associated with poor sleep quality, anxiety, depression and low self-esteem. J Adolesc. 2016;51:41-9.

29. Hale L, Guan S. Screen time and sleep among school-aged children and adolescents: a systematic literature review. Sleep Med Rev. 2015;21:50-8.

30. Wood B, Rea MS, Plitnick B, Figueiro MG. Light level and duration of exposure determine the impact of self-luminous tablets on melatonin suppression. Appl Ergon. 2013;44: 237-40. 
Study 3

The influence of adherence to the Mediterranean diet on academic performance is mediated by sleep quality in adolescents 


\title{
The influence of adherence to the Mediterranean diet on academic performance is mediated by sleep quality in adolescents
}

\author{
Mireia Adelantado-Renau' (D), Maria Reyes Beltran-Valls ${ }^{1,2}$ (iD), Irene Esteban-Cornejo $0^{3,4}$ (iD), Vicente Martínez-Vizcaíno ${ }^{5,6}$ (iD), \\ Alba María Santaliestra-Pasías $7,8,9,10$ (iD), Diego Moliner-Urdiales (dmoliner@uji.es) ${ }^{1}$ \\ 1.LIFE Research Group, Department of Education, University Jaume I, Castellon, Spain \\ 2.Escola Universitària de la Salut i l'Esport (EUSES), Universitat Rovira i Virgili, Tarragona, Spain \\ 3.Center for Cognitive and Brain Health, Department of Psychology, Northeastern University, Boston, MA, USA \\ 4.PROFITH "PROmoting FITness and Health through physical activity" Research Group, Department of Physical Education and Sports, Faculty of Sport Sciences, \\ University of Granada, Granada, Spain \\ 5.Health and Social Research Center, Universidad de Castilla-La Mancha, Cuenca, Spain \\ 6.Universidad Autónoma de Chile, Facultad de Ciencias de la Salud. Talca, Chile \\ 7.GENUD (Growth, Exercise, NUtrition and Development) Research Group, Facultad de Ciencias de la Salud, Universidad de Zaragoza, Zaragoza, Spain \\ 8.Instituto Agroalimentario de Aragón (IA2), Zaragoza, Spain \\ 9.Instituto de Investigación Sanitaria Aragón (IIS Aragón), Zaragoza, Spain \\ 10.Centro de Investigación Biomédica en Red de Fisiopatología de la Obesidad y Nutrición (CIBERObn), Zaragoza, Spain
}

\section{Keywords}

Academic achievement, Adolescence, Mediterranean diet, School performance, Sleep patterns

\section{Correspondence}

Diego Moliner-Urdiales, Department of Education, University Jaume I, Av. de Vicent Sos Baynat, s/n, 12071 Castellón, Spain.

Tel: +34964729782 |

Fax: +34964729264

Email: dmoliner@uji.es

\section{Received}

23 March 2018; revised 21 May 2018;

accepted 19 June 2018

DOI:10.1111/apa.14472

\begin{abstract}
Aim: This study examined the association of adherence to the Mediterranean diet with academic performance and tested whether this association was mediated by sleep in Spanish adolescents.

Methods: We recruited 269 adolescents ( $52 \%$ boys) aged $13.9 \pm 0.3$ years from the Deporte, ADOlescencia y Salud study of 38 secondary schools and sport clubs in Castellon, Spain, between February and May 2015. Adherence to the Mediterranean diet was assessed by the KIDMED questionnaire, sleep quality was evaluated with the Pittsburgh Sleep Quality Index test and sleep duration was objectively computed using a wrist-worn accelerometer. Academic performance was assessed through final school grades and a validated test.

Results: Greater adherence to the Mediterranean diet was associated with higher scores in language, core subjects, grade point average and verbal ability $(p<0.05)$. Sleep quality acted as a significant mediator of the association between adherence to the Mediterranean diet and final grades in maths, language, core subjects and the grade point average.

Conclusion: Our data show that the influence of adherence to the Mediterranean diet on academic performance was mediated by sleep quality in adolescents. Education and public health professionals should work together to achieve both improved health status and academic performance in adolescents.
\end{abstract}

\section{INTRODUCTION}

The Mediterranean diet is characterised by a high consumption of fruit, vegetables, breads, legumes, nuts and seeds, a low intake of red meat, a low-to-moderate consumption of wine, fish and poultry and the use of olive oil as the principal source of fat (1). In terms of nutrients, the Mediterranean diet is rich in polyunsaturated fatty acids, fibre, antioxidants and vegetable proteins (2). Greater adherence to the Mediterranean diet has been associated with a lower risk of morbidity and mortality (3), as well as better sleep patterns $(4,5)$ and cognition $(6,7)$.

\footnotetext{
Abbreviations

BMI, Body mass index; MVPA, Moderate and vigorous physical activity; PA, Physical activity; PSQI, Pittsburg Sleep Quality Index.
}

Academic performance during adolescence has a significant influence on future health (8) and work conditions (9). Individual behaviours, such as diet, may differently influence cognition (10), and in turn, academic

\section{Key notes}

- We recruited 269 adolescents (52\% boys) aged $13.9 \pm 0.3$ years from a study of 38 secondary schools and sport clubs in Castellon, Spain.

- Our results showed that adherence to the Mediterranean diet was positively associated with academic grades and verbal ability in our cohort.

- The study carried out between February and May 2015 also revealed the potential mediating effect that sleep quality had on that association. 
performance. For instance, consuming fish, milk, fruits and vegetables, and a lower intake of soft drinks and salty snacks, have been associated with better academic and cognitive performance in adolescents (11). However, dietary patterns seem to be more strongly associated with cognition than individual foods, due to the synergistic effects of each food component (11). Despite this growing evidence of the influence of diet on cognition, the effect of adherence to the Mediterranean diet on academic performance in adolescents has been poorly investigated (7).

Greater adherence to the Mediterranean diet has also been associated with better sleep patterns, such as duration and quality $(4,5)$, as a result of the effect of different nutrients $(12,13)$. Interestingly, prior research has shown that sleep has also been related to memory consolidation, brain plasticity and cognition (14), which, in turn, may improve academic performance in adolescents (15).

Given the association between adherence to the Mediterranean diet and academic performance in adolescents, and the independent associations of sleep patterns with Mediterranean diet and cognition mentioned above, the aims of the present study were: (i) to examine the association of adherence to Mediterranean diet with academic performance and (ii) to test whether the association of adherence to the Mediterranean diet with academic performance was mediated by sleep patterns in healthy adolescents.

\section{METHODS}

Study design and sample selection

A national three-year longitudinal research project, DADOS (Deporte, ADOlescencia y Salud; from 2015 to 2017), was performed to assess the influence of physical activity on health, cognition and psychological wellness through adolescence. Participants meeting the general inclusion criteria were recruited from secondary schools and sport clubs in Castellon; adolescents born in 2001, enrolled in the second grade of secondary school and free from any chronic disease. The results presented in this study come from baseline data obtained from February to May 2015. The sample analysed comprised 269 adolescents ( $52 \%$ boys) aged $13.9 \pm 0.3$ years with valid baseline data on sleep variables, Mediterranean dietary patterns and academic performance.

Adolescents and their parents or guardians were informed of the nature and characteristics of the study and all provided written, informed consent. The study protocol was designed in accordance with the ethical guidelines of the 2013 revision of the Declaration of Helsinki 1961 and approved by the Research Ethics Committee of the University Jaume I of Castellon.

\section{Adherence to the Mediterranean diet}

Adherence to the Mediterranean diet was assessed using KIDMED (16), a questionnaire that was based on the Mediterranean dietary guidelines for children and adolescents and provides an overall indication of their diet. The KIDMED includes 16 questions about if subjects consume fast food, sweets and soft drinks, daily fruit and vegetables and weekly fish and legumes, with yes or no answers required. The score for the subjects' adherence to the Mediterranean diet was calculated as the sum of each answer, ranging from zero to 12 . Levels of adherence were classified into three groups: poor (0-3), average (4-7) and good (8-12).

\section{Sleep patterns}

Sleep quality over the last month was assessed using the Spanish version of the Pittsburgh Sleep Quality Index (PSQI) test (17). The overall PSQI score ranges from zero to 21 , with scores $\leq 5$ defined as good sleep quality. Because the overall PSQI score is inversely related to sleep quality, it was multiplied by -1 in the first instance.

Daily sleep duration was objectively measured by a GENEActiv accelerometer (Activinsights Ltd, Cambridgeshire, UK), which is a lightweight $16 \mathrm{~g}$, triaxial and waterproof. It has been found to be reliable for examining sleep $\quad(k a p p a=0.85 \pm 0.06) \quad(18) . \quad$ Participants were instructed to wear 24-hours day the accelerometer on their left wrist for at least four consecutive days, including two weekend days and two weekdays. If the unit was removed, the data for that day were excluded from the analyses. Sleep duration was calculated by the algorithm included in the macro provided by the manufacturer. By combining all the registered days for each participant, sleep duration was then expressed as the average number of hours per day. Short sleep duration was defined as less than eight hours per night, as defined by the American National Sleep Foundation for the adolescent population (19).

\section{Academic performance}

Academic performance was assessed by two components. First, we looked at the final academic grades from the first year of secondary school, which were provided by each school. The following subjects were included in the analyses: individual grades for the core subjects of maths and the Catalan language, the official language taught at the school, an average of these core subjects and the grade point average score. The grade point average score was defined as the single average for geography and history, natural sciences, maths, Spanish, Catalan and English languages and physical education grades. All the subjects are measured on a ten-point scale, where one was the worst and 10 was the best. Second, we used the Spanish version of the validated Science Research Associates Test of Educational Abilities (20). This test measures the subject's ability to learn by evaluating three basic skills: verbal ability, which is their command of language; numerical ability, which refers to their speed and precision in performing operations with numbers and quantitative concepts; and reasoning ability, which refers to their aptitude to find logical ordination criteria in sets of numbers, figures or letters. Scores for the three areas were obtained by adding positive answers. Overall academic ability was calculated by adding 
the scores for the three areas of ability. This battery test provides three complexity levels based on the age range of the sample. The present study used level three, which is designed for adolescents aged 14-18 years. The alpha scores for its reliability have been reported to be 0.74 for verbal ability, 0.87 for numerical ability, 0.77 for reasoning ability and 0.89 for overall academic ability (20).

\section{Covariates}

Briefly, body weight was measured to the nearest $0.1 \mathrm{~kg}$ using a seca 861 electronic scale (seca, Hamburg, Germany) with the subjects lightly dressed and without shoes. Height was measured to the nearest $0.1 \mathrm{~cm}$ using a wall-mounted seca 213 stadiometer (seca, Hamburg, Germany). Measures were assessed in duplicate by trained members of the project's research group following standardised procedures and average measures were used for the data analysis (21). Body mass index (BMI) was calculated as weight/height square $\left(\mathrm{kg} / \mathrm{m}^{2}\right)$. Pubertal status was self-reported according to the five stages defined by Tanner and Whitehouse. Physical activity (PA) was objectively measured using the GENEActiv accelerometer, as stated above, which has shown an intra-assay and inter-assay precision coefficient of variation of $1.4 \%$ and $2.1 \%$, respectively. By combining all registered days for each participant and using the Excel macro (Microsoft Corp, Washington, USA) to summarise the data, PA was expressed as the average minutes per day spent in light, moderate and vigorous PA. Moderate and vigorous PA (MVPA) was calculated by adding moderate $\mathrm{PA}$ and vigorous $\mathrm{PA}$.

\section{Statistical analyses}

The descriptive characteristics are presented as means and standard deviations (SD) or percentages. Differences between sexes were examined using the $t$-test and chisquare test for continuous and nominal variables, respectively. All variables were checked for normality using both graphical normal probability plots and statistical Kolmogorov-Smirnov test procedures. Due to its skewed distribution, the PSQI score was log-transformed when required. As the preliminary analyses showed no significant interactions between sex and adherence to the Mediterranean diet and sleep variables in relation to academic performance (all $\mathrm{p}>0.10$ ), all the analyses were performed for the whole sample.

Partial correlations coefficients were used to confirm the relationships between adherence to the Mediterranean diet, sleep variables and academic performance indicators, controlled for sex, pubertal stage, BMI and MVPA.

Multiple linear regression was used to study the association of adherence to the Mediterranean diet and academic performance using three separate models: model 1 comprised sex, pubertal stage, BMI and MVPA; model 2 comprised model 1 plus sleep duration and model 3 comprised model 1 plus sleep quality.

In order to elucidate whether the associations between adherence to the Mediterranean diet and academic performance were mediated by sleep patterns, mediation analyses were conducted using the PROCESS macro according to the procedures proposed by Hayes (22) and controlling for sex, pubertal stage, BMI and MVPA. The first equation regressed the mediator (sleep) on the independent variable (adherence to the Mediterranean diet). The second equation regressed the dependent variable (academic performance) on the independent variable. The third equation regressed the dependent variable on both the independent and mediator variables. The mediation analyses included continuous variables and was considered significant when zero was not in the 95\% confidence interval of the indirect effects, estimated by bootstrapping, as recommended by Preacher and Hayes (23). The part of the total effect that was explained by the mediation, namely the percentage of mediation $\left(\mathrm{P}_{\mathrm{M}}\right)$ was calculated as follows: (indirect effect/total effect) $\mathrm{x} 100$. All the analyses were performed using SPSS Statistics for Windows version 22.0 (IBM Corp, New York, USA) and the level of significance was set to $\mathrm{p}<0.05$.

\section{RESULTS}

The descriptive characteristics of the study population are presented in Table 1. Overall, boys were taller, more physically active $(\mathrm{p}<0.001)$ and had greater adherence to the Mediterranean diet than girls $(\mathrm{p}<0.01)$. We found that $74 \%$ of boys and $54 \%$ of girls showed good sleep quality $(\mathrm{p}<0.001)$. The boys also had a better mean sleep quality score ( 4.2 vs $5.5, \mathrm{p}<0.01$ ), shorter sleep duration ( 7.8 vs 8.1 hours; $\mathrm{p}<0.01)$ and higher numerical ability (14.8 vs $11.9 ; \mathrm{p}<0.001)$ than the girls.

Partial correlations controlling for sex, pubertal stage, BMI and MVPA are shown in Table 2. Adherence to the Mediterranean diet was positively correlated with sleep quality, language, core subjects, grade point average and verbal ability (all $\mathrm{p}<0.05$ ). Sleep quality was positively correlated with academic grades (all $\mathrm{p}<0.01$ ), while sleep duration was negatively correlated with verbal ability $(\mathrm{p}<0.01)$.

The results of the multiple linear regression models showing the association of adherence to the Mediterranean diet with academic performance are presented in Table 3 . According to the academic grades, adherence to the Mediterranean diet was positively associated with language, core subjects and the grade point average (all p $<0.05$ ) after controlling for sex, pubertal stage, BMI and MVPA (model 1). These associations disappeared after further controlling for sleep duration (model 2) and sleep quality (model 3). Regarding academic abilities, adherence to the Mediterranean diet was positively associated with verbal ability (model 1), even after controlling for potential confounders (models 2 and 3 ).

Mediation analyses were carried out to test whether the associations between adherence to the Mediterranean diet (independent variable) and academic performance (dependent variables) were mediated by sleep patterns (mediator variables). Mediation analyses were not significant for the association of adherence to the Mediterranean diet with 


\begin{tabular}{|c|c|c|c|c|}
\hline n $(\%)$ & $\begin{array}{l}\text { All } \\
269(100)\end{array}$ & $\begin{array}{l}\text { Boys } \\
140(52)\end{array}$ & $\begin{array}{l}\text { Girls } \\
129(48)\end{array}$ & $\mathrm{p}$ \\
\hline \multicolumn{5}{|l|}{ Demographics } \\
\hline Age (years) & $13.9 \pm 0.3$ & $13.9 \pm 0.3$ & $13.9 \pm 0.3$ & \multirow[t]{2}{*}{0.903} \\
\hline Tanner stage (I-V) $(\%)$ & $0 / 8 / 34 / 48 / 10$ & $0 / 10 / 32 / 44 / 14$ & $0 / 5 / 36 / 54 / 5$ & \\
\hline \multicolumn{5}{|l|}{ Anthropometry } \\
\hline Height $(\mathrm{cm})$ & $163.0 \pm 7.9$ & $164.6 \pm 8.6$ & $161.2 \pm 6.8$ & $<0.001$ \\
\hline Weight (kg) & $54.1 \pm 9.2$ & $54.5 \pm 9.6$ & $53.7 \pm 8.8$ & 0.486 \\
\hline BMI $\left(\mathrm{kg} / \mathrm{m}^{2}\right)$ & $20.3 \pm 2.7$ & $20.0 \pm 2.5$ & $20.6 \pm 2.9$ & 0.059 \\
\hline \multicolumn{5}{|l|}{ Physical activity (min/day) } \\
\hline Light & $174.8 \pm 55.8$ & $173.7 \pm 58.8$ & $175.9 \pm 52.6$ & 0.748 \\
\hline Moderate & $76.7 \pm 25.4$ & $81.7 \pm 24.7$ & $71.4 \pm 25.2$ & $<0.001$ \\
\hline Vigorous & $12.5 \pm 8.4$ & $15.5 \pm 7.7$ & $9.2 \pm 7.8$ & $<0.001$ \\
\hline Moderate and vigorous & $89.2 \pm 30.3$ & $97.2 \pm 28.8$ & $80.5 \pm 29.6$ & $<0.001$ \\
\hline \multicolumn{5}{|c|}{ Adherence to the Mediterranean diet } \\
\hline Overall score $(0-12)$ & $7.0 \pm 2.2$ & $7.3 \pm 2.1$ & $6.6 \pm 2.2$ & 0.010 \\
\hline Categories (\%) & & & & 0.115 \\
\hline Poor $(0-3)$ & $14(5.2)$ & $5(3.6)$ & $9(7.0)$ & \\
\hline Average (4-7) & $139(51.7)$ & $67(47.9)$ & $72(55.8)$ & \\
\hline Good $(8-12)$ & $116(43.1)$ & $68(48.6)$ & $48(37.2)$ & \\
\hline \multicolumn{5}{|l|}{ Sleep patterns } \\
\hline Sleep quality score $(0-21)$ & $4.8 \pm 2.8$ & $4.2 \pm 2.7$ & $5.5 \pm 2.7$ & $<0.001$ \\
\hline Good sleep quality (\%) & $174(64.7)$ & $104(74.3)$ & $70(54.3)$ & $<0.001$ \\
\hline Sleep duration (hours) & $8.0 \pm 0.9$ & $7.8 \pm 1.0$ & $8.1 \pm 0.8$ & 0.005 \\
\hline Sleep duration $\geq 8$ hours $(\%)$ & $135(50.2)$ & $66(47.1)$ & $69(53.5)$ & 0.326 \\
\hline \multicolumn{5}{|l|}{ Academic grades $(0-10)$} \\
\hline Maths & $6.8 \pm 1.6$ & $7.0 \pm 1.6$ & $6.7 \pm 1.6$ & 0.196 \\
\hline Language & $6.8 \pm 1.5$ & $6.6 \pm 1.5$ & $6.9 \pm 1.5$ & 0.168 \\
\hline Core subjects & $6.8 \pm 1.4$ & $6.8 \pm 1.5$ & $6.8 \pm 1.4$ & 0.991 \\
\hline GPA & $7.1 \pm 1.3$ & $7.1 \pm 1.3$ & $7.2 \pm 1.3$ & 0.420 \\
\hline \multicolumn{5}{|l|}{ Academic abilities } \\
\hline Verbal ability (0-50) & $18.7 \pm 5.3$ & $19.1 \pm 5.9$ & $18.2 \pm 4.6$ & 0.127 \\
\hline Numerical ability $(0-30)$ & $13.4 \pm 4.8$ & $14.8 \pm 4.6$ & $11.9 \pm 4.5$ & $<0.001$ \\
\hline Reasoning ability $(0-30)$ & $16.5 \pm 5.8$ & $16.1 \pm 5.6$ & $16.9 \pm 6.0$ & 0.239 \\
\hline Overall score $(0-110)$ & $48.6 \pm 12.6$ & $50.0 \pm 12.8$ & $47.0 \pm 12.2$ & 0.049 \\
\hline
\end{tabular}

Data are presented as means \pm SDs or frequencies (percentages). Sex differences were examined by the $t$-test or chi-square test.

Statistically significant values are in bold.

$\mathrm{BMI}=$ body mass index; GPA = grade point average; Good sleep quality was measured by a Pittsburg sleep quality index of $\leq 5$. Core subjects indicate the mean of maths and language. Overall score indicates the sum of the three abilities scores: verbal, numerical and reasoning.

Table 2 Partial correlation coefficients between adherence to the Mediterranean diet score, sleep patterns and academic performance indicators controlling for sex, pubertal stage, body mass index and moderate and vigorous physical activity $(n=269)$

\begin{tabular}{|c|c|c|c|c|c|c|c|c|c|}
\hline & \multirow[b]{2}{*}{$\begin{array}{l}\text { Adherence to the } \\
\text { Mediterranean diet }\end{array}$} & \multicolumn{4}{|c|}{ Academic grades } & \multicolumn{4}{|c|}{ Academic abilities } \\
\hline & & Maths & Language & $\begin{array}{l}\text { Core } \\
\text { subjects }\end{array}$ & GPA & Verbal & Numerical & Reasoning & $\begin{array}{l}\text { Overall } \\
\text { score }\end{array}$ \\
\hline Adherence to the Mediterranean diet & - & 0.115 & $0.122 *$ & $0.121^{*}$ & $0.121^{*}$ & $0.130^{*}$ & 0.063 & -0.024 & 0.067 \\
\hline Sleep quality & $0.120^{*}$ & $0.205^{* * *}$ & $0.169^{* *}$ & $0.168^{* *}$ & $0.182^{* *}$ & 0.023 & 0.096 & 0.063 & 0.074 \\
\hline Sleep duration & -0.059 & -0.038 & -0.058 & -0.072 & -0.074 & $-0.194^{* *}$ & -0.022 & -0.008 & -0.094 \\
\hline
\end{tabular}

Core subjects indicate the mean of maths and language; GPA: grade point average; Overall score indicates the sum of the three abilities scores: verbal, numerical and reasoning. $\mathrm{p}$-value $=* * * \mathrm{p} \leq 0.001 ; * \mathrm{*}<0.01$ and ${ }^{*} \mathrm{p}<0.05$.

academic performance when sleep duration was included as a mediator variable (data not shown). According to our mediation analyses (Fig. 1), sleep quality acted as a mediator for the relationship of adherence to the Mediterranean diet with academic grades, but not with academic abilities (data not shown). In the first equation, adherence 


\begin{tabular}{|c|c|c|c|c|c|c|c|c|c|}
\hline & \multicolumn{3}{|l|}{ Model 1} & \multicolumn{3}{|l|}{ Model 2} & \multicolumn{3}{|l|}{ Model 3} \\
\hline & B & $\beta$ & $p$ & B & $\beta$ & $\mathrm{p}$ & B & $\beta$ & $p$ \\
\hline \multicolumn{10}{|l|}{ Academic grades } \\
\hline Maths & 0.085 & 0.116 & 0.062 & 0.084 & 0.114 & 0.067 & 0.068 & 0.092 & 0.132 \\
\hline Language & 0.085 & 0.121 & 0.048 & 0.082 & 0.118 & 0.055 & 0.072 & 0.102 & 0.094 \\
\hline Core subjects & 0.078 & 0.121 & 0.049 & 0.075 & 0.117 & 0.058 & 0.066 & 0.102 & 0.096 \\
\hline GPA & 0.071 & 0.121 & 0.049 & 0.069 & 0.117 & 0.058 & 0.059 & 0.101 & 0.100 \\
\hline \multicolumn{10}{|l|}{ Academic abilities } \\
\hline Verbal & 0.319 & 0.131 & 0.035 & 0.293 & 0.120 & 0.049 & 0.317 & 0.130 & 0.038 \\
\hline Numerical & 0.131 & 0.060 & 0.311 & 0.129 & 0.059 & 0.321 & 0.109 & 0.050 & 0.404 \\
\hline Reasoning & -0.065 & -0.024 & 0.699 & -0.066 & -0.025 & 0.693 & -0.086 & -0.032 & 0.608 \\
\hline Overall score & 0.386 & 0.067 & 0.280 & 0.355 & 0.061 & 0.319 & 0.340 & 0.059 & 0.345 \\
\hline
\end{tabular}

Model 1: controlled for sex, pubertal stage, body mass index, and moderate and vigorous physical activity. Model 2: controlled for model 1 plus sleep duration. Model 3: controlled for model 1 plus sleep quality. Core subjects indicate the mean of maths and language; GPA: Grade Point Average. Overall score indicates the sum of the three abilities scores: verbal, numerical and reasoning. Statistically significant values are highlighted in bold. $\beta$, standardised coefficient.

to the Mediterranean diet was positively associated with sleep quality $(\mathrm{p}<0.05)$. In the second equation, adherence to the Mediterranean diet was also positively associated with final grades $(\mathrm{p}<0.05)$. Finally, in the third equation, sleep quality was positively associated with final grades $(\mathrm{p}<0.01)$ and adherence to the Mediterranean diet was positively related with final grades, although the associations were not statistically significant. These results suggest that adherence to the Mediterranean diet could indirectly influence some academic performance variables through its effects on sleep quality: maths $\mathrm{P}_{\mathrm{M}}=20.24 \%$; language $\mathrm{P}_{\mathrm{M}}=15.44 \%$; core subjects $\mathrm{P}_{\mathrm{M}}=15.52 \%$ and grade point average $\mathrm{P}_{\mathrm{M}}=16.83 \%$.

\section{DISCUSSION}

To our knowledge this is the first study investigating the potential mediator role of sleep quality in the association between adherence to Mediterranean diet and academic performance in adolescents. The main finding of the present study indicates a positive association between adherence to the Mediterranean diet and academic performance in adolescents, revealing a mediating effect of sleep quality on this association.

No previous studies have investigated the association between adherence to the Mediterranean diet and academic abilities. However, we found three studies examining the association between adherence to the Mediterranean diet and school grades. In consonance with our results, Vassiloudis et al. found a positive association between adherence to the Mediterranean diet and self-reported academic performance in Greek children (6) and adolescents (24). Similarly, Esteban-Cornejo et al. (7) showed that greater adherence to the Mediterranean diet was related with higher academic performance scores in Spanish children and adolescents aged 10-15 years.

Our data show that adherence to the Mediterranean diet may have positively influenced the adolescents' academic grades, but not their academic abilities. The divergent results obtained for academic performance variables could have been due to methodological differences. In fact, academic abilities were assessed through a standardised test that evaluates individually specific content abilities in a single time-point trial, whilst the multifactorial character of academic grades involve other social, cultural and biological variables that have an impact on a final grade.

The association between the Mediterranean diet and academic performance could be related to the key role that dietary patterns and nutrients exert on brain. The consumption of polyunsaturated fatty acids, abundant in olives, nuts and fish, increases the levels of brain-derived neurotrophic factors, which stimulates cognitive functioning. This, in turn, may improve academic performance (25). Conversely, overconsumption of saturated fat and simple sugars decreases the levels of brain-derived neurotrophic factors and increases oxidative stress, which may impair cognitive processes $(26,27)$. In addition, the intake of flavonoid and non-flavonoid polyphenols, which are mainly found in fruits and vegetables, has antioxidant and antiinflammatory properties and promotes neuronal signalling with positive effects on learning and memory (25). Therefore, the foods rich in micronutrients and macronutrients that are found in the Mediterranean diet could act as key factors leading to better academic performance.

When we examined whether sleep duration and quality could be underlying mechanisms of the association between adherence to the Mediterranean diet and academic performance, only sleep quality was revealed as a mediator. Few studies have investigated the association between the Mediterranean diet and academic performance, and none of them has evaluated the mediating role of sleep quality. Our results add important information in relation to the relevance of sleep on academic performance and highlight that sleep quality could play a more important role than sleep duration in academic performance, which has also been previously suggested $(15,28)$. 


\begin{tabular}{|c|c|c|}
\hline \multirow{2}{*}{$\begin{array}{l}\text { Adherence to the } \\
\text { Mediterranean diet }\end{array}$} & Equation 2 & \multirow{2}{*}{ Maths } \\
\hline & $\mathrm{c}=0.085(0.045)$ & \\
\hline
\end{tabular}

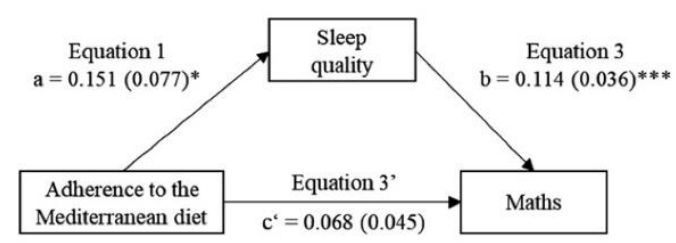

$P_{M}=20.24 \% \quad \beta=0.017[0.0006 ; 0.0434]$
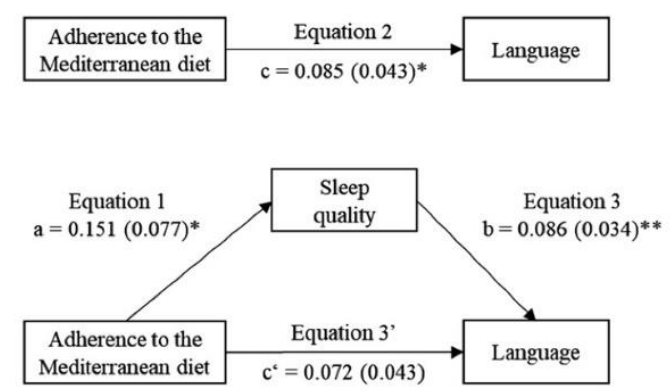

$P_{M}=15.44 \% \quad \beta=0.013[0.0007 ; 0.0350]$

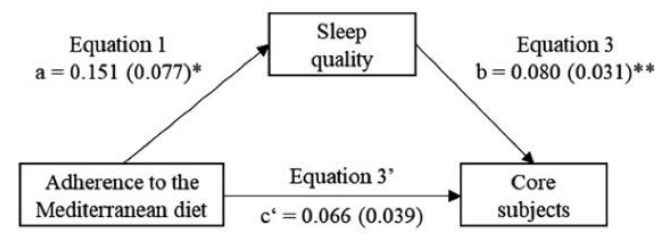

$\mathrm{P}_{\mathrm{M}}=15.52 \% \quad \beta=0.012[0.0002 ; 0.0342]$

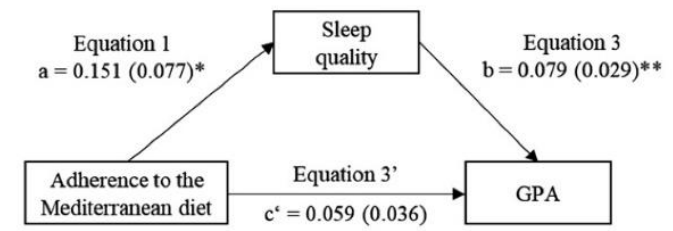

$\mathrm{P}_{\mathrm{M}}=16.83 \% \beta=0.012[0.0006 ; 0.0340]$

Figure 1 Sleep quality mediation models of the relationship between adherence to the Mediterranean diet and academic grades, controlling for sex, pubertal stage body mass index, and moderate and vigorous physical activity. Results showed as regression coefficients (standard error). $\beta=$ indirect effect; LLCI and ULCI = lower and upper levels for $95 \%$ confidence interval of the indirect effect between adherence to the Mediterranean diet and academic grades. Core subjects indicate the mean of maths and language. GPA: grade point average. $p$-value $=* * * p \leq 0.001, * * p<0.01$ and ${ }^{*} p<0.05$.

Several aspects of the Mediterranean diet, including specific nutrients, have been shown to modulate sleep quality. In fact, adequate amounts of proteins, fibre, carbohydrates, polyphenols, and monosaturated and polyunsaturated fatty acids intake have been associated with better sleep quality $(12,13)$. Moreover, the Mediterranean diet includes foods, such as seeds, nuts, fish and chicken that are rich in tryptophan, an amino acid that is related to the regulation of the circadian rhythms and which has been proposed as the most helpful promotor of sleep (29). On the other hand, better sleep quality has been positively related to synaptic plasticity and learning (30), with improvements in attention and working memory, which might contribute to better academic performance in adolescents (15). Therefore, despite the fact that we did not analyse the physiological mechanisms involved in the processes of diet, sleep and cognition, we speculate that high levels of specific compounds provided by the Mediterranean diet could contribute to better sleep (12), with benefits in cognitive functioning $(15,30)$, leading to higher academic performance in adolescents.

Limitations and strengths

The limitations of our study include its cross-sectional design, which prevents us from infering causal relationships, and the use of a questionnaire to assess adherence to the Mediterranean diet. Nonetheless, our mediation analysis strategy allowed us to provide data supporting the importance of improving adherence to the Mediterranean diet in order to enhance sleep and academic performance in adolescents. Moreover, the study included the use of objective and standardised measures of sleep duration and quality, respectively, and a relatively large and age-matched sample of adolescents aged $13.9 \pm 0.3$ years with no academic performance differences. In addition, the statistical analyses were controlled for sex, pubertal status, BMI and MVPA, which are relevant given their associations with diet, sleep and academic performance. 


\section{CONCLUSION}

The current study showed that sleep quality plays a key mediating role in the relationship between adherence to the Mediterranean diet and academic performance in adolescents. If our findings are confirmed in prospective studies, they would indicate that following Mediterranean dietary patterns may improve sleep quality, which could have potentially positive effects on academic performance in adolescents. Due to the benefits of healthy dietary patterns and good sleep behaviours, further longitudinal and intervention studies should examine the effects of diet and sleep patterns on academic performance in adolescents. Families, educators and policy-makers should take into account our results in order to promote school-based public health and educational support programmes that consider nutrition and sleep patterns as key behaviours that can improve academic performance.

\section{FINANCE}

DADOS study received funding from the Spanish Ministry of Economy and Competitiveness (DEP2013-45515-R) and by the Jaume I University of Castellon (P1.1A2015-05). This section of the research was partly supported by a Sunny Sport research grant from the Schweppes Suntory Spain Company. M.A.R is supported by a predoctoral research grant from the Jaume I University (PREDOC/2015/13).

\section{CONFLICT OF INTEREST}

The authors have no conflicts of interest to declare.

\section{References}

1. Willett WC, Sacks F, Trichopoulou A, Drescher G, Ferro-Luzzi A, Helsing E, et al. Mediterranean diet pyramid: a cultural model for healthy eating. Am J Clin Nutr 1995; 61(6 Suppl): $1402 \mathrm{~S}$ - 6 S.

2. Iaccarino Idelson P, Scalfi L, Valerio G. Adherence to the Mediterranean Diet in children and adolescents: a systematic review. Nutr Metab Cardiovasc Dis 2017; 27: 28399.

3. Estruch R, Ros E, Salas-Salvadó J, Covas M-I, Corella D, Arós F, et al. Primary prevention of cardiovascular disease with a Mediterranean diet. N Engl J Med 2013; 368: 1279-90.

4. Ferranti R, Marventano S, Castellano S, Giogianni G, Nolfo F, Rametta S, et al. Sleep quality and duration is related with diet and obesity in young adolescent living in Sicily, Southern Italy. Sleep Sci 2016; 9: 117-22.

5. Campanini MZ, Guallar-Castillón P, Rodríguez-Artalejo F, Lopez-Garcia E. Mediterranean diet and changes in sleep duration and indicators of sleep quality in older adults. Sleep 2017; 40: 1-9.

6. Vassiloudis I, Yiannakouris N, Panagiotakos DB, Apostolopoulos K, Costarelli V. Academic performance in relation to adherence to the Mediterranean diet and energy balance behaviors in Greek primary schoolchildren. J Nutr Educ Behav 2014; 46: 164-70.

7. Esteban-Cornejo I, Izquierdo-Gomez R, Gómez-Martínez S, Padilla-Moledo C, Castro-Pinero J, Marcos A, et al. Adherence to the Mediterranean diet and academic performance in youth: the UP\&DOWN study. Eur J Nutr 2016; 55: 1133-40.
8. Elovainio M, Rosenström T, Hakulinen C, Pulkki-Rảback L Mullola S, Jokela M, et al. Educational attainment and health transitions over the life course: testing the potential mechanisms. J Public Health (Oxf) 2016; 38: e254-62.

9. French MT, Homer JF, Popovici I, Robins PK. What you do in high school matters: high school GPA, educational attainment, and labor market earnings as a young adult. East Econ J 2015; 41: $370-86$

10. Vassalle C, Sabatino L, Pingitore A, Chatzianagnostou K, Mastorci F, Ceravolo R. Antioxidants in the Diet and cognitive function: Which role for the Mediterranean life-style? J Prev Alzheimer's Dis 2017; 4: 58-64.

11. Burrows T, Goldman S, Pursey K, Lim R. Is there an association between dietary intake and academic achievement: a systematic review. J Hum Nutr Diet 2017; 30: $117-40$.

12. St-Onge M-P, Mikic A, Pietrolungo CE. Effects of diet on sleep quality. Adv Nutr 2016; 7: 93849.

13. Grandner MA, Jackson N, Gerstner JR, Knutson KL. Sleep symptoms associated with intake of specific dietary nutrients. J Sleep Res 2014; 23: 22-34.

14. Kopasz M, Loessl B, Hornyak M, Riemann D, Nissen C, Piosczyk $\mathrm{H}$, et al. Sleep and memory in healthy children and adolescents - a critical review. Sleep Med Rev 2010; 14: 16777.

15. Dewald JF, Meijer AM, Oort FJ, Kerkhof GA, Bogels SM. The influence of sleep quality, sleep duration and sleepiness on school performance in children and adolescents: A metaanalytic review. Sleep Med Rev 2010; 14: 179-89.

16. Serra-Majem L, Ribas L, Ngo J, Ortega RM, García A, PérezRodrigo C, et al. Food, youth and the Mediterranean diet in Spain. Development of KIDMED, Mediterranean Diet Quality Index in children and adolescents. Public Health Nutr 2004; 7 : 931-5.

17. Royuela Rico A, Macías Fernández J. Propiedades Clinimétricas De La Versión Castellana Del Cuestionario De Pittsburg. Vigilia-Sueño 1997; 9: 81-94.

18. Te Lindert BHW, Van Someren EJW. Sleep estimates using Microelectromechanical systems (MEMS). Sleep 2013; 36: 781-9.

19. Hirshkowitz M, Whiton K, Albert SM, Alessi C, Bruni O, DonCarlos L, et al. National Sleep Foundation's sleep time duration recommendations: methodology and results summary. Sleep Health 2015; 1: 40-3.

20. Thurstone LL, Thurstone TG. TEA Test de Aptitudes Escolares (Scholar Aptitudes Test), 11th ed. volume 77. Madrid: TEA Ediciones S.A, 2004.

21. Beltran-Valls MR, García Artero E, Capdevila-Seder A, Legaz-Arrese A, Adelantado-Renau M, Moliner-Urdiales D. Regular practice of competitive sports does not impair sleep in adolescents: DADOS Study. Pediatr Exerc Sci 2017; 30: 229-36.

22. Hayes A. Introduction to mediation, moderation, and conditional process analysis: A regression-based approach. New York: Guilford, 2013.

23. Preacher KJ, Hayes AF. Asymptotic and resampling strategies for assessing and comparing indirect effects in multiple mediator models. Behav Res Methods 2008; 40: 879-91.

24. Vassiloudis I, Yiannakouris N, Panagiotakos DB, Apostolopoulos K, Costarelli V. Adherence to the Mediterranean diet and specific lifestyle habits are associated with academic performance in Greek adolescents. Med J Nutr Metab 2017; 10: 93-103.

25. Gomez-Pinilla F, Gomez AG. The influence of dietary factors in central nervous system plasticity and injury recovery. $P M R$ 2011; 3: S111-6. 
26. Vaynman S, Gomez-Pinilla F. Revenge of the "sit": how lifestyle impacts neuronal and cognitive health through molecular systems that interface energy metabolism with neuronal plasticity. J Neurosci Res 2006; 84: 699-715.

27. Wu A, Ying Z, Gomez-Pinilla F. The interplay between oxidative stress and brain-derived neurotrophic factor modulates the outcome of a saturated fat diet on synaptic plasticity and cognition. Eur J Neurosci 2004; 19: 1699-707.
28. Gruber R, Somerville G, Enros P, Paquin S, Kestler M, GilliesPoitras E. Sleep efficiency (but not sleep duration) of healthy school-age children is associated with grades in math and languages. Sleep Med 2014; 15: 1517-25.

29. Lindseth G, Murray A. Dietary macronutrients and sleep. West J Nurs Res 2016; 38: 938-58.

30. Frank MG, Benington JH. The role of sleep in memory consolidation and brain plasticity: dream or reality? Neuroscientist 2006; 12: 477-88. 
Study 4

The risk of eating disorders and academic performance in adolescents: DADOS study 


\title{
The risk of eating disorders and academic performance in adolescents: DADOS study Riesgo de padecer trastornos de la conducta alimentaria y rendimiento académico en adolescentes: proyecto DADOS
}

\author{
Mireia Adelantado-Renau', Maria Reyes Beltran-Valls' ${ }^{1}$, Miriam Toledo-Bonifás', Carlos Bou-Sospedra', M. ${ }^{2}$ Carmen Pastor ${ }^{2}$ and Diego Moliner-Urdiales ${ }^{1}$ \\ 'LIFE Research Group. Department of Education. Universitat Jaume I. Castellón de la Plana, Spain. 'MPAGER Research Group. Department of Basic and Clinical Psychology and \\ Psycho-biology. Universitat Jaume I. Castellón de la Plana, Spain
}

Key words:

Adolescence. Health. Weight status. Educational achievement.

Palabras clave:

Adolescencia.

Salud. Composición corporal. Rendimiento escolar.

\begin{abstract}
Introduction: eating disorders (ED) are complex multifactorial chronic diseases with adverse consequences on cognition in adolescence. Objectives: the main aim of the present study was to analyze the association between the risk of ED and academic performance in adolescents, considering the key role of weight status.

Methods: a total of 261 adolescents $(13.9 \pm 0.3$ years) from the DADOS (Deporte, Adolescencia y Salud) Study were included in the analysis. The risk of ED was assessed using the Sick Control on Fast Food (SCOFF) questionnaire. Weight status was assessed by body mass index (BMI) $\left(\mathrm{kg} / \mathrm{m}^{2}\right)$. Academic performance was assessed through final grades and through the Spanish version of the SRA Test of Educational Ability (TEA).

Results: the risk of ED was negatively associated with academic grades, and with verbal and numeric abilities measured through TEA. Adolescents with non-eating disorder risk showed higher scores in academic grades (but not in the TEA components). Overweight and obese adolescents reported higher risk of $\mathrm{ED}$.

Conclusions: the risk of ED is negatively associated with academic performance, being higher in overweight and obese adolescents. Interventional programs aimed to improve academic performance should take into account weight status and the risk of ED.
\end{abstract}

\begin{abstract}
Resumen
Introducción: los trastornos de la conducta alimentaria (TCA) son alteraciones psicológicas severas con graves consecuencias sobre la función cognitiva durante la adolescencia.

Objetivos: el principal objetivo de este estudio fue analizar la asociación entre el riesgo de padecer TCA y el rendimiento académico en adolescentes, considerando el papel clave de la composición corporal.

Métodos: la muestra estuvo formada por un total de 261 adolescentes $(13,9 \pm 0,3$ años), participantes del proyecto DADOS (Deporte, Adolescencia y Salud). La versión española del cuestionario Sick Control on Fast Food (SCOFF) se utilizó para determinar el riesgo de padecer TCA. La composición corporal se evaluó mediante el índice de masa corporal $(\mathrm{IMC})\left(\mathrm{kg} / \mathrm{m}^{2}\right)$. El rendimiento académico fue evaluado mediante las notas finales y mediante la versión española del cuestionario SRA Test of Educational Ability (TEA).

Resultados: el riesgo de padecer TCA estuvo inversamente asociado con las notas y con las habilidades verbales y numéricas medidas mediante el TEA. Los adolescentes que no presentaban riesgo de padecer TCA mostraron calificaciones más altas en las notas (pero no en los componentes del cuestionario TEA). Los adolescentes con sobrepeso u obesidad reportaron un mayor riesgo de padecer TCA.

Conclusiones: el riesgo de padecer TCA está asociado de forma inversa con el rendimiento académico y es más elevado en adolescentes con sobrepeso u obesidad. Las intervenciones cuyo objetivo sea mejorar el rendimiento académico deberían tener en cuenta la composición corporal y el riesgo de padecer TCA.
\end{abstract}

Received: 16/01/2018 • Accepted: 28/02/2018

Adelantado-Renau M, Beltran-Valls MR, Toledo-Bonifás M, Bou-Sospedra C, Pastor MC, Moliner-Urdiales D. The risk of eating disorders and academic performance in adolescents: DADOS study. Nutr Hosp 2018;35(5):1201-1207

DOl: http://dx.doi.org/10.20960/nh.1778

Correspondence:

Diego Moliner Urdiales. Human Sciences Faculty. Department of Education. Universitat Jaume I. Av. Vicent Sos Baynat. 12071 Castellon, Spain e-mail: dmoliner@uji.es

${ }^{\circ}$ Copyright 2018 SENPE y ${ }^{\circ}$ Arán Ediciones S.L. Este es un artículo Open Access bajo la licencia CC BY-NC-SA (http://creativecommons.org/licenses/by-nc-sa/4.0/). 


\section{INTRODUCTION}

Adolescence is a period of life characterized by important physical, behavioral and brain changes $(1,2)$. Nutritional requirements and dietary habits are modified during this age-span, which could lead to different nutrition-related disorders with adverse consequences for overall health status (3).

Eating disorders $(\mathbb{E D})$ are complex diseases characterized by disruptive eating behaviors linked to body shape dissatisfaction, disinterest in food and an intense fear of gaining weight (4). According to scientific literature, anorexia nervosa, bulimia nervosa and binge eating disorder are the most investigated severe clinically defined $E D$. The origin of ED is multifaceted, being involved a combination of psychological (i.e., positive self-esteem, emotional well-being), biological (i.e., sex) and social factors (i.e., family connectedness) (5). A peak of incidence in the number of ED has been reported in adolescents between 15-19 years old (6), with symptoms starting during pre-adolescence and early adolescence (7).

Since ED are associated to adverse consequences for physical health and psychosocial and cognitive functioning (5), the early detection of people at risk of developing ED is essential to prevent its progression. Evidence from previous studies in adolescents suggest that cognitive deficits pre-exist and underlie the etiology of ED (8), while high academic performance could act as a protective factor (9). However, limited and non-conclusive research has been undertaken regarding the link between the risk of developing ED and academic performance in adolescents. To this extent, Veses et al. (10) found higher risk of ED among non-overweight adolescent girls with low academic performance, and among overweight adolescent boys with low school grades in physical education (PE). Conversely, Gil et al. (11) did not find differences in academic performance between adolescents at risk and not at risk of ED.

Although ED is commonly related to normal or low body weight, obesity and ED may coexist (12). Since obesity is a weight-related disorder with a high prevalence among adolescents, it might affect body satisfaction and perception leading to disruptive eating behaviors. Overweight and obesity have been positively associated with an increased risk of developing ED in adolescents $(10,13,14)$. These disorders share multiple similarities and may occur simultaneously (15) or as a consequence of each other (16). In addition, recent research has also pointed out the negative association of body fatness with cognition in adolescents (17). Body image dissatisfaction, weight-related teasing, unhealthy behaviors, and health-related problems closely linked to overweight and obese adolescents have been postulated as potential mechanisms by which excess of body fat negatively influences academic outcomes and cognitive functions (17).

Given the high prevalence of obesity and the key role of body weight on the risk of developing ED and cognition in adolescents, the main aim of the present study was to analyze the association between the risk of ED and academic performance in healthy adolescents, considering the effect of weight status. We additionally examined: a) the differences in academic performance according to ED categories; and b) the risk of ED according to weight status.

\section{METHODS}

\section{PARTICIPANTS}

The DADOS (Deporte, Adolescencia y Salud) Study is a 3-year longitudinal research project (from 2015 to 2017) aimed to assess the influence of physical activity on health, cognition and psychological wellness through adolescence. All the participants were recruited from secondary schools and sport clubs of Castellon (Spain), and met the general DADOS inclusion criteria: born in 2001, enrolled in second grade of secondary school and free of any chronic disease. The results presented in this study belong to baseline data obtained between February and May of 2015. From the total DADOS study sample, 261 adolescents (138 boys) with valid data for at least risk of eating disorders, weight status, and academic performance were included in the analyses.

Adolescents and their parents or guardians were informed of the nature and characteristics of the study, and all provided a written informed consent. The DADOS study protocol was designed in accordance with the ethical guidelines of the Declaration of Helsinki of 1961 (last revision of Fortaleza, Brazil, 2013) and approved by the Research Ethics Committee of the Universitat Jaume I of Castellon.

\section{WEIGHT STATUS}

Briefly, body weight was measured to the nearest $0.1 \mathrm{~kg}$ using an electronic scale (Seca ${ }^{\circledR} 861$, Hamburg, Germany) with the participant lightly dressed and without shoes. Height was measured to the nearest $0.1 \mathrm{~cm}$ using a wall-mounted stadiometer $\left(\mathrm{Seca}^{\circledR} 213\right.$, Hamburg, Germany). Measures were assessed in duplicate by trained members of the DADOS research group following standardized procedures (18) and average measures were used for data analysis. Body mass index (BMI) was calculated as weight/height square $\left(\mathrm{kg} / \mathrm{m}^{2}\right)$.

\section{THE RISK OF EATING DISORDERS}

The risk of ED was assessed using the Sick Control on Fast Food (SCOFF) questionnaire (19). The questionnaire consists of five questions regarding deliberate vomiting, loss of control over eating, weight loss, body image distortion and impact of food on life. A value of 1 is assigned to each affirmative answer, ranging the SCOFF overall score from 0 to 5 . A score $\geq 2$ in the SCOFF score indicates a likely case of suffering from ED. The Spanish version of the SCOFF validated for adolescents was used (20), which has shown accurate internal consistency and criteria validity for screening ED in adolescents $(81.9 \%$ sensitivity and $78.7 \%$ specificity) (21).

\section{ACADEMIC PERFORMANCE}

Academic performance was assessed by two components:

1. The final academic grades from the $1^{\text {st }}$ course of secondary school provided by each school's secretary office. The fol- 
lowing indicators were included in the analyses: individual grades for Math, Language and Physical Education (PE) and grade point average (GPA) score. Language is the grade of Catalan, the official teaching language at school. GPA score was defined as the single average for Geography and History, Natural Science, Math, Spanish, Catalan, English and Physical Education grades. All the subjects are measured on a ten-point scale, where 1 is the worst and 10 is the best.

2. The Spanish version of the validated Science Research Associates Test of Educational Abilities (TEA) (22). This test measures three basic abilities: verbal ability (command of language), numeric ability (speed and precision in performing operations with numbers and quantitative concepts), and reasoning ability (the aptitude to find logical ordination criteria in sets of numbers, figures or letters). Scores for the three abilities were obtained by adding positive answers. Overall academic ability was calculated by adding the three abilities' scores (verbal + numeric + reasoning). This battery test provides three complexity levels based on the age range of the sample. The present work used the level 3 designed for adolescents aged 14 to 18 years (reliability: verbal $\alpha=$ 0.74 , numeric $\alpha=0.87$, reasoning $\alpha=0.77$ and overall academic ability $\alpha=0.89$ ) (22).

\section{COVARIATES}

Pubertal stage was self-reported according to the five stages defined by Tanner and Whitehouse (23). It is based on external primary and secondary sex characteristics, which are described by the participants using standard pictures according to Tanner instructions.

The Family Affluence Scale "FAS" developed by Currie et al. (24) was used as a proxy of socioeconomic status (SES), which is based on material conditions in the family such as car ownership, bedroom occupancy, computer ownership and home internet access.

Parental educational attainment was self-reported by both parents as primary school, secondary school, bachelor studies or university degree. Study levels were dichotomized in two groups: no university degree vs university degree for each parent. Maximum parental educational attainment was used in the analyses.

\section{STATISTICAL ANALYSIS}

Descriptive characteristics are presented as mean and standard deviation (SD) or percentages. Differences between sexes were examined using the t-test and Chi-square test for continuous and nominal variables, respectively. As preliminary analyses showed no significant interactions between sex and ED risk scores $(p>$ $0.10)$, all analyses were performed with the total sample.

Partial correlation analyses controlling for sex, pubertal stage, SES and parental educational attainment were performed to examine the associations of the risk of ED with weight status and academic performance.
Linear regression analyses were performed to investigate the associations of the risk of ED (SCOFF score ranging from 0 to 5) with academic performance. We created three regression models: a) unadjusted model; b) model adjusted for sex, pubertal stage, SES and parental educational attainment; and c) model adjusted for confounders in model 2 plus BMl. Analyses of covariance (ANCOVA) were conducted to examine whether academic performance differed between eating disorders risk categories (eating disorder risk vs non-eating disorder risk). These analyses were adjusted for sex, pubertal stage, SES, parental educational attainment and BMI.

Finally, binary logistic regression analysis controlling for sex, pubertal stage, SES and parental educational attainment was performed to estimate the probability of the risk of eating disorders according to weight status (non-overweight vs overweight including obesity). All the analyses were performed using the IBM SPSS Statistics for Windows version 22.0 (Armonk, NY: IBM Corp), and the level of significance was set to $p<0.05$.

\section{RESULTS}

Descriptive characteristics of the study sample by sex are displayed in table I. Weight status was similar for boys and girls, with a $13 \%$ of overweight or obese adolescents. The risk of developing ED was of $12 \%$, with no differences among sexes. Girls reported higher loss of control over eating and body image distortion than boys (26.0\% vs $13.8 \%$ and $17.9 \%$ vs $8.0 \%$, respectively; all $p<0.05)$. Academic performance did not show differences among sexes except for numeric ability that was higher in boys $(p<0.001)$.

Partial correlations among all the study variables controlling for sex, pubertal stage, SES and parental educational attainment are shown in table II. The risk of ED (SCOFF score) was positively associated with weight status $(r=0.262, p<0.001)$ and negatively associated with all the academic grades ( $r$ ranging from -0.261 to -0.186 ; all $p<0.01$ ), and with verbal and numeric abilities $(r=-0.146$ and -0.125 , respectively; all $p<0.05)$.

Table III presents the associations between the risk of ED and academic performance variables. In model 1 (unadjusted model), the risk of ED was negatively associated with all the academic grades (Math, Language, PE and GPA; $\beta$ ranging from -0.152 to -0.202 ), while no significant associations were found with academic abilities. After further controlling for sex, pubertal stage, SES and parental educational attainment (model 2; $\beta$ ranging from -0.181 to -0.253 ), and $\mathrm{BMI}$ (model $3 ; \beta$ ranging from -0.214 to -0.141 ), the results for academic grades remained the same. Regarding academic abilities, the risk of ED was negatively associated with verbal and numeric abilities in model 2 , and with verbal ability in model 3 (all $p<0.05$ ).

Figure 1 displays the differences in academic grades between categories of risk of developing ED, adjusting for potential confounders. Non-risk of ED adolescents (SCOFF score <2) showed higher academic grades (all $p<0.01$ ) compared with those adolescents with risk of ED (SCOFF score $\geq 2$ ). No differences were found for academic abilities between categories of ED risk (data not shown). 
Table I. Characteristics of the study sample for the overall sample and by sex

\begin{tabular}{|c|c|c|c|c|}
\hline & All & Boys & Girls & $\mathbf{p}$ \\
\hline & ( $n=261)$ & $(n=138)$ & $(n=123)$ & \\
\hline Age (y) & $13.9 \pm 0.3$ & $13.9 \pm 0.3$ & $13.9 \pm 0.3$ & 0.976 \\
\hline Pubertal stage (I-V) (\%) & $0 / 8 / 34 / 48 / 10$ & $0 / 10 / 33 / 43 / 14$ & $0 / 6 / 36 / 53 / 5$ & - \\
\hline Socioeconomic status $(0-8)$ & $4.2 \pm 1.4$ & $4.0 \pm 1.3$ & $4.4 \pm 1.4$ & 0.025 \\
\hline Parental university degree attainment (\%) & 48.3 & 43.5 & 53.7 & 0.100 \\
\hline \multicolumn{5}{|c|}{ Anthropometry } \\
\hline Height (cm) & $163.1 \pm 7.9$ & $164.6 \pm 8.6$ & $161.4 \pm 6.8$ & $<0.001$ \\
\hline Weight (kg) & $54.2 \pm 9.3$ & $54.4 \pm 9.6$ & $53.9 \pm 8.9$ & 0.630 \\
\hline BMI $\left(\mathrm{kg} / \mathrm{m}^{2}\right)$ & $20.3 \pm 2.7$ & $20.0 \pm 2.6$ & $20.7 \pm 2.9$ & 0.052 \\
\hline Overweight* $(\%)$ & 13.0 & 11.6 & 14.6 & 0.466 \\
\hline \multicolumn{5}{|c|}{ SCOFF affirmative answers (\%) } \\
\hline Q1: Deliberate vomiting & 7.3 & 6.5 & 8.1 & 0.618 \\
\hline Q2: Loss of control over eating & 19.5 & 13.8 & 26.0 & 0.013 \\
\hline Q3: Weight loss & 9.2 & 11.6 & 6.5 & 0.155 \\
\hline Q4: Body image distortion & 12.6 & 8.0 & 17.9 & 0.016 \\
\hline Q5: Impact of food on life & 8.4 & 8.0 & 8.9 & 0.778 \\
\hline SCOFF score $(0-5)$ & $0.6 \pm 0.9$ & $0.5 \pm 0.8$ & $0.7 \pm 1.0$ & 0.079 \\
\hline Eating disorder risk (\%) & 12.3 & 10.1 & 14.6 & 0.270 \\
\hline \multicolumn{5}{|c|}{ Academic grades $(0-10)$} \\
\hline Math & $6.9 \pm 1.6$ & $7.0 \pm 1.6$ & $6.8 \pm 1.6$ & 0.277 \\
\hline Language & $6.8 \pm 1.5$ & $6.7 \pm 1.5$ & $6.9 \pm 1.6$ & 0.173 \\
\hline PE & $8.1 \pm 1.1$ & $8.0 \pm 1.1$ & $8.1 \pm 1.1$ & 0.468 \\
\hline GPA & $7.1 \pm 1.3$ & $7.1 \pm 1.3$ & $7.2 \pm 1.3$ & 0.394 \\
\hline \multicolumn{5}{|c|}{ Academic abilities } \\
\hline Verbal $(0-50)$ & $18.7 \pm 5.4$ & $19.2 \pm 5.9$ & $18.2 \pm 4.7$ & 0.132 \\
\hline Numeric $(0-30)$ & $13.5 \pm 4.8$ & $14.8 \pm 4.6$ & $11.9 \pm 4.6$ & $<0.001$ \\
\hline Reasoning $(0-30)$ & $16.5 \pm 5.8$ & $16.1 \pm 5.7$ & $17.0 \pm 6.0$ & 0.198 \\
\hline Overall $(0-110)$ & $48.7 \pm 12.7$ & $50.1 \pm 12.9$ & $47.1 \pm 12.3$ & 0.060 \\
\hline
\end{tabular}

Data are presented as mean \pm SD or percentages. Differences between sexes were examined by $t$-test or Chi-square test. Statistically significant values are in italics. *Includes overweight + obese participants. BM: body mass index; SCOFF: Sick Control on Fast Food; PE: Physical Education; GPA: grade point average. A score $\geq 2$ in the SCOFF questionnaire indicates risk of eating disorders. Overall indicates the sum of the three abilities scores.

Table II. Partial correlations between the risk of ED and the study variables controlling for sex, pubertal stage, socioeconomic status, and parental educational attainment $(n=261)$

\begin{tabular}{|c|c|c|c|c|c|c|c|c|c|}
\hline & $\begin{array}{c}\text { Weight } \\
\text { status }\end{array}$ & \multicolumn{4}{|c|}{ Academic grades } & \multicolumn{4}{c|}{ Academic abilities } \\
\hline & BMI & Math & Language & PE & GPA & Verbal & Numeric & Reasoning & Overall \\
\hline $\begin{array}{c}\text { SCOFF } \\
\text { score }\end{array}$ & $0.262^{\ddagger}$ & $-0.186^{\dagger}$ & $-0.211^{\ddagger}$ & $-0.211^{\ddagger}$ & $-0.261^{\ddagger}$ & $-0.146^{*}$ & $-0.125^{\star}$ & 0.019 & -0.098 \\
\hline
\end{tabular}

BMI: body mass index; SCOFF: Sick Control on Fast Food; PE: Physical Education; GPA: grade point average. Overall indicates the sum of the three abilities scores. $p$-value $=$ and ${ }^{*} p<0.05,{ }^{t} p<0.01,{ }^{t} p \leq 0.001$. 
Table III. Associations of risk of ED with academic performance in adolescents $(n=261)$

\begin{tabular}{|l|c|c|c|c|c|c|}
\hline \multirow{2}{*}{} & \multicolumn{2}{|c|}{ Model 1 } & \multicolumn{2}{c|}{ Model 2 } & \multicolumn{3}{c|}{ Model 3 } \\
\cline { 2 - 7 } & $\beta$ & $\mathbf{p}$ & $\beta$ & $\mathbf{p}$ & \multicolumn{2}{c|}{$\mathbf{p}$} \\
\hline Math & -0.152 & 0.014 & -0.181 & 0.003 & -0.141 & 0.022 \\
\hline Language & -0.159 & 0.010 & -0.207 & $<0.001$ & -0.163 & 0.009 \\
\hline PE & -0.181 & 0.003 & -0.213 & $<0.001$ & -0.205 & 0.002 \\
\hline GPA & -0.202 & 0.001 & -0.253 & $<0.001$ & -0.214 & $<0.001$ \\
\hline \multicolumn{7}{|c|}{ Academic abilities } \\
\hline Verbal ability & -0.113 & 0.067 & -0.146 & 0.019 & -0.134 & 0.038 \\
\hline Numeric ability & -0.110 & 0.076 & -0.118 & 0.046 & -0.091 & 0.137 \\
\hline Reasoning ability & 0.043 & 0.491 & 0.020 & 0.757 & 0.052 & 0.425 \\
\hline Overall & -0.070 & 0.262 & -0.097 & 0.119 & -0.067 & 0.298 \\
\hline
\end{tabular}

PE: Physical Education; GPA: grade point average; $\beta$ : standardized coefficient. Model 1: unadjusted. Model 2: adjusted for sex, pubertal stage, socioeconomic status and parental educational attainment. Model 3: adjusted for model $2+$ body mass index. Overall indicates the sum of the three abilities scores. Statistically significant values are highlighted in italics.

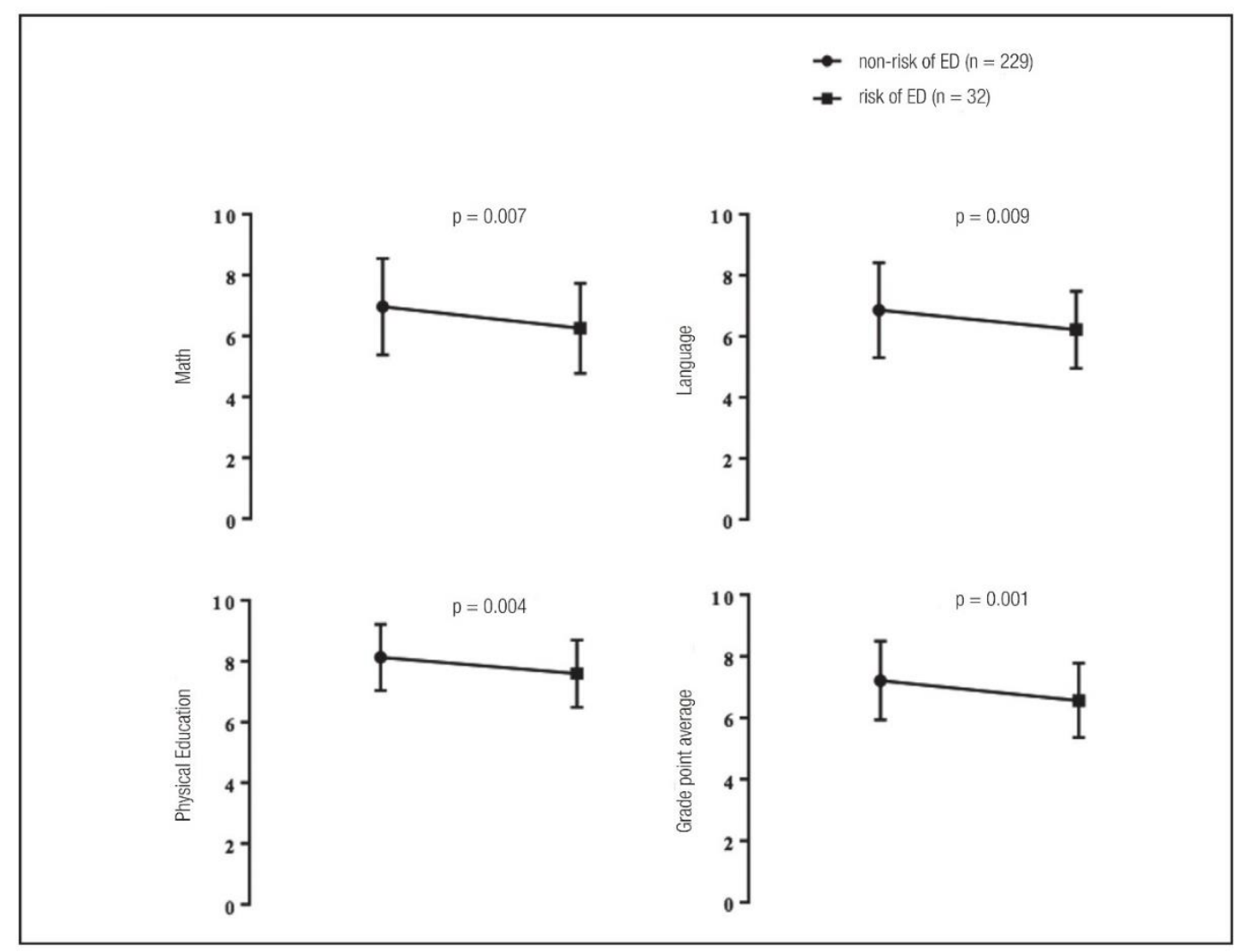

Figure 1.

ANCOVA analyses showing differences in academic grades between the categories of the risk of ED in adolescents. Estimated mean (dots) and SD represent values after adjustment for sex, pubertal stage, SES, parental educational attainment and BMI. 
Binary logistic regression analysis (Table IV) showed that the risk of ED was three times higher in overweight or obese adolescents than in non-overweight participants ( $O R=3.016 ; 95 \%$ $\mathrm{Cl}=[1.212 ; 7.504] ; \mathrm{p}=0.018)$.

\section{DISCUSSION}

The main finding of our study suggests an inverse association between the risk of ED and academic performance in adolescents. Adolescents without risk of ED had higher scores in all the academic grades. Moreover, overweight or obese adolescents showed higher risk of ED. These findings extend the existing scientific knowledge by highlighting the impact of ED on academic performance in adolescents and the importance of considering weight status.

The estimated prevalence of the risk of developing ED in our sample (12.3\%) did not show differences between sexes, concurring with Veses et al. (13). However, previous studies have reported higher prevalence rates of the risk of ED in Spanish (i.e., $17 \%$ or $21 \%)(10,25)$ and German (22\%) (26) adolescents showing differences between boys and girls.

The present study reveals an inverse association between the risk of ED and academic grades, verbal ability and numeric ability in adolescents. Additional analyses according ED categories showed higher scores in all the academic grades (Math, Language, PE and GPA) among those adolescents without risk of ED. Our results concur with Veses et al. (10), who analyzed a sample of 1,877 Spanish adolescents showing an inverse association between the risk of ED and academic grades. However, Gil García et al. (11) did not find differences in academic performance between Spanish adolescents with different levels of risk of developing ED (at risk vs not at risk). Such inconsistent findings may be due to methodological aspects, such as the different tools used to assess academic performance and ED or the multifactorial character of academic performance.

Previous studies in patients with ED have shown poor academic and cognitive performance (27). For instance, Yanover et al. (28) analyzed a sample of 1,584 college students concluding that eating disturbance may have a negative impact on academic outcomes. In 2011, Sarrar et al. (29) analyzed a

Table IV. Risk of ED according to weight
status, adjusting for sex, pubertal stage,
socioeconomic status and parental
educational attainment
\begin{tabular}{|c|c|c|c|}
\hline & OR & $95 \%$ Cl & p \\
\hline Non-overweight & 1 & Ref. & \multirow{2}{*}{0.018} \\
Overweight or obesity & 3.016 & $\begin{array}{c}1.212 ; \\
7.504\end{array}$ & \\
\hline
\end{tabular}

OR: odds ratio; $\mathrm{Cl}$ : confidence interval. sample of 30 patients with anorexia nervosa showing deficits in cognitive flexibility. More recently, Weider et al. (30) found that patients with anorexia nervosa showed lower performance when compared with the control group, on eight out of 13 cognitive measurements. A possible explanation might be that increased levels of metabolic factors (i.e., cortisol serum) in patients with ED alter synaptic function and brain areas closely linked to learning and memory (31), which may impair cognitive functioning (32). In addition, psychological aspects related to ED could affect attitude, interest, motivation and other behaviors linked to academic success which may impair academic performance in adolescents $(33,34)$.

Our analyses indicate that overweight and obese adolescents might present higher risk of ED than non-overweight and obese adolescents in accordance with prior research $(13,35,36)$. This finding highlights the importance of dealing with obesity and ED jointly (12) and could be explained by different mechanisms. Body dissatisfaction and weight-related teasing in overweight and obese adolescents may encourage behaviors associated with weight control, increasing the risk of $\operatorname{ED}(37,38)$. In addition, the lack of self-esteem derived from body image dislike might have relevance for the development of ED in overweight and obese adolescents (39).

\section{STRENGTHS AND LIMITATIONS}

These results should be interpreted cautiously because of some limitations. First, the cross-sectional design of our study does not allow to infer a causal relationship. A second significant limitation of this research is the small sample size. Despite these limitations, the main strengths of our study comprise the inclusion of potential confounders closely related with weight status and academic performance $(10,40)$. Another strength was the use of the SCOFF questionnaire as an effective screening instrument (before its clinical manifestation) with excellent psychometric properties for the early detection of the risk of ED in Spanish adolescents $(20,21)$. In addition, the SCOFF questionnaire has been validated in different languages making possible to establish comparisons between our data and other studies.

\section{CONCLUSIONS}

In conclusion, the results of this study suggest a negative association between the risk of ED and academic performance in adolescents, revealing higher risk of ED in overweight and obese adolescents. Early detection of youth at risk of developing ED is highly necessary not only to avoid academic failure, but also to limit its progression, since adolescents showing problematic eating behaviors are predisposed to ED later in life. Therefore, families, educators and policy makers should consider weight and the risk of ED assessments when designing programs aimed to improve academic outcomes. 


\section{REFERENCES}

1. Giedd JN, Denker AH. The adolescent brain: insights from neuroimaging. In: Brain crosstalk in puberty and adolescence. Research and perspectives in endocrine interactions; vol. 13. Switzerland: Springer International Publishing; 2015. pp. 85-96.

2. Patton GC, Viner R. Pubertal transitions in health. Lancet $2007 ; 369: 1130-9$.

3. Moreno LA, Gottrand F, Huybrechts I, Ruiz JR, González-Gross M, DeHenauw S. Nutrition and lifestyle in European adolescents: the HELENA (HealthyLiftestyle in Europe by Nutrition in Adolescence) study. Adv Nutr 2014;5(Part 2):615A-23AS

4. Mairs R, Nicholls D. Assessment and treatment of eating disorders in children and adolescents. Arch Dis Child 2016;101(12):1168-75.

5. Herpertz-Dahlmann B. Adolescent eating disorders. Child Adolesc Psychiatr Clin N Am 2015;24(1):177-96

6. Favaro A, Caregaro L, Tenconi E, Bosello R, Santonastaso P. Time trends in age at onset of anorexia nervosa and bulimia nervosa. J Clin Psychiatry 2009;70(12):1715-21.

7. Field AE, Javaras KM, Aneja P, Kitos N, Camargo CA, Taylor CB, et al. Family, peer, and media predictors of becoming eating disordered. Arch Pediatr Adolesc Med 2008;162(6):574-9.

8. Lena SM, Fiocco AJ, Leyenaar J. The role of cognitive deficits in the development of eating disorders. Neuropsychol Rev 2004;14(2):99-113.

9. Croll J, Neumark-Sztainer D, Story M, Ireland M. Prevalence and risk and protective factors related to disordered eating behaviors among adolescents: Relationship to gender and ethnicity. J Adolesc Heal 2002;31(2):166-75.

10. Veses AM, Gómez-Martínez S, Pérez de Heredia F, Esteban-Cornejo I, Castillo $\mathrm{R}$, Estecha S, et al. Cognition and the risk of eating disorders in Spanish adolescents : the AVENA and AFINOS studies. Eur J Pediatr 2015;174:229-36.

11. Gil García E, Ortiz Gómez T, Fernández Soto ML. Social profiles, diet, and prediction of eating disorders in urban Andalusian adolescents. Aten Primaria 2007;39(1):7-11.

12. Haines J, Neumark-Sztainer D. Prevention of obesity and eating disorders: a consideration of shared risk factors. Health Educ Res 2006;21(6):770-82.

13. Veses AM, Martínez-Gómez D, Gómez-Martínez S, Zapatera B, Veiga ÓL, Marcos A. Association between excessive body fat and eating-disorder risk in adolescents: the AFINOS Study. Med Clin 2011;136(14):620-2.

14. Babio N, Canals J, Pietrobelli A, Pérez S, Arija V, Arija V. A two-phase population study: relationships between overweight, body composition and risk of eating disorders. Nutr Hosp 2009;24(4):485-91.

15. Neumark-Sztainer D. Obesity and eating disorder prevention: an integrated approach? Adolesc Med 2003;14(1):159-73.

16. Reed ZE, Micali N, Bulik CM, Davey Smith G, Wade KH. Assessing the causal role of adiposity on disordered eating in childhood, adolescence, and adulthood: a Mendelian randomization analysis. Am J Clin Nutr 2017;106(3):764-72.

17. Martin A, Booth JN, McGeown S, Niven A, Sproule J, Saunders DH, et al. Longitudinal associations between childhood obesity and academic achievement: Systematic review with focus group data. Curr Obes Rep 2017;6(3):297-313.

18. Beltran-Valls MR, García Artero $E$, Capdevila-Seder A, Legaz-Arrese A Adelantado-Renau M, Moliner-Urdiales D. Regular practice of competitive sports does not impair sleep in adolescents: DADOS study. Pediatr Exerc Sci 2017:17:1-8

19. Morgan JF, Reid F, Lacey JH. The SCOFF questionnaire: assessment of a new screening tool for eating disorders. BMJ 1999;319:1467-8.

20. 20. García-Campayo J, Sanz-Carrillo C, Ibáñez JA, Lou S, Solano V, Alda M. Validation of the Spanish version of the SCOFF questionnaire for the screening of eating disorders in primary care. J Psychosom Res 2005;59(2):51-5.

21. Rueda Jaimes GE, Díaz Martínez LA, Ortiz Barajas DP, Pinzón Plata C, Rodríguez Martínez J, Cadena Afanador LP. Validation of the SCOFF questionnaire for screening the eating behaviour disorders of adolescents in school. Aten Primaria 2005;35(2):89-94.
22. Thurstone LL, Thurstone TG. TEA Test de Aptitudes Escolares (Scholar Aptitudes Test). 11th ed. Vol. 77. Madrid: TEA Ediciones S.A.; 2004.

23. Tanner JM, Whitehouse RH. Clinical longitudinal standards for height, weight, height velocity, weight velocity, and stages of puberty. Arch Dis Child 1976;51(3):170-9.

24. Currie C, Molcho M, Boyce W, Holstein B, Torsheim T, Richter M. Researching health inequalities in adolescents: the development of the Health Behaviour in School-Aged Children (HBSC) Family Affluence Scale. Soc Sci Med 2008;66:1429-36.

25. Jáuregui Lobera I, Romero Candau J, Bolaños Ríos P, Montes Berriatúa C, Diaz Jaramillo R, Montaña González MT, et al. Conducta alimentaria e imagen corporal en una muestra de adolescentes de Sevilla. Nutr Hosp 2009;24(5):568-73.

26. Hölling $H$, Schlack R. Eating disorders in children and adolescents. First results of the German Health Interview and Examination Survey for Children and Adolescents (KiGGS). Bundesgesundheitsblatt Gesundheitsforsch Gesundheitsschutz 2007;50(5-6):794-9.

27. Lang K, López C, Stahl D, Tchanturia K, Treasure J. Central coherence in eating disorders: an updated systematic review and meta-analysis. World $\mathrm{J}$ Biol Psychiatry 2014;15(8):586-98.

28. Yanover T, Thompson JK. Eating problems, body image disturbances, and academic achievement: preliminary evaluation of the eating and body image disturbances academic interference scale. Int J Eat Disord 2008;41(2):184-7.

29. Sarrar L, Ehrlich S, Merle JV, Pfeiffer E, Lehmkuhl U, Schneider N. Cognitive flexibility and agouti-related protein in adolescent patients with anorexia nervosa. Psychoneuroendocrinology 2011;36(9):1396-406.

30. Weider S, Indredavik MS, Lydersen S, Hestad K. Intellectual function in patients with anorexia nervosa and bulimia nervosa. Eur Eat Disord Rev 2014;22(1):15-24.

31. Moult PR, Harvey J. Hormonal regulation of hippocampal dendritic morphology and synaptic plasticity. Cell Adh Migr 2008;2(4):269-75.

32. Blakemore S-J, Choudhury S. Development of the adolescent brain: implications for executive function and social cognition. J Child Psychol Psychiatry 2006:47(3-4):296-312.

33. Petrides KV, Chamorro-Premuzic T, Frederickson N, Fumham A. Explaining individual differences in scholastic behaviour and achievement. Br J Educ Psychol 2005;75(2):239-55.

34. Steinmayr R, Spinath B. The importance of motivation as a predictor of school achievement. Learn Individ Differ 2009;19(1):80-90.

35. Urrila AS, Artiges E, Massicotte J, Miranda R, Vulser H, Bézivin-Frere P, et al. Sleep habits, academic performance, and the adolescent brain structure. Sci Rep 2017;7:41678.

36. Veses AM, Martínez-Gómez D, Gómez-Martínez S, Vicente G, Castillo

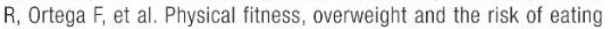
disorders in adolescents. The AVENA and AFINOS studies. Pediatr Obes $2014 ; 9(1): 1-9$.

37. Sepulveda AR, Carrobles JA, Gandarillas AM. Gender, school and academic year differences among Spanish university students at high-risk for developing an eating disorder: an epidemiologic study. BMC Public Health 2008;8(1):102.

38. Neumark-Sztainer D, Falkner N, Story M, Perry C, Hannan PJ, Mulert S. Weight-teasing among adolescents: correlations with weight status and disordered eating behaviors. Int J Obes 2002;26(1):123-31.

39. Haines J, Kleinman KP, Rifas-Shiman SL, Field AE, Bryn Austin S. Examination of shared risk and protective factors for overweight and disordered eating among adolescents. Arch Pediatr Adolesc Med 2010;164(4):336-43.

40. Jiménez Pavón D, Ortega FP, Ruiz JR, España Romero V, García Artero E, Moliner Urdiales D, et al. Socioeconomic status influences physical fitness in European adolescents independently of body fat and physical activity: the HELENA study. Nutr Hosp 2010;25(2):311-6. 
Study 5

Circulating inflammatory biomarkers and academic performance in adolescents: DADOS study 


\title{
CIRCULATING INFLAMMATORY BIOMARKERS AND ACADEMIC PERFORMANCE IN ADOLESCENTS: DADOS STUDY
}

\author{
Inflammation and academic performance
}

\begin{abstract}
Mireia Adelantado-Renau ${ }^{1}$, Maria Reyes Beltran-Valls ${ }^{1}$, Jorge Mota², Diego MolinerUrdiales $^{1}$

${ }^{1}$ LIFE research group, Universitat Jaume I, Castellon, Spain

${ }^{2}$ Research Center in Physical Activity, Health and Leisure (CIAFEL); Faculty of Sports at Porto University, Porto, Portugal
\end{abstract}

Corresponding author: Diego Moliner Urdiales, email address: dmoliner@uji.es; postal address: Human Sciences Faculty, Department of Education, University Jaume I, Av. Vicent Sos Baynat, PC 12071, Castellon, Spain. Telephone number: 0034964729782 ; Fax: 0034964 729264. ORCID ID: 0000-0001-9868-3396

\begin{abstract}
Introduction. Circulating inflammatory biomarkers have shown to play a key role on cognition during the early and late stages of the human lifespan; however, its relationship with academic performance during school age has been poorly investigated. Thus, the present study aimed (1) to examine the association between circulating inflammatory biomarkers and academic performance in adolescents, and (2) to identify the ability of circulating inflammatory biomarkers to predict low academic performance.
\end{abstract}

Methods. A total of 244 adolescents $(13.9 \pm 0.3$ years, 112 girls) from the DADOS (Deporte, ADOlescencia y Salud) study were included in the analysis. Four inflammatory biomarkers were quantified: white blood cell (WBC) count, interleukin-6, tumor necrosis factor-a (TNF-a), and Creactive protein (CRP). Academic performance was assessed through academic grades and the Spanish version of the Science Research Associates Test of Educational Abilities.
Results. TNF-a was negatively associated with math, Spanish and grade point average ( $\beta$ ranging from -0.166 to -0.124 ; all $p<0.05$ ), while CRP was negatively associated with verbal ability $(\beta=-0.128$; $p<0.05)$. Overall, receiver operating characteristic (ROC) curves analyses showed discriminatory ability of WBC and TNF-a in identifying low academic performance (all $\mathrm{p}<0.05$ ). Moreover, logistic regression analyses indicated that students with levels of WBC and TNF-a above the ROC cut-offs values showed between $78 \%$ to $87 \%$ increased likelihood of lower academic performance $(p<0.05)$.

Conclusion. Our findings suggest that circulating inflammatory biomarkers, particularly TNF-a and CRP, were negatively associated with academic performance in adolescents. Further studies are warranted to clarify the relationship between inflammation and academic performance in youths.

KEYWORDS. Inflammation, academic grades, academic abilities, cognition, adolescents, adolescence. 


\section{INTRODUCTION}

Inflammation is a natural immune system response to injury, infectious agent, or oxidative stress. This mechanism can confer immune protection, promoting tissue survival, repair, and recovery. However, a prolonged activation of the peripheral immune system could lead to a state of systemic low-grade inflammation. ${ }^{1}$ Prior research has suggested systemic low-grade inflammation to be both a cause, and a consequence of pathological processes related to several cardiovascular and metabolic diseases (e.g., atherosclerosis, diabetes, cancer), ${ }^{2,3}$ as well as to the development of neuropsychiatric disorders. ${ }^{4}$

Emerging evidence indicates that circulating inflammatory biomarkers might also play a key role on cognition during the early and late stages of the human lifespan. ${ }^{5}$ In fact, most of the studies reporting an inverse association between circulating inflammatory biomarkers and cognition have been focused on preterm infants, ${ }^{6,7}$ and aging populations, 8,9 as well as in populations with neuropsychiatric disorders. ${ }^{10}$ However, few studies have investigated the link between inflammation and cognitive function in adolescents, showing controversial results since not only negative, ${ }^{11}$ but also null ${ }^{12}$ associations have been found.

Cognition may be closely linked to academic performance, which has shown to predict future health status ${ }^{13}$ and work opportunities. ${ }^{14}$ However, only one study has analysed the association between inflammation and academic performance in children and adolescents, showing an inverse association between circulating inflammatory biomarkers and academic grades. ${ }^{15}$

Given the influence that inflammation may have on cognition, and the importance of academic performance for adolescents' future, it is of particular interest to clarify if inflammatory biomarkers are associated with academic performance in this age group. Thus, the present study aimed (1) to examine the association between circulating inflammatory biomarkers and academic performance in adolescents, and (2) to identify the ability of circulating inflammatory biomarkers to predict low academic performance.

\section{METHODS}

\section{Study design and sample selection}

The present work is part of the DADOS (Deporte, ADOlescencia y Salud) study, a research project aimed to analyse the influence of physical activity on health, academic performance, and psychological wellness through adolescence. ${ }^{16}$ All participants were recruited from secondary schools and sport clubs of Castellon (Spain) and met the general inclusion criteria: enrolled in $2^{\text {nd }}$ grade of secondary school (i.e., the $8^{\text {th }}$ grade) and free of any chronic disease. The results presented in this work belong to baseline data obtained between February and May of 2015. From the total sample $(n=274)$, a subsample of 244 students (112 girls) with valid data for at least one circulating inflammatory biomarker, and academic performance were included in the analyses.

Students and their parents or guardians were informed of the nature and characteristics of the study, and all provided written informed consent. The study protocol was designed in accordance with the ethical guidelines of the 1961 Declaration of Helsinki (last revision of Fortaleza, Brazil, 2013) and approved by the Research Ethics Committee of the Jaume I University of Castellon.

\section{Circulating inflammatory biomarkers}

Blood samples were drawn from the antecubital vein after an overnight fast of at least 10 h (at 8:00 a.m.), and collected in two tubes containing EDTA (Greiner bioone, Kremsmünster, Austria). One tube was kept refrigerated at $4^{\circ} \mathrm{C}$ for immediate analyses in whole blood, while the other tube was centrifuged to obtain serum (3500 rpm for $10 \mathrm{~min}$ at $4{ }^{\circ} \mathrm{C}$ ). The following inflammatory biomarkers were quantified: white blood cell (WBC, $\left.10^{3} / \mu \mathrm{L}\right)$ count, interleukin-6 (IL-6, $\left.\mathrm{pg} / \mathrm{mL}\right)$, tumor necrosis factor-a (TNF-a, $\mathrm{pg} / \mathrm{mL}$ ), and C-reactive protein (CRP, $\mathrm{mg} / \mathrm{dL}$ ). WBC count was measured in whole blood by automated blood cell counters (ABX Pentra XL 80, Horiba ABX SAS; Montpellier, France) with an intra-assay precision coefficient of variation (CV) of $<2 \%$. IL-6 and TNF-a were determined in serum using specific sensitive Enzyme-Linked Immunosorbent Assay (ELISA) kits (DRG Instruments $\mathrm{GmbH}$, Marburg, Germany) with a sensitivity of $2 \mathrm{pg} / \mathrm{mL}$ for $\mathrm{IL}-6$ and $0.7 \mathrm{pg} / \mathrm{mL}$ for 
TNF-a. The intra- and inter-assay precision CVs were $4.2 \%$ and $4.4 \%$ for IL-6, and $6.6 \%$ and $4.5 \%$ for TNF-a, respectively. The CRP concentration was quantified in serum by immunoturbidimetry (CRP 981699, Thermo Fisher Scientific Oy; Vantaa, Finlandia) with a sensitivity of $6 \mathrm{pg} / \mathrm{mL}$ and intra- and inter-assay CVs of $2.6 \%$ and $0.8 \%$, respectively.

\section{Academic performance}

Academic performance was assessed using academic grades and a standardized test of academic abilities. Academic grades were taken from the participants' official report cards obtained at the end of the academic year, which were provided by parents or guardians. Individual grades for math, Spanish and English, as well as the grade point average score were included in the analyses. The grade point average score was calculated as the single average for geography and history, natural sciences, maths, Spanish, Catalan and English languages and physical education grades. All the subjects were measured on a ten-point scale, where 0 was the worst and 10 was the best. Academic abilities were assessed through the Spanish version of the Science Research Associates Test of Educational Abilities. ${ }^{17}$ This test measures three basic academic abilities: verbal ability (command of language), numeric ability (speed and precision in performing operations with numbers and quantitative concepts), and reasoning ability (the aptitude to find logical ordination criteria in sets of numbers, figures, or letters). Scores for the three abilities were obtained by adding positive answers. Overall academic ability was calculated by adding the three abilities' scores (verbal + numeric + reasoning). The present study used level three, which is designed for adolescents aged 14-18 years. The alpha scores for its reliability have been reported to be 0.74 for verbal ability, 0.87 for numerical ability, 0.77 for reasoning ability and 0.89 for overall academic ability. ${ }^{17}$ Participants were classified in high academic performance $(\geq 50$ th of the median) and low academic performance ( $<50$ th of the median) for each academic performance indicator.

\section{Covariates}

Sex, pubertal stage, parental educational level, type of school, waist circumference and adherence to the Mediterranean diet were included as covariates.

Pubertal stage. Pubertal stage was selfreported according to the five stages described by Tanner $^{18}$ based on the assessment of two components: pubic hair growth for boys and girls, plus breast development in girls, and genital development in boys. A 5-point maturity rating was used where stage 1 corresponds to the prepubertal state and stage 5 to mature state, and the highest rating of the two components was used for the analyses.

Parental educational level. Parental educational level was used as a proxy of socioeconomic status. ${ }^{19}$ Both parents reported their educational level and responses were combined as: neither of the parents had a university degree, and at least one of the parents had a university degree.

Type of school. Students' school type was classified into 'public' or 'private' school, and entered as a dummy variable.

Anthropometry. Measures were assessed in duplicate by experienced researchers following standardized procedures, ${ }^{20}$ and average measures were used for the analyses. Briefly, body weight was measured to the nearest $0.1 \mathrm{~kg}$ using an electronic scale (SECA 861, Hamburg, Germany). Height was measured to the nearest $0.1 \mathrm{~cm}$ using a wallmounted stadiometer (SECA 213, Hamburg, Germany). Body mass index (BMI) was calculated as weight/height squared $\left(\mathrm{kg} / \mathrm{m}^{2}\right)$. Waist circumference was measured to the nearest $1 \mathrm{~mm}$ with a nonelastic tape applied horizontally midway between the lowest rib margin and the iliac crest, at the end of gentle expiration with the adolescent in a standing position.

Adherence to the Mediterranean diet. Adherence to the Mediterranean diet was evaluated using the KIDMED questionnaire, which includes 16 yes/no questions related to participants consumption of fast food, sweets and soft drinks, daily fruit and vegetables, and weekly fish and legumes. ${ }^{21}$ Regarding the affirmative answers, a value of +1 was assigned to the questions with positive connotation in relation to Mediterranean diet (e.g., regular fruit consumption), while a value of -1 was assigned to the questions that constitute 
negative aspects (e.g., fast food consumption). Questions answered with "no" scored 0. The score for the students' level of adherence to the Mediterranean diet was calculated as the sum of each answer, ranging from 0 to 12 .

\section{Statistical analysis}

Descriptive characteristics of the study sample are presented as means \pm standard deviation or frequency (\%). Differences between sexes were examined by independent two-tailed ttests and Chi-squared tests for continuous and categorical variables, respectively. All variables were checked for normality using both graphical (normal probability plots) and statistical (KolmogorovSmirnov test) procedures. Due to its skewed distribution, circulating inflammatory biomarkers were log-transformed when required. As preliminary analyses showed no significant interactions of sex with circulating inflammatory biomarkers in relation to academic performance indicators (all $p>0.1$ ), all analyses were performed with the total sample.

Linear regression analyses were used to study the association between circulating inflammatory biomarkers and academic performance indicators adjusting for sex, pubertal stage, parental educational level, type of school, waist circumference and adherence to the Mediterranean diet.

Receiver operating characteristic (ROC) curves were conducted to investigate the ability of circulating inflammatory biomarkers (i.e., WBC, IL-6, TNF- $a$, and CRP) in discriminating low academic performance. The area under the curve (AUC) ranges between 0 and 1 , where 0 represents a worthless test, and 1 a perfect ability of circulating inflammatory biomarkers to identify students with low academic performance. When the AUC was statistically significant, cut-off points were selected according to the highest Youden index, which is calculated with the best trade-off between sensitivity and specificity.

Based on the ROC curves analyses, logistic regression analyses were conducted to examine the relationships between high circulating inflammatory biomarkers concentrations (i.e., zcutoff values) and low academic performance, adjusting for sex, pubertal stage, parental educational level, type of school, waist circumference and adherence to the Mediterranean diet. These analyses were performed only for those circulating inflammatory biomarkers that showed a discriminatory ability to predict low academic performance (AUC>0.5 and $p<0.05)$. All the analyses were performed using the IBM SPSS Statistics for Windows version 22.0 (Armonk, NY: IBM Corp), and the level of significance was set to $p<0.05$.

\section{RESULTS}

Table 1 summarizes adolescents' characteristics by sex. Our study included 244 adolescents aged $13.9 \pm 0.3$ years old, of which 112 (45.9\%) were girls. Boys presented higher values in height (164.7 vs. 160.9; $p<0.001)$, waist circumference (68 vs. 66; $p<0.01)$, TNF-a (5.6 vs. 4.8; $p<0.01)$, and numeric ability (14.9 vs. 12.4; $p<0.001$ ) than girls.

Linear regression analyses between circulating inflammatory biomarkers and academic performance indicators after adjustment for sex, pubertal stage, parental educational level, type of school, waist circumference, and adherence to the Mediterranean diet are shown in Table 2. WBC and IL-6 were not associated with academic performance indicators. TNF-a was negatively associated with math $(\beta=-0.166 ; p<0.01)$, Spanish $(\beta=-0.127 ; p<0.05)$, and grade point average $(\beta=-$ $0.124 ; p<0.05)$, while CRP was negatively associated with verbal ability $(\beta=-0.128 ; p<0.05)$.

Table 3 presents the parameters of the ROC curve analyses regarding the diagnostic ability of circulating inflammatory biomarkers to predict low academic performance in adolescents. ROC analyses showed that IL- 6 and CRP concentrations did not discriminate among academic performance categories. However, significant AUC were found for WBC with English, and for TNF-a with all the academic grades indicators (all AUC>0.5 and $p>0.05)$. No circulating inflammatory biomarker showed discriminatory ability to identify low academic abilities (data not shown).

Figure 1 shows logistic regression analyses for the associations between high circulating inflammatory biomarkers (i.e., above the cut-off values provided by the ROC curve analysis) and low academic performance (i.e., <50th of the 
median) after adjustment for sex, pubertal stage, parental educational level, type of school, waist circumference, and adherence to the Mediterranean diet. High levels of WBC were associated with low academic performance in English ( $O R=1.78$; 95\% Cl:1.00-3.15). In addition, students with high concentration of TNF-a had 79\%, 86\% and $87 \%$ increased odds of achieving low academic performance in math, Spanish and English, respectively.

\section{DISCUSSION}

The main finding of the present study reveals an inverse association of TNF-a with math, Spanish and grade point average after adjusting for potential confounders. In addition, CRP was negatively associated with verbal ability. Our study indicates that WBC presented discriminatory ability in identifying low academic performance in English, while TNF-a showed discriminatory ability in identifying low academic performance in all the academic grades analysed. Overall, students with high levels of WBC and TNF-a showed between 78\% to $87 \%$ increased likelihood of low academic performance. These results further contribute to the scarce prior literature suggesting that inflammation may negatively influence academic performance in healthy adolescents. ${ }^{15}$

To the best of our knowledge, no previous studies have examined the association between circulating inflammatory biomarkers and academic abilities, neither their ability for identifying low academic performance, which hampers comparisons among studies. To date, there is only one study that has investigated the association between inflammatory biomarkers and academic grades. ${ }^{15}$ In contrast to our results, Esteban-Cornejo et al. ${ }^{15}$ found that WBC, IL-6 and CRP, but not TNF-a, were negatively associated with academic grades in math, Spanish, the mean of math and Spanish, and grade point average, independently of adiposity, in a sample of Spanish children and adolescents aged 618 years.

The reasons underlying the inverse association of TNF-a with academic grades and of CRP with verbal ability cannot be elucidated in the current study. However, these findings may be partially related to the key role that these inflammatory biomarkers play on brain functioning.
In fact, in a review examining in vitro studies, TNF-a has been suggested to reduce neurogenesis, increasing apoptosis of neurons, and consequently, inhibiting synaptic plasticity and memory consolidation, ${ }^{4}$ which could affect academic outcomes. In addition, prior research suggested that CRP may negatively influence under-developed frontal brain regions involved in letter fluency-related skills, ${ }^{11}$ which in turn, might affect verbal ability.

On the other hand, in the present study there was a lack of association of WBC and IL- 6 with academic performance. Similarly, other previous interventional $^{22}$ and prospective $^{12}$ studies investigating the association between inflammation and cognitive function in youth have reported null findings. There are several hypotheses that could partially explain the lack of association found in our study. First, it is interesting to highlight that the lack of association found between IL- 6 and academic performance indicators is generally consistent with previous research, suggesting that IL-6 does not affect proliferation and gliogenesis, ${ }^{4}$ which in turn, may have no influence on cognition or academic performance. Second, the fact that circulating inflammatory biomarkers at physiological levels can act with both, anti- and pro-inflammatory effects ${ }^{9}$ could partially explain the divergent results found in the present study. Third, our sample showed optimal values of adherence to the Mediterranean diet and body composition, which have been related to lower levels of inflammatory biomarkers. ${ }^{23,24}$ Thus, it is likely that those concentrations do not affect students' academic performance. Lastly, the academic performance indicators included in the current study might not entirely capture the adverse effects that some circulating inflammatory biomarkers could have on cognition in adolescents.

The mixed results found in prior literature investigating the relationship of inflammation with cognition and academic performance in youths could be due to differences in participants' socioeconomic status, ${ }^{25}$ ethnicity ${ }^{26}$ and lifestyles, as well as, to methodological issues. In fact, divergent results could be related to the matrix (whole blood, serum or plasma, saliva) in which inflammatory biomarkers are measured in the studies, ${ }^{11}$ and even to the different technics of analysis implemented. 


\section{Limitations and strengths}

The results of the present study should be interpreted with caution. The cross-sectional design of our study does not allow us to draw any conclusion on the causal direction of the associations. In addition, the inclusion of a sample of healthy adolescents limits the generalizability of our findings across the population. However, the strengths of the study comprise the use of different blood-derived inflammatory biomarkers, and the inclusion of a standardized test of academic abilities. In addition, as suggested by previous research, our statistical analyses were controlled for pubertal stage, parental educational level,27 waist circumference $^{24}$ and adherence to the Mediterranean diet, ${ }^{23}$ which are relevant given their association with inflammation and academic performance.

\section{Conclusions}

In conclusion, our results suggest that circulating inflammatory biomarkers, particularly TNF-a and CRP, were negatively associated with academic performance in adolescents. Additionally, our results revealed the utility of inflammatory biomarkers in identifying students with higher risk of low academic performance. Since academic performance has shown to play a key role on future employability ${ }^{14}$ and health status, ${ }^{13}$ further studies are warranted to clarify the relationship between inflammation and academic performance in youths.

\section{ACKNOWLEDGEMENTS}

The DADOS Study is funded by the Spanish Ministry of Economy and Competitiveness, MINECO (DEP2013-45515-R) and by the Jaume I University of Castellon, UJI (P1-1A2015-05). This work is partly supported by a Sunny Sport research grant from the Schweppes Suntory Spain Company. M.A.R is supported by a Predoctoral Research Grant from UJI (PREDOC/2015/13 and E-2018-21). J.M was supported by grants: FCT: SFRH/BSAB/142983/2018 and UID/DTP/00617/2019, as well as Programa de Bolsas Santander Universidades 2018.

\section{REFERENCES}

1. Bruunsgaard $H$. Physical activity and modulation of systemic low-level inflammation. J Leukoc Biol. 2005; 78(4): 819-835. doi:10.1189/jlb.0505247

2. Libby P. Inflammation and cardiovascular disease mechanisms. Am J Clin Nutr. 2006; 83(2): 456S460S. doi:10.1093/ajcn/83.2.456S

3. Hotamisligil GS. Inflammation and metabolic disorders. Nature. 2006; 444(7121): 860-867. doi:10.1038/nature05485

4. Borsini A, Zunszain PA, Thuret S, Pariante CM. The role of inflammatory cytokines as key modulators of neurogenesis. Trends Neurosci. 2015; 38(3): 145157. doi:10.1016/j.tins.2014.12.006

5. McAfoose J, Baune BT. Evidence for a cytokine model of cognitive function. Neurosci Biobehav Rev. 2009; 33(3): 355-366.

doi:10.1016/j.neubiorev.2008.10.005

6. Kuban KCK, Joseph RM, O'Shea TM, Heeren T, Fichorova RN, Douglass L, Jara H, Frazier JA, Hirtz D, Rollins JV, Paneth N. Circulating inflammatoryassociated proteins in the first month of life and cognitive impairment at age 10 years in children born extremely preterm. J Pediatr. 2017; 180: 116123.e1.

doi:10.1016/j.jpeds.2016.09.054

7. Rose J, Vassar R, Cahill-Rowley K, Hintz SR, Stevenson DK. Neonatal biomarkers of inflammation: correlates of early neurodevelopment and gait in very-low-birth-weight preterm children. Am J Perinatol. 2015; 33(1): 71-78. doi:10.1055/s0035-1557106

8. Frodl T, Amico F. Is there an association between peripheral immune markers and structural/functional neuroimaging findings? Prog Neuro-Psychopharmacology Biol Psychiatry. 2014; 48: 295-303. doi:10.1016/j.pnpbp.2012.12.013

9. Sartori AC, Vance DE, Slater LZ, Crowe M. The impact of inflammation on cognitive function in older adults: implications for healthcare practice and research. J Neurosci Nurs. 2012; 44(4): 206-217. doi:10.1097/JNN.0b013e3182527690 
10. Dantzer R, O'Connor JC, Freund GG, Johnson RW, Kelley KW. From inflammation to sickness and depression: when the immune system subjugates the brain. Nat Rev Neurosci. 2008; 9(1): 46-56. doi:10.1038/nrn2297

11. Cullen AE, Tappin BM, Zunszain PA, Dickson $H$, Roberts RE, Nikkheslat N, Khondoker M, Pariante $\mathrm{CM}$, Fisher $\mathrm{HL}$, Laurens $\mathrm{KR}$. The relationship between salivary C-reactive protein and cognitive function in children aged 11-14 years: Does psychopathology have a moderating effect? Brain Behav Immun. 2017; 66: 221-229. doi:10.1016/j.bbi.2017.07.002

12. Jonker I, Klein HC, Duivis HE, Yolken RH, Rosmalen JGM, Schoevers RA. Association between exposure to HSV1 and cognitive functioning in a general population of adolescents. The TRAILS Study. Morton JB, ed. PLoS One. 2014; 9(7): e101549. doi:10.1371/journal.pone.0101549

13. Lê-Scherban F, Diez Roux A V., Li Y, Morgenstern $H$. Does academic achievement during childhood and adolescence benefit later health? Ann Epidemiol. 2014; 24(5): 344-355.

doi:10.1016/j.annepidem.2014.02.008

14. French MT, Homer JF, Popovici I, Robins PK. What you do in high school matters: high school GPA, educational attainment, and labor market earnings as a young adult. East Econ J. 2015; 41(3): 370-386. doi:10.1057/eej.2014.22

15. Esteban-Cornejo I, Martinez-Gomez D, GómezMartínez S, Del Campo-Vecino J, Fernández-Santos $J$, Castro-Piñero J, Marcos A, Veiga OL. Inflammatory biomarkers and academic performance in youth. The UP \& DOWN Study. Brain Behav Immun. 2016; 54: 122-127. doi:10.1016/j.bbi.2016.01.010

16. Adelantado-Renau M, Beltran-Valls MR, EstebanCornejo I, Martínez-Vizcaíno V, Santaliestra-Pasías AM, Moliner-Urdiales D. The influence of adherence to the Mediterranean diet on academic performance is mediated by sleep quality in adolescents. Acta Paediatr Int J Paediatr. 2018: 108(2): 339-346.

doi:10.1111/apa.14472
17. Thurstone LL, Thurstone TG. TEA Test de Aptitudes Escolares (Scholar Aptitudes Test). Vol 77. 11th ed. Madrid; 2004.

18. Tanner JM, Whitehouse RH. Clinical longitudinal standards for height, weight, height velocity, weight velocity, and stages of puberty. Arch Dis Child. 1976; 51(3): 170-179.

19. Huppertz C, Bartels M, de Geus EJC, van Beijsterveldt CEM, Rose RJ, Kaprio J, Silventoinen K. The effects of parental education on exercise behavior in childhood and youth: a study in Dutch and Finnish twins. Scand J Med Sci Sports. 2017; 27(10): 1143-1156. doi:10.1111/sms. 12727

20. Beltran-Valls MR, García Artero E, CapdevilaSeder A, Legaz-Arrese A, Adelantado-Renau M, Moliner-Urdiales D. Regular practice of competitive sports does not impair sleep in adolescents: DADOS Study. Pediatr Exerc Sci. 2017; 30(2): 229-236. doi:10.1123/pes.2017-0129

21. Serra-Majem L, Ribas L, Ngo J, Ortega RM, García A, Pérez-Rodrigo C, Aranceta J. Food, youth and the Mediterranean diet in Spain. Development of KIDMED, Mediterranean Diet Quality Index in children and adolescents. Public Health Nutr. 2004; 7(07): 931-935. doi:10.1079/PHN2004556

22. Grigoleit JS, Oberbeck JR, Lichte $P$, Kobbe $P$, Wolf OT, Montag T, del Rey A, Gizewski ER, Engler H, Schedlowski M. Lipopolysaccharide-induced experimental immune activation does not impair memory functions in humans. Neurobiol Learn Mem. 2010; 94(4): 561-567. doi:10.1016/j.nlm.2010.09.011

23. Schwingshackl L, Hoffmann G. Mediterranean dietary pattern, inflammation and endothelial function: a systematic review and meta-analysis of intervention trials. Nutr Metab Cardiovasc Dis. 2014; 24(9): 929-939. doi:10.1016/j.numecd.2014.03.003

24. Miller A, Jong $H$, Lumeng J. Obesity-associated biomarkers and executive function in children. Pediatr Res. 2015; 77(0): 143-147. doi:10.1038/pr.2014.158.Obesity-Associated

25. Lee SE, West KP, Cole RN, Schulze KJ, Wu LS, Yager JD, Groopman J, Christian P. General intelligence is associated with subclinical inflammation in Nepalese children: a population- 
based plasma proteomics study. Brain Behav Immun. 2016; 56: 253-263.

doi:10.1016/j.bbi.2016.03.023

26. Windham BG, Simpson BN, Lirette S, Bridges J, Bielak L, Peyser PA, Kullo I, Turner S, Griswold ME, Mosley TH. Associations between inflammation and cognitive function in African Americans and European Americans. J Am Geriatr Soc. 2014; 62(12): 2303-2310. doi:10.1111/jgs.13165

27. Donnelly JE, Hillman $\mathrm{CH}$, Castelli DM, Etnier JL, Lee S, Tomporowski P, Lambourne K, Szabo-Reed AN. Physical activity, fitness, cognitive function, and academic achievement in children: a systematic review. Med Sci Sports Exerc. 2016; 48(6): 11971222. doi: 10.1249/MSS.0000000000000901 
Table 1. Descriptive characteristics for the study sample.

\begin{tabular}{|c|c|c|c|c|}
\hline & All & Boys & Girls & $\mathrm{p}$ \\
\hline$n(\%)$ & $244(100)$ & $132(54)$ & $112(46)$ & \\
\hline Age (y) & $13.9 \pm 0.3$ & $13.9 \pm 0.3$ & $13.9 \pm 0.3$ & 0.709 \\
\hline Pubertal stage (II-V) (\%) & $8 / 35 / 47 / 10$ & 9/33/43/15 & $0 / 6 / 38 / 52 / 4$ & - \\
\hline Height (cm) & $163.0 \pm 8.1$ & $164.7 \pm 8.6$ & $160.9 \pm 7.0$ & $<0.001$ \\
\hline Weight (kg) & $53.8 \pm 9.1$ & $54.4 \pm 9.3$ & $53.1 \pm 8.8$ & 0.297 \\
\hline Body mass index $\left(\mathrm{kg} / \mathrm{m}^{2}\right)$ & $20.2 \pm 2.6$ & $19.9 \pm 2.4$ & $20.5 \pm 2.8$ & 0.106 \\
\hline Waist circumference (cm) & $67.1 \pm 5.6$ & $68.0 \pm 5.2$ & $66.0 \pm 5.8$ & 0.006 \\
\hline Adherence to the Mediterranean diet (0-12) & $7.1 \pm 2.1$ & $7.3 \pm 2.2$ & $6.8 \pm 2.1$ & 0.059 \\
\hline \multicolumn{5}{|l|}{ Parental educational level } \\
\hline University studies (\%) & $118(48)$ & $58(44)$ & $60(54)$ & 0.134 \\
\hline \multicolumn{5}{|l|}{ School type } \\
\hline Private (\%) & $67(28)$ & $41(31)$ & $26(23)$ & 0.171 \\
\hline \multicolumn{5}{|l|}{ Circulating inflammatory biomarkers a } \\
\hline White blood cells $\left(10^{3} / \mu \mathrm{L}\right)$ & $5.7 \pm 1.4$ & $5.6 \pm 1.3$ & $5.8 \pm 1.4$ & 0.426 \\
\hline Interleukin-6 (pg/mL) $(\mathrm{n}=206)$ & $3.1 \pm 3.0$ & $3.1 \pm 3.1$ & $3.1 \pm 2.9$ & 0.975 \\
\hline Tumor necrosis factor-a $(\mathrm{pg} / \mathrm{mL})$ & $5.2 \pm 2.2$ & $5.6 \pm 2.3$ & $4.8 \pm 2.1$ & 0.004 \\
\hline C-reactive protein (mg/dL) & $0.53 \pm 0.21$ & $0.54 \pm 0.25$ & $0.52 \pm 0.14$ & 0.312 \\
\hline \multicolumn{5}{|l|}{ Academic grades (0-10) } \\
\hline Math & $6.5 \pm 1.7$ & $6.5 \pm 1.7$ & $6.6 \pm 1.7$ & 0.423 \\
\hline Spanish & $6.7 \pm 1.7$ & $6.5 \pm 1.7$ & $7.0 \pm 1.7$ & 0.014 \\
\hline English & $6.9 \pm 1.7$ & $6.7 \pm 1.7$ & $7.2 \pm 1.7$ & 0.025 \\
\hline Grade point average & $6.9 \pm 1.4$ & $6.8 \pm 1.3$ & $7.0 \pm 1.4$ & 0.136 \\
\hline \multicolumn{5}{|l|}{ Academic abilities } \\
\hline Verbal (0-50) & $19.0 \pm 5.4$ & $19.2 \pm 6.0$ & $18.8 \pm 4.5$ & 0.579 \\
\hline Numeric (0-30) & $13.8 \pm 4.7$ & $14.9 \pm 4.6$ & $12.4 \pm 4.4$ & $<0.001$ \\
\hline Reasoning (0-30) & $16.7 \pm 5.8$ & $16.2 \pm 5.7$ & $17.3 \pm 5.8$ & 0.131 \\
\hline Overall (0-110) & $49.5 \pm 12.4$ & $50.3 \pm 13.0$ & $48.5 \pm 11.7$ & 0.262 \\
\hline
\end{tabular}

Data are presented as mean \pm standard deviation or frequency (\%). Differences between sexes were examined by t test or chi-square test. Statistically significant values are in bold.

a Values were log-transformed before analysis, but non-transformed values are presented. 
Table 2. Linear regression analysis examining the association between circulating inflammatory biomarkers and academic performance.

\begin{tabular}{|c|c|c|c|}
\hline White blood cells & Interleukin-6 & $\begin{array}{l}\text { Tumor necrosis } \\
\text { factor-a }\end{array}$ & $\begin{array}{l}\text { C-reactive } \\
\text { protein }\end{array}$ \\
\hline $\mathrm{p}$ & $p$ & $\beta$ & $\beta$ \\
\hline
\end{tabular}

\begin{tabular}{lcccccccc}
\hline Academic grades & & & & & & & & \\
Math & -0.072 & 0.252 & 0.020 & 0.765 & -0.166 & 0.008 & -0.068 & 0.275 \\
Spanish & -0.058 & 0.357 & -0.042 & 0.532 & -0.127 & 0.043 & -0.082 & 0.190 \\
English & -0.108 & 0.084 & 0.053 & 0.426 & -0.112 & 0.072 & -0.087 & 0.160 \\
Grade point average & -0.066 & 0.281 & 0.009 & 0.897 & -0.124 & 0.042 & -0.071 & 0.242 \\
\hline Academic abilities & & & & & & & & \\
$\quad$ Verbal & -0.041 & 0.512 & 0.083 & 0.243 & 0.020 & 0.745 & -0.128 & 0.036 \\
Numeric & -0.017 & 0.773 & 0.105 & 0.117 & -0.067 & 0.250 & 0.015 & 0.790 \\
Reasoning & -0.113 & 0.910 & 0.057 & 0.431 & -0.096 & 0.125 & -0.058 & 0.355 \\
Overall & -0.027 & 0.664 & 0.100 & 0.159 & -0.061 & 0.319 & -0.075 & 0.220 \\
\hline
\end{tabular}

$\beta$ : standardized coefficient. Analyses were adjusted for sex, pubertal stage, parental educational level, type of school, waist circumference and adherence to the Mediterranean diet. 
Table 3. Parameters of the receiver operating characteristic curve analysis for the diagnostic performance of circulating inflammatory biomarkers in identifying low academic grades.

\begin{tabular}{|c|c|c|c|c|c|}
\hline $\begin{array}{l}\text { Low academic } \\
\text { grades }\end{array}$ & & White blood cells & Interleukin-6 & $\begin{array}{l}\text { Tumor necrosis } \\
\text { factor-a }\end{array}$ & $\begin{array}{l}\text { C-reactive } \\
\text { protein }\end{array}$ \\
\hline \multirow[t]{6}{*}{ Math } & AUC & 0.499 & 0.496 & 0.582 & 0.536 \\
\hline & $95 \% \mathrm{Cl}$ & $0.426-0.572$ & $0.417-0.575$ & $0.510-0.653$ & $0.463-0.609$ \\
\hline & $\mathrm{p}$ & 0.982 & 0.929 & 0.028 & 0.329 \\
\hline & Cut-off & - & - & $\geq 5.75$ & - \\
\hline & Sensitivity (\%) & - & - & 0.713 & - \\
\hline & Specificity (\%) & - & - & 0.425 & - \\
\hline \multirow[t]{6}{*}{ Spanish } & AUC & 0.549 & 0.491 & 0.604 & 0.505 \\
\hline & $95 \% \mathrm{Cl}$ & $0.477-0.622$ & $0.412-0.570$ & $0.533-0.675$ & $0.431-0.579$ \\
\hline & $\mathrm{p}$ & 0.186 & 0.822 & 0.005 & 0.893 \\
\hline & Cut-off & - & - & $\geq 5.85$ & - \\
\hline & Sensitivity (\%) & - & - & 0.732 & - \\
\hline & Specificity (\%) & - & - & 0.443 & - \\
\hline \multirow[t]{6}{*}{ English } & AUC & 0.581 & 0.500 & 0.585 & 0.552 \\
\hline & $95 \% \mathrm{Cl}$ & $0.508-0.653$ & $0.420-0.580$ & $0.513-0.658$ & $0.479-0.626$ \\
\hline & $\mathrm{p}$ & 0.032 & 0.992 & 0.023 & 0.166 \\
\hline & Cut-off & $\geq 5.25$ & - & $\geq 5.85$ & - \\
\hline & Sensitivity (\%) & 0.493 & - & 0.721 & - \\
\hline & Specificity (\%) & 0.654 & - & 0.442 & - \\
\hline \multirow{6}{*}{$\begin{array}{l}\text { Grade point } \\
\text { average }\end{array}$} & $A \cup C$ & 0.562 & 0.514 & 0.598 & 0.506 \\
\hline & $95 \% \mathrm{Cl}$ & $0.490-0.634$ & $0.435-0.593$ & $0.524-0.667$ & $0.433-0.579$ \\
\hline & $\mathrm{p}$ & 0.094 & 0.727 & 0.010 & 0.872 \\
\hline & Cut-off & - & - & $\geq 5.85$ & - \\
\hline & Sensitivity (\%) & - & - & 0.727 & - \\
\hline & Specificity (\%) & - & - & 0.430 & - \\
\hline
\end{tabular}

AUC: area under the curve; $\mathrm{Cl}$ : confidence interval; Values in bold font indicate statistically significant AUC. 


\begin{tabular}{|c|c|c|c|}
\hline \multicolumn{4}{|l|}{ White blood cells } \\
\hline English & $\geq 5.25$ & 139 & $1.78(1.00,3.15)$ \\
\hline \multicolumn{4}{|l|}{ Tumor necrosis factor- $a$} \\
\hline Math & $\geq 5.75$ & 86 & $1.79(1.01,3.17)$ \\
\hline Spanish & $\geq 5.85$ & 85 & $1.86(1.05,3.30)$ \\
\hline English & $\geq 5.85$ & 85 & $1.87(1.05,3.33)$ \\
\hline Grade Point Average & $\geq 5.85$ & 85 & $1.75(0.98,3.13)$ \\
\hline
\end{tabular}

Figure 1. Logistic regression model predicting low academic grades according to high concentration of circulating inflammatory biomarkers (above the cut-off values provided by the ROC curve analysis).

Analysis adjusted for sex, pubertal stage, parental educational level, type of school, waist circumference and adherence to the Mediterranean diet. Values in bold font indicate statistically significant results. OR: Odds ratio; Cl: confidence interval. Reference $(\mathrm{OR}=1.00)$ : students with low concentration of circulating inflammatory biomarkers. $n$ indicates number of students from the total sample $(n=244)$ over the cut-off values. 
Study 6

Fitness and academic performance in adolescents. The mediating role of leptin: DADOS study 


\title{
Fitness and academic performance in adolescents. The mediating role of leptin: DADOS study
}

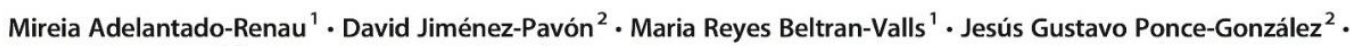 \\ Óscar Chiva-Bartoll ${ }^{3}$. Diego Moliner-Urdiales ${ }^{1}$ (C)
}

Received: 29 March 2018 / Revised: 12 July 2018 / Accepted: 15 July 2018

(C) Springer-Verlag GmbH Germany, part of Springer Nature 2018

\begin{abstract}
We tested the mediating effect of leptin on the association between physical fitness (PF) components and academic performance indicators in healthy adolescents. A total of 263 adolescents ( $13.9 \pm 0.3$ years, $47.5 \%$ girls, $12.5 \%$ overweight) from the DADOS (Deporte, ADOlescencia y Salud) Study were included in the analysis. PF components were assessed by the handgrip test for upper-limb muscular strength, standing long jump test for lower-limb muscular strength, $4 \times 10$-m shuttle run test for speedagility, and 20-m shuttle run test for cardiorespiratory fitness. Plasma leptin concentration was assessed from antecubital vein blood after an overnight fast using a sensitive ELISA kit. Academic performance indicators were assessed through final school grades and through the Spanish version of the SRA Test of Educational Ability. Body composition was assessed by body mass index and skinfold thicknesses. Boot-strapped mediation procedures were performed and indirect effects with confidence intervals not including zero were interpreted as statistically significant. Our findings suggest that the positive associations observed between cardiorespiratory fitness and lower-limb muscular strength with academic performance indicators were mediated by leptin concentration after adjusting for sex, pubertal stage, socioeconomic status, and adiposity (percentage of mediation ranging from 54.61 to $82.02 \%$ ). Conclusions: Improvements on PF components, particularly in cardiorespiratory fitness and lower-limb muscular strength, might reduce leptin concentration with potential benefits on academic performance in adolescents, independently of adiposity.
\end{abstract}

What is Known:

- Academic performance is associated with physical fitness and leptin concentration in children and adolescents.

- Fitness modulates leptin concentration levels, regardless of physical activity and adiposity.

What is New:

- Leptin concentration mediates the association of cardiorespiratory fitness and muscular strength with academic performance in adolescents.

- Improvements in cardiorespiratory fitness and muscular strength might reduce leptin concentration levels enhancing academic performance.

Keywords Cognition $\cdot$ Health $\cdot$ School grades $\cdot$ Adolescence $\cdot$ Leptin

Communicated by Mario Bianchetti

Diego Moliner-Urdiales

dmoliner@uji.es

Mireia Adelantado-Renau adelantm@uji.es

David Jiménez-Pavón david.jimenez@uca.es

Maria Reyes Beltran-Valls vallsm@uji.es

Jesús Gustavo Ponce-González jesusgustavo.ponce@uca.es
Óscar Chiva-Bartoll ochiva@uji.es

1 LIFE Research Group, University Jaume I, Av. de Vicent Sos Baynat, $\mathrm{s} / \mathrm{n}, 12071$ Castellon, Spain

2 MOVE-IT Research Group, Department of Physical Education, Faculty of Education Sciences, University of Cádiz, Cádiz, Spain

3 Universitat Jaume I, Castellón de la Plana, Spain 


$\begin{array}{ll}\text { Abbreviations } \\ \text { CRF } & \text { Cardiorespiratory fitness } \\ \text { GPA } & \text { Grade point average } \\ \text { MS } & \text { Muscular strength } \\ \text { PF } & \text { Physical fitness } \\ \text { SES } & \text { Socioeconomic status } \\ \text { SRT } & \text { Shuttle run test }\end{array}$

\section{Introduction}

In the last decades, the role of physical fitness (PF) as a key determinant of current and future health status has been demonstrated in childhood and adolescence [33, 35]. Cardiorespiratory fitness (CRF), muscular strength (MS), and speed-agility have been proposed as the components of PF more closely related with health status [35, 39]. European children and adolescents, on average, meet the standards for healthy CRF ( $78 \%$ of boys and $83 \%$ of girls); however, these percentages decrease yearly [41].

Empirical evidence and systematic reviews have suggested a positive association between PF components and academic performance in children and adolescents [5, 12, 16, 34, 37]. For instance, Marques et al. [26] have shown that there is a strong evidence for the association between CRF and academic performance which may be related to the positive effects of CRF on brain structure and cognitive functions [7]. In addition, Esteban-Cornejo et al. [13] showed that CRF and speedagility, but not MS, positively influenced academic performance in youths independently of adiposity. By contrast, in a study conducted by Olivares et al. [30], MS was the fitness component most associated with academic performance, while no association was found between CRF and academic performance when adiposity was considered. The divergent results found in the scientific literature may be related to the fact that some of the studies analyzing the associations between $\mathrm{PF}$ and academic performance used measures scaled by body mass (i.e., $\mathrm{VO}_{2}$ in $\mathrm{mL} / \mathrm{min} / \mathrm{kg}$ ), without recognizing the influence that adiposity could have in these associations [33].

Leptin is a 167 amino acid adipokine classically involved in the regulation of energy homeostasis and appetite by sending signals to receptors within the hypothalamus [28]. Physiologically normal leptin levels, based on healthy European adolescent reference values, have been established at $<12.41 \mathrm{ng} / \mathrm{mL}$ in males and $<38.61 \mathrm{ng} / \mathrm{mL}$ in females [25]. Leptin has been associated with enhanced cognitive processes at normal concentrations, while at high levels, it has been related with several cardiovascular disease risk factors [42], impaired cognitive function [14], and poor academic performance $[9,19]$. In parallel, an inverse association between PF and circulating leptin concentration levels has been reported in youth $[22,24,27]$. Although prior research assessing the association between CRF and leptin in adolescents has shown an inverse relationship independently of adiposity [24, 27], Hosick et al. [22] found that this association was explained by adiposity, suggesting that not considering adiposity could lead to misleading conclusions.

Despite Haapala et al. identified a mediating role of motor performance on the association between leptin and reading fluency in a sample of 106 boys aged 6-8 years [19], no previous studies have examined the mediating role of leptin concentration on the association between PF and academic performance. Given the growing body of research highlighting the key role of PF on academic performance, and the previously argued independent inverse associations of leptin with $\mathrm{PF}$ and academic performance, we hypothesized that leptin concentration could act as an underlying mechanism for the influence of PF on academic performance. Thus, the objective of the current study was to test the mediating role of leptin concentration levels on the association between PF components and academic performance indicators in healthy adolescents, adjusting by several potential confounders including adiposity.

\section{Methods}

\section{Participants}

The present study is part of the DADOS (Deporte, ADOlescencia y Salud) study, a 3-year longitudinal research project (from 2015 to 2017) aimed to analyze the influence of competitive sport practice on health, academic performance, and psychological wellness through adolescence. All participants were recruited from secondary schools and sport clubs of Castellon (Spain) and met the general DADOS inclusion criteria; born in 2001, enrolled in 2nd grade of secondary school and free of any chronic disease. The results presented in this study belong to baseline data obtained between February and May of 2015. From the total DADOS study sample ( $n=274)$, a subsample of 263 adolescents ( 125 girls) with valid data for at least PF, academic performance and leptin concentration were included in the analysis.

\section{Physical fitness}

PF was assessed using the ALPHA (Assessing Levels of Physical Activity) health-related fitness test battery for adolescents [36]. In brief, CRF was assessed using the 20-m Shuttle Run Test. The final number of completed stages was used in the analyses. Speed-agility was assessed using the $4 \times$ $10-\mathrm{m}$ Shuttle Run Test. The test was performed twice and the best time (s) was used in the analyses. Because speed-agility is inversely related to high physical fitness, it was first multiplied by -1 . Upper-limb MS was assessed using a hand 
dynamometer with adjustable grip (TKK 5401 Grip D; Takey Scientific Instruments, Tokyo, Japan). The test was performed twice for each hand alternatively, using the optimal grip-span. The handgrip score $(\mathrm{kg})$ was calculated as the average of the best score for each hand. Lower-limb MS was assessed using the standing long jump test. The test was performed twice and the longest distance $(\mathrm{cm})$ was used in the analyses.

\section{Plasma leptin concentrations}

After an overnight fast of at least $10 \mathrm{~h}$, blood samples were drawn from the antecubital vein while subjects remained in seated position. Blood samples in EDTA tubes (Greiner bioone, Kremsmünster, Austria) were used for plasma collection after centrifugation $\left(3500 \mathrm{rpm} \times 10 \mathrm{~min}\right.$ at $\left.4{ }^{\circ} \mathrm{C}\right)$. Plasma leptin concentrations were measured using a sensitive ELISA kit (EIA-2395, Enzyme-Linked Immunosorbent Assay; DRG Instruments GmbH, Marburg, Germany). The sensitivity of the leptin concentration assay was $0.7 \mathrm{ng} / \mathrm{mL}$, with intraassay and inter-assay coefficients of variation of $<10$ and $<$ $15 \%$, respectively.

\section{Academic performance indicators}

Academic performance was assessed using school grades and an academic questionnaire. (1) School grades: the final school grades from the 1st course of secondary school on a ten-point scale were provided by the participants. Four indicators were included in the analyses: math, language, the average of math and language, and grade point average (GPA). Language is the grade of Catalan, the official teaching language at school. GPA was defined as the single average of the grades of geography and history, natural science, math, Spanish, Catalan, English, and physical education. (2) Academic questionnaire: the Spanish version of the Science Research Associates Test of Educational Abilities was completed by the participants. This test measures three basic abilities: verbal ability (command of language), numeric ability (speed and precision in performing operations with numbers and quantitative concepts), and reasoning ability (the aptitude to find logical ordination criteria in sets of numbers, figures, or letters). Scores for the three abilities were obtained by adding positive answers. Overall academic ability was calculated by adding the three abilities' scores (verbal + numeric + reasoning). As previously published from DADOS study [5], this work used the level 3 of the TEA test.

\section{Covariates}

Measures were assessed in duplicate by trained members of the DADOS research group following standardized procedures [23], and average measures were used for the analysis. Briefly, body weight was measured to the nearest $0.1 \mathrm{~kg}$ using an electronic scale (SECA 861, Hamburg, Germany). Height was measured to the nearest $0.1 \mathrm{~cm}$ using a wall-mounted stadiometer (SECA 213, Hamburg, Germany). Body mass index (BMI) was calculated as weight/height squared (kg/ $\mathrm{m}^{2}$ ). Participants were classified into normal weight and overweight or obese, according to the BMI cutoffs proposed by Cole et al. [8]. The BMI values were transformed into standard deviation scores (SDS) according to WHO reference population for sex and age [32]. In addition, skinfold thicknesses were measured at the left side of the body to the nearest $0.2 \mathrm{~mm}$ using a Holtain skinfold caliper at two sites (triceps and subscapular). Sum of both skinfolds was used for data analyses as indicator of adiposity.

Pubertal stage was self-reported according to the five stages described by Tanner and Whitehouse [40] based on external primary and secondary sex characteristics. Standardized pictures were used to assess two components: pubic hair growth for boys and girls, plus breast development in girls, and genital development in boys. A 5-point maturity rating was used where stage 1 corresponds to the prepubertal state and stage 5 corresponds to mature state. The highest rating of the two components was used for data analyses.

The Family Affluence Scale (FAS) developed by Currie et al. [10] was used as a proxy of socioeconomic status (SES), which is based on material conditions in the family such as car ownership, bedroom occupancy, computer ownership, and home Internet access.

\section{Statistical analyses}

Characteristics of the sample are presented as mean \pm standard deviation (SD) unless otherwise stated. Differences between sexes were assessed by $t$ test for continuous variables and Chisquare test for nominal variables. All variables were checked for normality using both graphical (normal probability plots) and statistical (Kolmogorov-Smirnov test) procedures. Due to its skewed distribution, leptin concentrations were logtransformed before the analysis. As preliminary analyses did not show significant interactions of sex with leptin and PF variables in relation to academic performance indicators (all $P>0.05$ ), all analyses were performed for boys and girls together.

Partial correlation analysis controlling for sex, pubertal stage, and SES was performed to examine the relationships between PF components, leptin concentration, adiposity, and academic performance indicators. Additionally, linear regression analyses were performed to clarify the potential role of leptin concentration as mediator variable in the association between PF components (independent variables) and academic performance indicators (dependent variables) using two separate models. Model 1 included sex, pubertal stage, and SES, and model 2 included model 1 plus leptin concentration. Finally, separate mediation analyses were performed in order 
to elucidate whether the associations between PF and academic performance were mediated by leptin concentration. The PROCESS macro version 2.16.3, model 4, with 5000 biascorrected bootstrap samples and $95 \%$ confidence intervals was used for these analyses. Mediation is assessed by the indirect effect of the PF (independent variable) on academic performance (dependent variable) through leptin concentration (mediator). The total (c path), direct ( $\mathrm{c}^{\prime}$ path), and indirect effects ( $a^{*} b$ paths) are presented (Fig. 1). Indirect effects (ab) with confidence intervals not including zero were interpreted as statistically significant [20], which can be so regardless of the significance of the total effect (the effect of PF on academic performance) and the direct effect (the effect on academic performance when both PF and leptin concentration are included as independent variables). Percentage of mediation $\left(\mathrm{P}_{\mathrm{M}}\right)$ was calculated as '(indirect effect / total effect) $\times 100$ ' to know how much of the total effect was explained by the mediation when the following assumptions were achieved; the total effect is larger than the indirect effect and of the same sign. These analyses were adjusted by sex, pubertal stage, SES, and adiposity. All the analyses were performed using the IBM SPSS Statistics for Windows version 22.0 (Armonk, NY: IBM Corp), and the level of significance was set to $P<0.05$.

\section{Results}

The baseline characteristics of the final sample included in the analyses are shown in Table 1. Girls had significantly higher SES ( 4.4 vs. $4.0 ; P<0.05)$, sum of skinfold thicknesses $(30.3$ vs. $21.7 ; P<0.001)$, and leptin concentration levels (6.1 vs. 1.6; $P<0.001)$ than boys. Meanwhile, boys were taller and showed higher levels for all PF components than girls (all $P<$ $0.001)$. No differences were reported for academic performance, except for numeric ability that was higher in boys (14.7 vs. 12.0 ; all $P<0.001$ ).

Partial correlations between PF components, leptin concentration, adiposity, and academic performance indicators, after adjustment for sex, pubertal stage, and SES are presented at Table 2. CRF was positively associated with math, math and language, GPA, and numeric ability (all $P<0.05$ ). Lowerlimb MS was positively associated with verbal ability $(P<$ 0.05 ). Leptin concentration was negatively associated with all the PF components, adiposity, school grades, and numeric ability (all $P<0.05$ ).

Linear regression analyses examining the associations between PF components and academic indicators showed positive associations of CRF and lower-limb MS with academic performance, which disappeared after including leptin concentration as a confounder (data not shown).

The results of the separated mediation models after controlling for sex, pubertal stage, SES, and adiposity are in Tables 3
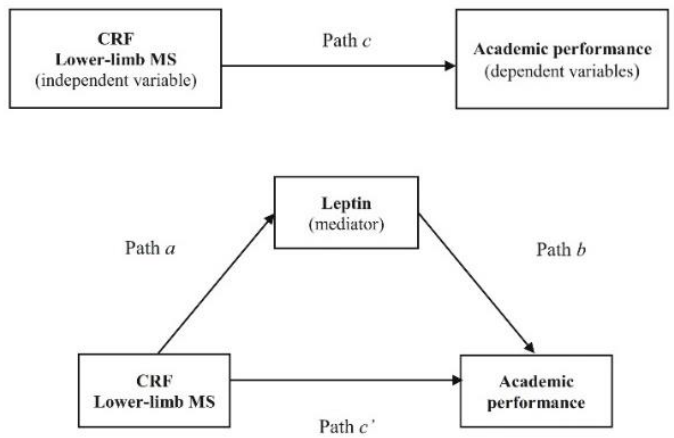

Fig. 1 Causal diagram reflecting the study simple mediation analyses. Path c shows the association between independent and dependent variables. Arrows $\mathrm{a} \times \mathrm{b}$ show the natural indirect effect pathway, and $\mathrm{c}^{\prime}$ shows the natural direct effect pathway. CRF: cardiorespiratory fitness; MS: muscular strength

and 4. Mediation analyses were not significant for the association of speed-agility $(4 \times 10-\mathrm{m}$ test $)$ and upper-limb MS (handgrip test) with academic performance indicators (data not shown). According to the mediation analyses, CRF was positively associated with numeric ability (total effect, c; $P<$ 0.05 ) and negatively associated with leptin concentration (path $\mathrm{a}=-1.101 ; P<0.001$ ). In path $\mathrm{b}$, leptin concentration was negatively associated with academic performance, although the associations were not statistically significant. The direct effect (path c') of CRF on academic performance when leptin was included in the model was not significant. There was a significant mediating effect of leptin in the relationship of CRF with GPA, reasoning ability, and overall academic ability $\left(\mathrm{P}_{\mathrm{M}}\right.$ ranged from 52.9 to $\left.58.2 \%\right)$. Regarding the analysis of leptin concentration as a potential mediator of the relationship between lower-limb MS and academic performance, lower-limb MS was positively associated with verbal ability $(P<0.01)$ and negatively associated with leptin concentration (path a $=-1.867 ; P<0.001$ ). In path $\mathrm{b}$, leptin concentration was negatively associated with language, math and language, and GPA $(P<0.05)$ and the direct effect (path $\left.\mathrm{c}^{\prime}\right)$ of lower-limb MS on academic performance was not statistically significant. These results suggest a significant mediating effect of leptin concentration in the relationship of lower-limb MS with all the school grades and with numeric, reasoning, and overall academic abilities $\left(\mathrm{P}_{\mathrm{M}}\right.$ ranged from 42.2 to $75.1 \%)$.

\section{Discussion}

The main finding of the present study revealed a mediating effect of leptin concentration on the relationship between PF components (CRF and lower-limb MS) and academic performance indicators after controlling for sex, pubertal stage, SES, 
Table 1 Characteristics of the study population by sex

\begin{tabular}{|c|c|c|c|c|}
\hline & All & Boys & Girls & $P$ \\
\hline$n(\%)$ & $263(100)$ & $138(52.5)$ & $125(47.5)$ & \\
\hline \multicolumn{5}{|l|}{ Demographics } \\
\hline Age (year) & $13.9 \pm 0.3$ & $13.9 \pm 0.3$ & $13.9 \pm 0.3$ & 0.797 \\
\hline Pubertal stage $(I-V)(\%)^{a}$ & $0 / 8 / 33 / 49 / 10$ & $0 / 10 / 32 / 44 / 14$ & $0 / 6 / 35 / 54 / 5$ & \\
\hline SES score $(0-8)$ & $4.2 \pm 1.4$ & $4.0 \pm 1.3$ & $4.4 \pm 1.4$ & 0.031 \\
\hline \multicolumn{5}{|l|}{ Anthropometry } \\
\hline Height $(\mathrm{cm})$ & $163.1 \pm 7.9$ & $164.6 \pm 8.6$ & $161.4 \pm 6.7$ & $<0.001$ \\
\hline Weight (kg) & $54.2 \pm 9.2$ & $54.5 \pm 9.6$ & $53.9 \pm 8.8$ & 0.600 \\
\hline Body mass index $\left(\mathrm{kg} / \mathrm{m}^{2}\right)$ & $20.3 \pm 2.7$ & $20.0 \pm 2.6$ & $20.6 \pm 2.9$ & 0.054 \\
\hline Overweight $(\%)^{\mathrm{b}}$ & 12.5 & 11.6 & 13.7 & 0.710 \\
\hline Body mass index SDS $^{\mathrm{c}}$ & $0.29 \pm 0.89$ & $0.30 \pm 0.91$ & $0.28 \pm 0.88$ & 0.838 \\
\hline Triceps skinfold (mm) & $16.0 \pm 6.8$ & $13.1 \pm 6.1$ & $19.2 \pm 6.2$ & $<0.001$ \\
\hline Subscapular skinfold (mm) & $9.9 \pm 3.5$ & $8.7 \pm 2.9$ & $11.3 \pm 3.5$ & $<0.001$ \\
\hline Sum of skinfold thickness (mm) & $25.8 \pm 9.7$ & $21.7 \pm 8.5$ & $30.3 \pm 9.0$ & $<0.001$ \\
\hline \multicolumn{5}{|l|}{ PF components } \\
\hline 20-m SRT (stages) & $7.7 \pm 2.5$ & $9.0 \pm 2.0$ & $6.2 \pm 2.2$ & $<0.001$ \\
\hline $4 \times 10-\mathrm{m} \mathrm{SRT}(\mathrm{s})$ & $12.6 \pm 1.0$ & $12.0 \pm 0.7$ & $13.1 \pm 1.0$ & $<0.001$ \\
\hline Handgrip strength (kg) & $28.9 \pm 5.9$ & $30.8 \pm 6.7$ & $26.8 \pm 4.0$ & $<0.001$ \\
\hline Standing long jump (cm) & $171.1 \pm 26.3$ & $180.1 \pm 24.2$ & $161.2 \pm 25.0$ & $<0.001$ \\
\hline \multicolumn{5}{|l|}{ School grades $(0-10)$} \\
\hline Math & $6.9 \pm 1.6$ & $7.0 \pm 1.6$ & $6.8 \pm 1.6$ & 0.281 \\
\hline Language & $6.8 \pm 1.5$ & $6.7 \pm 1.5$ & $6.9 \pm 1.5$ & 0.147 \\
\hline Math and language & $6.8 \pm 1.4$ & $6.8 \pm 1.5$ & $6.8 \pm 1.4$ & 0.859 \\
\hline GPA & $7.1 \pm 1.3$ & $7.1 \pm 1.3$ & $7.2 \pm 1.3$ & 0.346 \\
\hline \multicolumn{5}{|l|}{ Academic abilities } \\
\hline Verbal $(0-50)$ & $18.7 \pm 5.3$ & $19.1 \pm 5.8$ & $18.2 \pm 4.6$ & 0.167 \\
\hline Numeric $(0-30)$ & $13.4 \pm 4.7$ & $14.7 \pm 4.5$ & $12.0 \pm 4.5$ & $<0.001$ \\
\hline Reasoning $(0-30)$ & $16.5 \pm 5.9$ & $16.1 \pm 5.7$ & $17.0 \pm 6.1$ & 0.214 \\
\hline Overall $(0-110)$ & $48.6 \pm 12.6$ & $49.9 \pm 12.8$ & $47.2 \pm 12.3$ & 0.074 \\
\hline Leptin concentration (ng/mL) & $3.7 \pm 4.5$ & $1.6 \pm 2.8$ & $6.1 \pm 4.9$ & $<0.001$ \\
\hline
\end{tabular}

Data are presented as mean \pm standard deviation or percentages. Differences between sexes were examined by $t$ tests. Statistically significant values are in italics

Pubertal stage described by Tanner and Whitehouse [40] was based on pubic hair growth for boys and girls, plus breast development in girls and genital development in boys. Overweight includes obese adolescents according to the age- and sex-specific BMI cutoffs proposed by Cole et al. [8]. Body mass index SDS was calculated using the WHO 2007 reference values [32]. Skinfold thicknesses indicate the sum of two skinfolds (triceps and subscapular). Overall indicates the sum of the three ability scores

SES socioeconomic status, SDS standard deviations scores, $P F$ physical fitness, SRT shuttle run test, GPA grade point average

and adiposity. These results contribute to the current scientific knowledge by suggesting that leptin concentration could partially explain the positive association between PF and cognition in adolescents.

In consonance with prior research, the present study showed a positive association between PF, particularly CRF and lower-limb MS, and some academic performance indicators in adolescents $[2,5,12,16,34,37,38]$, which disappeared after further adjustment for leptin concentration. The association of CRF with academic performance could be explained by the positive effects that this fitness component has on cognition and brain. For instance, Chaddock et al. found greater bilateral hippocampal volumes and memory performance in those preadolescent children with higher levels of CRF [7]. In another study, Buck et al. analyzed a sample of 74 preadolescents showing a positive association between aerobic fitness and interference control [6]. Therefore, it is plausible that CRF produces structural and functional brain changes with potential improvements in cognitive processes [21] which may lead to better academic performance in adolescents. The mechanisms by which MS influences academic performance have been less explored showing uncertain 
Table 2 Partial correlations of PF components, leptin concentration, adiposity, and academic performance indicators controlling for sex, pubertal stage, and SES

\begin{tabular}{|c|c|c|c|c|c|c|c|c|c|}
\hline & \multirow[t]{2}{*}{ Leptin } & \multicolumn{4}{|c|}{ School grades } & \multicolumn{4}{|c|}{ Academic abilities } \\
\hline & & Math & Language & Math and language & GPA & Verbal & Numeric & Rcasoning & Overall \\
\hline \multicolumn{10}{|l|}{ PF Components } \\
\hline 20-m SRT (stages) & $-0.552^{* * * *}$ & $0.153^{*}$ & 0.102 & $0.138^{*}$ & $0.146^{*}$ & 0.098 & $0.144 *$ & 0.022 & 0.103 \\
\hline $4 \times 10-\mathrm{m}$ SRT $(\mathrm{s})$ & $-0.491 * * *$ & 0.109 & 0.066 & 0.094 & 0.101 & 0.103 & 0.042 & -0.033 & 0.043 \\
\hline Handgrip strength (kg) & $-0.126 \%$ & -0.117 & -0.107 & -0.121 & -0.112 & -0.007 & 0.002 & -0.035 & -0.019 \\
\hline Standing long jump $(\mathrm{cm})$ & $-0.452 * * *$ & 0.119 & 0.048 & 0.091 & 0.106 & $0.176^{*}$ & 0.111 & 0.014 & 0.121 \\
\hline Leptin (ng/mL) & - & $-0.137^{*}$ & $-0.136^{*}$ & $-0.147^{*}$ & $-0.167 * *$ & -0.072 & $-0.127 *$ & -0.047 & -0.099 \\
\hline Adiposity (mm) & $0.688^{* * * *}$ & -0.093 & -0.092 & -0.097 & -0.114 & -0.023 & -0.002 & -0.065 & -0.144 \\
\hline
\end{tabular}

Adiposity indicates the sum of two skinfolds (triceps and subscapular). Overall indicates the sum of the three abilities scores

$P F$ physical fitness, $S R T$ shuttle run test, GPA grade point average

$* * * P \leq 0.001, * * P<0.01$, and $* P<0.05$

results [39]. However, we speculate that better MS, as a result of strength training, may positively influence academic performance by inducing the expression of neurotrophic factors [11] and synaptogenesis [1].

Our results showed that the association between PF and academic performance disappeared when including leptin as a confounder. This fact could be related to the strong link between leptin and adipose tissue [28] which could indirectly affect academic performance. In fact, overweight and obese adolescents, who have shown lower PF levels than their normal-weight peers [15], have also reported several psychological and behavioral disturbances [17, 18], such as weightrelated teasing and low self-confidence, which could impair school functioning and academic outcomes. In addition, leptin has shown to induce brain-derived neurotrophic factor, which also plays a key role on control of body weight, and promotes neuron survival and neural plasticity [29], which in turn, might improve academic performance.

In our sample of physically active and mainly normal weight adolescents, leptin was revealed as an underlying mechanism of the association between PF and academic performance, after adjustment of sex, pubertal stage, SES, and adiposity. Similarly to previous studies, we found an inverse association between PF and leptin concentration [4, 24, 27], which could significantly influence academic performance $[9$, 19]. According to prior research, high levels of CRF and MS might stimulate insulin and leptin sensitivity which translates into lower leptin circulating levels [24, 27]. For instance,

Table 3 Total, direct, and indirect effects of the simple mediation analyses investigating leptin concentration as a mediator between cardiorespiratory fitness and academic performance $(N=263)$

\begin{tabular}{|c|c|c|c|c|c|c|c|}
\hline Outcome & Total effect $(c)$ & $\begin{array}{l}\text { Direct effect } \\
\left(c^{\prime}\right)\end{array}$ & Path $a$ & Path $b$ & $\begin{array}{l}\text { Indirect effect } \\
(a b)\end{array}$ & $\begin{array}{l}\mathrm{BC} 95 \% \mathrm{CI} \\
\text { lower; upper }\end{array}$ & $\mathrm{P}_{\mathrm{M}}(\%)$ \\
\hline \multicolumn{8}{|l|}{ School grades } \\
\hline Math & $0.097(0.052)$ & $0.058(0.057)$ & $-1.101(0.144)^{* * * * *}$ & $-0.036(0.023)$ & $0.039(0.022)$ & $-0.006 ; 0.084$ & - \\
\hline Language & $0.077(0.053)$ & $0.035(0.058)$ & $-1.101(0.144)^{* * * * *}$ & $-0.039(0.023)$ & $0.042(0.027)$ & $-0.009 ; 0.098$ & - \\
\hline Math and language & $0.083(0.047)$ & $0.043(0.052)$ & $-1.101(0.144)^{* * * * *}$ & $-0.036(0.021)$ & $0.040(0.022)$ & $-0.003 ; 0.084$ & - \\
\hline GPA & $1.137(0.649)$ & $0.536(0.716)$ & $-1.101(0.144)^{\text {*水菂 }}$ & $-0.546(0.281)$ & $0.602(0.312)$ & $0.030 ; 1.241$ & 52.90 \\
\hline \multicolumn{8}{|l|}{ Academic abilities } \\
\hline Verbal & $0.080(0.066)$ & $0.039(0.073)$ & $-1.101(0.144)^{* * * *}$ & $-0.037(0.0 .29)$ & $0.041(0.033)$ & $-0.024 ; 0.107$ & - \\
\hline Numeric & $0.221(0.090)^{* * *}$ & $0.154(0.099)$ & $-1.101(0.144) * * *$ & $-0.060(0.039)$ & $0.066(0.038)$ & $-0.007 ; 0.1411$ & - \\
\hline Reasoning & $0.063(0.108)$ & $-0.023(0.120)$ & $-1.101(0.144)^{* * * *}$ & $-0.078(0.047)$ & $0.086(0.046)$ & $0.004 ; 0.183$ & N/A \\
\hline Overall & $0.106(0.062)$ & $0.044(0.068)$ & $-1.101(0.144)^{* k * *}$ & $-0.056(0.027)$ & $0.062(0.028)$ & $0.011 ; 0.121$ & 58.21 \\
\hline
\end{tabular}

Results showed as unstandardized coefficients (standard error, SE) and BC $95 \% \mathrm{CI}$ based on 5000 bootstraps. All analyses were adjusted for sex, pubertal stage, SES, and adiposity

$B C$ bias corrected, $C I$ confidence interval, $P_{M}$ percentage of mediation, GPA grade point average score, $N / A$ non-applicable according to statistical assumptions specified previously

Statistical significant indirect effects indicating that 0 is not in the $95 \%$ confidence interval $(\mathrm{CI})$ of the indirect effect are presented in italics $* P<0.05, * * P<0.01, * * * P<0.001$ 
Table 4 Total, direct, and indirect effects of the simple mediation analyses investigating leptin concentration as a mediator between lower-limb muscular strength and academic performance $(N=263)$

\begin{tabular}{|c|c|c|c|c|c|c|c|}
\hline Outcome & Total effect $(c)$ & $\begin{array}{l}\text { Direct effect } \\
\left(c^{\prime}\right)\end{array}$ & Path $a$ & Path $b$ & $\begin{array}{l}\text { Indirect effect } \\
(a b)\end{array}$ & $\begin{array}{l}\text { BC 95\% CI } \\
\text { lower; upper }\end{array}$ & $\mathrm{P}_{\mathrm{M}}(\%)$ \\
\hline \multicolumn{8}{|l|}{ School grades } \\
\hline Math & $0.160(0.105)$ & $0.087(0.112)$ & $-1.867(0.302)^{* * * *}$ & $-0.039(0.022)$ & $0.073(0.039)$ & $0.005 ; 0.161$ & 45.80 \\
\hline Language & $0.044(0.108)$ & $-0.045(0.114)$ & $-1.867(0.302)^{* * *}$ & $-0.048(0.022)^{*}$ & $0.089(0.047)$ & $0.008 ; 0.197$ & $\mathrm{~N} / \mathrm{A}$ \\
\hline Math and language & $0.104(0.097)$ & $0.026(0.103)$ & $-1.867(0.302)^{* * * *}$ & $-0.042(0.020)^{*}$ & $0.078(0.039)$ & $0.010 ; 0.160$ & 75.08 \\
\hline GPA & $0.105(0.081)$ & $0.037(0.086)$ & $-1.867(0.302)^{* * * *}$ & $-0.036(0.017)^{*}$ & $0.068(0.032)$ & $0.011 ; 0.136$ & 64.54 \\
\hline \multicolumn{8}{|l|}{ Academic abilities } \\
\hline Verbal & $0.323(0.132)^{* * *}$ & $0.277(0.141)$ & $-1.867(0.302)^{* * *}$ & $-0.024(0.027)$ & $0.046(0.051)$ & $-0.052 ; 0.155$ & - \\
\hline Numeric & $0.325(0.183)$ & $0.188(0.195)$ & $-1.867(0.302)^{* * * *}$ & $-0.073(0.038)$ & $0.137(0.064)$ & $0.022 ; 0.279$ & 42.15 \\
\hline Reasoning & $0.069(0.220)$ & $-0.079(0.235)$ & $-1.867(0.302)^{* * * *}$ & $-0.079(0.045)$ & $0.148(0.079)$ & $0.012 ; 0.328$ & $\mathrm{~N} / \mathrm{A}$ \\
\hline Overall & $0.221(0.126)$ & $0.118(0.134)$ & $-1.867(0.302)^{* * * *}$ & $-0.055(0.026) *$ & $0.103(0.047)$ & $0.022 ; 0.210$ & 46.48 \\
\hline
\end{tabular}

Results showed as unstandardized coefficients (standard error, SE) and BC $95 \% \mathrm{CI}$ based on 5000 bootstraps. All analyses were adjusted for sex, pubertal stage, SES, and adiposity

$B C$ bias corrected, $C I$ confidence interval, $P_{M}$ percentage of mediation, GPA grade point average score, $N / A$ non-applicable according to statistical assumptions specified previously

Statistical significant indirect effects indicating that 0 is not in the $95 \%$ confidence interval $(\mathrm{CI})$ of the indirect effect are presented in italics $* P<0.05, * * P<0.01, * * * P<0.001$

Olmedillas et al. found higher MS and hypertrophy in the dominant arm of professional tennis players, with an increased expression of leptin receptors and signaling compared to the contralateral arm [31]. Moreover, a previous study in rodents showed that aerobic training increased leptin receptor in hippocampus and prefrontal cortex, enhancing leptin signaling in the hypothalamus of mice through the phosphorylation of signal transducer and activator of transcription 3 (STAT3) [43]. Therefore, higher CRF and MS seem to be related with lower leptin concentration, which may improve synaptic plasticity, cognitive processes (e.g., memory), and mood [14], enhancing academic performance.

\section{Limitations and strengths}

The results of the present study should be interpreted with caution. First, the cross-sectional design of our analyses prevents us from inferring causal relationships; however, our mediation analysis strategy allows us to provide data supporting the importance of leptin concentration in the fitness-cognition relationship. Second, despite some methodological limitations [3], the 20-m shuttle run test was used as indirect measure of cardiorespiratory fitness. Third, pubertal stage was self-reported. However, the strengths of the study comprise the use of objective and standardized measures of PF, leptin concentration, and academic indicators, as well as a relatively large and age-matched sample of healthy adolescents $(13.9 \pm 0.3$ years $)$ with no academic performance differences. In addition, as suggested by previous research [12, 22], our statistical analyses were controlled for sex, pubertal stage, SES, and adiposity, which are relevant given their association with PF and cognition.

\section{Conclusions}

In conclusion, the present study reveals a mediating effect of leptin in the association between PF and academic performance in adolescents. Therefore, if confirm prospectively, improvements on PF components, specifically in CRF and MS, may reduce leptin concentration with potential benefits on academic performance. Health and education professionals could benefit from collaborating to achieve both enhanced health status and academic performance. Our findings extend prior knowledge about the positive influence of PF on cognition by suggesting a novel physiological mechanism. Further research is needed to clarify the pathway by which leptin is closely linked to PF and cognition.

Author's contribution MAR was involved in the data collection and analysis, and drafting of the initial manuscript. MRBV was involved in the data collection and critical revision of the manuscript. DJP, JGPG, and OCB were involved in the critical revision of the manuscript. DMU was involved in the study design and data collection, manuscript preparation, and critical revision. All authors have read and approved the final manuscript.

Funding The DADOS Study is funded by the Spanish Ministry of Economy and Competitiveness, MINECO (DEP2013-45515-R) and by the Jaume I University of Castellon, UJI (P1-1A2015-05). This work is partly supported by a Sunny Sport research grant from the Schweppes Suntory Spain Company. DJP was supported by a grant from the Spanish Ministry of Science and Innovation-MINECO (RYC-2014-16938). M.A.R is supported by a Predoctoral Research Grant from UJI (PREDOC/2015/13). 


\section{Compliance with ethical statements}

Conflict of interest The authors declare that they have no conflict of interest.

Informed consent Adolescents and their parents or guardians were informed of the nature and characteristics of the study, and all signed an informed written consent. The DADOS study protocol was designed in accordance with the ethical guidelines of the Declaration of Helsinki 1961 (last revision of Fortaleza, Brazil, 2013) and approved by the Research Ethics Committec of the University Jaume I of Castellon (Spain).

\section{References}

1. Adkins DL, Boychuk J, Remple MS, Kleim JA (2005) Motor training induces experience-specific patterns of plasticity across motor cortex and spinal cord. J Appl Physiol 101:1776-1782. https://doi. org/10.1152/japplphysiol.00515.2006

2. Ardoy DN, Fernández-Rodríguez JM, Jiménez-Pavón D, Castillo R, Ruiz JR, Ortega FB (2014) A physical education trial improves adolescents' cognitive performance and academic achievement: the EDUFIT study. Scand J Med Sci Sports 24:e52-c61. https://doi.org/ $10.1111 / \mathrm{sms} .12093$

3. Armstrong $\mathrm{N}$ (2017) Top 10 rescarch questions related to youth acrobic fitness. Res Q Excrc Sport 88(2):130-148. https://doi.org/ $10.1080 / 02701367.2017 .1303298$

4. Artero EG, España-Romero V, Jiménez-Pavón D, Martínez-Gómez D, Warnberg J, Gómez-Martínez S, González-Gross M, Vanhelst J, Kafatos A, Molnar D, De Henauw S, Moreno LA, Marcos A, Castillo MJ (2013) Muscular fitness, fatness and inflammatory biomarkers in adolescents. 391-400. https://doi.org/10.1111/j.20476310.2013.00186.x

5. Beltran-Valls MR, Adelantado-Renau M, Castro-Piñero J, SánchezLópez M, Moliner-Urdiales D (2018) Cardiorespiratory fitness and academic performance association is mediated by weight status in adolescents: DADOS study. Eur J Pediatr 177(7):1037-1043. https://doi.org/10.1007/s00431-018-3159-1

6. Buck SM, Hillman CH, Castelli DM (2008) The relation of aerobic fitness to stroop task performance in preadolescent children. Med Sci Sports Exerc 40:166-172. https://doi.org/10.1249/mss. 0b013e318159b035

7. Chaddock L, Erickson KI, Prakash RS, Kim JS, Voss MW, VanPatter M, Pontifex MB, Raine LB, Konkel A, Hillman CH, Cohen NJ, Kramer AF (2010) A neuroimaging investigation of the association between aerobic fitness, hippocampal volume, and memory performance in preadolescent children. Brain Res 1358: 172-183. https://doi.org/10.1016/j.brainres.2010.08.049

8. Cole TJ, Bellizzi MC, Flegal KM, Dietz WH (2000) Establishing a standard definition for child overweight and obesity worldwide: international survey. BMJ 320:1240-1243

9. Correa-Burrows P, Blanco E, Reyes M, Castillo M, Peirano P, Algarín C, Lozoff B, Gahagan S, Burrows R (2016) Leptin status in adolescence is associated with academic performance in high school: a cross-sectional study in a Chilean birth cohort. BMJ Open 6:e010972. https://doi.org/10.1136/bmjopen-2015-010972

10. Currie C, Molcho M, Boyce W, Holstein B, Torsheim T, Ritcher M (2008) Researching health inequalities in adolescents : the development of the health behaviour in school-aged children (HBSC) family affluence scale. Soc Sci Med 66:1429e1436-1429e1436. https:// doi.org/10.1016/j.socscimed.2007.11.024

11. Dominguez Sanchez MA, Bustos Cruz RH, Velasco-Orjuela GP, Quintero AP, Tordecilla-Sanders A, Correa-Bautista JE, Triana Reina HR, Garcia-Hermoso A, González-Ruíz K, Peña-Guzmán
CA, Hernández E, Peña Ibagón JC, Téllez-T LA, Izquierdo M, Ramírez-Vélez R (2018) Acute effects of high intensity, resistance or interval protocol on the increase of level of neurotrophic factors in physically inactive overweight adults: the BrainFit study. Front Physiol 9:741. https://doi.org/10.3389/FPHYS.2018.00741

12. Donnelly JE, Hillman CH, Castelli DM, Etnier JL, Lee S, Tomporowski P, Lambourne K, Szabo-Reed AN (2016) Physical activity, fitness, cognitive function, and academic achievement in children: a systematic review. Med Sci Sports Exerc 48:11971222. https://doi.org/10.1249/MSS.0000000000000901.Physical

13. Esteban-Cornejo I, Tejero-González CM, Martinez-Gomez D, delCampo J, González-Galo A, Pallida-Moledo C, Sallis JF, Veiga OL (2014) Independent and combined influence of the components of physical fitness on academic performance in youth. J Pediatr 165: 306-312.e2. https://doi.org/10.1016/j.jpeds.2014.04.044

14. Farr OM, Tsoukas MA, Mantzoros CS (2015) Leptin and the brain: influences on brain development, cognitive functioning and psychiatric disorders. Metabolism 64:114-130. https://doi.org/10.1016/J. METABOL.2014.07.004

15. Fernández I, Canet $\mathrm{O}$, Giné-Garriga M (2017) Assessment of physical activity levels, fitness and perceived barriers to physical activity practice in adolescents: cross-sectional study. Eur J Pediatr 176(1): 57-65. https://doi.org/10.1007/s00431-016-2809-4

16. Fonseca Del Pozo FJ, Valle Alonso J, Vaquero Álvarez M, Orr S, Llorente Cantarero FJ (2017) Physical fitness as an indicator of health status and its relationship to academic performance during the prepubertal period. Health Promot Perspect 7:197-204. https:// doi.org/10.15171/hpp.2017.35

17. Griffiths LJ, Parsons TJ, Hill AJ (2010) Self-esteem and quality of life in obese children and adolescents: a systematic review. Int J Pediatr Obes 5:282-304. https://doi.org/10.3109/17477160903473697

18. Gunnarsdottir T, Njardvik U, Olafsdottir AS, Craighead LW, Bjarnason R (2012) Teasing and social rejection among obese children enrolling in family-based behavioural treatment: effects on psychological adjustment and academic competencies. Int J Obes 36:35-44. https://doi.org/10.1038/ijo.2011.181

19. Haapala EA, Lintu N, Eloranta A-M, Venäläinen T, Poikkeus AM, Ahonen T, Lindi V, Lakka TA (2018) Mediating effects of motor performance, cardiorespiratory fitness, physical activity, and sedentary behaviour on the associations of adiposity and other cardiometabolic risk factors with academic achievement in children. J Sports Sci 00:1-8. https://doi.org/10.1080/02640414.2018.1449562

20. Hayes AF (2009) Beyond baron and Kenny: statistical mediation analysis in the new millennium. Commun Monogr 76:408-420. https://doi.org/10.1080/03637750903310360

21. Hillman CH, Buck SM, Themanson JR, Pontifex MB, Castelli DM (2009) Aerobic fitness and cognitive development: event-related brain potential and task performance indices of executive control in preadolescent children. Dev Psychol 45:114-129. https://doi.org/ $10.1037 / \mathrm{a} 0014437$

22. Hosick PA, McMurray RG, Cooper DM (2010) The relationships between leptin and measures of fitness and fatness are dependent upon obesity status in youth. Pediatr Exerc Sci 22:195-204. https:// doi.org/10.1123/pes.22.2.195

23. International Society for the Advancement of Kinanthropometry (2001) International Standards for Anthropometric Assessment

24. Jiménez-Pavón D, Ortega FB, Artero EG, Labayen I, VicenteRodriguez G, Huybrechts I, Moreno LA, Manios Y, Béghin L, Polito A, De Henauw S, Sjöström M, Castillo MJ, GonzálezGross M, Ruiz JR (2012) Physical activity, fitness, and serum leptin concentrations in adolescents. J Pediatr 160:598-603.e2. https:// doi.org/10.1016/j.jpeds.2011.09.058

25. Koester-Weber T, Valtueña J, Breidenassel C, Beghin L, Plada M, Moreno S, Huybrechts I, Palacios G, Gómez-Martínez S, Albers U, de Henauw S, Maiani G, Kafatos A, Molnar D, Sjöström M, Widhalm K, Manios Y, Moreno LA, Marcos A, Castillo MJ, 
Stehle P, González-Gross M (2014) Reference values for leptin, cortisol, insulin and glucose, among European adolescents and their association with adiposity: the HELENA study. Nutr Hosp 30: 1181-1190. https://doi.org/10.3305/nh.2014.30.5.7982

26. Marques A, Santos DA, Hillman CH, Sardinha LB (2017) How does academic achievement relate to cardiorespiratory fitness, self-reported physical activity and objectively reported physical activity: a systematic review in children and adolescents aged 6-18 years. Br J Sports Med:1-11. https://doi.org/10.1136/bjsports2016-097361

27. Martinez-Gomez D, Eisenmann JC, Gomez-martinez S, Veses A, Romeo J, Veiga OL, Marcos A (2012) Associations of physical activity and fitness with adipocytokines in adolescents: the AFINOS study. Nutr Metab Cardiovase Dis 22:252-259. https:// doi.org/10.1016/j.numecd.2010.07.010

28. Münzberg H, Morrison C (2015) Structure, production and signaling of leptin. Metabolism 64:13-23. https://doi.org/10.1016/j. jneumeth.2010.08.011.Autogenic

29. Noble EE, Billington CJ, Kotz CM, Wang C (2011) The lighter side of BDNF. Am J Physiol Regul Integr Comp Physiol 300:R1053R1069. https://doi.org/10.1152/ajpregu.00776.2010

30. Olivares PR, García-Rubio J (2016) Associations between different components of fitness and fatness with academic performance in Chilean youths. PeerJ 4:e2560. https://doi.org/10.7717/peeri.2560

31. Olmedillas H, Sanchis-Moysi J, Fuentes T, Guadalupe-Grau A, Ponce-González JG, Morales-Alamo D, Santana A, Dorado C, Calbet JAL, Guerra B (2010) Muscle hypertrophy and increased expression of leptin receptors in the musculus triceps brachii of the dominant arm in professional tennis players. Eur J Appl Physiol 108:749-758. https://doi.org/10.1007/s00421-009-1281-5

32. de Onis M, Onyango AW, Borghi E, Siyam A, Nishida C, Siekmann J (2007) Development of a WHO growth reference for school-aged children and adolescents. Bull World Health Organ 85: 660-667

33. Ortega FB, Ruiz JR, Castillo MJ, Sjöström M (2008) Physical fitness in childhood and adolescence: a powerful marker of health. Int J Obes 32:1-11. https://doi.org/10.1038/sj.ijo.0803774

34. Raine LB, Biggan JR, Baym CL, Saliba BJ, Cohen NJ, Hillman CH (2017) Adolescent changes in aerobic fitness are related to changes in academic achievement. Pediatr Exerc Sci 30:1-9. https://doi.org/ 10.1123/pes.2015-0225
35. Ruiz JR, Castro-Pinero J, Artero EG, Ortega FB, Sjöström M, Suni J, CastilloMJ (2009) Predictive validity of health-related fitness in youth: a systematic review. Br J Sports Med 43:909-923. https:// doi.org/10.1136/bjsm.2008.056499

36. Ruiz JR, Castro-Pinero J, Espana-Romero V, Artero EG, Ortega FB, Cuenca MM, Jimenez-Pavon D, Chillon P, Girela-Rejon MJ, Mora J, Gutierrez A, Suni J, Sjostrom M, Castillo MJ (2011) Field-based fitness assessment in young people: the ALPHA health-related fitness test battery for children and adolescents. Br J Sports Med 45:518524. https://doi.org/10.1136/bjsm.2010.075341

37. Santana CCA, Azevedo LB, Cattuzzo MT, Hill JO, Andrade LP, Prado WL (2017) Physical fitness and academic performance in youth: a systematic review. Scand J Med Sci Sport 27:579-603. https://doi.org/10.1111/sms.12773

38. Sardinha LB, Marques A, Minderico C, Palmeira A, Martins S, Santos DA, Ekelund U (2016) Longitudinal relationship between cardiorespiratory fitness and academic achievement. Med Sci Sports Exerc 48:839-844. https://doi.org/10.1249/MSS. 0000000000000830

39. Smith JJ, Eather N, Morgan PJ, Plotnikoff RC, Faigenbaum AD, Lubans DR (2014) The health benefits of muscular fitness for children and adolescents: a systematic review and meta-analysis. Sport Med 44:1209-1223. https://doi.org/10.1007/s40279-014-0196-4

40. Tanner JM, Whitehouse RH (1976) Clinical longitudinal standards for height, weight, height velocity, weight velocity, and stages of puberty. Arch Dis Child 51:170-179

41. Tomkinson GR, Carver KD, Atkinson F, Daniell ND, Lewis LK, Fitzegerald JS, Lang JJ, Ortega FB (2017) European normative values for physical fitness in children and adolescents aged 9-17 years: results from 2779165 Eurofit performances representing 30 countries. Br J Sports Med:1-13. https://doi.org/10.1136/bjsports2017-098253

42. Tsai J-P (2017) The association of serum leptin levels with metabolic diseases. Tzu Chi Med J 29:192-196. https://doi.org/10.4103/ tcmj.tcmj_123_17

43. Uysal N, Agilkaya S, Sisman AR, Camsari UM, Gencoglu C, Dayi A, Aksu I, Baykara B, Cingoz S, Kiray M (2017) Exercise increases leptin levels correlated with IGF-1 in hippocampus and prefrontal cortex of adolescent male and female rats. J Chem Neuroanat 81: 27-33. https://doi.org/10.1016/j.jchemneu.2017.02.004 
Study 7

Cardiorespiratory fitness and academic performance association is mediated by weight status in adolescents: DADOS study 


\title{
Cardiorespiratory fitness and academic performance association is mediated by weight status in adolescents: DADOS study
}

\author{
María Reyes Beltran-Valls ${ }^{1}$ - Mireia Adelantado-Renau ${ }^{1} \cdot$ Jose Castro-Piñero $^{2}$ - Mairena Sánchez-López ${ }^{3,4}$. \\ Diego Moliner-Urdiales ${ }^{1}$
}

Received: 3 January 2018 / Revised: 17 April 2018 / Accepted: 20 April 2018

(C) Springer-Verlag GmbH Germany, part of Springer Nature 2018

\section{Abstract}

The aim of our study was to examine the mediation effect of weight status on the association between cardiorespiratory fitness (CRF) and academic performance (AP). Two hundred sixty-nine adolescents (140 boys) aged $13.9 \pm 0.3$ years old from the DADOS study were included in this cross-sectional analysis. CRF was assessed by the 20 -m shuttle run test and estimated maximum oxygen uptake was used in the analysis. AP was assessed through the final academic grades and the Science Research Associates Test of Educational Abilities for assessing reasoning, verbal, and numeric abilities. Weight status was assessed by body mass index $\left(\mathrm{kg} / \mathrm{m}^{2}\right)$. Boot-strapped mediation procedures were performed and indirect effects (IE) with confidence intervals (CI) not including zero were considered statistically significant. Mediation analysis revealed that weight status acted as a mediator of the relationship of $\mathrm{CRF}$ with reasoning ability $(\mathrm{IE}=0.039 ; \mathrm{CI}=0.001 ; 0.091)$ and the final grades in $\mathrm{Math}(\mathrm{IE}=0.011 ; \mathrm{CI}=$ $0.002 ; 0.025)$, Language $(\mathrm{IE}=0.013 ; \mathrm{CI}=0.004 ; 0.027)$, and $\mathrm{GPA}(\mathrm{IE}=0.011 ; \mathrm{CI}=0.003 ; 0.023)$.

Conclusions: Our data show that the influence of CRF on academic performance is mediated by weight status in adolescents. We suggest that our data could be considered by educators, families, and policy makers, so that active lifestyles might be promoted when designing programs aimed to improve AP among adolescents.

What is Known:

- Academic performance is associated with both, cardiorespiratory fitness and weight status.

- The role of weight status in the association between cardiorespiratory fitness and academic performance is poorly understood.

What is New:

-We support the scarce research investigating the mediating role of weight status as mechanism in the association between fitness and academic performance in youth.

- Previous knowledge is expanded by suggesting that cardiorespiratory fitness is related to weight status which in turn may positively influence academic performance in adolescents.

Keywords Adolescence $\cdot$ Body mass index $\cdot$ Health $\cdot$ School-performance

Communicated by Mario Bianchetti

Diego Moliner-Urdiales

dmoliner@uji.es

María Reyes Beltran-Valls

reyes.bel@outlook.com

Mireia Adelantado-Renau

adelantm@uji.es

Jose Castro-Piñero

jose.castro@uca.es

Mairena Sánchez-López

mairena.sanchez@uclm.es
1 LIFE Research Group, Faculty of Humanities and Social Sciences, Department of Education, University Jaume I, Av. Vicent Sos Baynat, 12071 Castellon, Spain

2 Cadiz University, Av. República Saharaui, s/n, 11519 Puerto Real, Spain

3 Faculty of Education, Universidad de Castilla La Mancha, Ronda de Calatrava, s/n, 13071 Ciudad Real, Spain

4 Social and Health Research Centre, Universidad de Castilla-La Mancha, St. Santa Teresa Jornet, s/n, 16071 Cuenca, Spain 


$\begin{array}{ll}\text { Abbreviations } \\ \text { AP } & \text { Academic performance } \\ \text { BMI } & \text { Body mass index } \\ \text { CRF } & \text { Cardiorespiratory fitness } \\ \text { GPA } & \text { Grade point average } \\ \text { SD } & \text { Standard deviation } \\ \text { SDS } & \text { Standard deviation scores } \\ \text { SES } & \text { Socioeconomic status } \\ \mathrm{VO}_{2} \text { max } & \text { Maximum oxygen uptake }\end{array}$

\section{Introduction}

Adolescence is a period of life characterized by important changes in the body and brain which shape cognition and physical capacities [25]. A growing body of literature suggests that achieving optimal levels of health-related markers during adolescence, such as physical fitness and weight status, may be crucial for cognition and physical health across the lifespan [12].

Cardiorespiratory fitness (CRF) is one of the most studied physical fitness indicators. Besides its well-known health-related positive association with weight control [22] and cardiometabolic disease risk factors in adolescents [24], increasing evidences support that CRF is also positively associated to brain structures integrity and brain vascularization [11, 12], as well as better cognitive skills [13], which may result in improved academic performance (AP).

AP refers to the student's attainment of educational goals in school and is usually assessed through the final grades or standardized reading and arithmetic skills tests [5]. AP in adolescents has been positively associated with CRF [27, 29] and inversely associated with weight status $[9,18,28]$. The association with weight status is potentially related to the physiological consequences derived from energy and metabolic unbalance [20], as well as to the cognitive detriments linked to unhealthy weight status [13]. Active lifestyles might play a key role for weight control, fitness enhancement, and consequently, cognition and AP improvements [12].

Despite the fact that previous studies intended to investigate the combined or independent association of fitness, weight status, and AP in adolescents, only Kantomaa et al. [14] have performed mediation analyses using weight status as a mediator variable in this association. This study revealed that obesity mediated the association between motor ability fitness capacity and academic grades in adolescents. Despite motor ability and cardiorespiratory fitness capacities seem both to be positively associated with AP $[14,27]$, the mediating role of weight status in the association between CRF and AP has been poorly investigated. Although Kantomaa et al. [14] performed their prospective study in a large cohort, our study includes an objective measure of weight status and takes into account several confounders such as age, pubertal status, sex, socioeconomic status (SES), and psychological wellbeing [5].

Given the high prevalence of overweight in children and adolescents worldwide [1], and the growing body of research showing a positive association between CRF and AP [27], further comprehending of the relationship of these key factors and its potential impact on AP is needed. Based on the previous knowledge, we hypothesized that CRF positive association with AP could be mediated by weight status. Thus, the aim of our study was to examine whether weight status exerts a mediation effect on the association between CRF and AP in adolescents.

\section{Materials and methods}

\section{Study design and participants}

The present study is part of the DADOS (Deporte, ADOlescencia y Salud) research project, a 3-year longitudinal study (from 2015 to 2017) aimed to analyze the influence of competitive physical activity on health, academic performance, and psychological well-being through adolescence. All participants were volunteers recruited from secondary schools and sport clubs of Castellon (Spain) and met the general DADOS inclusion criteria: born in 2001, enrolled in 2nd grade of secondary school, and free of any chronic disease. The results presented in this cross-sectional analysis belong to baseline data obtained between February and May of 2015. A total of 269 adolescents ( 140 boys) aged $13.9 \pm 0.3$ years with valid data for CRF, body mass index (BMI), final grades, and pubertal and socioeconomic status were included in the analysis. Adolescents and their parents or guardians were informed of the nature and characteristics of the study, and all provided a written informed consent.

\section{Anthropometric measurements}

Measures were assessed in duplicate by trained researchers and average measures were used for the analyses. Body weight was measured to the nearest $0.1 \mathrm{~kg}$ using an electronic scale (SECA 861, Hamburg, Germany). Height was measured to the nearest $0.1 \mathrm{~cm}$ using a wall-mounted stadiometer (SECA 213, Hamburg, Germany). BMI was calculated as weight/height squared $\left(\mathrm{kg} / \mathrm{m}^{2}\right)$. The BMI values were transformed into standard deviation scores (SDS) according to WHO reference population for sex and age [21], and they were used as weight status.

\section{Cardiorespiratory fitness}

CRF was assessed using the 20-m shuttle run test as described by Léger [17]. Each participant runs straight between 2 lines 
$20 \mathrm{~m}$ apart at a pace established by recorded audio signals. The initial speed was $8.5 \mathrm{~km} / \mathrm{h}$ and it was increased $0.5 \mathrm{~km} / \mathrm{h}$ each minute. The test was completed when participants could not reach the end lines at the pace of the audio signals for 2 consecutive times or when they stopped because of fatigue. The maximum oxygen uptake was estimated. The last stage number completed was used to predict maximal oxygen uptake $(\mathrm{VO} 2 \mathrm{max}, \mathrm{ml} / \mathrm{kg} / \mathrm{min}$ ) using the following equation reported by Léger [17]: VO2 $\max =31.025+(3.238 \times(8+$ $0.5 \times$ last stage number completed $)-(3.248 \times$ age $)+$ $(0.1536 \times(8+0.5 \times$ last stage number completed $) \times$ age $)$.

\section{Academic performance}

AP was assessed by two components: (1) the final academic grades from the first course of secondary school provided by each school's secretary office on a ten-point scale. Individual grades for Math and Language (Spanish), and grade point average score (GPA) were included in the analyses. GPA score was defined as the single average grade for Geography and History, Natural Science, Math, Spanish, Catalan, English, and Physical Education. (2) The Spanish version of the Science Research Associates Test of Educational Abilities [31]. This test measures verbal ability (command of language), numeric ability (speed and precision in performing operations with numbers and quantitative concepts), and reasoning ability (aptitude to find logical ordination criteria in sets of numbers, figures, or letters). Direct scores were obtained for each of these specific abilities, and an overall ability (range, $0-110$ ) was calculated by summing the 3 direct scores. This battery test provides three complexity levels based on the age range of the sample. The present work used the level 3 designed for adolescents aged 14 to 18 years (reliability: verbal $\alpha=0.74$, numeric $\alpha=0.87$, reasoning $\alpha=0.77$, and overall ability $\alpha=0.89$ ) [31].

\section{Covariates}

The statistical analyses were controlled for sex, age, pubertal status, SES, and psychological well-being. These are relevant cofounders given the association of SES and psychological well-being with AP, fitness, and weight status in adolescents $[3,8]$. Since adolescence is a period of developmental changes at a different pace, age, pubertal status, and sex were also considered as covariates [23].

Pubertal status was self-reported according to the 5 stages defined by Tanner and Whitehouse [30]. It is based on external primary and secondary sex characteristics, which are described by the participants using standard pictures according to Tanner instructions. SES was self-reported by the parents using the Family Affluence Scale developed by Currie et al. [4] based on material conditions in the family such as car ownership, bedroom occupancy, computer ownership, and home internet access. Psychosocial well-being was assessed by the Spanish version of the Behavior Assessment System for Children, using the level-3 form for 14-year-old participants [26]. The psychological well-being indicators included in the present study as covariates were anxiety, interpersonal relations, self-esteem, social stress, depression, and sense of inadequacy.

\section{Statistical analysis}

Study sample characteristics are presented as mean \pm standard deviation (SD) unless otherwise stated. Differences between boys and girls were examined using independent $t$ test. Since we did not observe a significant interaction effect for sex (e.g., sex $\times$ main effect variables) (all $P>0.05$ ), all analyses were performed together for boys and girls. Partial correlations were performed to confirm the relationships between weight status, CRF, and AP variables, controlling for age, pubertal status, SES, sex, and psychological well-being. Boot-strapped mediation procedures were performed to examine whether the association between CRF and AP variables was mediated by weight status, controlling for age, pubertal status, SES, sex, and psychological well-being. The PROCESS SPSS Macro version 2.16.3, model four, with 5.000 bias-corrected bootstrap samples and 95\% confidence intervals (CIs) was used for these analyses [10]. Mediation was assessed by the indirect effect of the CRF (independent variable) on AP (variables individually entered as the dependent variable) through weight status (mediator). The total (c path), direct ( $\mathrm{c}^{\prime}$ path), and indirect effect ( $\mathrm{a} * \mathrm{~b}$ paths) are presented (Fig. 1). Indirect effects $(a b)$ with CIs not including zero were interpreted as statistically significant, which can be so regardless of the significance of the total effect (the effect of CRF on AP) and the direct effect (the effect on AP when both CRF and BMI SDS are included as predictors) [10]. Percentage of mediation (PM) was calculated as (indirect effect/total effect) $\times 100$ to know how much of the total effect was explained by the mediation when the following assumptions where achieved: the total effect is larger than the indirect effect and with the same direction of the effect [10]. These analyses were adjusted by age, pubertal status, SES, sex, and psychological well-being. All the analyses were performed using the IBM SPSS Statistics for Windows version 22.0 (Armonk, NY: IBM Corp), and the level of significance was set at $P<0.05$.

\section{Results}

According to descriptive data of the study population (Table 1), boys and girls were only significantly different in height, CRF, numeric ability, and pubertal status distribution $(P<0.001)$. 

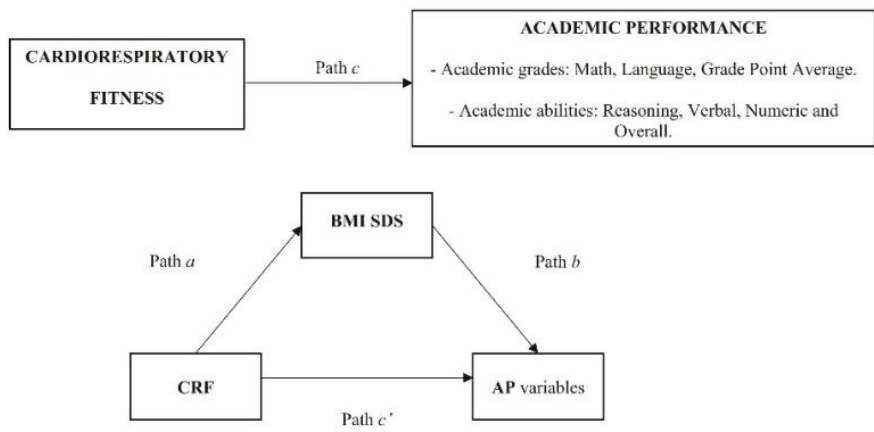

Fig. 1 Simple mediation model of cardiorespiratory fitness (independent variable) on academic performance variables (dependent variable) through weight status measured by body mass index standard deviations' scores (BMI SDS) (mediator variable). Path $a$, association

Partial correlations between CRF, weight status, and AP outcomes, accounting for age, pubertal status, SES, sex, and psychological well-being, are presented in Table 2. Overall, weight status was negatively correlated with AP whereas CRF was positively correlated to AP $(P<0.05)$. All the academic grades were positively correlated to all the academic abilities (all $P<0.001$ ).

Simple mediation analyses' results are presented in Table 3, which shows that CRF indirectly influenced some AP variables through its association with weight status, between independent and mediator variables; Path $b$, association between mediator and dependent variables; Path $c$, overall association between independent and dependent variables; Path $c^{\prime}$, unmediated direct effect of independent variable on dependent variable

controlling for age, pubertal status, SES, sex, and psychological well-being. There was a significant indirect relationship (path $a^{*} b$ ) between CRF and all final grades as well as reasoning ability when weight status was included in the mediation analyses, indicating that weight status mediated the relationship between CRF and these AP variables. The total effect of CRF on AP explained by BMI SDS was $34 \%$ in Math, $63 \%$ in Language, and $40 \%$ in GPA. CRF was negatively associated with weight status (path $a$ ) and weight status was negatively associated with final grades (path $b$ ). A significant total
Table 1 Descriptive data by gender

\begin{tabular}{llllc}
\hline Variable & All $(n=269)$ & Boys $(n=140)$ & Girls $(n=129)$ & $P$ value \\
\hline Age $($ years $)$ & $13.9 \pm 0.3$ & $13.9 \pm 0.3$ & $13.9 \pm 0.3$ & 0.39 \\
Weight $(\mathrm{kg})$ & $54.1 \pm 9.2$ & $54.5 \pm 9.6$ & $53.7 \pm 8.8$ & 0.50 \\
Height $(\mathrm{cm})$ & $163.0 \pm 7.9$ & $164.6 \pm 8.6$ & $131.2 \pm 6.7$ & $<0.001$ \\
BMI $\left(\mathrm{kg} / \mathrm{m}^{2}\right)$ & $20.3 \pm 2.1$ & $20.0 \pm 2.5$ & $20.6 \pm 2.9$ & 0.05 \\
BMI SDS & $0.29 \pm 0.89$ & $0.27 \pm 0.89$ & $0.30 \pm 0.90$ & 0.83 \\
Tanner $(\mathrm{I}-\mathrm{V})^{\mathrm{a}}$ & $0 / 21 / 91 / 130 / 25$ & $0 / 14 / 44 / 61 / 19$ & $0 / 7 / 47 / 69 / 6$ & \\
$\mathrm{VO}_{2}$ max. $(\mathrm{ml} / \mathrm{kg} / \mathrm{min})$ & $50.4 \pm 6.7$ & $54.1 \pm 5.3$ & $46.4 \pm 5.8$ & $<0.001$ \\
Academic abilities & & & & 0.23 \\
Reasoning & $16.6 \pm 5.8$ & $16.1 \pm 5.6$ & $16.9 \pm 6.0$ & $<0.001$ \\
Numeric & $13.3 \pm 4.7$ & $14.7 \pm 4.5$ & $11.9 \pm 4.5$ & 0.19 \\
Verbal & $18.5 \pm 5.3$ & $19.0 \pm 5.8$ & $18.2 \pm 4.6$ & 0.07 \\
Overall & $48.4 \pm 12.6$ & $49.8 \pm 12.8$ & $47.0 \pm 12.2$ & 1.17 \\
Academic grades & & & & 0.09 \\
Math & $6.8 \pm 1.8$ & $7.0 \pm 1.6$ & $6.7 \pm 1.6$ & 0.48 \\
Language & $6.9 \pm 1.5$ & $6.7 \pm 7.5$ & $7.1 \pm 1.5$ & $7.2 \pm 1.3$ \\
GPA & $7.1 \pm 1.3$ & $7.1 \pm 1.3$ & & \\
\hline
\end{tabular}

Data are presented as mean \pm SD. Differences between boys and girls were examined by independent $t$ test. Data presented as frequency, differences between boys and girls analyzed by chi-square test

BMI body mass index, SDS standard deviations scores using the WHO 2007 reference values [21], GPA grade point average

${ }^{\mathrm{a}}$ Values in italic font indicate significant results: $P<0.05$ 
Table 2 Partial correlation among academic performance variables, weight status, and cardiorespiratory fitness controlling for sex, pubertal status, socioeconomic status, and psychological well-being $(n=269)$

\begin{tabular}{|c|c|c|c|c|c|c|c|c|}
\hline & $\mathrm{CRF}$ & Math & Language & GPA & Reasoning & Numeric & Verbal & Overall \\
\hline BMI SDS & $-0.30^{* * * *}$ & $-0.17 * *$ & $-0.19 * *$ & $-0.20 * *$ & 0.12 & $-0.14^{*}$ & -0.08 & $-0.14^{*}$ \\
\hline CRF & - & $0.13 *$ & 0.09 & $0.14^{*}$ & 0.25 & $0.14 *$ & 0.10 & 0.11 \\
\hline Math & & - & $0.74^{* * * *}$ & $0.85^{* * *}$ & $0.38^{* * * *}$ & $0.46^{* * * *}$ & $0.30^{* * *}$ & $0.47^{* * * *}$ \\
\hline Language & & & - & $0.87^{* * * *}$ & $0.37^{\text {**** }}$ & $0.36^{* * * * *}$ & 0.34 *水水 & $0.45^{* * * *}$ \\
\hline GPA & & & & - & $0.39^{* * * *}$ & $0.43^{* * * *}$ & $0.33^{* * *}$ & $0.48 * * *$ \\
\hline Reasoning & & & & & - & $0.56^{* * * *}$ & $0.36^{* * * *}$ & $0.83^{* * * *}$ \\
\hline Numeric & & & & & & & $0.4 I^{* * * *}$ & $0.80^{* * * *}$ \\
\hline Verbal & & & & & & & - & $0.75 * * *$ \\
\hline
\end{tabular}

Data are presented in the correlation coefficient $R$. Values in italic font indicate significant results: $* P<0.05, * * P<0.01, * * * P<0.001$. Reasoning, verbal, numeric and overall refers to the test of academic abilities. Overall: Sum of academic abilities

$B M I S D S$ body mass index standard deviations scores used as measure of weight status, $C R F$ cardiorespiratory fitness evaluated by estimated $\mathrm{VO}_{2}$ max, GPA grade point average score

effect (path $c$ ) was observed for CRF and Math, GPA, and numeric ability. The direct effect (path $c^{\prime}$ ) of CRF on AP variables was not significant.

\section{Discussion}

Previous studies have investigated the combined or independent relationship of AP with CRF and weight status in adolescents $[13,28,29]$. However, to our knowledge, only one previous study has examined in adolescents the role of weight status in the relationship between CRF and AP using mediation statistical analyses. Our results suggest that, after controlling for potential confounders, weight status mediated the association between CRF and final academic grades as well as reasoning ability in healthy adolescents (PM ranging from 34 to $63 \%$ ). These data strengthen the positive association between CRF and AP and add new knowledge about the potential underlying mechanisms through weight status.

The findings of the present study suggest that CRF is inversely associated with weight status, which may contribute to better final academic grades and better reasoning ability. These findings are consistent with previous studies showing that improvements in CRF are associated with BMI reductions [22] along with better AP [9, 29]. Our results agree with the only previous study using weight status as mediator between

Table 3 Total, direct, and indirect effects, $a$ and $b$ pathways, of the simple mediation analyses investigating weight status as a mediator between cardiorespiratory fitness and academic performance outcome variables $(n=269)$

\begin{tabular}{|c|c|c|c|c|c|c|c|c|}
\hline \multirow[t]{2}{*}{ Outcome } & \multirow[t]{2}{*}{ Total effect $(c)$} & \multirow[t]{2}{*}{ Direct effect $\left(c^{\prime}\right)$} & \multirow[t]{2}{*}{ Path $a$} & \multirow[t]{2}{*}{ Path $b$} & \multirow[t]{2}{*}{ Indirect effect $(a b)$} & \multicolumn{2}{|c|}{$\mathrm{BC} 95 \% \mathrm{CI}$} & \multirow[t]{2}{*}{$\mathrm{P}_{\mathrm{M}(\%}$} \\
\hline & & & & & & Lower & Upper & \\
\hline \multicolumn{9}{|c|}{ Academic grades } \\
\hline Math & $0.034(0.017)^{*}$ & $0.022(0.018)$ & $-0.047(0.009)^{* * *}$ & $-0.247(0.114)^{*}$ & $0.011(0.006)$ & 0.002 & 0.025 & 34 \\
\hline Language & $0.021(0.016)$ & $0.001(0.018)$ & $-0.047(0.009)^{* * *}$ & $-0.281(0.106)^{* *}$ & $0.013(0.006)$ & 0.004 & 0.027 & 63 \\
\hline GPA & $0.028(0.014)^{*}$ & $0.017(0.014)$ & $-0.047(0.009)^{* * *}$ & $-0.245(0.090)^{* *}$ & $0.011(0.005)$ & 0.003 & 0.023 & 40 \\
\hline \multicolumn{9}{|c|}{ Academic abilities } \\
\hline Reasoning & $0.021(0.068)$ & $-0.017(0.071)$ & $-0.047(0.009)^{* * * *}$ & $-0.829(0.452)$ & $0.039(0.022)$ & 0.001 & 0.091 & N/A \\
\hline Verbal & $0.095(0.061)$ & $0.080(0.064)$ & $-0.047(0.009)^{* * * *}$ & $-0.334(0.411)$ & $0.016(0.021)$ & -0.024 & 0.059 & \\
\hline Numeric & $0.113(0.051)^{*}$ & $0.087(0.054)$ & $-0.047(0.009)^{* * *}$ & $-0.548(0.344)$ & $0.026(0.017)$ & -0.005 & 0.064 & \\
\hline Overall & $0.230(0.143)$ & $0.150(0.149)$ & $-0.047(0.009)^{* * * *}$ & $-1.712(0.953)$ & $0.080(0.047)$ & -0.001 & 0.192 & \\
\hline
\end{tabular}

Results showed as unstandardized coefficients (standard error, SE) and BC $95 \%$ CI based on 5000 bootstrap. All analyses were adjusted for sex, pubertal status, socioeconomic status, and psychological wellbeing. Indirect effects in italics indicate that 0 is not in the $95 \% \mathrm{CI}$ of the indirect effect, thus reflecting significant indirect effect

$C R F$ cardiorespiratory fitness, $A P$ academic performance, $B C$ bias corrected, $C I$ confidence interval, $P_{M}$ percentage of mediation, $G P A$ grade point average score, $N / A$ non-applicable according to statistical assumptions specified previously

$* P<0.05 ; * * P<0.05 ; * * * P<0.001$ 
physical fitness (measured as motor ability) and AP [14], which showed that obesity is an important factor driving the association of physical fitness with AP.

The divergent mediation results obtained for the final academic grades and some of the academic abilities for which weight status did not mediate the relationship could be due to the fact that they rely on different forms of assessment. The academic abilities' test is a standardized test that evaluates specific abilities in a single time-point trial while final grades are the result of the student progression for each subject evaluated by different teachers and tasks [2].

In our opinion, the mediating role of weight status in the association between CRF and AP might partially be explained by both psychosocial and physiological mechanisms. On the one hand, research in obese adolescents has shown that they are perceived by teachers to be less socially, physically, and cognitively skillful, so this biased perception towards obesity could also impact on AP [15]. Previous data have shown that weight status influences school experience of students by increasing teasing and psychological maladjustment, which could also worsen their AP [8]. Thus, we speculate that fitness improvements could positively influence weight-related psychological factors, which may also shape adolescents AP. The psychological mechanisms proposed might not be reflected in our results from the specific academic abilities tests. On the other hand, we suggest that CRF metabolic adaptations related to weight control could influence cognitive functioning, and thus AP. This idea might be related to the fact that the adipose tissue drives biological processes involved in the regulation of obesity-related indicators such as adipokines, inflammatory cytokines, and gut hormones which have been associated with learning, memory, and general cognitive function in youth [20].

Although the mediation analysis used is a robust measure of statistical analyses [10], the cross-sectional design of the study limits our ability to make assumptions about the causal nature of the relationship analyzed [19]. Thus, since mediation may occur over time, our results should be taken with caution since we did not control for previous values of the variables [19]. This study has been carried out in a group of adolescents from south Europe, which have shown particular cognitive and physical capacities [6]; thus, different results could be obtained from different populations. Nevertheless, the study has some strengths including the use of objective and standardized measures of AP and a relatively large and homogeneous sample in terms of age. In addition, following the recommendations of a recent review [5], the statistical analyses were controlled for age, pubertal status, SES, sex, and psychological well-being.

In conclusion, this study suggests that weight status mediates the association between CRF and AP in healthy adolescents. Thus, if confirmed prospectively, our data point out that improvements in $\mathrm{CRF}$ during adolescence may contribute to better AP partially via improvements in weight status. Our findings may have significant implications from an educational and public health point of view given the high prevalence of overweight in children and adolescents [1]. Academic outcomes are of high importance to adolescents, families, and society due to its relationship with future personal events such as employability [7] and health [16]. Despite the crosssectional nature of our findings limits our ability to establish definite conclusion, we consider that our data could be of interest to educators, families, and policy makers, so that active lifestyles might be promoted when designing programs aimed to improve AP among adolescents.

Authors' contributions Maria Reyes Beltran-Valls was involved in the data collection and analysis, and drafting of the initial manuscript. Mircia Adelantado-Renau was involved in the data collection and critical revision of the manuscript. Jose Castro-Piñero and Mairena SánchezLópez were involved in the critical revision of the manuscript. Diego Moliner-Urdiales was involved in the study design and data collection, manuscript preparation, and critical revision. All authors have read and approved the final manuscript.

Funding DADOS Study is funded by the Spanish Ministry of Economy and Competitiveness, MINECO (DEP2013-45515-R) and by the Jaume I University of Castellon, UJI (P1·1A2015-05). This work is partly supported by a Sunny Sport research grant from the Schweppes Suntory Spain Company. M.A.R is supported by a Predoctoral Research Grant from UJI (PREDOC/2015/13).

\section{Compliance with ethical standards}

Conflict of interest The authors declare that they have no conflict of interest.

Informed consent Informed consent was obtained from all individual participants included in the study.

Ethical approval The DADOS study protocol was designed in accordance with the ethical guidelines of the Declaration of Helsinki 1961 (last revision of Fortaleza, Brazil, 2013) and was approved by the Research Ethics Committee of the University Jaume I of Castellon.

\section{References}

1. Abarca-Gómez L, NCD Risk Factor Collaboration (NCD-RisC). Worldwide trends in body-mass index, underweight, overweight, and obesity from 1975 to 2016 : a pooled analysis of 2416 population-based measurement studies in 128.9 million children, adolescents, and adults. Lancet 2017;390(10113):2627-2642. doi: https://doi.org/10.1016/S0140-6736(17)32129-3.

2. Baker JA (2006) Contributions of teacher-child relationships to positive school adjustment during elementary school. J Sch Psychol 44(3):211-229. https://doi.org/10.1016/J.JSP.2006.02.002

3. Coe DP, Peterson T, Blair C, Schutten MC, Peddie H (2013) Physical fitness, academic achievement, and socioeconomic status in school-aged youth. J Sch Health. 83(7):500-507. https://doi.org/ $10.1111 /$ josh. 12058

4. Currie C, Molcho M, Boyce W, Holstein B, Torsheim T, Richter M (2008) Researching health inequalities in adolescents: the 
development of the Health Behaviour in School-Aged Children (HBSC) Family Affluence Scale. Soc Sci Med 66(6):1429-1436. https://doi.org/10.1016/j.socscimed.2007.11.024

5. Donnelly JE, Hillman $\mathrm{CH}$, Castelli D, Etnier JL, Lee S, Tomporowski P, Lambourne K, Szabo-Reed AN (2016) Physical activity, fitness, cognitive function, and academic achievement in children: a systematic review. Med Sci Sports Exerc 48(6):11971222. https://doi.org/10.1249/MSS.0000000000000901

6. Esteban-Cornejo I, Cadenas-Sanchez C, Vanhelst J, Michels N, Lambrinou CP, González-Gross M, Widhalm K, Kersting M, de la O Puerta A, Kafatos A, Moreno LA, Ortega FB. Attention capacity in European adolescents: role of different health-related factors. The HELENA study. Eur J Pediatr 2017;176(10):1433-1437. doi:https://doi.org/10.1007/s00431-017-3000-2.

7. French MT, Homer JF, Popovici I, Robins PK (2015) What you do in high school matters: high school GPA, educational attainment, and labor market earnings as a young adult. East Econ J 41(3):370 386. https://doi.org/10.1057/ecj.2014.22

8. Gunnarsdottir T, Njardvik U, Olafsdottir AS, Craighead LW, Bjarnason R (2012) Teasing and social rejection among obese children enrolling in family-based behavioural treatment: effects on psychological adjustment and academic competencies. Int J Obes 36(1):35-44. https://doi.org/10.1038/ijo.2011.181

9. Haapala EA, Lintu N, Eloranta A-M, Venäläinen T, Poikkeus AM, Ahonen T, Lindi V, Lakka TA (2018) Mediating effects of motor performance, cardiorespiratory fitness, physical activity, and sedentary behaviour on the associations of adiposity and other cardiometabolic risk factors with academic achievement in children. J Sports Sci 9:1-8. https://doi.org/10.1080/02640414.2018.1449562

10. Hayes AF (2013) Introduction to mediation, moderation, and conditional process analysis: a regression-based approach. The Guilford Press, New York

11. Herting MM, Nagel BJ (2012) Aerobic fitness relates to learning on a virtual Morris Water Task and hippocampal volume in adolescents. Behav Brain Res 233(2):517-525. https://doi.org/10.1016/j. bbr.2012.05.012

12. Hillman CH, Khan NA, Kao SC (2015) The relationship of health behaviors to childhood cognition and brain health. Proc Ann Nutr Metab 66(3):1-4. https://doi.org/10.1159/000381237.

13. Huang T, Tarp J, Domazet SL, Thorsen AK, Karsten F, Andersen LB, Bugge A (2015) Associations of adiposity and aerobic fitness with executive function and math performance in Danish adolescents. J Pediatr 167(4):810-815. https://doi.org/10.1016/j.jpeds. 2015.07.009

14. Kantomaa MT, Stamatakis E, Kankaanpää A, Kaakinen M, Rodriguez A, Taanila A, Ahonen T, Järvelin MR, Tammelin T (2013) Physical activity and obesity mediate the association between childhood motor function and adolescents' academic achievement. Proc Natl Acad Sci U S A 110(5):1917-1922. https://doi.org/10.1073/pnas. 1214574110

15. Kenney EL, Redman MT, Criss S, Sonneville KR, Austin SB (2017) Are K-12 school environments harming students with obesity? A qualitative study of classroom teachers. Eat Weight Disord 22(1):141-152. https://doi.org/10.1007/s40519-016-0268-6

16. Lê-Scherban F, Diez Roux AV, Li Y, Morgenstern H (2014) Does academic achievement during childhood and adolescence benefit later health? Ann Epidemiol 24(5):344-355. https://doi.org/10. 1016/j.annepidem.2014.02.008

17. Léger LA, Mercier D, Gadoury C, Lambert J (1988) The multistage 20 metre shuttle run test for aerobic fitness. J Sports Sci 6(2):93101. https://doi.org/10.1080/02640418808729800

18. Martin A, Booth JN, McGeown S, Niven A, Sproule J, Saunders DH, Reilly JJ (2017) Longitudinal associations between childhood obesity and academic achievement: systematic review with focus group data. Curr Obes Rep 6(3):297-313. https://doi.org/10.1007/ s13679-017-0272-9

19. Maxwell SE, Cole DA, Mitchell MA (2011) Bias in cross-sectional analyses of longitudinal mediation: partial and complete mediation under an autoregressive model. Multivariate Behav Res 46(5):816841. https://doi.org/10.1080/00273171.2011.606716

20. Miller AL, Lee HJ, Lumeng JC (2015) Obesity-associated biomarkers and executive function in children. Pediatr Res 77(1-2): 143-147. https://doi.org/10.1038/pr.2014.158.

21. de Onis M, Onyango AW, Borghi E, Siyam A, Nishida C, Sickmann J (2007) Development of a WHO growth reference for school-aged children and adolescents. Bull World Health Organ 85(9):660-667

22. Ortega FB, Labayen I, Ruiz JR, Kurvinen E, Loit HM, Harro J, Veidebaum T, Sjöström M (2011) Improvements in fitness reduce the risk of becoming overweight across puberty. Med Sci Sports Exerc 43(10):1891-1897. https://doi.org/10.1249/MSS. 0b013e3182190d71

23. Ortega FB, Ruiz JR, Castillo MJ, Moreno LA, Urzanqui A, González-Gross M, Sjöström M, Gutiérrez A, Group AVENA Study (2008) Health-related physical fitness according to chronological and biological age in adolescents. The AVENA study. J Sports Med Phys Fitness 48(3):371-379

24. Ortega FB, Ruiz JR, Castillo MJ, Sjöström M (2008) Physical fitness in childhood and adolescence: a powerful marker of health. Int J Obes 32(1):1-11. https://doi.org/10.1038/sj.ijo.0803774

25. Patton GC, Viner R (2007) Pubertal transitions in health. Lancet 369(9567):1130-1139. https://doi.org/10.1016/S0140-6736(07) 60366-3

26. Reynolds C, Kamphaus R (2004) Behavior assessment system for children, 2nd edn. American Guidance Service, Circle Pines, MN

27. Santana CCA, Azevedo LB, Cattuzzo MT, Hill JO, Andrade LP, Prado WL (2017) Physical fitness and academic performance in youth: a systematic review. Scand J Med Sci Sport 27(6):579603. https://doi.org/10.1111/sms.12773

28. Sardinha LB, Marques A, Martins S, Palmeira A, Minderico C (2014) Fitness, fatness, and academic performance in seventhgrade elementary school students. BMC Pediatr 14(1):176. https:// doi.org/10.1186/1471-2431-14-176

29. Suchert V, Hanewinkel R, Isensee B (2016) Longitudinal relationships of fitness, physical activity, and weight status with academic achievement in adolescents. J Sch Health 86(10):734-741. https:// doi.org/10.1111/josh. 12424

30. Tanner JM, Whitehouse RH (1976) Clinical longitudinal standards for height, weight, height velocity, weight velocity, and stages of puberty. Arch Dis Child 51(3): 170-179

31. Thurstone LL, Thurstone TG. TEA Test de Aptitudes Escolares (Scholar Aptitudes Test). Vol 77. 11 th ed. Madrid; 2004. 
Study 8

Independent and combined influence of healthy lifestyle factors on academic performance in adolescents: DADOS Study 


\title{
POPULATION STUDY ARTICLE \\ Independent and combined influence of healthy lifestyle factors on academic performance in adolescents: DADOS Study
}

\author{
Mireia Adelantado-Renau', David Jiménez-Pavón², Maria Reyes Beltran-Valls' and Diego Moliner-Urdiales'
}

BACKGROUND: Few studies have analyzed the combined effect of lifestyle factors on academic performance (AP) in adolescents. The aim of this study was to analyze the independent and combined effects of weight status, screen time, sleep quality, daily meal frequency, cardiorespiratory fitness, and physical activity (PA) on AP in adolescents.

METHODS: A total of 262 adolescents $(13.9 \pm 0.3$ years) from the DADOS study were included in the analysis. Weight status was assessed through body mass index $\left(\mathrm{kg} / \mathrm{m}^{2}\right)$. Participants completed questionnaires to evaluate screen time, sleep quality, and daily meal frequency. Cardiorespiratory fitness was assessed by the 20-m shuttle run test. PA was evaluated by a wrist-worn GENEActiv accelerometer. AP was assessed through the final academic grades and a validated questionnaire.

RESULTS: Non-overweight status, low screen time, good sleep quality, and proper meal frequency showed independent, positive influence on AP. Moreover, adolescents achieving at least three healthy lifestyles were more likely to be in the high-performance group for academic grades than those achieving $\leq 1$ (math OR: 3.02-9.51, language OR: 3.51-6.76, and grade point average OR: 4.22-9.36).

CONCLUSIONS: Although individual healthy lifestyles are independently and positively associated with AP, the cumulative effect of multiple healthy lifestyles have a stronger impact.

Pediatric Research_\#\#\#\#\#\#\#\#\#\#\#\#\#\#\#\#\#\#_; https://doi.org/10.1038/s41390-019-0285-z

\section{INTRODUCTION}

A healthy lifestyle during adolescence improves physical and cognitive health with potential benefits on academic performance (AP). ${ }^{1}$ AP refers to educational goals that students have to reach in a particular period of time, ${ }^{2}$ and is usually assessed through academic grades or using standardized tests of academic abilities or achievement. Although AP seems to be strongly related to cognition, it also involves non-cognitive skills such as motivation, effort, attitude, interest, family support, personality, or teaching influence. ${ }^{3}$ Successful AP during adolescence is considered a strong predictor of future health, wealth, employability, and social triumph., 4

Prior research has widely analyzed the impact of healthy lifestyle factors on AP during childhood and adolescence. ${ }^{1}$ For instance, high screen time or an overweight and obesity status have been related to several brain areas with impairments in cognition and associated with lower school performance. ${ }^{6-8}$ On the other hand, proper sleep has shown to improve brain plasticity and memory consolidation ${ }^{9}$ leading to better AP in children and adolescents. $^{10}$ Following adequate dietary patterns, such as regular five-meal-a-day or not skipping breakfast has also been related to high school performance in this age population. ${ }^{11}$ Results from recent reviews suggest that high levels of physical fitness, particularly cardiorespiratory fitness (CRF), might positively influence adolescents' AP by altering brain structure, plasticity and improving attention, memory and cognitive function. ${ }^{12}$ In accordance, scientific literature examining the relationship between physical activity (PA) and AP has stated that PA increases concentration, self-esteem, and self-discipline with improvements in academic performance indicators. ${ }^{12,13}$
Interestingly, it has been previously suggested that individual healthy lifestyles may not act in isolation in their influence on AP. ${ }^{1}$ However, to date only three studies have examined the combined effect of multiple healthy lifestyle factors on AP in children ${ }^{14,15}$ and adolescents ${ }^{16}$ showing a positive relationship. Although previous research also included a wide range of healthy lifestyle factors, it would be interesting to include objective measures of physical activity (i.e., accelerometry), valid measures of sleep, or an overall academic performance measurement. Therefore, given the paucity of knowledge and the need for valid and objective lifestyle measurements, more studies are necessary to clarify the cumulative effect of a cluster of healthy lifestyles on AP in adolescents, which would help to design more effective schoolbased programs to improve AP.

Thus, the aim of the present study was to analyze the independent and combined effect of healthy lifestyle factors (i.e., weight status, screen time, sleep quality, daily meal frequency, CRF, and PA) on AP in adolescents.

\section{METHODS}

Study design and sample selection

This study is part of the DADOS (Deporte, ADOlescencia y Salud) research project, a 3-year longitudinal study aimed to analyze the influence of PA on health, AP, and psychological wellness through adolescence. All participants were recruited from secondary schools located in Castellon (Spain) and met the general DADOS inclusion criteria: born in 2001, enrolled in second grade of secondary school and free of any chronic disease. The results

\footnotetext{
'LIFE research group, University Jaume I, Castellon, Spain and ${ }^{2}$ MOVE-IT Research Group, Department of Physical Education, Faculty of Education Sciences University of Cádiz, Cádiz, Spain
}

Correspondence: Diego Moliner-Urdiales (dmoliner@uji.es)

Received: 14 August 2018 Revised: 8 November 2018 Accepted: 30 December 2018

Published online: 17 January 2019 
Independent and combined influence of healthy lifestyle factors on... M Adelantado-Renau et al.

2

presented in this study belong to baseline data obtained between February and May of 2015. A total of 262 adolescents aged 13.9 0.3 years ( $48 \%$ girls) completed the baseline assessment with valid data for weight status, screen time, sleep quality, daily meal frequency, CRF, PA, and AP.

Adolescents and their parents or guardians were informed of the nature and characteristics of the study, and all provided a written informed consent. The DADOS study protocol was designed in accordance with the ethical guidelines of the Declaration of Helsinki 1961 (last revision of Fortaleza, Brazil, 2013) and approved by the Research Ethics Committee of the University Jaume I of Castellon (Spain)

Healthy lifestyle factors

Body weight status. Measures of weight and height were assessed in duplicate by trained members of the DADOS research group following standardized procedures. ${ }^{17}$ Body mass index (BMI) was calculated as weight/height square $\left(\mathrm{kg} / \mathrm{m}^{2}\right)$. Participants were classified into normal weight and overweight or obese, according to the international age- and sex-specific BMI cutoffs proposed by Cole et al. ${ }^{18}$

Screen time. Screen time was assessed using the HELENA (Healthy Lifestyle in Europe by Nutrition in Adolescence) sedentary questionnaire, designed ad hoc. ${ }^{19}$ For both, weekdays and weekend days, adolescents reported the number of hours spent on television, videogames, internet and mobile phone. Seven possible answers were available for each item: no time $<30 \mathrm{~min}, \geq 30$ to $<60 \mathrm{~min}, \geq 1$ to $<2 \mathrm{~h}, \geq 2$ to $<3 \mathrm{~h}, \geq 3$ to $<4 \mathrm{~h}$, and $\geq 4 \mathrm{~h}$. Total screen time for weekend and weekdays was calculated adding the mean time of each screen-based activity. The overall time was established as follows: $1 / 7 \times(2 \times$ weekend day $+5 \times$ weekday), and participants under the sex-specific 25 th percentile were categorized as low screen time.

Sleep quality. Sleep quality was assessed through the Spanish version of Pittsburgh Sleep Quality Index (PSQI) questionnaire. ${ }^{20}$ It includes 19 questions that assess 7 components of sleep quality: subjective sleep quality, sleep duration, sleep latency, habitual sleep efficiency, sleep disturbance, use of sleep medication, and daytime dysfunction. The 7 component scores are rated on a 3-point ascending scale. The global score of the PSQI (Cronbach's $a=0.81$ ) was used in the analysis as the sum of all component scores ranging from 0 to 21 . According to Buysse et al. the PSQ questionnaire provides a sensitive measure to identify good sleep quality if total PSQI score is $\leq 5$. $^{2}$

Daily meal frequency. Daily meal eating frequency was assessed through the question "Do you usually have the following meals? (1) breakfast, (2) morning snack, (3) lunch, (4) afternoon snack, and (5) dinner". Possible answers for each meal were dichotomous (yes/no), and the number of meals per day was calculated by adding affirmative answers, with a final score ranging from 0 to 5 . According to Jääskeläinen et al., ${ }^{22}$ five-meal-a-day was considered as the optimal daily meal frequency pattern.

Cardiorespiratory fitness. CRF was assessed using the 20-m Shuttle Run Test as described by Léger et al. ${ }^{23}$ The final score computed as the number of stages completed (precision of 0.5 stages) was used in the analyses. Participants with CRF $\geq$ sexspecific 75th percentile were categorized as high CRF.

Physical activity. Levels of PA were objectively measured using the GENEActiv accelerometer. This device provides a reliable (coefficient of variation intra- and inter-instrument of $1.4 \%$ and $2.1 \%$, respectively) ${ }^{24}$ and valid assessment of PA in young people $(r=0.925, p=0.001){ }^{25}$ Participants were instructed to wear the accelerometer on their non-dominant wrist for at least 6 consecutive days (including sleeping and water-based activities). At least 4 complete days including 2 weekend days were included in the analysis. Accelerometers were programmed to collect data at a sampling frequency of $100 \mathrm{~Hz}$ and stored in gravity (g) units. The raw acceleration output was aggregated in 1-s epochs using the GENEActiv postprocessing PC software (version 2.2; GENEActiv). By combining all registered days for each participant and using the Excel macro provided by the commercial brand to summarize the data, PA was expressed as average minutes per day in light, moderate, and vigorous PA. Participants with vigorous $P A \geq$ sex-specific 75th percentile were categorized as high vigorous $P A$.

Healthy lifestyle index. A healthy lifestyle index ranging from 0 to 6 was specifically defined for our sample according to the number of factors fulfilled by each adolescent: (1) optimal weight status (non-overweight or non-obese); (2) low screen time; (3) good sleep quality; (4) optimal daily meal frequency; (5) high levels of CRF, and (6) high levels of vigorous PA.

\section{Academic performance}

AP was assessed by two components: academic grades and a standardized test of academic abilities. The final academic grades from the 1st course of secondary school were provided by each school's secretary office on a ten-point scale. Individual grades for math and language, and grade point average (GPA) were used in the analyses. GPA was defined as the single average for geography and history, natural science, math, Spanish, Catalan, English, and physical education. In addition, participants completed the Spanish version of Science Research Associates Test of Educational Abilities which evaluates three basic skills: verbal ability (command of language), numeric ability (speed and precision in performing operations with numbers and quantitative concepts), and reasoning ability (aptitude to find logical ordination criteria in sets of numbers, figures, or letters). This battery test provides three complexity levels based on the age range of the sample. The present study used level three, which is designed for adolescents aged 14-18 years. This test was performed in a limited time period: $10 \mathrm{~min}$ for 2 activities of verbal ability, $11 \mathrm{~min}$ for 1 activity of numeric ability, and $6 \mathrm{~min}$ for 1 activity of reasoning ability. The alpha scores for its reliability have been reported to be 0.74 for verbal ability, 0.87 for numerical ability, and 0.77 for reasoning ability ${ }^{26}$ Participants were classified in high AP ( $\geq 50$ th of the median) and low AP ( $<50$ th of the median) for each AP indicator.

\section{Covariates}

Pubertal stage. Pubertal stage was self-reported according to the five stages defined by Tanner and Whitehouse. ${ }^{27}$ It is based on external primary and secondary sexual characteristics, which are described by the participants using standard pictures according to Tanner instructions.

Socioeconomic status. The Family Affluence Scale (FAS) developed by Currie and collaborators ${ }^{28}$ was used as a proxy of socioeconomic status (SES; ranging from 0 to 8 ), which is based on material conditions in the family such as car ownership, bedroom occupancy, computer ownership, and home internet access.

\section{Statistical analysis}

Study sample characteristics are presented as mean \pm standard deviation (SD) and percentages for continuous and categorical variables. All variables were checked for normality using both graphical (normal probability plots) and statistical (Kolmogorov-Smirnov test) procedures. As preliminary analyses did not show a significant interaction of sex with the study variables in relation to AP (all $p>0.10$ ), all analyses were performed with the total sample. 
Independent and combined influence of healthy lifestyle factors on... M Adelantado-Renau et al.

Sex differences were assessed using $t$-test for continuous variables and chi-square test for nominal variables. The independent associations between individual healthy lifestyle factors and AP using dichotomized variables were analyzed by binary logistic regression adjusting for sex, pubertal stage, and SES.

One-way analysis of covariance (ANCOVA), with a Bonferroni post hoc test, was used to investigate whether AP indicators differed depending on the number of healthy lifestyle factors achieved. The analyses were adjusted for sex, pubertal stage, and SES. Additionally, logistic regression was conducted to examine the likelihood of achieving high AP depending on the number of healthy lifestyle factors achieved, after adjustment for sex, pubertal stage, and SES. For these analyses, the following categories of achieved healthy lifestyle factors (independent variable) were used: $\leq 1,2,3,4$, and $\geq 5$. Logistic regression analyses were repeated using a dichotomous independent variable according to the number of achieved healthy lifestyle factors ( $\leq 3$ vs. $\geq 4$ ). All the analyses were performed using the IBM SPSS Statistics for Windows version 22.0 (Armonk, NY: IBM Corp), and the level of significance was set to $p<0.05$.

\section{RESULTS}

Descriptive characteristics of the study population by sex are presented at Table 1. Overall, boys were taller, showed better sleep quality ( 4.2 vs. $5.5 ; p \leq 0.001)$, higher meal frequency ( $4.6 \mathrm{vs.}$ $4.4 ; p<0.05)$, higher CRF $(9.0$ vs. $6.2 ; p<0.001)$ and were more physically active than girls according to moderate and vigorous PA (all $p \leq 0.001$ ). Boys and girls did not significantly differ in weight status and screen time $\left(20.0\right.$ vs $20.6 \mathrm{~kg} / \mathrm{m}^{2}$, and 4.7 vs. $5.0 \mathrm{~h} /$ day; all $p>0.05$ ). Regarding AP, no differences were found between boys and girls, except for numeric ability that was better in boys (14.8 vs. $12.0 ; p \leq 0.001$ ).

The independent associations of individual healthy lifestyle factors with AP are shown in Table 2. Non-overweight, low screen time ( $<25$ th percentile), good sleep quality (PSQI scores $\leq 5$ ), and optimal daily meal frequency (five-meal-a-day) were positively associated with likelihood of achieving high academic grades ( $\geq 50$ th of the median) after adjusting for sex, pubertal stage, and SES. Regarding academic abilities, non-overweight or non-obese adolescents had 3.17 times the odds of achieving high numeric ability.

Figure 1 shows the differences in AP indicators according to the healthy lifestyle index, after adjustment for sex, pubertal stage, and SES. Overall, adolescents with a healthy lifestyle index $\geq$ 4 showed higher academic grades than those with a healthy lifestyle index $\leq 2$.

The combined effect of weight status, screen time, sleep quality, daily meal frequency, CRF, and vigorous PA on AP is shown in Table 3. Logistic regression analysis showed that adolescents with a healthy lifestyle index $\geq 3$ were more likely to be in the highperformance group for academic grades. In terms of odds ratios, adolescents with a healthy lifestyle index $\geq 5$ were $9.51,6.76$, and 9.36 times more likely of achieving high academic grades in math, language and GPA, respectively. The association of healthy lifestyle index and academic abilities was only significant for reasoning with a healthy lifestyle index of $3(\mathrm{OR}=2.85 ; 95 \% \mathrm{Cl}=1.17-6.92)$, and for numeric ability with a healthy lifestyle index of $4(O R=3.05$; $95 \% \mathrm{Cl}=1.15-8.10)$. Results from logistic regression analysis using a dichotomous healthy lifestyle index $(<4$ vs. $\geq 4)$ are illustrated in Fig. 2. Similarly, adolescents with a healthy lifestyle index $\geq 4$ were more likely to show higher academic grades (OR: 2.08-2.25).

\section{DISCUSSION}

This study supports prior research by confirming the independent, positive influence of non-overweight and non-obese status, low screen time, good sleep quality and proper meal frequency on high AP in adolescents. In addition, our results show that

\begin{tabular}{|c|c|c|c|c|}
\hline & All & Boys & Girls & $p$ \\
\hline$n(\%)$ & $262(100)$ & $137(52.3)$ & $125(47.7)$ & \\
\hline \multicolumn{5}{|l|}{ Demographics } \\
\hline Age $(y)$ & $13.9 \pm 0.3$ & $13.9 \pm 0.3$ & $13.9 \pm 0.3$ & 0.956 \\
\hline $\begin{array}{l}\text { Tanner stage } \\
(I-V)(\%)\end{array}$ & $0 / 8 / 34 / 49 / 9$ & $\begin{array}{l}0 / 10 / 32 / 44 / \\
14\end{array}$ & $0 / 6 / 35 / 54 / 5$ & - \\
\hline SES score $(0-8)$ & $4.2 \pm 1.4$ & $4.0 \pm 1.3$ & $4.4 \pm 1.4$ & 0.031 \\
\hline \multicolumn{5}{|l|}{ Weight status } \\
\hline Height $(\mathrm{cm})$ & $163.1 \pm 7.9$ & $164.7 \pm 8.6$ & $161.4 \pm 6.7$ & $<0.001$ \\
\hline Weight (kg) & $54.2 \pm 9.3$ & $54.5 \pm 9.7$ & $53.9 \pm 8.8$ & 0.574 \\
\hline $\begin{array}{l}\text { Body mass index } \\
\left(\mathrm{kg} / \mathrm{m}^{2}\right)\end{array}$ & $20.3 \pm 2.7$ & $20.0 \pm 2.6$ & $20.6 \pm 2.9$ & 0.053 \\
\hline Overweight (\%) & 13.0 & 11.7 & 14.4 & 0.513 \\
\hline Screen time (h/day) & $4.8 \pm 2.5$ & $4.7 \pm 2.5$ & $5.0 \pm 2.6$ & 0.299 \\
\hline $\begin{array}{l}\text { Sleep quality score } \\
(0-21)\end{array}$ & $4.8 \pm 2.8$ & $4.2 \pm 2.7$ & $5.5 \pm 2.7$ & $<0.001$ \\
\hline $\begin{array}{l}\text { Good sleep quality } \\
(\%)\end{array}$ & 64.1 & 73.7 & 53.6 & $<0.001$ \\
\hline $\begin{array}{l}\text { Daily meal } \\
\text { frequency (meals/ } \\
\text { day) }\end{array}$ & $4.5 \pm 0.8$ & $4.6 \pm 0.8$ & $4.4 \pm 0.9$ & 0.014 \\
\hline $\begin{array}{l}\text { Optimal daily meal } \\
\text { frequency }(\%)\end{array}$ & 58.0 & 67.2 & 47.9 & 0.002 \\
\hline CRF (stages) & $7.7 \pm 2.5$ & $9.0 \pm 2.0$ & $6.2 \pm 2.2$ & $<0.001$ \\
\hline \multicolumn{5}{|l|}{$\begin{array}{l}\text { Physical activity } \\
\text { (min/day) }\end{array}$} \\
\hline Light & $174.6 \pm 56.4$ & $173.7 \pm 59.1$ & $175.6 \pm 53.4$ & 0.781 \\
\hline Moderate & $76.7 \pm 25.6$ & $81.6 \pm 24.8$ & $71.2 \pm 25.4$ & $<0.001$ \\
\hline Vigorous & $12.4 \pm 8.3$ & $15.6 \pm 7.8$ & $8.9 \pm 7.6$ & $<0.001$ \\
\hline \multicolumn{5}{|c|}{ Academic grades $(1-10)$} \\
\hline Math & $6.9 \pm 1.6$ & $7.0 \pm 1.6$ & $6.8 \pm 1.6$ & 0.316 \\
\hline Language & $6.8 \pm 1.5$ & $6.6 \pm 1.5$ & $6.9 \pm 1.5$ & 0.123 \\
\hline GPA & $7.1 \pm 1.3$ & $7.0 \pm 1.3$ & $7.2 \pm 1.3$ & 0.306 \\
\hline \multicolumn{5}{|l|}{ Academic abilities } \\
\hline Verbal (0-50) & $18.7 \pm 5.3$ & $19.1 \pm 5.8$ & $18.2 \pm 4.6$ & 0.154 \\
\hline Numeric $(0-30)$ & $13.4 \pm 4.7$ & $14.8 \pm 4.5$ & $12.0 \pm 4.5$ & $<0.001$ \\
\hline Reasoning $(0-30)$ & $16.5 \pm 5.9$ & $16.1 \pm 5.7$ & $17.0 \pm 6.1$ & 0.220 \\
\hline
\end{tabular}

Data are presented as mean $\pm S D$ or percentages. Differences between sexes were examined by $t$ test or chi-square test. Statistically significant values are in bold

SES socioeconomic status, CRF cardiorespiratory fitness, GPA grade point average

Includes obese adolescents. Good sleep quality was defined as PSQI scores $\leq 5$. Optimal daily meal frequency was defined as five-meal-a-day

academic grades are higher in adolescents with a healthy lifestyle index $\geq 4$ comparing with those achieving $\leq 2$ healthy lifestyle factors. The main finding of the present study reveals that the combined effect of a cluster of healthy lifestyle factors (healthy lifestyle index) including non-overweight or non-obese status, low screen time, good sleep quality, optimal daily meal frequency, high CRF, and high vigorous PA had a stronger impact on AP than their respective individual effects.

In the present study, healthy lifestyle factors showed independent and combined associations with academic grades, but not with academic abilities. These divergent results for academic performance indicators may be partially explained by several issues: (1) academic grades represent the student progression over a whole school year, while academic abilities are measurements from standardized tests which assess specific abilities in a 
Independent and combined influence of healthy lifestyle factors on...

M Adelantado-Renau et al.

Table 2. Logistic regression analyses examining independent influence of healthy lifestyle factors on academic performance in adolescents $(n=262)$

\begin{tabular}{|c|c|c|c|c|c|c|c|}
\hline & & $\begin{array}{l}\text { Academic } \\
\text { grades }\end{array}$ & & & $\begin{array}{l}\text { Academic } \\
\text { abilities }\end{array}$ & & \\
\hline & & Math & Language & GPA & Verbal & Numeric & Reasoning \\
\hline \multirow[t]{2}{*}{ Weight status } & Overweight $^{\mathrm{a}}$ & 1 (ref.) & 1 (ref.) & 1 (ref.) & 1 (ref.) & 1 (ref.) & 1 (ref.) \\
\hline & Non-overweight & $\begin{array}{l}3.09 \\
(1.40-6.80)\end{array}$ & $\begin{array}{l}2.77 \\
(1.27-6.05)\end{array}$ & $\begin{array}{l}2.45 \\
(1.14-5.30)\end{array}$ & $1.92(0.91-4.02)$ & $\begin{array}{l}3.17 \\
(1.44-6.97)\end{array}$ & $\begin{array}{l}1.70 \\
(0.80-3.58)\end{array}$ \\
\hline \multirow[t]{2}{*}{ Screen time } & High & 1 (ref.) & 1 (ref.) & 1 (ref.) & 1 (ref.) & 1 (ref.) & 1 (ref.) \\
\hline & Low & $\begin{array}{l}2.14 \\
(1.18-3.86)\end{array}$ & $\begin{array}{l}1.98 \\
(1.11-3.54)\end{array}$ & $\begin{array}{l}1.88 \\
(1.05-3.36)\end{array}$ & $1.18(0.67-2.09)$ & $1.64(0.90-2.99)$ & $\begin{array}{l}1.71 \\
(0.96-3.06)\end{array}$ \\
\hline \multirow[t]{2}{*}{ Sleep quality } & Poor & 1 (ref.) & 1 (ref.) & 1 (ref.) & 1 (ref.) & 1 (ref.) & 1 (ref.) \\
\hline & Good & $\begin{array}{l}1.80 \\
(1.06-3.07)\end{array}$ & $\begin{array}{l}1.88 \\
(1.11-3.20)\end{array}$ & $\begin{array}{l}1.83 \\
(1.02-1.47)\end{array}$ & $0.90(0.53-1.52)$ & $1.35(0.79-2.30)$ & $\begin{array}{l}0.96 \\
(0.57-1.62)\end{array}$ \\
\hline \multirow[t]{2}{*}{ Daily meal frequency } & Poor & 1 (ref.) & 1 (ref.) & 1 (ref.) & 1 (ref.) & 1 (ref.) & 1 (ref.) \\
\hline & Optimal & $\begin{array}{l}1.94 \\
(1.11-3.40)\end{array}$ & $\begin{array}{l}2.41 \\
(1.37-4.23)\end{array}$ & $\begin{array}{l}2.53 \\
(1.43-4.48)\end{array}$ & $1.13(0.66-1.95)$ & $1.28(0.74-2.24)$ & $\begin{array}{l}1.32 \\
(0.76-2.28)\end{array}$ \\
\hline \multirow[t]{2}{*}{ Cardiorespiratory fitness } & Low & 1 (ref.) & 1 (ref.) & 1 (ref.) & 1 (ref.) & 1 (ref.) & 1 (ref.) \\
\hline & High & $1.41(0.81-2.45)$ & $1.10(0.64-1.89)$ & $1.56(0.90-2.71)$ & $1.01(0.58-1.74)$ & $1.27(0.72-2.24)$ & $\begin{array}{l}0.87 \\
(0.51-1.51)\end{array}$ \\
\hline \multirow{2}{*}{$\begin{array}{l}\text { Vigorous physical } \\
\text { activity }\end{array}$} & Low & 1 (ref.) & 1 (ref.) & 1 (ref.) & 1 (ref.) & 1 (ref.) & 1 (ref.) \\
\hline & High & $1.52(0.85-2.72)$ & $1.25(0.71-2.21)$ & $1.34(0.75-2.38)$ & $1.45(0.81-2.58)$ & $1.28(0.71-2.32)$ & $\begin{array}{l}1.10 \\
(0.62-1.95)\end{array}$ \\
\hline \multicolumn{8}{|c|}{$\begin{array}{l}\text { Odds ratio ( } 95 \% \text { Confidence Intervals) above represents increased odds of achieving high AP ( } \geq 50 \text { th of the median). Analyses were adjusted for sex, pubert } \\
\text { stage, and socioeconomic status. Statistically significant values are in bold } \\
\text { GPA grade point average } \\
\text { a Includes obese adolescents. Low screen time was calculated as }<\text { the } 25 \text { th sex-specific percentile. Good sleep quality was defined as PSQI scores } \leq 5 \text {. Optim } \\
\text { daily meal frequency was defined as five-meal-a-day. High levels of cardiorespiratory fitness and vigorous physical activity were defined as } \geq 75 \text { th sex-specif } \\
\text { percentile }\end{array}$} \\
\hline
\end{tabular}
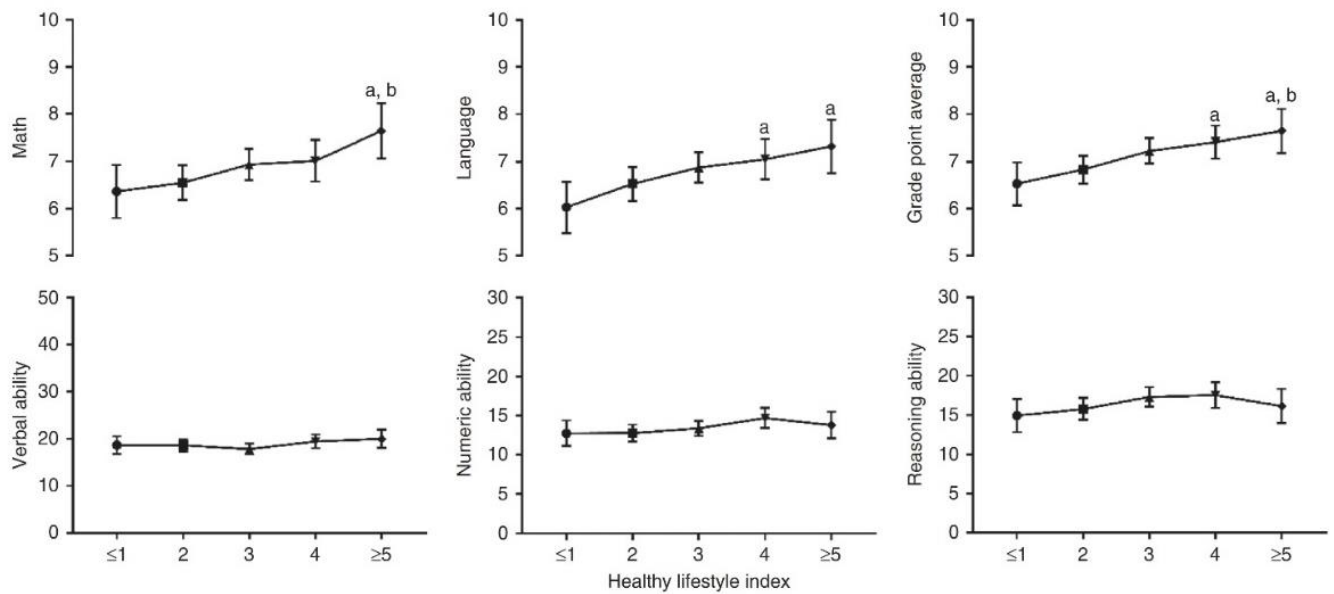

Fig. 1 Differences in academic performance indicators according to the healthy lifestyle index using ANCOVA, after adjustment for sex, pubertal stage, and socioeconomic status. Estimated marginal means with their $95 \%$ Confidence Intervals are presented. $\leq 1$ ( $n=31$ ), 2 $(n=69), 3(n=85), 4(n=49)$, and $\geq 5(n=28)$. "a" indicates significant differences $(p<0.05)$ with the first group (healthy lifestyle index $\leq 1)$; "b" indicates significant differences $(p<0.05)$ with the second group (healthy lifestyle index $=2$ )

single time point; (2) unlike academic abilities' test, which mainly requires good cognitive skills, the multidimensional nature of academic grades also involves emotional and social factors (i.e. effort, teacher influence, attitude); ${ }^{3}$ (3) academic grades, but not abilities, have shown to be determinant for college selection and admission, ${ }^{4}$ which might increase adolescents' motivation and effort to achieve higher grades; and (4) it is likely that teachers assign better grades to healthier adolescents because of their higher school attendance and commitment to long-term educational goals. 5,29

The results about the independent associations of the studied healthy lifestyle factors with $\mathrm{AP}$ in adolescents concur with 
Independent and combined influence of healthy lifestyle factors on... M Adelantado-Renau et al.

\begin{tabular}{|c|c|c|c|c|c|c|}
\hline & \multicolumn{3}{|l|}{ Academic grades } & \multicolumn{3}{|l|}{ Academic abilities } \\
\hline & Math & Language & GPA & Verbal & Numeric & Reasoning \\
\hline \multicolumn{7}{|c|}{ Healthy lifestyle index } \\
\hline$\leq 1$ & 1 (ref.) & 1 (ref.) & 1 (ref.) & 1 (ref.) & 1 (ref.) & 1 (ref.) \\
\hline 2 & $1.70(0.68-4.26)$ & $1.96(0.78-4.91)$ & $2.68(1.03-6.97)$ & $0.91(0.38-2.18)$ & $1.21(0.50-2.95)$ & $1.27(0.53-3.09)$ \\
\hline 3 & $3.02(1.22-7.48)$ & $3.51(1.41-8.77)$ & $4.22(1.63-10.89)$ & $0.85(0.36-2.01)$ & $2.26(0.93-5.46)$ & $2.85(1.17-6.92)$ \\
\hline 4 & $3.03(1.14-8.08)$ & $4.14(1.54-11.12)$ & $5.47(1.96-15.26)$ & $1.21(0.47-3.09)$ & $3.05(1.15-8.10)$ & $2.19(0.84-5.67)$ \\
\hline$\geq 5$ & $9.51(2.78-35.53)$ & $6.76(2.11-21.64)$ & $9.36(2.83-31.03)$ & $1.40(0.48-4.15)$ & $2.19(0.73-6.55)$ & $1.28(0.43-3.76)$ \\
\hline
\end{tabular}

Odds ratio ( $95 \%$ Confidence Intervals) above represents increased odds of achieving high AP ( $\geq 50$ th of the median). Analyses were adjusted for sex, pubertal stage, and socioeconomic status. Statistically significant values are in bold. $\leq 1 \quad(n=31), 2(n=69), 3(n=85), 4(n=49)$, and $\geq 5$ ( $n=28)$

GPA grade point average

OR $(95 \% \mathrm{Cl})$

\begin{tabular}{llll}
\hline Academic grades \\
Math \\
Language \\
Grade point average \\
Academic abilities \\
Verbal \\
Numeric \\
Reasoning
\end{tabular}

Fig. 2 Logistic regression model predicting high academic performance ( $\geq 50$ th of the median) according to the healthy lifestyle index ( $<4$ vs. $\geq 4)$. Analysis adjusted for sex, pubertal stage, and socioeconomic status. OR odds ratio, $\mathrm{Cl}$, confidence intervals. Reference $(\mathrm{OR}=1.00)$ : adolescents with a healthy lifestyle index $<4(n=185)$

previous research showing that non-overweight status, $^{30}$ low screen time, ${ }^{31}$ good sleep quality, ${ }^{10}$ and optimal daily meal frequency ${ }^{11}$ were independently and positively associated with AP. Conversely, CRF and vigorous PA were not independently associated with AP.

The association between weight status and AP might be partially explained by psychological and behavioral disturbances (e.g., isolation, bullying, low self-confidence) common in obese children and adolescents. ${ }^{32}$ In addition, overweight-derived health problems may increase school absenteeism, ${ }^{29}$ while other related behaviors (e.g., poor sleep, unhealthy dietary patterns, low levels of PA) could also negatively influence academic results. ${ }^{2,30}$ Regarding screen time, our findings could be partially explained by the hypotheses of time and energy displacement which suggests that screen time replaces other activities such as verbal interaction or sleep, with adverse consequences over AP. ${ }^{33}$ Interestingly, prior research revealed that screen time for entertainment, particularly internet usage, was negatively related with AP in adolescents, but positively associated when used for educational purposes, ${ }^{34}$ highlighting the importance of the usage purpose when analyzing screen-based activities. Concerning sleep, previous scientific evidence suggested that poor sleep quality was associated with sleepiness, which may have negative effects on attention, memory and learning abilities. ${ }^{9}$ Finally, with respect to the regular consumption of five-meal-a-day, the facilitated blood glucose response after each meal might help cognitive processes with improvements in academic results. ${ }^{11,35}$ In addition, prior literature suggested that food insecurity (i.e., insufficient financial resources to access to a varied and balanced diet) may lead to irregular meal patterns and insufficient nutrients intake, negatively influencing physical and mental health (i.e., psychological and emotional well-being), which in turn, might affect alertness, school attendance, and achievement. ${ }^{36}$

Although CRF and vigorous PA showed no association with AP on an individual level, recent literature has stated multiple benefits of high levels of CRF and vigorous PA on AP, ${ }^{12,13}$ which are related with changes in brain structure and function, ${ }^{37}$ as well as with better cognitive skills. ${ }^{38}$ Thus, since healthy lifestyle factors seem not to act in isolation, it is likely that on a combined level, both factors may contribute to AP. Therefore, these factors were included in the healthy lifestyle index to examine combined associations.

The combined effect analysis revealed that adolescents with a healthy lifestyle index $\geq 4$ showed higher scores in academic grades compared with those with an index $\leq 2$. Moreover, adolescents with a healthy lifestyle index $\geq 3$ had increased likelihood of achieving high AP. To date only three studies have analyzed the combined influence of diverse health-related factors on AP; $;^{14-16}$ however, none of them has investigated the influence of the six healthy lifestyle factors included in this study. MartinezGómez et al. ${ }^{16}$ noted similar results in a sample of 1825 Spanish adolescents - girls meeting 3 or 4 recommendations for health behaviours including indicators of PA, television viewing, sleep duration and fruit consumption, were 1.75 and 3.18 times more likely to achieve better results in math and language respectively, compared with those meeting $0-1$ health behaviours. Another study performed in the United States, analyzed 14 "health assets" (related to weight status, physical fitness, diet, PA, screen time, smoking, well-being, and sleep quality) concluding that children fulfilling more health recommendations were more likely to achieve goals for math, reading and writing. ${ }^{15}$ In a recent study, Faught et al. found that children fulfilling from 7 to 9 lifestyle 
recommendations (including $P A$, television viewing, sleep duration and 6 items related to dietary patterns) showed higher odds of achieving better results for math, reading and writing. ${ }^{14}$ Our results could be explained by the cumulative effect of each individual healthy lifestyle factor on AP. The reasons underlying the positive relationship between these factors and AP cannot be elucidated in the current study. However, a possible explanation could be that the cumulative effect of the factors included in the healthy lifestyle index might improve attention, concentration, memory, and cognitive functioning, which, in turn, may result in higher academic outcomes in adolescents.

An important question to mention is the possible reverse causation. Academic success could also positively influence health status by improving adolescents' knowledge about healthy lifestyles, as well as, psychological (e.g., self-esteem, personal control) and social aspects. ${ }^{39}$ Therefore, further longitudinal studies are needed to shed light on the bidirectional relationship between healthy lifestyles and AP in adolescents.

Strengths and limitations

Unfortunately, the cross-sectional design of the present study does not allow us to establish causal relationships. A second limitation was the use of self-reported data (i.e., screen time, sleep quality, and daily meal frequency). The properties of self-reported health information in adolescents have been poorly examined; nonetheless, self-reported measures related to non-compromising topics have demonstrated good reliability. ${ }^{40}$ Moreover, the present study did not include measures of nutritional status, using daily meal frequency as a proxy of regular meal pattern. Additionally, most of the participants were physically active, which could limit the generalizability of our findings to other populations. Finally, the use of a standardized test of academic abilities, and academic grades, although socially valid measures of AP, can be subject to biases. This study have several strengths such as the relatively large and age-matched sample of adolescents $(13.9 \pm$ $0.3 \mathrm{y}$ ), the use of validated and standardized tests to assess weight status, sleep quality, CRF and academic abilities, and the inclusion of objective measures of PA by accelerometry. In addition, the statistical analyses were controlled for SES which is relevant given its relation with health status ${ }^{41}$ and academic performance. ${ }^{2}$

\section{CONCLUSIONS}

In summary, the results of our study suggest that although individual healthy lifestyle factors are independently and positively associated with AP, the cumulative effect of multiple healthy lifestyle factors has a stronger impact on AP. Our findings are of paramount importance because of the key role of AP on future work achievement ${ }^{4}$ and health status. ${ }^{5}$ Health and education professionals could benefit from collaborating to achieve both improved health status, and academic performance. Further prospective research analyzing the combined effect of several healthy lifestyles on cognition in different specific populations are needed for a better understanding of the mechanisms involved.

\section{ACKNOWLEDGEMENTS}

The DADOS Study is funded by the Spanish Ministry of Economy and Competitiveness, MINECO (DEP2013-45515-R) and by the Jaume I University of Castellon, UJ (P1-1A2015-05). This work is partly supported by a Sunny Sport research grant from the Schweppes Suntory Spain Company. D.J.P. was supported by a grant from the Spanish Ministry of Science and Innovation - MINECO (RYC-2014-16938). M.A.R. is supported by a Predoctoral Research Grant from UJI (PREDOC/2015/13).

\section{AUTHOR CONTRIBUTIONS}

M.A.R. was involved in the data collection and analysis, drafting of the initial manuscript. D.J.P. was involved in the data analysis and critical revision of the

manuscript. M.R.B.V. was involved in the data collection and critical revision of the manuscript. D.M.U. was involved in the study design and data collection, manuscript preparation, and critical revision. All authors have read and approved the final manuscript.

\section{ADDITIONAL INFORMATION}

Competing interests: The authors declare no competing interests.

Publisher's note: Springer Nature remains neutral with regard to jurisdictional claims in published maps and institutional affiliations.

\section{REFERENCES}

1. Bradley, B. J. \& Greene, A. C. Do health and education agencies in the United States share responsibility for academic achievement and health? A review of 25 years of evidence about the relationship of adolescents' academic achievement and health behaviors. J. Adolesc. Health 52, 523-532 (2013).

2. Donnelly, J. E. et al. Physical activity, fitness, cognitive function, and academic achievement in children: a systematic review. Med. Sci. Sports Exerc. 48, 1197-1222 (2016).

3. Petrides, K. V., Chamorro-Premuzic, T., Frederickson, N. \& Furnham, A. Explaining individual differences in scholastic behaviour and achievement. Br. J. Educ. Psychol. 75, 239-255 (2005).

4. French, M. T., Homer, J. F., Popovici, I. \& Robins, P. K. What you do in high school matters: high school GPA, educational attainment, and labor market earnings as a young adult. East. Econ. J. 41, 370-386 (2015).

5. Lê-Scherban, F., Diez Roux, A. V., Li, Y. \& Morgenstern, H. Does academic achievement during childhood and adolescence benefit later health? Ann. Epidemiol. 24, 344-355 (2014).

6. Liang, J., Matheson, B. E., Kaye, W. H. \& Boutelle, K. N. Neurocognitive correlates of obesity and obesity-related behaviors in children and adolescents. Int. J. Obes. 38, 494-506 (2014)

7. Horowitz-Kraus, T. \& Hutton, J. S. Brain connectivity in children is increased by the time they spend reading books and decreased by the length of exposure to screen-based media. Acta Paediatr. 107, 685-693 (2017).

8. Carson, V. et al. Systematic review of sedentary behaviour and health indicators in school-aged children and youth: an update. Appl. Physiol. Nutr. Metab. 41, S240-S265 (2016)

9. Carskadon, M. A. Sleep's effects on cognition and learning in adolescence. Prog. Brain Res. 190, 137-143 (2011).

10. Dewald, J. F., Meijer, A. M., Oort, F. J., Kerkhof, G. A. \& Bogels, S. M. The influence of sleep quality, sleep duration and sleepiness on school performance in children and adolescents: A meta-analytic review. Sleep. Med. Rev. 14, 179-189 (2010).

11. Kim, S. Y. et al. Dietary habits are associated with school performance in adolescents. Medicine 95, e3096 (2016).

12. Marques, A., Santos, D. A., Hillman, C. H. \& Sardinha, L. B. How does academic achievement relate to cardiorespiratory fitness, self-reported physical activity and objectively reported physical activity: a systematic review in children and adolescents aged 6-18 years. Br. J. Sports Med. 52, 1039 (2018).

13. Álvarez-Bueno, C. et al. Academic achievement and physical activity: a metaanalysis. Pediatrics 140, e20171498 (2017)

14. Faught, E. L. et al. The combined impact of diet, physical activity, sleep and screen time on academic achievement: a prospective study of elementary school students in Nova Scotia, Canada. Int. J. Behav. Nutr. Phys. Act. 14, 29 (2017).

15. Ickovics, J. R. et al. Health and academic achievement: cumulative effects of health assets on standardized test scores among urban youth in the United States*. J. Sch. Heal. 84, 40-48 (2014).

16. Martínez-Gómez, D. et al. Gender-specific influence of health behaviors on academic performance in Spanish adolescents: the AFINOS study. Nutr. Hosp. 27 724-730 (2012)

17. Beltran-Valls, M. R., et al. Regular practice of competitive sports does not impair sleep in adolescents: DADOS Study. Pediatr. Exerc. Sci. 30, 229-236 (2018).

18. Cole, T. J., Bellizzi, M. C., Flegal, K. M., \& Dietz, W. H. Establishing a standard definition for child overweight and obesity worldwide: international survey. BMJ (Clinical Research Ed.), 320, 1240-1243 (2000).

19. Rey-López, J. P. et al. Sedentary patterns and media availability in European adolescents: The HELENA study. Prev. Med. 51, 50-55 (2010).

20. Royuela Rico, A. \& Macías Fernández, J. Propiedades Clinimétricas De La Versión Castellana Del Cuestionario De Pittsburg. Vigilia-Sueño 9, 81-94 (1997).

21. Buysse, D. J., Reynolds, C. F. Monk, T. H., Berman, S. R. \& Kupfer, D. J. The Pittsburgh sleep quality index: a new instrument for psychiatric practice and research. Psychiatry Res. 28, 193-213 (1989). 
Independent and combined influence of healthy lifestyle factors on... M Adelantado-Renau et al.

22. Jääskeläinen, A. et al. Associations of meal frequency and breakfast with obesity and metabolic syndrome traits in adolescents of Northern Finland Birth Cohort 1986. Nutr. Metab. Cardiovasc. Dis. 23, 1002-1009 (2013).

23. Léger, L. A., Mercier, D., Gadoury, C. \& Lambert, J. The multistage 20 metre shuttle run test for aerobic fitness. J. Sports Sci. 6, 93-101 (1988).

24. Esliger, D. W. et al. Validation of the GENEA accelerometer. Med Sci. Sport Exerc 43, 1085-1093 (2011).

25. Phillips, L., Parfitt, G. \& Rowlands, A. Calibration of the GENEA accelerometer for assessment of physical activity intensity in children. J. Sci. Med. Sport. 16, 124-128 (2013).

26. Thurstone, L. L. \& Thurstone, T. G. TEA Test de Aptitudes Escolares (Scholar Aptitudes Test). 11th edn. (Ediciones TEA, S.A., Madrid, 2004).

27. Tanner, J. M. \& Whitehouse, R. H. Clinical longitudinal standards for height weight, height velocity, weight velocity, and stages of puberty. Arch. Dis. Child. 51, 170-179 (1976).

28. Currie, C. et al. Researching health inequalities in adolescents: The development of the Health Behaviour in School-Aged Children (HBSC) Family Affluence Scale. Soc. Sci. Med. 66, 1429e1436 (2008).

29. Pan, L., Sherry, B., Park, S. \& Blanck, H. M. The association of obesity and school absenteeism attributed to illness or injury among adolescents in the United States, 2009. J. Adolesc. Health 52, 64-69 (2013).

30. Larsen, J. K., Kleinjan, M., Engels, R. C., Fisher, J. O. \& Hermans, R. C. Higher weight, lower education: a longitudinal association between adolescents' body mass index and their subsequent educational achievement level? J. Sch. Health $\mathbf{8 4}$ 769-776 (2014).

31. Carson, V. et al. Systematic review of sedentary behaviour and health indicators in school-aged children and youth: an update. Appl. Physiol. Nutr. Metab. 41 (6Suppl 3), S240-S265 (2016).
32. Gunnarsdottir, T., Njardvik, U., Olafsdottir, A. S., Craighead, L. W. \& Bjarnason, R. Teasing and social rejection among obese children enrolling in family-based behavioural treatment: effects on psychological adjustment and academic competencies. Int. J. Obes. 36, 35-44 (2012).

33. Kostyrka-Allchorne, K., Cooper, N. R. \& Simpson, A. The relationship between television exposure and children's cognition and behaviour: a systematic review. Dev. Rev. 44, 19-58 (2017).

34. Kim, S. Y., Kim, M. S., Park, B., Kim, J. H. \& Choi, H. G. The associations between internet use time and school performance among Korean adolescents differ according to the purpose of internet use. PLOS ONE 12, 1-14 (2017).

35. Benton, D. The influence of dietary status on the cognitive performance of children. Mol. Nutr. Food Res. 54, 457-470 (2010).

36. Shankar, P., Chung, R. \& Frank, D. A. Association of food insecurity with children's behavioral, emotional, and academic outcomes: a systematic review. J. Dev. Behav. Pediatr. 38, 135-150 (2017).

37. Chaddock, L., Pontifex, M. B., Hillman, C. H. \& Kramer, A. F. A review of the relation of aerobic fitness and physical activity to brain structure and function in children. J. Int. Neuropsychol. Soc. 17, 975-985 (2011).

38. Moore, R. D. et al. Aerobic fitness and intra-individual variability of neurocognition in preadolescent children. Brain Cogn. 82, 43-57 (2013).

39. Jackson, M. I. Understanding links between adolescent health and educational attainment. Demography 46, 671-694 (2009).

40. Brener, N. D., Billy, J. O. G. \& Grady, W. R. Assessment of factors affecting the validity of self-reported health-risk behavior among adolescents: evidence from the scientific literature. J. Adolesc. Health 33, 436-457 (2003).

41. Jiménez Pavón, D. et al. Socioeconomic status influences physical fitness in European adolescents independently of body fat and physical activity: the HELENA study. Nutr. Hosp. 25, 311-316 (2010). 


\section{Conclusions}

[Conclusiones] 


\section{CONCLUSIONS}

The main conclusions of the present PhD Thesis are:

SECTION 1. SLEEP AND ACADEMIC PERFORMANCE

- Sleep quality, but not sleep duration, is positively associated with academic performance in secondary school students.

- Internet use time plays a mediating role on the association between sleep quality and academic performance in secondary school students.

\section{SECTION 2. DIET AND ACADEMIC PERFORMANCE}

- $\quad$ Adherence to the Mediterranean diet is positively associated with academic performance in secondary school students.

- Sleep quality plays a mediating role on the association between adherence to the Mediterranean diet and academic performance in secondary school students.

- Daily meal frequency of five-meal-aday is positively associated with academic performance in secondary school students.

- The risk of eating disorders is negatively associated with academic performance in secondary school students.

\section{SECTION 3. CIRCULATING}

INFLAMMATORY BIOMARKERS AND ACADEMIC PERFORMANCE

- Tumor necrosis factor-a is negatively associated with academic performance in secondary school students.
- White blood cells, interleukin-6 and Creactive are not associated with academic performance in secondary school students.

SECTION 4. PHYSICAL FITNESS AND ACADEMIC PERFORMANCE

- Cardiorespiratory fitness is positively associated with academic performance in secondary school students.

- Muscular strength and speed-agility are not associated with academic performance in secondary school students.

- Circulating leptin concentration plays a mediating role on the association of cardiorespiratory fitness and muscular strength with academic performance in secondary school students.

- Body composition plays a mediating role on the association between cardiorespiratory fitness and academic performance in secondary school students.

SECTION 5. PHYSICAL ACTIVITY, SEDENTARY BEHAVIOURS AND ACADEMIC PERFORMANCE

- Very high levels of physical activity are not associated with low academic performance in secondary school students.

- Screen media usage is negatively associated with academic performance in secondary school students.

Overall, the present $\mathrm{PhD}$ Thesis indicates a positive association between healthy lifestyle factors and academic performance in secondary school students. 


\section{CONCLUSIONES}

Las principales conclusiones de la presente Tesis Doctoral son:

SECCIÓN 1. SUEÑO Y RENDIMIENTO ACADÉMICO

- La calidad del sueño, pero no la duración, se asocia positivamente con el rendimiento académico en estudiantes de educación secundaria obligatoria.

- El tiempo de uso de internet juega un papel mediador en la asociación entre la calidad del sueño y el rendimiento académico en estudiantes de educación secundaria obligatoria.

SECCIÓN 2. DIETA Y RENDIMIENTO ACADÉMICO

- La adherencia a la dieta Mediterránea se asocia positivamente con el rendimiento académico en estudiantes de educación secundaria obligatoria.

- La calidad del sueño juega un papel mediador en la asociación entre la adherencia a la dieta Mediterránea y el rendimiento académico en estudiantes de educación secundaria obligatoria.

- Realizar cinco comidas al día se asocia positivamente con el rendimiento académico en estudiantes de educación secundaria obligatoria.

- El riesgo de padecer trastornos de la alimentación se asocia negativamente con el rendimiento académico en estudiantes de educación secundaria obligatoria.
SECCIÓN 3. BIOMARCADORES DE INFLAMACIÓN Y RENDIMIENTO ACADÉMICO

- La concentración del factor de necrosis tumoral-a en sangre se asocia negativamente con el rendimiento académico en estudiantes de educación secundaria obligatoria.

- La concentración de leucocitos, interleucina-6 y proteína $\mathrm{C}$ reactiva en sangre no se asocia con el rendimiento académico en estudiantes de educación secundaria obligatoria.

SECCIÓN 4. CONDICIÓN FISICA Y RENDIMIENTO ACADEMICO

- La resistencia cardiorrespiratoria se asocia positivamente con el rendimiento académico en estudiantes de educación secundaria obligatoria.

- La fuerza muscular y la velocidadagilidad no se asocian con el rendimiento académico en estudiantes de educación secundaria obligatoria.

- La concentración de leptina en sangre juega un papel mediador en la asociación de la resistencia cardiorrespiratoria y la fuerza muscular con el rendimiento académico en estudiantes de educación secundaria obligatoria.

- La composición corporal juega un papel mediador en la asociación entre la resistencia cardiorrespiratoria y el rendimiento académico en estudiantes de educación secundaria obligatoria. 
SECCIÓN 5. ACTIVIDAD FISICA, COMPORTAMIENTOS SEDENTARIOS Y RENDIMIENTO ACADÉMICO

- Niveles elevados de actividad física no se asocian con un bajo rendimiento académico en estudiantes de educación secundaria obligatoria.

- El tiempo empleado en actividades de pantalla se asocia negativamente con el rendimiento académico en estudiantes de educación secundaria obligatoria.

En resumen, la presente Tesis Doctoral pone de manifiesto una asociación positiva entre los hábitos saludables y el rendimiento académico en estudiantes de educación secundaria obligatoria. 


\section{Implications and \\ Future Perspectives}




\section{IMPLICATIONS AND FUTURE PERSPECTIVES}

The main findings of the present PhD Thesis indicate a positive association between healthy lifestyle factors and academic performance in secondary school students. This scientific evidence reveals an additional reason to promote the collaborative work between educators and health professionals. During school age, educational centres seem to be the ideal place to implement health promotion strategies and programs, which may contribute to the improvement of academic performance.

The present PhD Thesis also identifies the main limitations of the current scientific knowledge. Further longitudinal and interventional research is warranted to address the question of causality, and thus, to elucidate the influence of healthy lifestyle factors on academic performance in children and adolescents. Moreover, future investigations should also consider cognitive function and structural imaging data, instead of focusing only on academic performance measurements. 
Annexes 


\section{SHORT CURRICULUM VITAE}

\section{Personal information}

Name: Mireia Adelantado Renau

Date of birth: August 2, 1990

Place of birth: Castelló (Spain)

Nationality: Spanish

Phone: +34 964729840

Email: adelantm@uji.es

\section{University education}

10/2015-09/2019: PhD student - Doctoral Program in Education [Tesis Doctoral Programa de Doctorado en Educación], Universitat Jaume I

10/2017-07/2018: Master in social health research, [Máster Universitario en Investigación Sociosanitaria], Universidad de Castilla-La Mancha

10/2014-07/2015: Master in teacher education, [Master en Formación del Profesorado de Educación Secundaria Obligatoria y Bachillerato, Formación Profesional y Enseñanzas de Idiomas], Universitat Jaume I

09/2008-06/2013: 5-year Bachelor degree in Chemistry [Licenciatura en Químicas], Universitat Jaume I

\section{Research projects}

01/2016-12/2018: Name of the project: Influencia de la actividad física sobre la salud cardiovascular y la capacidad cognitiva durante la adolescencia

Funding entity: Universitat Jaume I (Castelló, Spain)

Code according to the funding entity: P1·1A2015-05

Total amount: $40.000 €$

01/2014-12/2017: Name of the project: Influencia de la práctica deportiva competitiva sobre la salud física, el bienestar psicológico y el rendimiento académico durante la adolescencia

Funding entity: Ministerio de Economía y Competitividad. Programa Estatal de Investigación, Desarrollo e Innovación Orientada a los Retos de la Sociedad

Code according to the funding entity: DEP2013-45515-R

Total amount: $48.400 €$ 


\section{Research stays}

09/2018-01/2019: Entity: University of Porto (Porto, Portugal)

12/2017-04/2018: Entity: University of Granada (Granada, Spain)

10/2017-11/2017: Entity: University of Cádiz (Cádiz, Spain)

\section{Courses and extracurricular activities}

Courses attended

01/2018 - 15h: Name: Análisis estadístico de ensayos clínicos aleatorizados

Organising entity: Unidad Científica de Excelencia Ejercicio y Salud de la Universidad de Granada

06/2016 - 2h: Name: Novedades en la Web Of Science (Nuevas versiones JCR y $\mathrm{ESI})$

Organising entity: Fundación Española para la Ciencia y la Tecnología

06/2016 - 60h: Name: Análisis de datos y manejo de programas de análisis de datos SPSS y R.

Organising entity: Universitat Jaume I

05/2016 - 10h: Name: Ética y deontología profesional: código de buenas prácticas, tratamiento de datos y comisión deontológica.

Organising entity: Universitat Jaume I

02/2016 - 10h: Name: Planificación de la Investigación

Organising entity: Universitat Jaume I

02/2016 - 10h: Name: Investigación sobre actividad física y salud en jóvenes

Organising entity: Universitat Jaume I

01/2016-30h: Name: Herramientas de Información Bibliográfica para la Investigación

Organising entity: Universitat Jaume I

Courses and lectures taught

12/2018 - 4h: Name: Cómo escribir y publicar un artículo científico

Organising entity: Universitat Jaume I. Centro de Estudios de Postgrado y Formación Continuada

04/2018-2h: Name: Introducción a los análisis de moderación y mediación: estilos de vida saludables y rendimiento académico

Organising entity: Unidad de Excelencia en Ejercicio Físico y Salud (UCEES) de la Universidad de Granada

03/2018 - 1h: Name: The ActiveBrains-SmarterMove International Seminar: Exercise, Cognition and Brain in Childhood and Older Age Organising entity: Unidad Científica de Excelencia en Ejercicio y Salud (UCEES) y Programa Visiting Scholars, Plan Propio, Universidad de Granada 


\section{Works submitted to conferences}

04/2019: V Jornadas de Investigación para el alumnado de la Facultad de Ciencias de la Salud (Castelló, Spain)

- Relación entre la práctica deportiva y la autoestima en adolescentes: Proyecto DADOS

- Estrés social y rendimiento académico en adolescentes: Proyecto DADOS

- Estado de salud y rendimiento académico en adolescentes: Proyecto DADOS

03/2019: XVI Congreso de Psicología de la Actividad Física y del Deporte (Zaragoza, Spain)

- Análisis del efecto combinado de la composición corporal y la capacidad aeróbica sobre la autoestima en adolescentes: estudio DADOS

- Asociación de la composición corporal y la autoestima en Adolescentes: proyecto DADOS

- Asociación entre condición física y estrés social en adolescentes: Proyecto DADOS

- Riesgo de padecer trastornos de alimentación y desajuste escolar en adolescentes: proyecto DADOS

02/2019: I Congreso Nacional de Investigadores del PTS (Granada, Spain)

- Asociación entre trastornos respiratorios relacionados con el sueño y rendimiento académico, función ejecutiva y volumen cerebral en niños con sobrepeso/obesidad: Proyecto ActiveBrains

01/2019: I Congreso Internacional de Ciencias de la Actividad Física y el Deporte (Valencia, Spain)

- Physical activity and risk of depression in active adolescents. The role of Mediterranean diet: DADOS study

- The combined effect of physical activity and other health-related factors on cognition in adolescents: DADOS study

- The effects of high physical activity levels on physical fitness in adolescents: DADOS study

11/2018: XXIII Jornadas de Fomento de la Investigación en Ciencias Humanas y Sociales (Castelló, Spain)

- Autoestima y rendimiento académico en alumnos de Educación Secundaria Obligatoria: Proyecto DADOS

- ¿Puede la actividad física y la práctica deportiva disminuir el riesgo de depresión en estudiantes de secundaria? Proyecto DADOS

11/2018: II Congreso Internacional de Evaluación e Intervención en Inteligencia Emocional (Castelló, Spain) 
- Association of physical activity and sport practice with self-esteem in secondary school students: DADOS study

- Physical activity practice is associated with reduced levels of social stress in secondary school students: DADOS study

10/2018: Symposio EXERNET. Investigación en Ejercicio, Salud y Bienestar. "Exercise is Medicine" (Pamplona, Spain)

- Associations of body composition, physical fitness and physical activity with self-esteem in adolescents: DADOS study

- The cumulative effect of several health-related factors on academic performance in adolescents: DADOS study

- Relación entre conductas sedentarias, capacidad cardiorrespiratoria y composición corporal con los trastornos respiratorios relacionados con el sueño en niños con sobrepeso/obesidad: Proyecto ActiveBrains

10/2018: Physiology and Pharmacology of Temperature Regulation (Split, Croatia)

- The mediator role of brown adipose tissue and skeletal muscle in the thermoregulatory system of young adults

09/2018: 9 th Symposium European Youth Heart Study (Lisboa, Portugal)

- The longitudinal association between objectively measured physical activity and physical fitness in adolescents: DADOS study

04/2018: IV Jornadas de investigación para el alumnado de salud (Castelló, Spain)

- Comportamientos sedentarios de pantalla y su relación con el sueño en adolescentes: Proyecto DADOS

- Composición corporal, condición física, actividad física y depresión en adolescentes: Proyecto DADOS

03/2018: XVIII Congreso de la Sociedad Castellano-Manchega de Geriatría y Gerontología (Albacete, Spain)

- Mediterranean diet may be beneficial for the prevention and treatment of cognitive decline and dementia in older age

12/2017: Jornadas Internacionales en Actividad Física y Salud (Cuenca, Spain)

- Body central fatness as mediator of the association between skipping breakfast and academic performance in adolescents: DADOS Study

- Cardiorespiratory fitness association with circulating BDNF in adolescents: DADOS Study

- The association between meal frequency and academic indicators in adolescents is mediated by weight status: DADOS Study

- The benefits of fruit and vegetable intake on cognitive decline and dementia in healthy elderly population: a mini review

- Zumos de frutas y su relación con la obesidad infantil: una revisión 
sistemática

06/2017: International Symposium. ActiveBrains for all: exercise, cognition and mental health (Granada, Spain)

- Serum leptin as a mediator of the relationship between cardiorespiratory fitness and academic performance in adolescents: DADOS study

- The association between cardiorespiratory fitness and academic performance is mediated by weight status: DADOS Study

04/2017: III Jornadas de Investigación para alumnado de la Facultad de Ciencias de la Salud (Castelló, Spain)

- Association between sport specialities and physical fitness in adolescents: DADOS Study

04/2017: I Congreso Internacional en Ciencias de la Salud y del Deporte: Actividad Física Segura y Saludable en la Montaña. Trabajo Interdisciplinar en Salud (Huesca, Spain)

- Adiponectin is inversely associated with physical activity in adolescents: DADOS study

- Associations between self-reported physical fitness and sleep patterns in adolescents: DADOS study

- Extracurricular sports practice and self-reported physical fitness in adolescents: DADOS study

- Physical activity level is associated with sleep quality and duration in adolescents: DADOS study

11/2016: XXI Jornadas de Fomento de la Investigación de la Facultad de Ciencias Humanas y Sociales (Castelló, Spain)

- Vigorous physical activity could diminish the relationship between inflammation and educational abilities

10/2016: Simposio EXERNET. Investigación en Ejercicio, Salud y Bienestar: "Exercise is Medicine" (Cádiz, Spain)

- Chronic inflammation and academic performance in healthy adolescents: influence of cardiorespiratory fitness

- Influencia del nivel de desarrollo madurativo y el nivel de actividad física sobre la calidad del sueño en niñas adolescentes: Proyecto DADOS

06/2016: 21st Annual Congress of the European College of Sport Science: Crossing borders through sport science (Vienna, Austria)

- High levels of physical activity does not impair sleep quality in adolescents: DADOS Study

05/2016: XX Congreso del Instituto Universitario de Estudios Feministas y de Género Purificación Escribano "Salud, emociones y género" (Castelló, Spain)

- Análisis de la influencia del nivel de desarrollo madurativo sobre la 
composición corporal, la actividad física y el riesgo de padecer trastornos de la conducta alimentaria en niñas adolescentes: proyecto DADOS

- Importancia de los hábitos de estudio en el rendimiento académico durante la adolescencia: diferencias de género

- Sleep quality is inversely associated with regular sport participation in adolescent girls: DADOS study

12/2015 X Jornadas de Fomento de la Investigación de la Facultad de Ciencias Humanas y Sociales (Castelló, Spain)

- Análisis de la condición física y el rendimiento académico en niñas adolescentes

\section{Scientific publications}

1. Adelantado-Renau $M^{\star}$, Martinez-Tellez $B^{*}$, Acosta FM, Sanchez-Delgado G, MartinezNicolas A, Boon MR, Llamas-Elvira JM, Martinez-Vizcaino V, Ruiz JR. The mediating role of brown fat and skeletal muscle measured by ${ }^{18} \mathrm{~F}$-fluorodeoxyglucose in the thermoregulatory system in young adults. Obesity. 2019; 27(6): 963-970. doi:10.1002/oby.22461. [Epub ahead of print]

WOS (JCR) Impact Factor: 4.042; Category: Nutrition \& Dietetics; Rank: 19/83 (Q1)

2. Adelantado-Renau M Jiménez-Pavón D, Beltran-Valls MR, Moliner-Urdiales D. Independent and combined influence of healthy lifestyle factors on academic performance in adolescents: DADOS Study. Pediatric Research. 2019; 85, 456-462. doi:10.1038/s41390-019-0285-z. [Epub ahead of print]

WOS (JCR) Impact Factor: 3.123; Category: Pediatrics; Rank: 16/124 (Q1)

3. Adelantado-Renau M, Beltran-Valls MR, Migueles JH, Artero EG, Legaz-Arrese A, Capdevila-Seder A, Moliner-Urdiales D. Associations between objectively measured and self-reported sleep with academic and cognitive performance in adolescents: DADOS study. Journal of Sleep Research. 2019; e12811. doi:10.1111/jsr.12811. [Epub ahead of print]

WOS (JCR) Impact Factor: 3.433; Category: Neurosciences; Rank: 100/261 (Q2)

4. Adelantado-Renau M, Beltran-Valls MR, Esteban-Cornejo I, Martínez-Vizcaíno V, Santaliestra-Pasías AM, Moliner-Urdiales D. The influence of adherence to the Mediterranean diet on academic performance is mediated by sleep quality in adolescents. Acta Paediatrica. 2019; 108(2): 339-346. doi:10.1111/apa. 14472.

WOS (JCR) Impact Factor: 2.580; Category: Pediatrics; Rank: 28/124 (Q1) 
5. Adelantado-Renau M, Beltran-Valls MR, Toledo-Bonifás M, Bou-Sospedra C, Pastor MC, Moliner-Urdiales D. The risk of eating disorders and academic performance in adolescents: DADOS study. Nutrición Hospitalaria. 2018; 35(5): 1201-1207. doi:10.20960/nh.1778.

WOS (JCR) Impact Factor: 0.845; Category: Nutrition \& Dietetics; Rank: 70/83 (Q4)

6. Adelantado-Renau M, Jiménez-Pavón D, Beltran-Valls MR, Ponce-González JG, ChivaBartoll Ó, Moliner-Urdiales D. Fitness and academic performance in adolescents. The mediating role of leptin: DADOS study. European Journal of Pediatrics. 2018; 177(10): 1555-1563. doi:10.1007/s00431-018-3213-z.

WOS (JCR) Impact Factor: 2.242; Category: Pediatrics; Rank: 42/124 (Q2)

7. Beltran-Valls MR, Adelantado-Renau M, Moliner-Urdiales D. Association between objectively measured physical activity and plasma BDNF in adolescents: DADOS Study. J Mol Neurosci. 2018; 65(4): 467-471. doi:10.1007/s12031-018-1122-2.

WOS (JCR) Impact Factor: 2.454; Category: Neurosciences; Rank: 171/261 (Q3)

8. Adelantado-Renau M, Diez-Fernandez A, Beltran-Valls MR, Soriano-Maldonado A, Moliner-Urdiales D. The effect of sleep quality on academic performance is mediated by Internet use time: DADOS study. Jornal de Pediatria (Rio J). 2018; S00217557(18)30013-5. doi:10.1016/j.jped.2018.03.006. [Epub ahead of print]

WOS (JCR) Impact Factor: 1.690; Category: Pediatrics; Rank: 63/124 (Q3)

9. Beltran-Valls MR, Adelantado-Renau M, Castro-Piñero J, Sánchez-López M, MolinerUrdiales D. Cardiorespiratory fitness and academic performance association is mediated by weight status in adolescents: DADOS study. European Journal of Pediatrics. 2018; 177(7): 1037-1043. doi:10.1007/ s00431-018-3159-1.

WOS (JCR) Impact Factor: 2.242; Category: Pediatrics; Rank: 42/124 (Q2)

10. Beltran-Valls MR, Artero EG, Capdevila-Seder A, Legaz-Arrese A, Adelantado-Renau M, Moliner-Urdiales D. Regular practice of competitive sports does not impair sleep in adolescents: DADOS Study. Pediatr Exerc Sci. 2018; 30(2): 229-236. doi:10.1123/pes.2017-0129.

WOS (JCR) Impact Factor: 1.353; Category: Pediatrics; Rank: 81/124 (Q3)

* These authors share first authorship

The Web of Science (WOS) Journal Citation Reports (JCR) statistics reported refer to the most recent data (year 2017). 


\section{ACKNOWLEDGEMENTS [AGRADECIMIENTOS]}

